
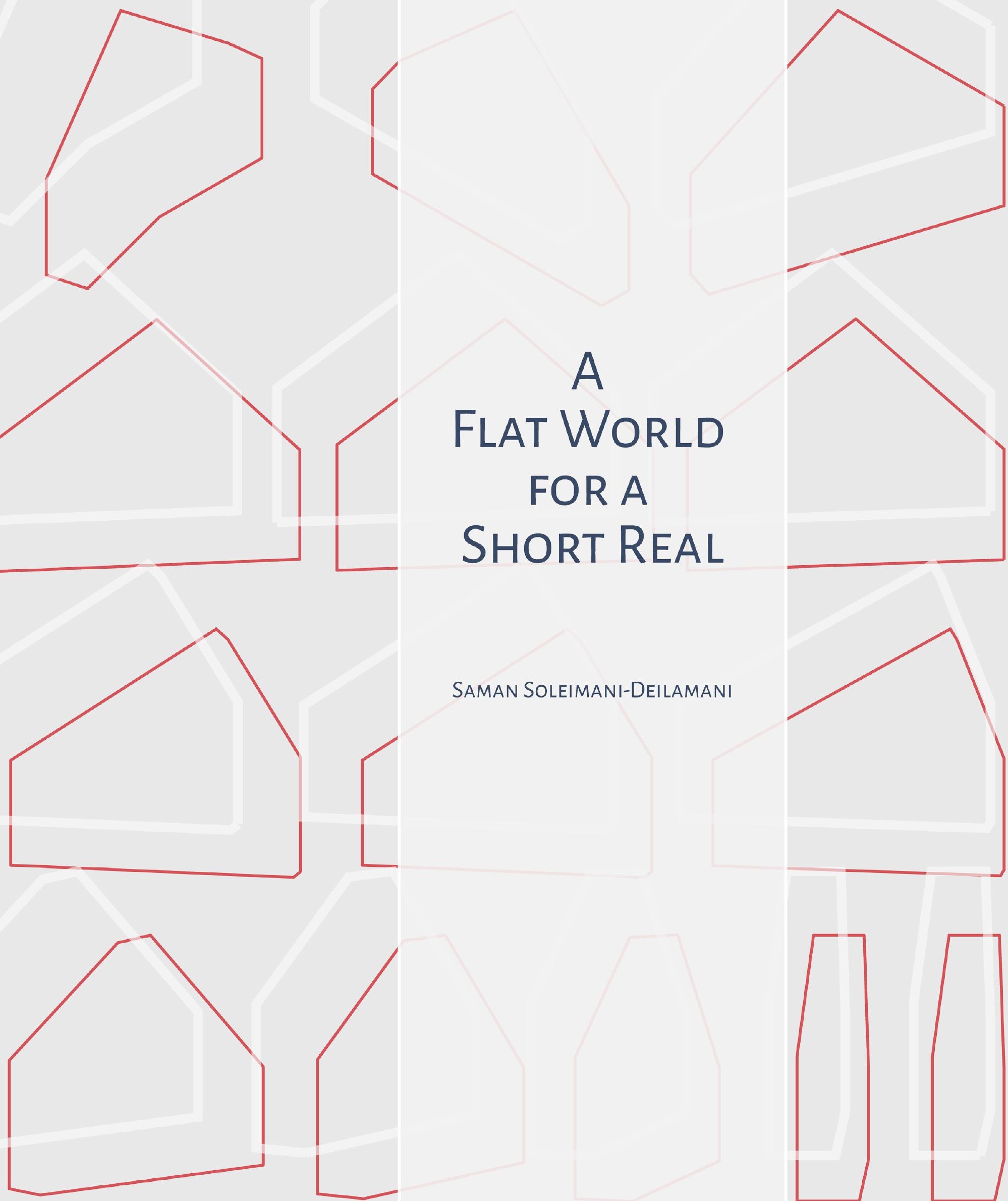



\title{
A Flat WORLD FOR A SHORT REAL
}

\author{
by Saman Soleimani-DeILAmanI \\ Bachelor of Architectural Science, Ryerson University, 2006
}

\author{
a thesis \\ presented to RYERSON UNIVERSITY \\ in partial fulfillment of the requirements for \\ the degree of \\ MASTER OF ARCHITECTURE \\ in the Program of Master of Architecture \\ Toronto, Ontario, Canada
}


ii A Flat World for a Short Real 


\section{AUTHOR'S DECLARATION}

AUTHOR'S DECLARATION FOR ELECTRONIC SUBMISSION OF A THESIS

I hereby declare that I am the sole author of this thesis. This is a true copy of the thesis, including any required final revisions, as accepted by my examiners.

I authorize Ryerson University to lend this thesis to other institutions or individuals for the purpose of scholarly research.

I further authorize Ryerson University to reproduce this thesis by photocopying or by other means, in total or in part, at the request of other institutions or individuals for the purpose of scholarly research.

I understand that my thesis may be made electronically available to the public. 
iv A Flat World for a Short Real 
A FLAT WORLD FOR A SHORT REAL

Saman Soleimani-Deilamani

Master of Architecture, 2017

Ryerson University

\section{ABSTRACT}

SHORT REAL is the territory where the discourse of architecture thrives on binary oppositions and metaphors at the expense of the everyday and earthly realities of architecture. It produces a CONSPIRACY that propagates that the HINGED-DOOR-LEAF (the door) only becomes architecture when it is 'a self-referential sign' ('doorness') or a subjective 'place' (the 'threshold'). Although seemingly contradictory, both concepts bestow 'architecture' with an 'essence': something that 'happens in the mind', is absolute and is analogous to philosophical Ideals. These concepts undermine the CENIUS of architecture as a unique design discipline that is 'deceptive', contingent and paradoxical. FLAT WORLD, as the territory of operation for the projects presented here, forges DESICN-CONSPIRACIES tO NECOTIATE the CONSPIRACIES of SHORT REAL by focusing on the ubiquitous WORKINCS of the HINCED-DOORLEAF and employing the Paranoid-critical Method (PCM) of Surrealism. It situates its operations at 'point supreme' where all oppositions are present without being 'contradictory'. The DESICN-CONSPIRACIES challenge conventions and rethink the relationship of ELEMENTS OF CONSTRUCTION that make the HINGED-DOOR-LEAF architects' greatest invention. In the process, DESICN-CONSPIRACIES manage to envision another way that architecture, humans and the built world can relate to one another. 
vi A Flat World for a Short Real 


\section{ACKNOWLEDGEMENTS}

I would like to thank ARTHUR WRIGCLESWORTH, my supervisor, for his support, encouragement and critical feedback before and during this thesis. He saw potential and possibilities in this work when at times I was unsure about its direction. His enthusiasm and optimism for the ideas here-combined with stimulating conversations about doors, architecture and everything else-made the experience of this year much richer.

I would like to thankJOHN CIRKA, my second reader, who has been engaged with my work throughout my Masters studies. His wealth of knowledge and keen observations have guided me to a more fruitful direction, more than a few times.

I would like to thank LEILA FARAH, my program representative, for her valuable insights, criticality and patience at each presentation.

Also, I would also like to thank my colleagues (with whom I shared the joys and 'pains' of doing a Master of Architecture thesis), the staff of the Department of Architectural Science and my family. 
viii A Flat World for a Short Real 
Sassan, Masi \& Tabban 
$x \quad$ A Flat World for a Short Real 


\section{CONTENTS}

Author's Declaration

Abstract $\quad v$

Acknowledgements vii

Contents $\quad x i$

Illustrations $\quad x v$

1 THIS IS NOT ARCHITECTURE?

$\begin{array}{ll}1.1 \text { LEXICON } & 10\end{array}$

1.2 SHORT REAL (1) 14

$\begin{array}{ll}1.2 .1 & \text { the door (1) } \\ 1.2 .2 & 14\end{array}$

$\begin{array}{ll}1.2 .2 \text { 'doorness' (1) } & 15\end{array}$

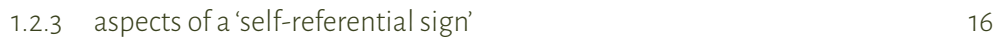

$\begin{array}{ll}\text { 1.2.4 } & \text { the 'threshold' (1) } \\ \end{array}$

2 FLAT WORLD 29

$\begin{array}{ll}2.1 \text { NECOTIATIONS } & 30\end{array}$

2.1.1 elements of construction (1) 30

$\begin{array}{ll}2.1 .2 & \text { allegories } \\ 2.1 .3 & 31\end{array}$

$\begin{array}{ll}\text { 2.1.3 Surrealism \& Flat World } & 34\end{array}$

$\begin{array}{ll}\text { 2.1.4 'point supreme' } & 34\end{array}$

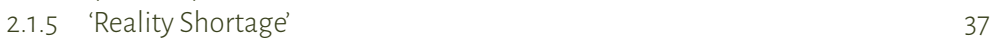

$\begin{array}{lll}2.1 .6 & \text { PcM (1) } & 37\end{array}$

$\begin{array}{ll}\text { 2.1.7 'concrete irrationalities' } & 38\end{array}$

2.1.8 a poetic dimension $\quad 40$

$\begin{array}{ll}2.1 .9 & \text { Surrationalism } \\ 2.1 .10 & 45\end{array}$

$\begin{array}{ll}2.1 .10 & \text { snafus }\end{array}$

2.1.11 Short Real (2) $\quad 46$

$\begin{array}{ll}2.1 .12 & \text { PcM(2) } \\ 2.1 .13 & 46\end{array}$

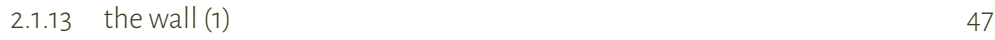

2.1.14 'tactics' \& 'strategies'

2.2 'TACTICS' OF DESICN-CONSPIRACIES 49

2.2.1 hypothetical question $\quad 50$

2.2.2 Flattening 50

$\begin{array}{ll}2.2 .3 \text { Sectioning } & 50\end{array}$

2.2.4 interaction of 'tactics'

2.2.5 flat $\quad 52$ 
3 A STRING OF CONSPIRACIES

$\begin{array}{ll}3.1 \text { CONSPIRACY OF SYMMETRY } & 60\end{array}$

$\begin{array}{ll}3.1 .1 & \text { two disciplines }\end{array}$

3.2 METAPHORS \& ARCHITECTURE 61

3.2.1 metaphors 61

$\begin{array}{ll}3.2 .2 & \text { the door (2) } \\ 3.2 .3 & 62\end{array}$

3.2.3 'monodic' (1) 62

3.2.4 the 'threshold' (2) 63

3.2.5 monadic (2) 64

3.2.6 PCM (3) 64

3.3 CONSPIRACY OF 'FORM' 65

3.3.1 idealism (1) $\quad 65$

3.3.2 'monodic'(3) 66

$\begin{array}{ll}\text { 3.3.3 'sufficient conditions' } & 67\end{array}$

3.4 LANGUAGE CONSPIRACY 68

3.4.1 'monodic' (4) $\quad 68$

$\begin{array}{ll}3.4 .2 & 68\end{array}$

$\begin{array}{ll}\text { 3.4.3 'transdisciplinary' } & 69\end{array}$

$\begin{array}{ll}\text { 3.4.4 MorphoSyntax } & 60\end{array}$

3.5 A DIVIDED OBJECTHOOD

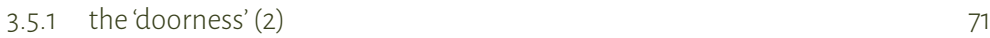

3.5.2 the 'threshold' (3) 71

$\begin{array}{ll}3.5 .3 \text { architectural objects } & 71\end{array}$

3.5.4 elements of construction (2) 72

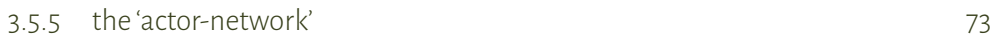

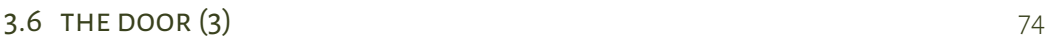

$\begin{array}{ll}3.6 .1 & \text { a fraud and a tease }\end{array}$

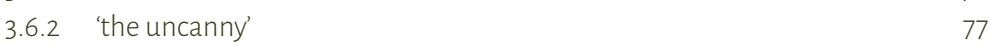

$\begin{array}{ll}3.6 .3 & \text { the door (4) } \\ \end{array}$

3.7 A 'WALL PROJECTION' 80

3.7.1 the window (1) 82

$\begin{array}{ll}3.7 .2 & \text { binary oppositions } \\ 3.7 .3 & 85\end{array}$

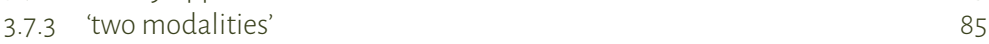

$\begin{array}{lr}3.7 .4 \text { 'event' } & 86\end{array}$

4 DOM-INO CONSPIRACIES 89

4.1 'DOORNESS' (3): AN 'OTHERNESS' 90

4.2 RGB DOM-INO 92

$\begin{array}{lll}4.2 .1 & \text { deconstruction } & 98\end{array}$

4.2.2 cooperation 100

$\begin{array}{ll}\text { 4.2.3 interpretations/synthesis } & 105\end{array}$

4.3 A WOODEN DOM-INO 106

$\begin{array}{ll}4.3 .1 \text { 'one-to-one' } & 106\end{array}$

4.3.2 'monodic' (5) 106

$\begin{array}{ll}\text { 4.3.3 possibilities of a wooden dom-ino } & 107\end{array}$ 


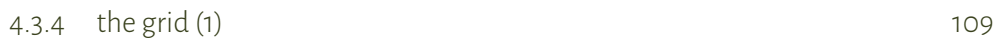

$\begin{array}{ll}\text { 4.3.5 Blueline Manhattan } & 110\end{array}$

4.4 ECONOMY 112

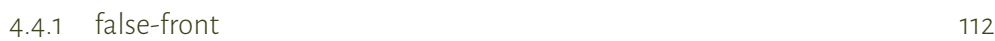

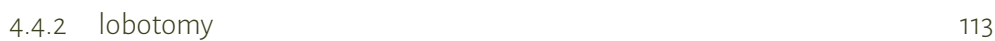

$\begin{array}{ll}\text { 4.4.3 a balloon-framed conspiracy } & 115\end{array}$

$\begin{array}{ll}\text { 4.4.4 plywood dom-ino } & 119\end{array}$

$\begin{array}{lll}4.4 .5 & 3 D \text { printed Dom-ino? } & 119\end{array}$

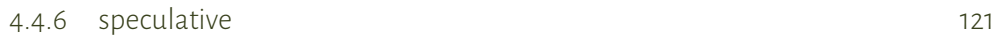

4.5 Oblique Dom-Ino 123

$\begin{array}{ll}\text { 4.5.1 the door (5) } & 123\end{array}$

5 THE CONSPIRATORS 129

$\begin{array}{ll}5.1 \text { THE DOOR (6) } & 130\end{array}$

5.2 THE UNDERDOC 132

5.3 THE WINDOW (2) 136

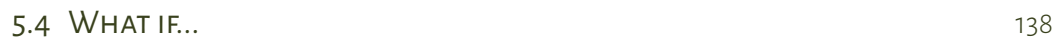

5.5 A HOUSE THAT SWINGS OPEN 141

$\begin{array}{ll}\text { 5.5.1 constructing a house that swings open } & 141\end{array}$

$\begin{array}{ll}\text { 5.5.2 Hinge (1) } & 144\end{array}$

5.5.3 approaching a house that swings open 146

$\begin{array}{ll}5.5 .4 & 148\end{array}$

5.6 WHEN IT IS THE HOUSE THAT SWINGS OPEN... 150

$\begin{array}{ll}\text { 5.6.1 Wall: a parachute wall } & 150\end{array}$

$\begin{array}{ll}\text { 5.6.2 Window : a roller window } & 151\end{array}$

5.6.3 Slab: floating slab 152

5.7 THE COMMUNity (1): BLUELINE PARK 154

5.8 A FLAT DWELLING 160

$\begin{array}{lll}5.8 .1 & \text { the wall (2) } & 161\end{array}$

$\begin{array}{ll}5.8 .2 \text { Toilet } & 164\end{array}$

6 ZERO, ZERO 167

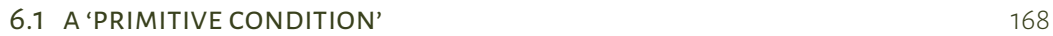

6.1.1 'monodic' (6) 169

$\begin{array}{ll}\text { 6.1.2 Hinge (2) } & 171\end{array}$

6.2 Flat WORLD (2) 173

6.3 RULE NO.1 OF FLAT WORLD 174

6.4 RULE NO.2 OF FLAT WORLD 176

6.5 THE COMMUNITY (2): DIPLOMATS

6.6 RULE NO.3 OF FLAT WORLD 184

$\begin{array}{ll}\text { 6.6.1 'space-place opposition' } & 186\end{array}$

$\begin{array}{ll}\text { 6.6.2 a humanist conspiracy } & 187\end{array}$ 
$\begin{array}{ll}\text { 6.6.3 an anthropological fallacy } & 188\end{array}$

6.6.4 idealism (2) 189

6.6.5 'monodic' (6) 192

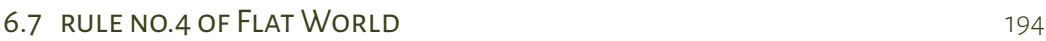

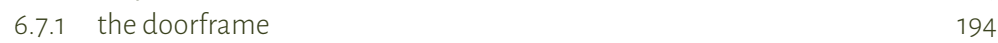

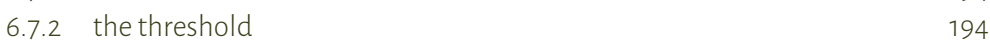

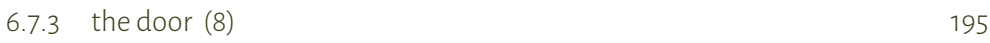

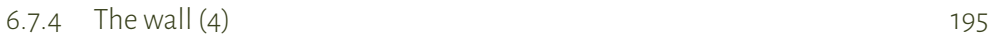

6.7.5 'portare' 196

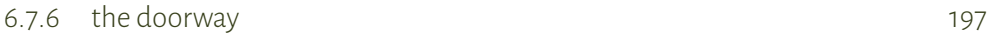

$\begin{array}{ll}\text { 6.7.7 } & \text { the door (7) } \\ \end{array}$

6.8 RULE NO.5 OF FLAT WORLD: 204

$\begin{array}{ll}6.8 .1 & \text { the grid } \\ 6.8 .2 & 204\end{array}$

$\begin{array}{ll}6.8 .2 \text { Door } & 206\end{array}$

$\begin{array}{lll}6.8 .3 \text { 'form' } & 208\end{array}$

6.9 SHORT REAL (2): A WALL-LIKE WORLD 214

6.9.1 Wall-like barriers: inside or outside $\quad 214$

$\begin{array}{ll}6.10 & \text { BUILDING PARALLEL } \\ & 6.10 .16\end{array}$

$\underline{6.10 .1}$ Door-like Walls or Wall-like Doors 216

6.10.2 house-that-swings-open-3 220

$\begin{array}{ll}6.10 .3 & \text { The grid (2) } \\ 6.10 .4 & 228\end{array}$

$\begin{array}{ll}6.10 .4 & \text { house-that-swings-open-4 } 230\end{array}$

7 THE GENIUS OF THE HINGED-DOOR-LEAF 235

$\begin{array}{lll}7.1 & \text { THE ORDER OF THINCS } & 236\end{array}$

7.1.1 house-that-swings-open-5: possibility 12240

$\begin{array}{ll}\text { 7.1.2 house-that-swings-open-5: possibility } 2 & 241\end{array}$

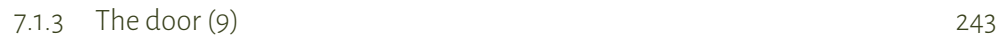

7.2 THE COMMUNITY (3): NEIGHBOURS IN DIFFERENT 'PLACES' 246

$\begin{array}{ll}7.3 \text { CODA } & 252\end{array}$

8 APPENDIX 255

8.1 Diagram: Nutrient SYNTHESIS 256

8.2 ONe Door, Few Flat Houses 260

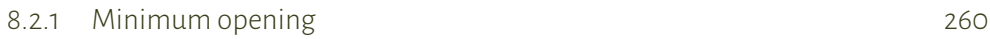

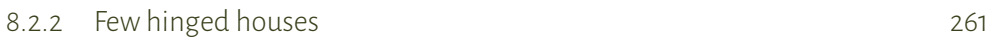

8.2.3 Few sliding houses 263

$\begin{array}{ll}\text { 8.2.4 Few revolving houses } & 265 \\ 8.2 .5 & 263\end{array}$

8.2.5 The House That Swings Open (v.6) 265

9 BIBLIOGRAPHY 269 


\section{ILLUSTRATIONS}

coverimage: Saman Soleimani-Deilamani, 2017

fig. 1-1 Marcel Duchamp, Door, 11 rue Larrey (Paris, 1927)

SOURCE: Jane Alison, Mary Ann Caws, and Barbican Art Gallery, eds., The Surreal House (London: New Haven, CT: Barbican Art Gallery ; In association with Yale University Press, 2010), 23.

fig. 1-2 Francesca Woodman, Untitled (Providence, Rhode Island), 1976

SOURCE: Jane Alison, Mary Ann Caws, and Barbican Art Gallery, eds., The Surreal House (London: New Haven, CT: Barbican Art Gallery; In association with Yale University Press, 2010), 187.

fig. 1-3 Gerhard Richter, 5 Türen (II) / 5 Doors (II), 1967

SOURCE: https://www.gerhard-richter.com/en/art/paintings/photo-paintings/ doors-10/5-doors-ii-5875? \&categoryid=10\&p=2\&sp=20tab=literature-tabs\&sort=3,0

fig. 1-4 origin of the door, 'doorness' and the 'threshold' SOURCE: Saman Soleimani-Deilamani, 2016

fig. 1-5 Gordon Matta-Clark, A W-Hole House, Genoa, Italy. Rooftop atrium and datum cut, 1973 SOURCE: Bingham, Neil. 100 Years of Architectural Drawing: 1900-2000. London: Laurence King, 2013, 237.

FIC.1-6 FLAT WORLD is the relfection of SHORT REAL. SOURCE: Saman Soleimani-Deilamani, 2017

fig. 1-7 how 'doorness' and the 'threshold' see the door. SOURCE: Saman Soleimani-Deilamani, 2016

fig. 1-8 how 'doorness' and the 'threshold' see the door. SOURCE: Saman Soleimani-Deilamani, 2017

fig. 1-9 paradoxical WORKINCS of the door that is ignored by 'doorness' and the 'threshold'. SOURCE: Saman Soleimani-Deilamani, 2016

fig. 1-10 Aspects of Dom-ino: 'A B relationship SOURCE: Saman Soleimani-Deilamani, after Peter Eisenman, 2016

fig.1-11 Aspects of Dom-ino: 'a new object-man relationship' SOURCE: Saman Soleimani-Deilamani, after Peter Eisenman, 2016

fig. 1-12 Aspects of Dom-ino: 'a new object-man relationship' SOURCE: Saman Soleimani-Deilamani, after Peter Eisenman, 2016

fig. 1-13 Aspects of Dom-ino: how the staircase attaches to the slab SOURCE: Saman Soleimani-Deilamani, after Peter Eisenman, 2016

fig. 1-14 Aspects of Dom-ino: a 'primitive condition' SOURCE: Saman Soleimani-Deilamani, after Peter Eisenman, 2016

fig. 1-15 Aldo van Eyck, Otterlo Circles, 1959-62

SOURCE: Strauven, Francis. "Aldo van Eyck. Shaping the New Reality From the In-between to the Aesthetics of Number." CCA Study Centre Mellon Lectures, 2007. http://taak.me/ wp-content/uploads/2013/05/in-betweenness_Aldo-van-Eyck.pdf, Fig. 1.

fig. 1-16 theories in SHORT REAL: two contrasting theories: similar sets of binary oppositions SOURCE: Saman Soleimani-Deilamani, 2017

fig. 1-17 changing view of the door. SOURCE: Saman Soleimani-Deilamani, 2016 
fig. 2-1 It's an onion, not a ball.

SOURCE: https://upload.wikimedia.org/wikipedia/commons/b/b5/OblateSpheroid.PNG

fig. 2-2 Buster Keaton, One Week, 1920

SOURCE: Cline, Edward F., and Buster Keaton. One Week. Black and white, Silent, Comedy. Metro Picture Company, 1920. http://archive.org/details/OneWeek

fig. 2-3 Buster Keaton, The Scarecrow, 1920

SOURCE: Cline, Edward F., and Buster Keaton. The Scarecrow. Silent, Black and White, 1.33:1, Silent, Comedy. Metro Picture Company, 1920. http://archive.org/details/heScarecrow1920.

fig. 2-4 In SHORT REAL, negations and subversion are affected by the power of binary oppositions. SOURCE: Saman Soleimani-Deilamani, 2017

fig. 2-5 In FLAT WORLD, the binary oppositions are present but have as much power as any other element. Negotiations play with the means of materializing ideas and not the ideas themselves.

SOURCE: Saman Soleimani-Deilamani, 2017

fig. 2-6 Dorothy Tanning, Birthday, 1942

SOURCE: Finger, Brad. Surrealism: 50 Works of Art You Should Know. Munich; London; New York: Prestel, 2013, 101

fig. 2-7 Bernard Tschumi, Manhattan Transcripts, 1976-1981

SOURCE: http://www.tschumi.com/media/files/01292.jpg

fig. 2-8 Giorgio de Chirico, Melancholia, date 1916, painted ca. 1940

SOURCE: https://www.menil.org/collection/objects/4810-melancholia

fig. 2-9 René Magritte, Empire of Light, II 1950

SOURCE: https://www.moma.org/collection/works/78456

fig. 2-10 Salvador Dali, Diagram of the workings of the Paranoid-critical Method [text added by author] SOURCE: Koolhaas, Rem. Delirious New York: A Retroactive Manifesto for Manhattan. New ed. New York: The Monacelli Press, 1994, 236.

fig. 2-11 A plywood board fastened to a brick wall: a door is a concrete irrationality of a wall.

fig. 2-12 Genetic process of transduction SOURCE: http://choolworkhelper.net/prokaryotic-f-factor-transforma-tion-transduction/

fig. 2-13 Madelon Vriesendorp, Freud Unlimited SOURCE: Koolhaas, Rem. Delirious New York: A Retroactive Manifesto for Manhattan. New ed. New York: The Monacelli Press, 1994, 234.

fig. 2-14 cover, Delirious New York

SOURCE: http://oma.eu/publications/delirious-new-york

fig. 2-15 Buster Keaton, The Scarecrow, 1920

SOURCE: Cline, Edward F., and Buster Keaton. The Scarecrow. Silent, Black and White, 1.33:1, Silent, Comedy. Metro Picture Company, 1920. http://archive.org/details/heScarecrow1920.

fig. 2-16 Plane Dom-ino

SOURCE: Source: Saman Soleimani-Deilamani, 2016 [base images= planes: Le Corbusier's Towards a New Architecture; Dom-ino sections: Benton, Tim. "Dom-Ino and the Phantom 'Pilotis." AA Files, no. 69 (2014): 23-47

fig. 2-17 how the 'tactics' of this thesis relate to PcM

SOURCE: Saman Soleimani-Deilamani [base image: Koolhaas, Rem. Delirious New York: A Retroactive Manifesto for Manhattan. New ed. New York: The Monacelli Press, 1994, 236]

fig. 2-18 Dom-ino Flattened

SOURCE: Saman Soleimani-Deilamani, 2016

fig. 2-19 Scale of objects FLATTENED

SOURCE: Saman Soleimani-Deilamani, 2016 
fig. 2-20 differences and perceptions between everyday things and ELEMENTS OF CONSTRUCTIONS FLATTENED, sketch

SOURCE: Saman Soleimani-Deilamani, 2016

fig. 2-21 Few different types of doors, sketch SOURCE: Saman Soleimani-Deilamani, 2016

fig. 2-22 perspectives of all the doors of a house Flattened SOURCE: Saman Soleimani-Deilamani, 2016

fig. 2-23 a suburban house through all its doors, perspective SOURCE: Saman Soleimani-Deilamani, 2016

fig. 2-24 a suburban house through all its doors, plan SOURCE: Saman Soleimani-Deilamani, 2016

fig. 2-25 A suburb through all its doors, perspective [top image] SOURCE: Saman Soleimani-Deilamani, 2016

fig. 2-26 A suburb through all its doors, plan [opposite page] SOURCE: Saman Soleimani-Deilamani, 2016

fig. 3-1 Buster Keaton, The Scarecrow, 1920

SOURCE: Cline, Edward F., and Buster Keaton. The Scarecrow. Silent, Black and White, 1.33:1, Silent, Comedy. Metro Picture Company, 1920. http://archive.org/details/heScarecrow1920.

fig. 3-2 The workings of metaphors are exclusive SOURCE: Saman Soleimani-Deilamani, 2017

fig. 3-3 When architecture is a language = a categorical error SOURCE: Saman Soleimani-Deilamani, 2017

fig. 3-4 a transdisciplinary approach SOURCE: Saman Soleimani-Deilamani, 2017

fig. 3-5 cavemen were their own hinges. Their doors were sliding doors! SOURCE: Saman Soleimani-Deilamani, 2017

fig. 3-6 flexible space/field of a HINGED-DOOR-LEAF (the door) = where matter moves from one location to another, photographs SOURCE: Saman Soleimani-Deilamani, 2017

fig. 3-7 flexible space/field of a HINGED-DOOR-LEAF (the door) = where matter moves from one location to another, diagram SOURCE: Saman Soleimani-Deilamani, 2017

fig. 3-8 10 Downing Street

SOURCE: “10_Downing_Street._MOD_45155532.Jpg (JPEG Image, $3000 \times 1738$ Pixels)." Accessed December 9, 2016. http://www.adrianzorzi.com.au/sites/default/files/field/image/10_ Downing_Street._MOD_45155532.jpg.

fig. 3-9 Eugene Atget, Avenue des Cobelins, 1927 SOURCE: https://upload.wikimedia.org/wikipedia/commons/d/dd/Atget_-_Avenue_des_Gobelins.jpg

fig. 3-10 Wittgenstein House, Vienna

SOURCE: http://socks-studio.com/2015/04/26/ order-and-failure-wittgensteins-haus-on-kundmangasse/

fig. 3-11 Wittgenstein House, intermediate-level plan, building permit drawing SOURCE: Turnovský, Jan. The Poetics of a Wall Projection. Epub. AA Words ; 3. London: Architectural Association, 2009, Figure 13.

fig. 3-12 Jan Turnovský, Fig.14 The Nature of Syntax: 'works only if it fails'!

SOURCE: Turnovský, Jan. The Poetics of a Wall Projection. Epub. AA Words ; 3. London: Architectural Association, 2009, Figure 14. 
fig. 3-13 Marcel Duchamp, Fresh Window, 1920, replica 1964

SOURCE: Jane Alison, Mary Ann Caws, and Barbican Art Gallery, eds., The Surreal House (London: New Haven, CT: Barbican Art Gallery ; In association with Yale University Press, 2010), 74

fig. 3-14 an 'event'

SOURCE: Tschumi, Bernard. Questions of Space: Lectures on Architecture. Architectural Association. London: Architectural Association, 1990, 30.

fig. 4-1 Le Corbusier, Maison Dom-ino perspective, 1914-15 source: Benton, Tim. "Dom-Ino and the Phantom 'Pilotis." AA Files, no. 69 (2014): 23-47, 23.

fig. 4-2 Dom-ino like a domino! SOURCE: Le Corbusier. Le Corbusier Le Grand. New York: Phaidon Press, 2008, 78.

fig. 4-3 Dom-ino perspective $=2 \mathrm{D}$ construction SOURCE: Saman Soleimani-Deilamani, 2016

fig. 4-4 Dom-ino Mall SOURCE: Saman Soleimani-Deilamani, 2017

fig. 4-5 Dom-ino Condo SOURCE: Saman Soleimani-Deilamani, 2017

fig. 4-6 Dom-ino: constructed with shadows SOURCE: Saman Soleimani-Deilamani, 2017

fig. 4-7 R Dom-ino SOURCE: Saman Soleimani-Deilamani, 2016

fig. 4-8 G Dom-ino SOURCE: Saman Soleimani-Deilamani, 2017

fig. 4-9 B Dom-ino SOURCE: Saman Soleimani-Deilamani, 2016

fig. 4-10 Grey Dom-ino SOURCE: Saman Soleimani-Deilamani, 2016

fig. 4-11 RGB Dom-ino SOURCE: Saman Soleimani-Deilamani, 2016

fig. 4-12 RGB Dom-ino: cooperation SOURCE: Saman Soleimani-Deilamani, 2016

fig. 4-13 RGB Dom-ino: cooperation SOURCE: Saman Soleimani-Deilamani, 2016

fig. 4-14 RGB Dom-ino: cooperation SOURCE: Saman Soleimani-Deilamani, 2016

fig. 4-15 RGB Dom-ino: cooperation SOURCE: Saman Soleimani-Deilamani, 2016

fig. 4-16 RGB Dom-ino: cooperation SOURCE: Saman Soleimani-Deilamani, 2016

fig. 4-17 RGB Dom-ino: synthesis SOURCE: Saman Soleimani-Deilamani, 2016

fig. 4-18 "one-to-one dom-ino" at 2014 Venice Biennale SOURCE: https://static.dezeen.com/uploads/2014/06/Maison-Dom-ino-Venice-ArchitectureBiennale-2014_dezeen_784_2.jpg

fig. 4-19 Blueline B7088-16S sheet: the accountant's grid SOURCE: Scanned by Saman Soleimani-Deilamani

fig. 4-20 Blueline Manhattan SOURCE: Saman Soleimani-Deilamani, 2016 
fig. 4-21 evolution of the commercial false front

SOURCE: Heath, Kingston Wm. "False-Front Architecture on Montana's Urban Frontier." Perspectives in Vernacular Architecture 3 (1989): 199-213. doi:10.2307/3514305, 204.

fig. 4-23 evolution of the commercial false front

SOURCE: Heath, Kingston Wm. "False-Front Architecture on Montana's Urban Frontier." Perspectives in Vernacular Architecture 3 (1989): 199-213. doi:10.2307/3514305, 208.

fig. 4-22 evolution of the commercial false front

SOURCE: Heath, Kingston Wm. "False-Front Architecture on Montana's Urban Frontier." Perspectives in Vernacular Architecture 3 (1989): 199-213. doi:10.2307/3514305, 205.

fig. 4-24 evolution of the commercial false front

SOURCE: Heath, Kingston Wm. "False-Front Architecture on Montana's Urban Frontier." Perspectives in Vernacular Architecture 3 (1989): 199-213. doi:10.2307/3514305, 209.

fig. 4-25 balloon frame

SOURCE: Monteyne, David. "Framing the American Dream." Journal of Architectural Education 58 , no. 1 (September 1, 2004): 24-33. doi:10.1162/1046488041578194, 25.

fig. 4-26 platform frame

SOURCE: Monteyne, David. "Framing the American Dream." Journal of Architectural Education 58, no. 1 (September 1, 2004): 24-33. doi:10.1162/1046488041578194, 26.

fig. 4-27 Subfloor: balloon frame and platform frame

SOURCE: Saman Soleimani-Deilamani, 2017

fig. 4-28 Buster Keaton, One Week, 1920

SOURCE: Cline, Edward F., and Buster Keaton. One Week. Black and white, Silent, Comedy. Metro Picture Company, 1920. http://archive.org/details/OneWeek.

fig. 4-29 Space Caviar (Joseph Grima), 99 Dom-Ino, at 2014 Venice Architecture Biennale

SOURCE: http://www.archdaily.com/484728/latest-details-released-on-

koolhaas-venice-biennale-2014-fundamentals/5320b8dfco7a8o

e82b000003-latest-details-released-on-koolhaas-venice-biennale-2014-fundamentals-photo

fig. 4-30 Platform Dom-ino

SOURCE: Saman Soleimani-Deilamani, 2017

fig. 4-31 Le Corbusier, Maison Dom-ino, Sections

SOURCE: Benton, Tim. "Dom-Ino and the Phantom 'Pilotis." AA Files, no. 69 (2014): 23-47, 45. fig. 4-31

fig. 4-32 interior view of "one-to-one dom-ino" at 2014 Venice Architecture Biennale

SOURCE: from: http://www.dezeen.com/2014/06/09/

le-corbusiers-maison-dom-ino-realised-at-venice-architecture-biennale/

fig. 4-33 changing view of the door: elevation to section and back to elevation SOURCE: Saman Soleimani-Deilamani, 2017

fig. 4-34 Oblique Dom-ino, animation [click to paly] architecture. SOURCE: Saman Soleimani-Deilamani, 2016

fig. 4-35 frames from Oblique Dom-ino animation SOURCE: Saman Soleimani-Deilamani, 2016

fig. 4-36 a familar form? SOURCE: Saman Soleimani-Deilamani, 2017

fig. 4-37 back of Oblique Dom-ino looks like a suburban house! SOURCE: Saman Soleimani-Deilamani, 2017

fig. 4-38 the pitched roof embedded in Oblique Dom-ino SOURCE: Saman Soleimani-Deilamani, 2017

fig. 4-39 behind Oblique Dom-ino SOURCE: Saman Soleimani-Deilamani, 2016 
fig. 5-1 cover image, Medium is the Massage SOURCE: http://mocanomi.org/wp-content/uploads/2013/09/the-medium-of-message.jpg

fig. 5-2 a door at Palladio Museum in Vicenza, Italy SOURCE: Saman Soleimani-Deilamani, 2016

fig. 5-3 the door remedies the 'sick wall'. SOURCE: Saman Soleimani-Deilamani, 2016

fig. 5-4 Buster Keaton, One Week, 1920

SOURCE: Cline, Edward F., and Buster Keaton. One Week. Black and white, Silent, Comedy. Metro Picture Company, 1920. http://archive.org/details/OneWeek.

fig. 5-5 a temple door SOURCE: Saman Soleimani-Deilamani, 2016

fig. 5-6 Hinges at Farnsworth House SOURCE: Saman Soleimani-Deilamani, 2016

fig. 5-7 Hinges of Carlo Scarpa at Fondazione Querini Stampalia, Venice, Italy SOURCE: Saman Soleimani-Deilamani, 2016

fig. 5-8 The window negates the door! SOURCE: Saman Soleimani-Deilamani, 2016

fig. 5-9 Diller + Scofidio, Slow House Project, 1989 (left)

SOURCE: Jane Alison, Mary Ann Caws, and Barbican Art Gallery, eds., The Surreal House (London: New Haven, CT: Barbican Art Gallery; In association with Yale University Press, 2010), 254.

fig. 5-10 Diller + Scofidio, Slow House, 1991 (right)

SOURCE: Jane Alison, Mary Ann Caws, and Barbican Art Gallery, eds., The Surreal House (London: New Haven, CT: Barbican Art Gallery; In association with Yale University Press, 2010), 255.

fig. 5-11 HOUSE-THAT-SWINCS-OPEN-1, animation SOURCE: Saman Soleimani-Deilamani, 2016

fig. 5-12 stills from the animation of HOUSE-THAT-SWINCS-OPEN-1 SOURCE: Saman Soleimani-Deilamani, 2016

fig. 5-14 HOUSE-THAT-SWINGS-OPEN-1, first functioning SOURCE: Saman Soleimani-Deilamani, 2016

fig. 5-13 HOUSE-THAT-SWINCS-OPEN-1: diagram SOURCE: Saman Soleimani-Deilamani, 2016

fig. 5-16 HOUSE-THAT-SWINGS-OPEN-1: diagram SOURCE: Saman Soleimani-Deilamani, 2016

fig. 5-15 HOUSE-THAT-SWINGS-OPEN-1, plan/diagram SOURCE: Saman Soleimani-Deilamani, 2016

fig. 5-18 relationship between the door, the hinge and the wall SOURCE: Saman Soleimani-Deilamani, 2016

fig. 5-17 various possibilities for the shape of the door for a house that swings open SOURCE: Saman Soleimani-Deilamani, 2016

fig. 5-19 [opposite page, top] conventional perception of the relationship between the three elements of construction (the door, the hinge and the wall) responsible for making the door swing open SOURCE: Saman Soleimani-Deilamani, 2016

fig. 5-21 [opposite page, middle] the relationship between the door, the hinge and the wall when they are Flattened so the house can swing open. SOURCE: Saman Soleimani-Deilamani, 2016

fig. 5-20 HOUSE-THAT-SWINGS-OPEN-1 (second functioning model): the hinge is as the most important component SOURCE: Saman Soleimani-Deilamani, 2016 
fig. 5-22 HOUSE-THAT-SWINGS-OPEN-1 (first digital model): the hinge has BEAM-LIKE and COLUMN-LIKE WORKINCS

SOURCE: Saman Soleimani-Deilamani, 2016

fig. 5-24 direction of approach to the house that swings open SOURCE: Saman Soleimani-Deilamani, 2016

fig. 5-23 HOUSE-THAT-SWINGS-OPEN-1 (second functioning model): in motion to open SOURCE: Saman Soleimani-Deilamani, 2016

fig. 5-25 HOUSE-THAT-SWINGS-OPEN-1 (second functioning model): in motion to open SOURCE: Saman Soleimani-Deilamani, 2016

fig. 5-26 HOUSE-THAT-SWINCS-OPEN-1 (second functioning model: how light is emitted SOURCE: Saman Soleimani-Deilamani, 2016

fig. 5-27 HOUSE-THAT-SWINCS-OPEN-1 (second functioning model: how light is emitted, diagram SOURCE: Saman Soleimani-Deilamani, 2017

fig. 5-28 the PARACHUTE WALL CONDITION, sketch SOURCE: Saman Soleimani-Deilamani, 2017

fig. 5-29 screenshot from Hell on Wheels SOURCE: Davidson, Adam. "Eminent Domain." Hell on Wheels. United States: AMC, August 10, 2013. Netflix.

fig. 5-30 sketch, the window roller house, when it is the house that swings open and the wall is a parachute.

SOURCE: Saman Soleimani-Deilamani, 2017

fig. 5-31 HOUSE-THAT-SWINCS-OPEN-2: first functioning model SOURCE: Saman Soleimani-Deilamani, 2017

fig. 5-32 HOUSE-THAT-SWINGS-OPEN-2, second functioning model, with parachute walls and floating slabs

SOURCE: Saman Soleimani-Deilamani, 2017

fig. 5-33 when the wall is a parachute, the height of the building is flexible. The doorway is now a column.

SOURCE: Saman Soleimani-Deilamani, 2017

fig. 5-34 Blueline Park, sketch

SOURCE: Saman Soleimani-Deilamani, 2017

fig. 5-35 Blueline Park, sketch SOURCE: Saman Soleimani-Deilamani, 2017

fig. 5-36 Blueline Park, animation SOURCE: Saman Soleimani-Deilamani, 2017

fig. 5-37 stills from Blueline Park animation SOURCE: Saman Soleimani-Deilamani, 2017

fig. 5-38 workings of Blueline Park, houses on rollers SOURCE: Saman Soleimani-Deilamani, 2017

fig. 5-39 plan of the community on the Blueline Sheet SOURCE: Saman Soleimani-Deilamani, 2017

fig. 5-40 workings of Blueline Park SOURCE: Saman Soleimani-Deilamani, 2017

fig. 5-41 J. C. van Epen, Study for Skyscraper apartment block, 1926 SOURCE: Bingham, Neil. 100 Years of Architectural Drawing: 1900-2000. London: Laurence King, 2013.

fig. 5-42 FLATTENINC the relationship between the wall and humans SOURCE: Saman Soleimani-Deilamani, 2017 
fig. 5-43 case studies for the thinnest houses around the world

SOURCE: Keret House:http://www.businessinsidercomkeret-house-now-open-for-toursphotos-2013-8

SOURCE: The Little House: http://design-ties.blogspot.ca/2009/09/torontos-teeny-tiny-house.html

SOURCE: Slim House: https:/www.dezeen.com/2013/02/02/slim-house-extension-by-alma-nac/

SOURCE: Iami House: https://www.dezeen.com/2013/02/02/slim-house-extension-by-alma-nac/

fig. 5-44 Flat House, plans and sections

SOURCE: Saman Soleimani-Deilamani, 2017

fig. 5-45 FLAT HOUSE, other possibilities for the WORKINCS of a PARACHUTE WALL.

SOURCE: Saman Soleimani-Deilamani, 2017

fig. 5-46 the toilet as the foyer or the foyer as the toilet

SOURCE: Saman Soleimani-Deilamani, 2017

fig. 5-47 Antione Laugier's the primitive hut

SOURCE: https://deconstructionand.files.wordpress.com/2010/08/hut4.jpg

fig. 6-1 Buster Keaton, One Week, 1920

SOURCE: Cline, Edward F., and Buster Keaton. One Week. Black and white, Silent, Comedy. Metro Picture Company, 1920. http://archive.org/details/OneWeek.

fig. 6-2 a photo of Dogon people published along side van Eyck's essay in the book Meaning in

Architecture

SOURCE: Jencks, Charles, and George Baird. Meaning in Architecture. New York, N.Y: G. Braziller, 1970, 211

FIC. 6-3 HOUSE-THAT-SWINCS-OPEN-1 as a new beginning

SOURCE: Saman Soleimani-Deilamani, 2017

fig. 6-4 because of the hinge, the sequence of construction for HOUSE-THAT-SWINGS-OPEN-1 is very different from conventional methods.

SOURCE: Saman Soleimani-Deilamani, 2016

fig. 6-5 personas of elements of construction when involved in building the HOUSE-THAT-SWINCS-OPEN-1 SOURCE: Saman Soleimani-Deilamani, 2017

fig. 6-6 economy is an element of architecture. SOURCE: Saman Soleimani-Deilamani, 2016

fig. 6-7 light is an element of architecture. SOURCE: Saman Soleimani-Deilamani, 2016

fig. 6-8 Sebastiano Serlio, Elevations for the City palace for the King SOURCE: "Renaissance Paris." Accessed September 6, 2017.http://publishing.cdlib.org/ucpressebooks/ w?docId=ftoxon99zf\&chunk.id=doe1238\&toc.id=\&brand=ucpress, figure 57.

fig. 6-9 Sebastiano Serlio, House for bourgeois in the Italian and French manner SOURCE: "Renaissance Paris." Accessed September 6, 2017.http://publishing.cdlib.org/ucpressebooks/ w?docId=ftoxon99zf\&chunk.id=doe $94 \&$ toc.depth $=1 \&$ toc.id=doe89\&brand=ucpress;query=a rchitecture., figure 2.

FIG. 6-10 NEGOTIATIONS: Man-Dog-Bee

SOURCE: Saman Soleimani-Deilamani, 2015

FIC. 6-11 NECOTIATIONS at a community of houses that swing open SOURCE: Saman Soleimani-Deilamani, 2017

fig. 6-12 a community of houses that swing open, plan SOURCE: Saman Soleimani-Deilamani, 2017

fig. 6-13 studies into the dynamics of a community made up of houses that swing open SOURCE: Saman Soleimani-Deilamani, 2017 
fig. 6-14 studies into the dynamics of a community made up of houses that swing open: houses that form a wall

SOURCE: Saman Soleimani-Deilamani, 2017

fig. 6-15 munition?

SOURCE: Saman Soleimani-Deilamani, 2017

fig. 6-16 Sou Fujimoto, Everything is Architecture

SOURCE: photo: Saman Soleimani-Deilamani, 2017

fig. 6-17 Rural Studio, The Theathre of the Useful

SOURCE: photo: Saman Soleimani-Deilamani, 2017

fig. 6-18 The Family of Man, Museum of Modern Art, exhibition view,

fig. 6-19 how 'doorness', the 'threshold' and critical regionalism connect to each other in SHORT REAL SOURCE: Saman Soleimani-Deilamani, 2017

fig. 6-20 the rite of 'The First Furrow'

SOURCE: Rykwert, Joseph. The Idea of a Town: The Anthropology of Urban Form in Rome, Italy and the Ancient World. MIT Press, 1988.

fig. 6-21 in modernism, it is the doorframe the holds up the wall. (set from Mad Men television series) SOURCE: https://www.pinterest.ca/pin/407294360034812509/

fig. 6-22 inherent binary oppositions in the rite of first furrow SOURCE: Saman Soleimani-Deilamani, 2017

fig. 6-23 What is wrong with this image? SOURCE: Saman Soleimani-Deilamani, 2017

fig. 6-24 the door is never symmetrical. SOURCE: Saman Soleimani-Deilamani, 2017

fig. 6-25 all the doorways in the grid SOURCE: Saman Soleimani-Deilamani, 2017

fig. 6-26 the door, the doorway and Door

fig. 6-27 all Doors in the grid SOURCE: Saman Soleimani-Deilamani, 2017

fig. 6-31 a 'walled world'

SOURCE: Rice-Oxley, Mark, Guardian Interactive team, and Guardian correspondents. "Walled World: How Walls Are Springing up to Divide Populations Everywhere.” The Guardian, November 19, 2013, online edition, sec. World News. https://www.theguardian.com/world/ ng-interactive/2013/nov/walls\#intro.

fig. 6-32 how SHORT REAL sees the wall

SOURCE: Saman Soleimani-Deilamani, 2017

fig. 6-34 sketch, building parallel SOURCE: Saman Soleimani-Deilamani, 2017

fig. 6-36 how FLAT WORLD sees the wall SOURCE: Saman Soleimani-Deilamani, 2017

fig. 6-37 when a house that swings open attaches to a wall-like door. SOURCE: Saman Soleimani-Deilamani, 2017

fig. 6-38 building parallel, sketch SOURCE: Saman Soleimani-Deilamani, 2017

fig. 6-39 HOUSE-THAT-SWINCS-OPEN-3, functioning model SOURCE: Saman Soleimani-Deilamani, 2017

fig. 6-40 HOUSE-THAT-SWINCS-OPEN-3, axonometric drawings and plans SOURCE: Saman Soleimani-Deilamani, 2017 
fig. 6-41 HOUSE-THAT-SWINGS-OPEN-3 NECOTIATES the WALL-LIKE BARRIER SOURCE: Saman Soleimani-Deilamani, 2017

fig. 6-42 HOUSE-THAT-SWINGS-OPEN-3 in Sao Paolo, Brazil NEGOTIATING a WALL-LIKE barrier that divides Alphaville from the rest of the city SOURCE: Saman Soleimani-Deilamani, 2017

FIC. 6-43 HOUSE-THAT-SWINCS-OPEN-3 in Jeruselum NECOTIATING a WALL-LIKE barrier SOURCE: Saman Soleimani-Deilamani, 2017

fig. 6-44 grid elevationas SOURCE: Saman Soleimani-Deilamani, 2017

fig. 6-45 (left) HOUSE-THAT-SWINCS-OPEN-4, axonometric drawings

fig. 6-46 (centre) HOUSE-THAT-SWINCS-OPEN-4, diagram SOURCE: Saman Soleimani-Deilamani, 2017

fig. 6-47 (right) HOUSE-THAT-SWINCS-OPEN-4, plan SOURCE: Saman Soleimani-Deilamani, 2017

fig. 6-48 (right) HOUSE-THAT-SWINGS-OPEN-4 NECOTIATING a WALL-LIKE tower in Toronto, Canada SOURCE: Saman Soleimani-Deilamani, 2017

fig. 7-1 houses that sit on walls, sketch SOURCE: Saman Soleimani-Deilamani, 2017

fig. 7-2 HOUSE-THAT-SWINCS-OPEN-5, sketch SOURCE: Saman Soleimani-Deilamani, 2017

fig. 7-3 the WORKINGS of the HOUSE-THAT-SWINCS-OPEN-5, plan and elevation SOURCE: Saman Soleimani-Deilamani, 2017

fig. 7-4 from the 'house' to the houses that swing open SOURCE: Saman Soleimani-Deilamani, 2017

FIC. 7-5 HOUSE-THAT-SWINCS-OPEN-5, possibility-1 SOURCE: Saman Soleimani-Deilamani, 2017

fig. 7-6 how 'doorness' and the 'threshold' see the door SOURCE: Saman Soleimani-Deilamani, 2017

fig.7-7 HOUSE-THAT-SWINCS-OPEN-5, possibility-2 SOURCE: Saman Soleimani-Deilamani, 2017

fig. 7-8 GENIUS OF THE HINGED-DOOR-LEAF (THE DOOR): NECOTIATION SOURCE: Saman Soleimani-Deilamani, 2017

fig. 7-9 HOUSE-THAT-SWINCS-OPEN-5, NECOTIATIONS SOURCE: Saman Soleimani-Deilamani, 2017

fig. 7-10 HOUSE-THAT-SWINGS-OPEN-5, NEGOTIATIONS SOURCE: Saman Soleimani-Deilamani, 2017

fig. 7-11 neighbours in different 'places', sketch SOURCE: Saman Soleimani-Deilamani, 2017

fig. 7-12 HOUSE-THAT-SWINCS-OPEN-5: neightbours in different 'places' SOURCE: Saman Soleimani-Deilamani, 2017

fig. 7-13 HOUSE-THAT-SWINGS-OPEN-5: neightbours in different 'places' SOURCE: Saman Soleimani-Deilamani, 2017

fig. 7-14 HOUSE-THAT-SWINCS-OPEN-5, functional models SOURCE: Saman Soleimani-Deilamani, 2017

fig. 7-15 HOUSE-THAT-SWINCS-OPEN-5, functional models SOURCE: Saman Soleimani-Deilamani, 2017 
fig. 8-1 Salvador Dali, Diagram of the workings of the Paranoid-critical Method [text added by author] SOURCE: Koolhaas, Rem. Delirious New York: A Retroactive Manifesto for Manhattan. New ed. New York: The Monacelli Press, 1994, 236.

fig. 8-2 material synthesis of PcM diagram SOURCE: Saman Soleimani-Deilamani, 2016

fig. 8-3 material synthesis of PcM diagram SOURCE: Saman Soleimani-Deilamani, 2016

fig. 8-4 scanographs of the material synthesis of PcM diagram SOURCE: Saman Soleimani-Deilamani, 2016

fig. 8-5 minimum opening of a flat house SOURCE: Saman Soleimani-Deilamani, 2017

fig. 8-6 few hinged houses SOURCE: Saman Soleimani-Deilamani, 2017

fig. 8-7 possibilities of a sliding house, sketch SOURCE: Saman Soleimani-Deilamani, 2017

fig. 8-8 possibilities of a sliding house, sketch SOURCE: Saman Soleimani-Deilamani, 2017

fig. 8-9 few sliding houses SOURCE: Saman Soleimani-Deilamani, 2017

fig. 8-10 flexible space of a revolving door SOURCE: Saman Soleimani-Deilamani, 2016

fig. 8-11 possibilities of a revolving house, sketch SOURCE: Saman Soleimani-Deilamani, 2017

fig. 8-12 possibilities of a revolving house, sketch SOURCE: Saman Soleimani-Deilamani, 2017

fig. 8-13 few revolving houses? SOURCE: Saman Soleimani-Deilamani, 2017

fig. 8-14 few revolving houses?

fig. 8-15 house-that-swings-open-6, sketch SOURCE: Saman Soleimani-Deilamani, 2017

fig. 8-16 house-that-swings-open-6, sketch SOURCE: Saman Soleimani-Deilamani, 2017

fig. 8-17 house-that-swings-open-6, sketch SOURCE: Saman Soleimani-Deilamani, 2017

fig. 8-18 house-that-swings-open-6, diagram SOURCE: Saman Soleimani-Deilamani, 2017 
xxvi A Flat World for a Short Real 


\section{A \\ FLAT WORLD \\ FOR A \\ SHORT REAL}




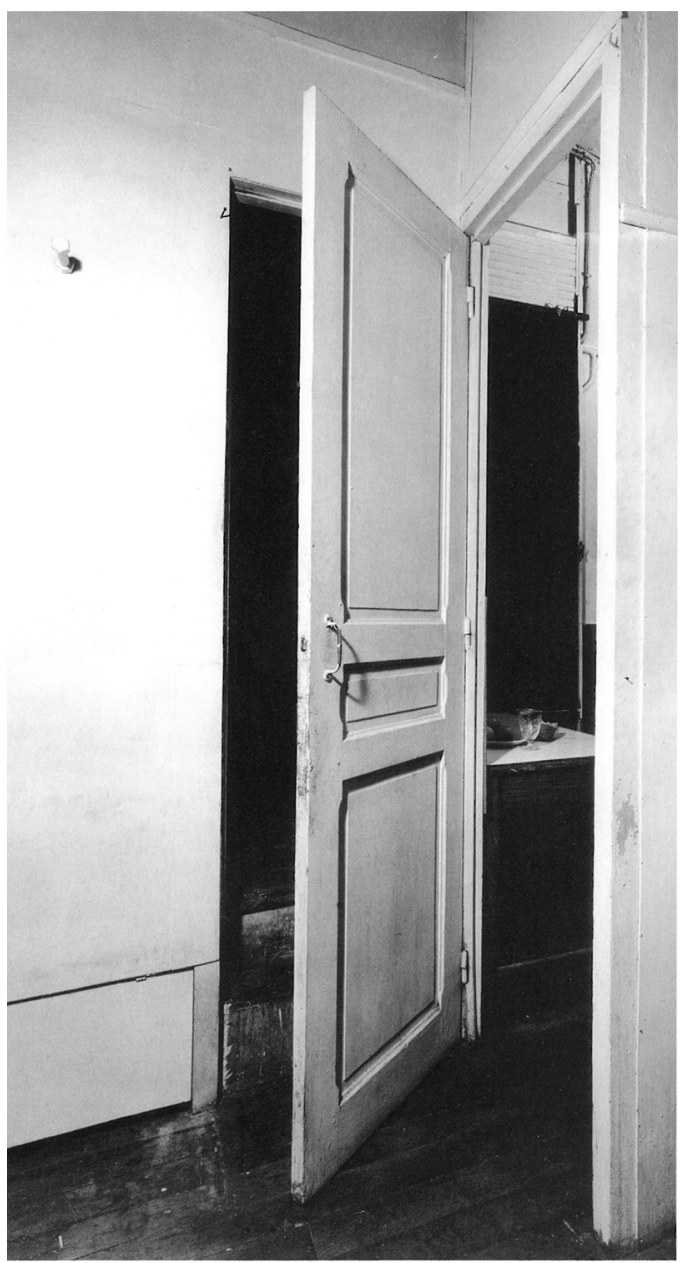

fig. 1-1 Marcel Duchamp, Door, 11 rue Larrey (Paris, 1927) 
"Door leafs are quite possibility the most unarchitectonic architectural element. To begin with, they largely violate the very natural assumption that they should be a proper part of a wall. [...] They are often fastened on one side only $[\ldots]$ a door is usually left half open, half obscuring some piece of furniture hitting a cupboard in the face. All it permits is an inexact, suspect, slinking entrance into a room."

-Jan Turnovský

"Walls are a nice invention, but if there were no holes in them there would be no way to get in or out -- they would be mausoleums or tombs. [...] So architects invented this hybrid: a wall hole, often called a door, which although common enough has always struck me as a miracle of technology."

-Bruno Latour

"the door is arguably the single most critical architectural element. [...] in our society (meaning North American society in general) [it is] the culturally mandated means of penetrating the barrier. It is in this sense the device that makes architecture possible. [...] The door is a convention established by society. $[. .$.$] the designer who recognizes this therefore tries, whenever the$ need for change arises, to pursue a strategy of creatively augmenting existing convention."”3

\section{-Claus Seligman}




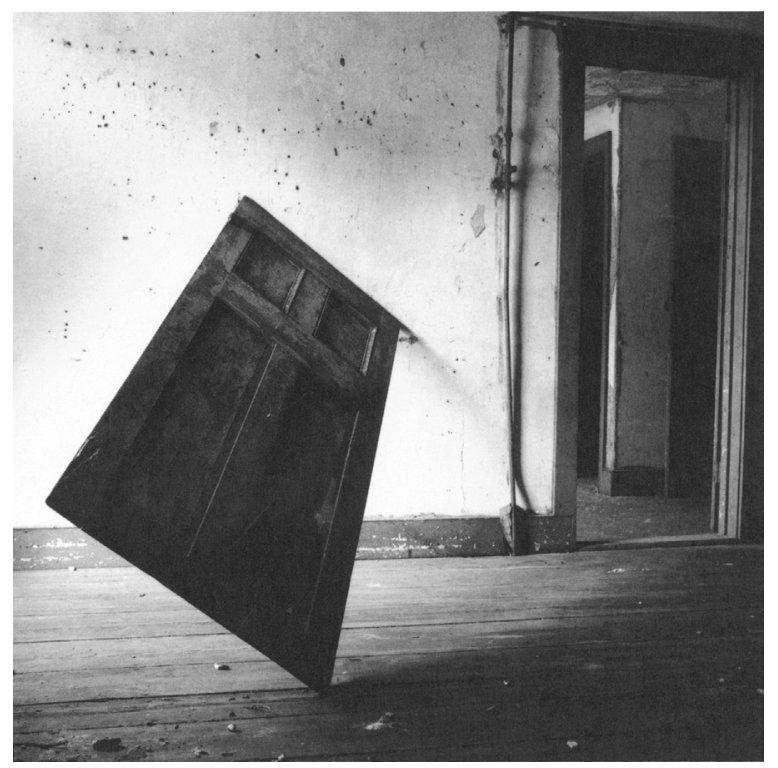

fig. 1-2 Francesca Woodman, Untitled (Providence, Rhode Island), 1976

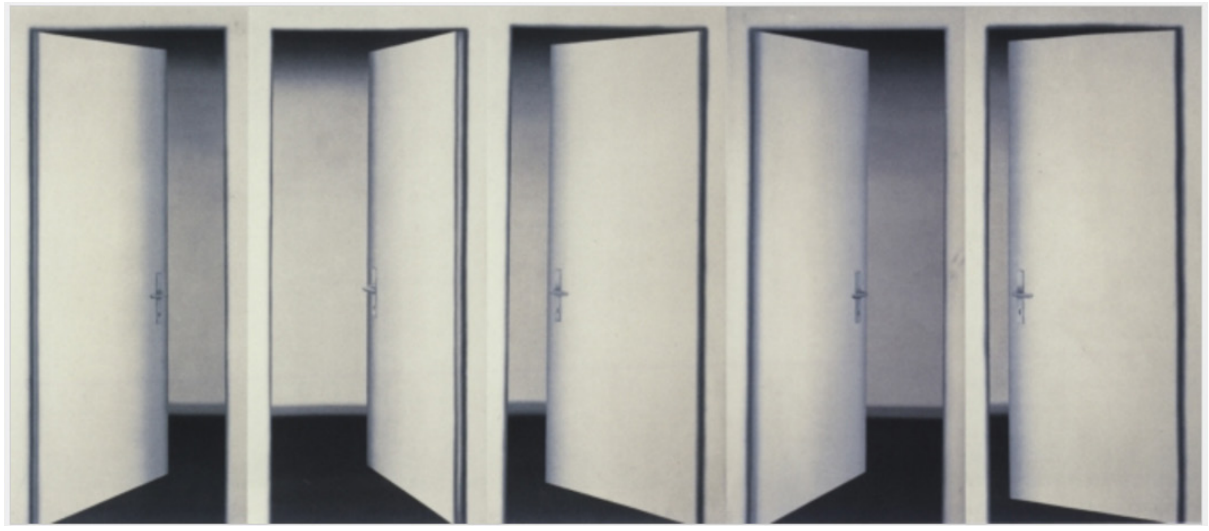

fig.1-3 Gerhard Richter, 5 Türen (II) / 5 Doors (II), 1967 


\section{THIS IS NOT ARCHITECTURE?}

THIS CHAPTER INTRODUCES SHORT REAL AS THE TERRITORY WHERE THE DISCOURSE OF ARCHITECTURE USES METAPHORS, BINARY OPPOSITIONS AND IDEALISTIC PERCEPTIONS OF ARCHITECTURE. THIS ASSUMPTION IS INTRODUCED THROUCH THE TWO CONCEPTS OF 'DOORNESS' AND THE 'THRESHOLD' THAT DIMINISH THE VALUE OF THE HINGEDDOOR-LEAF (THE DOOR) AS ARCHITECTS' GREATEST INVENTION. 
These days, there is a CONSPIRACY at play in the discourse of architecture which says that the everyday and earthly HINGED-DOOR-LEAF (the door) is not architecture. This CONSPIRACY insists on paring the door with incorporeal concepts, philosophical ideologies, and metaphors from other disciplines (like linguistics). This conspiracy does not only affect our appreciation of the door, or other ELEMENTS OF CONSTRUCTION, but also influences our interpretations and speculations of architecture, and how we 'design, 'build' and attach 'meaning' to any work of architecture. ${ }^{4}$ This CONSPIRACY insists that architecture has an 'essence' beyond its everyday and earthly manifestations-its "ultimate reality is based in the mind."

For this CONSPIRACY, architecture is an 'art' and as such the primary concern for any design should be 'form'. This CONSPIRACY defines architecture with a pre-selected set of disciplinary qualities and a restricted disciplinary boundary that inevitably works against the GENIUS of architecture as a complex design discipline. All in all, the implications of this CONSPIRACY reveal a discourse that is fearful of the paradoxical WORKINCS of the very discipline that it represents.

This CONSPIRACY has a hard time accepting that architecture is speculation made material, which means all oppositions are already present in its WORKINCS. This CONSPIRACY employs binary oppositions and directs architects to take sides on a spectrum of extreme approaches to 'design', 'making' and interpretation of architecture. It promotes an axiomatic perception of architecture that diminishes architecture's ability to address the challenges of our built world through its GENIUS.

$$
* * *
$$

To challenge, expose and NECOTIATE the CONSPIRACY of the discourse, this thesis creates two territories: SHORT REAL and FLAT WORLD.

SHORT REAL is where the discourse of architecture engages metaphors and binary oppositions to fuel its Idealist/Essentialist theories, which happens at the expense of the everyday and earthly realities of architecture. Also, SHORT REAL could mean the short-sightedness of the discourse and its failure to recognize the inherent GENIUS of ELEMENTS OF CONSTRUCTION as architectural objects. SHORT REAL is also a play on words of the concept

4 A reference to Thomas Mical, "Breton was incapable of understanding the design/making/meaning of architecture as Dali could..." Mical, "Introduction," 4.

5 Weston, 100 Ideas That Changed Architecture, 51. 
of "Reality Shortage" 6 (as expressed by Rem Koolhaas, which will be examined later in this chapter).

FLAT WORLD is the territory for the projects of this thesis that NECOTIATES the conspiracy of SHORT REAL through the GENIUS of THE HINCED-DOOR-LEAF (and other ELEMENTS OF CONSTRUCTION). FLAT can mean something that is ordinary, without any perceived uniqueness (or without 'real' architectural merit) like the HINGED-DOOR-LEAF.

Also, a FLAT surface s can reflect objects, sound waves or light back to their sources. Therefore, it is possible to conceptualize FLAT WORLD as a territory where the CONSPIRACY (or conspiracies) of SHORT REAL are reflected to their source in the discourse.
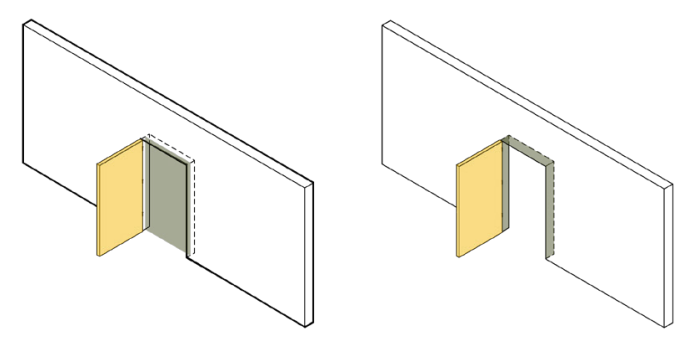

fig. 1-4 origin of the door, 'doorness' and the 'threshold'

fig. 1-5 Gordon Matta-Clark, $A$ W-Hole House, Genoa, Italy. Rooftop atrium and datum cut, 1973
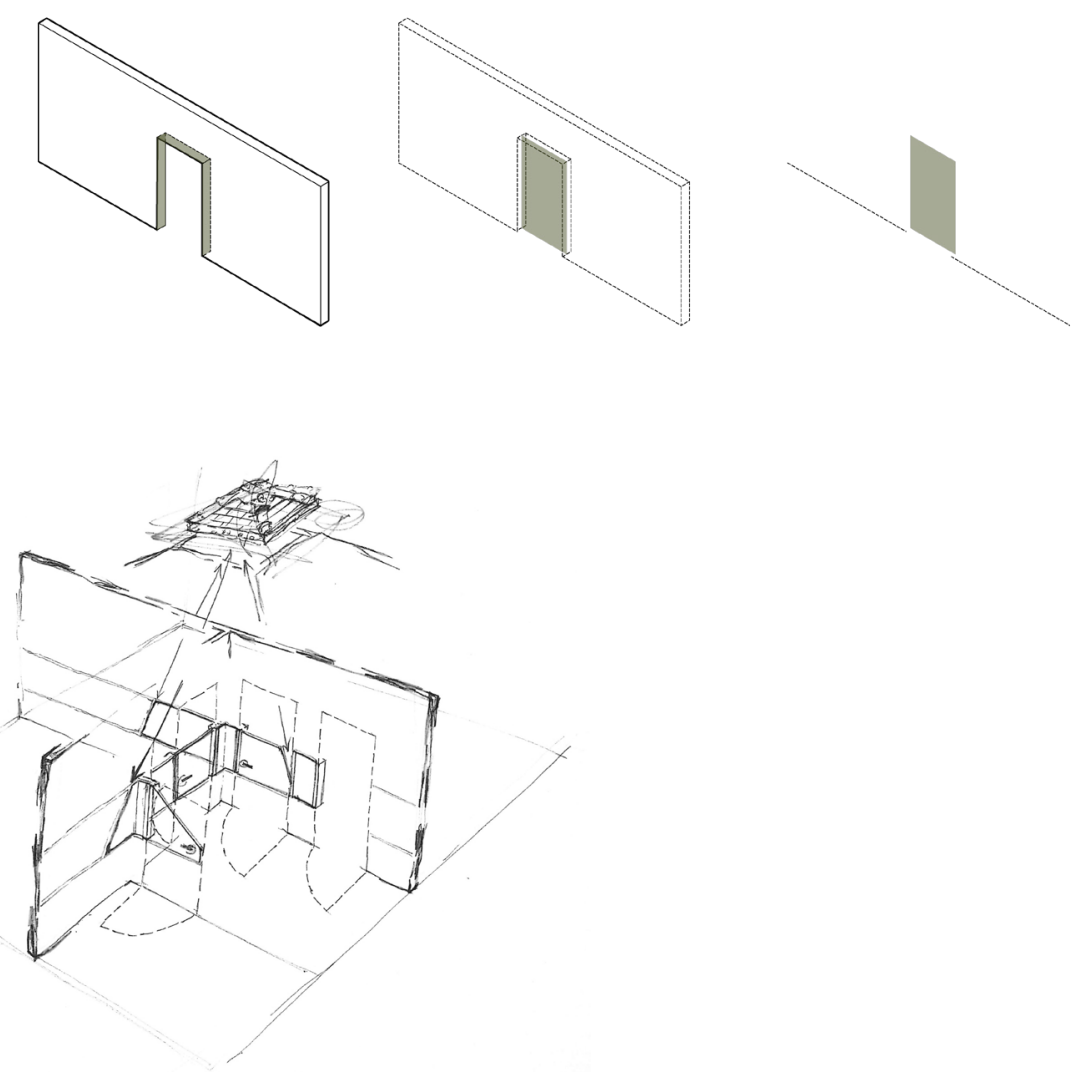

"The dotted lines are features to be removed - slices through doors, walls, floors and ceilings - whereby the architect deconstructed constructed space."

-Neil Bingham 
However, no reflection is ever the real thing. Any reflection (or deflection) includes some form of distortion of the original object to its image.

Therefore, FLAT WORLD also stands in for a territory that mirrors SHORT REAL by simultaneously reflecting it and distorting it. In a sense, FLAT WORLD takes the CONSPIRACIES of SHORT REAL and forges its own DESICNCONSPIRACIES that look like their counter-parts in SHORT REAL, but are in fact only their 'uncanny' versions. In short, the DESIGN-CONSPIRACIES of FLAT WORLD, question, undermine and weaken the axiomatic perception of architecture that is propagated by the CONSPIRACY (or CONSPIRACIES) of SHORT REAL. 
FIC.1-6 FLAT WORLD is the relfection of SHORT REAL.

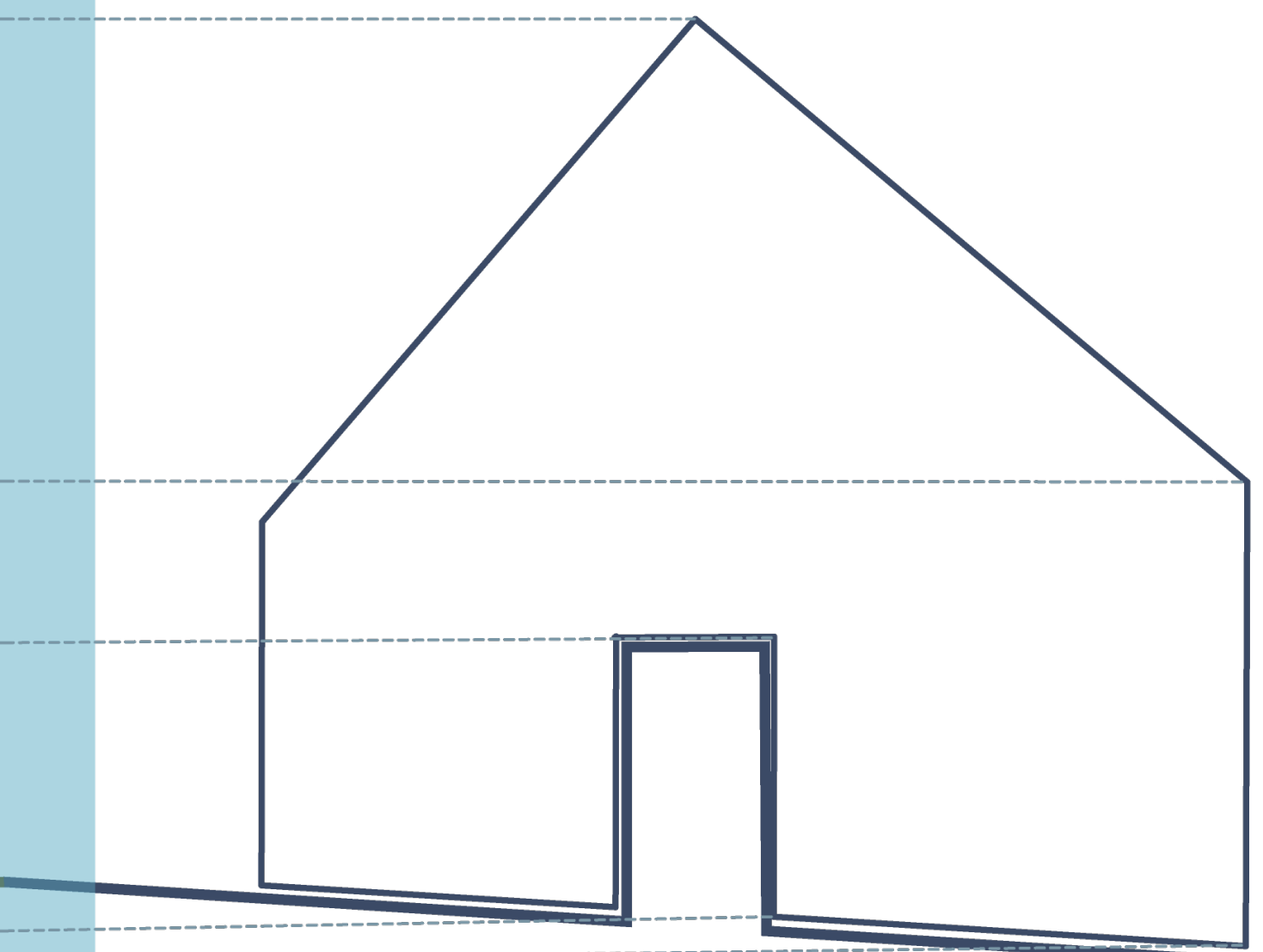




\subsection{LEXICON}



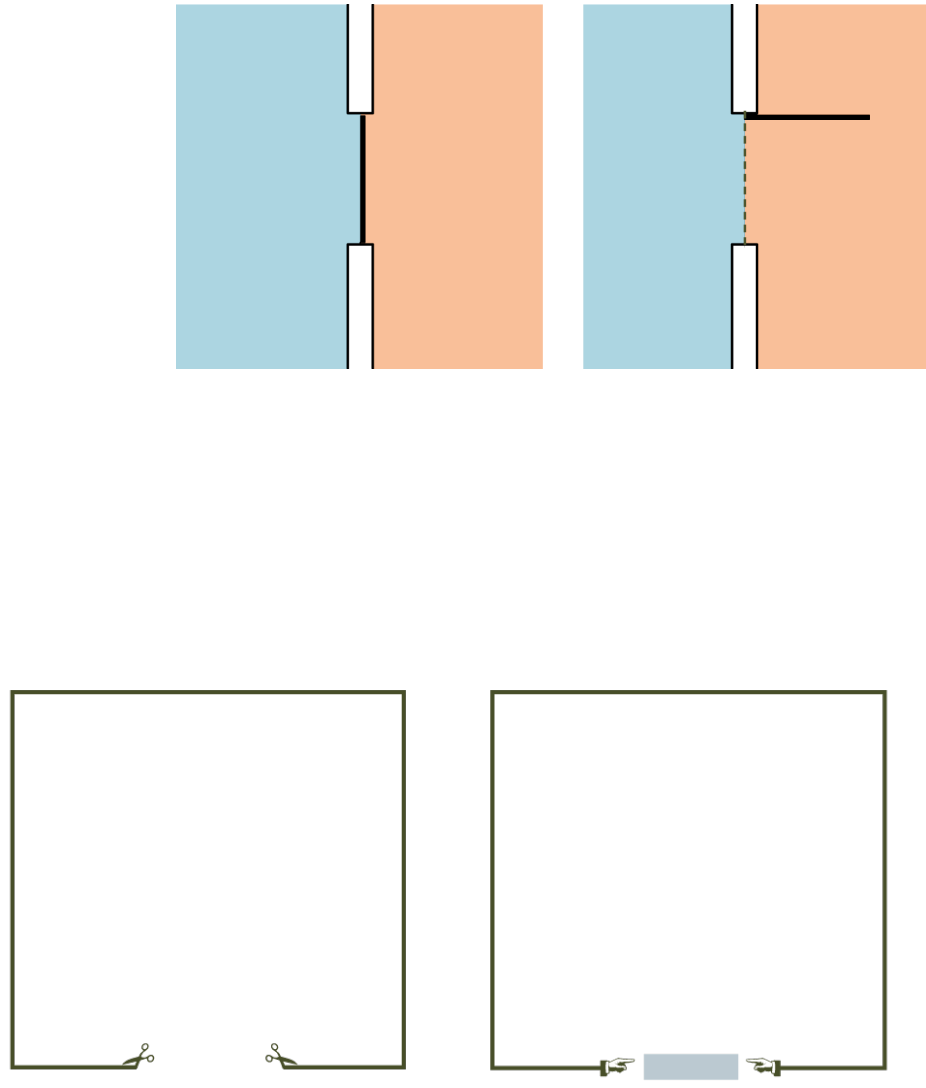

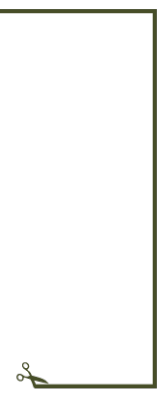

'DOORNESS'

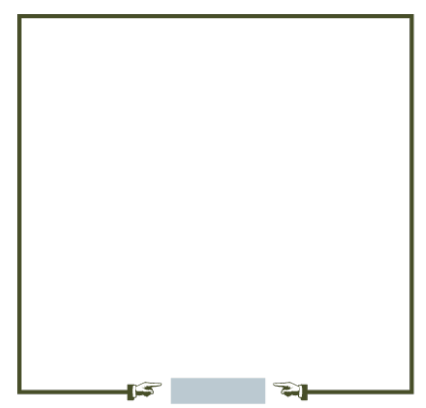

THE 'THRESHOLD' fig. 1-7 how 'doorness' and the 'threshold' see the door.

fig. 1-8 how 'doorness' and the 'threshold' see the door.

For 'doorness', the door is nothing but an interruption in the "discontinuous line that signifies a 'door"'s as different from its "material assembly." For 'threshold', on the other hand, the door only exists in the two positions of fully-opened or fullyclosed' that resembles a wall that is either there or not-there.

The 'threshold' and the 'doorness' belong to the doorway. The doorway is the immaterialized wall. 

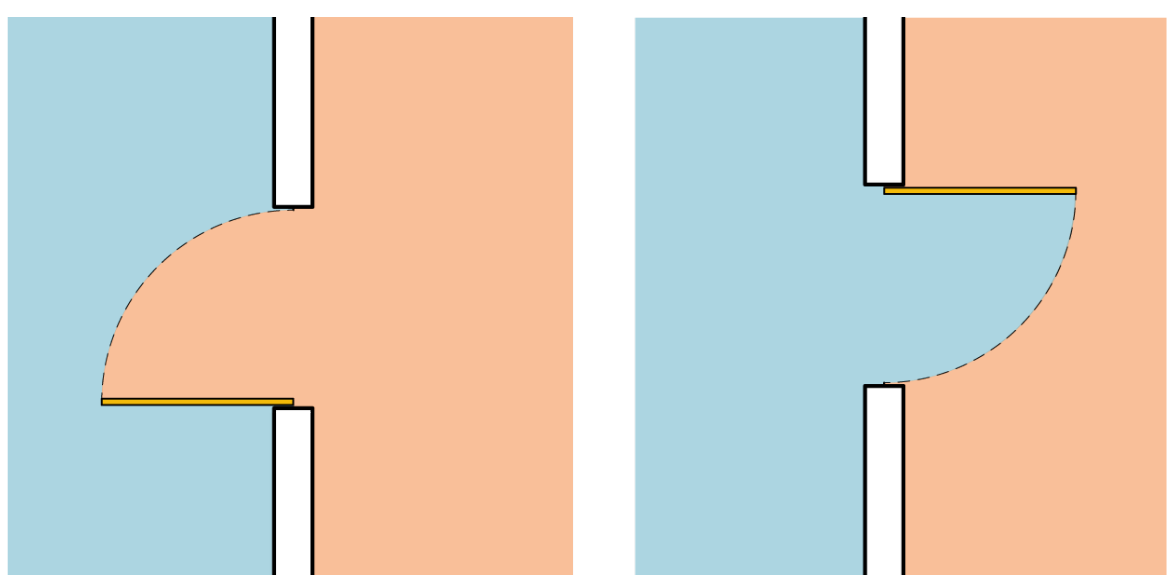

fig. 1-9 paradoxical WORKINCS of the door that is ignored by 'doorness' and the 'threshold'. 


\subsection{ShORT ReAl (1)}

\subsubsection{THE DOOR (1)}

When it comes to the HINGED-DOOR-LEAF (the door), the CONSPIRACY of SHORT REAL runs so deep in the discourse that seemingly contradictory theories find common 'strategies' to dismiss its everyday, earthly and functional realities. For instance, Peter Eisenman and Aldo van Eyck were two architects that critiqued the conventional perception of architecture of the time through their theories. Their approach to architecture places them at extreme ends of the discourse. For Eisenman, and his theory of a 'self-referential sign,' architecture is 'objective' and free from any 'humanist' ambitions. On the other hand, for Aldo van Eyck, architecture is all 'subjective' and should serve 'humanist' needs.

Despite the chasm between their conceptions of two different architectures, both Eisenman and van Eyck build their theories on out-of-disciplinary metaphors, binary oppositions and Platonic Idealism, and operate with an assumption that the WORKINCS of architecture are analogous to philosophical concepts.

Not surprisingly, when it comes to the door, Eisenman and van Eyck are equally dismissive of its everyday and earthly realities. In "Aspects of Modernism," Eisenman writes:

A floor slab or a door, a window or a wall may be necessary conditions for building or function, but they are not sufficient in themselves to define 'architecture'. ${ }^{9}$

Similarly, as quoted by Pierre von Meiss in The Elements of Architecture, Aldo van Eyck praises the simplicity of the door while pitying its everyday existence:

what is a door? A flat surface comprising hinges, a lock establishing an extremely tough barrier. When you go through such a door are you not divided? Split into two! Perhaps you no longer notice it. Think simply of this: a rectangle. What horrifying poverty of expression. Is that the reality of a door? ${ }^{10}$ 
What enables both Eisenman and van Eyck to theorize two separate visions for architecture, and at the same time dismiss its everyday realities, is their reliance on the 'strategies' of SHORT REAL.

For Eisenman, the door is only architecture when it has a certain 'doorness', becomes a Modernist object-a 'self-referential sign'. This way, to become architecture, the door needs to be understood and engaged with as something that exists beyond its everyday manifestation and materiality. ${ }^{11}$ For van Eyck, on the other hand, the door is only architectural when it becomes a 'place' for human activities that he defines through the philosophical metaphor of 'threshold'. ${ }^{12}$

\subsection{2 'DOORNESS' (1)}

It must be noted that although Eisenman does not use a term like 'doorness' (this thesis's term), he does mention "wallness' and 'beamness"'13 as examples of the "sufficient condition" needed for architectural objects to become "architecture." Therefore, in this discussion, the definition of 'doorness' is an expansion of the general idea of what Eisenman deems as "sufficient conditions of architecture." For Eisenman, 'architecture' and 'building' are two separate things, and the door, as a "necessary condition" for building, is only architecture when it finds an 'essence'- a 'doorness' - that "exists as a separate, parallel, and potentially intrinsic condition"14 which "overcomes" its "function," and imbues it with a "sufficient condition" to be architecture.

According to Eisenman, "all buildings have doors, windows, walls, and floors" but "all buildings are not necessarily architecture." ${ }^{15}$ In this respect, the everyday qualities of a "physical" object, like the door, that possesses "spatial dimensions" and can "be recorded and understood geomotrically" are not enough to make it architecture [see 3.3]. This statement reflects Eisenman's long-standing assertion that, parallel to our everyday perception of architecture, "there exists 'an unarticulated universe of form which remains to be excavated'."16 Therefore, what Eisenman seeks is "the structure of form" that exists separate from "function" or "meaning."

11 Eisenman, "Aspects of Modernism."

12 Meiss and Hakola, Elements of Architecture.

13 Eisenman, "Aspects of Modernism," 127.

14 Ibid., 127.

15 Ibid., 122.

16 Ibid., 168. 
In his 1979 essay, "Aspects of Modernism," Eisenman offered a rereading of the perspective drawing of "Maison Dom-ino" (Dom-ino) design by Le Corbusier and treats it as a vehicle to demonstrate his notion of a work of architecture as a 'self-referential sign'.

\subsubsection{ASPECTS OF A 'SELF-REFERENTIAL SIGN'}

Within the "Dom-ino diagram," ${ }^{17}$ Eisenman searches for "an other condition of representation, an other significance, an other realm, which exists simultaneously with the accepted interpretations" of the famous project by Le Corbusier. This goal affords Eisenman the opportunity to explain the "otherness" of Dom-ino as a possible "Modernist context" for its creation as a 'self-referential sign.' To support this argument, Eisenman discusses four aspects of the design of Dom-ino.

First, in "Dom-ino's diagram"18 the constant appearance of the "A B relationship" ${ }^{19}$ of the columns and slabs denotes "an intention to be something more than a notion of a physical presence from the facts of literal existence." ${ }^{\circ 0}$ For Eisenman, the repetition of the "A B relationship" ${ }^{21}$ explicates "a significant redundancy" beyond functional, spatial or "structural" need. Instead, it "underscores a condition of being" and that "there is something present other than either the geometry or the function of the column and slab." Therefore, for Eisenman, this 'redundancy' beyond 'geometry' or 'function', makes Dom-ino a "truly Modernist" work of architecture "that speaks about its mere existence and its own condition of being."
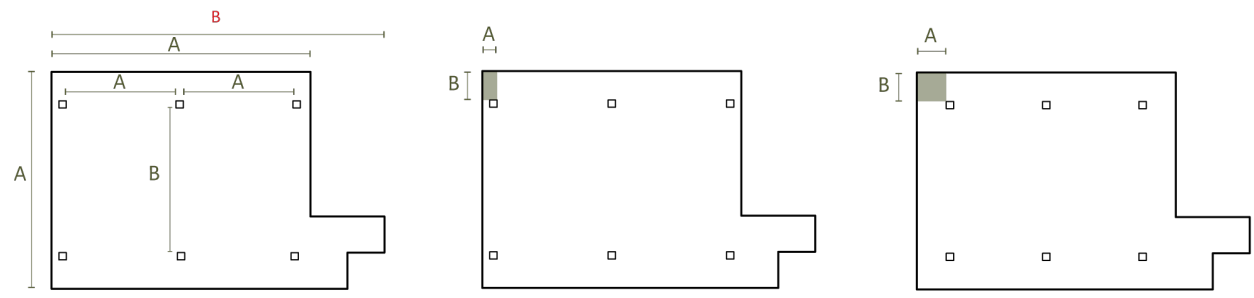

fig. 1-10 Aspects of Dom-ino: 'A B relationship 


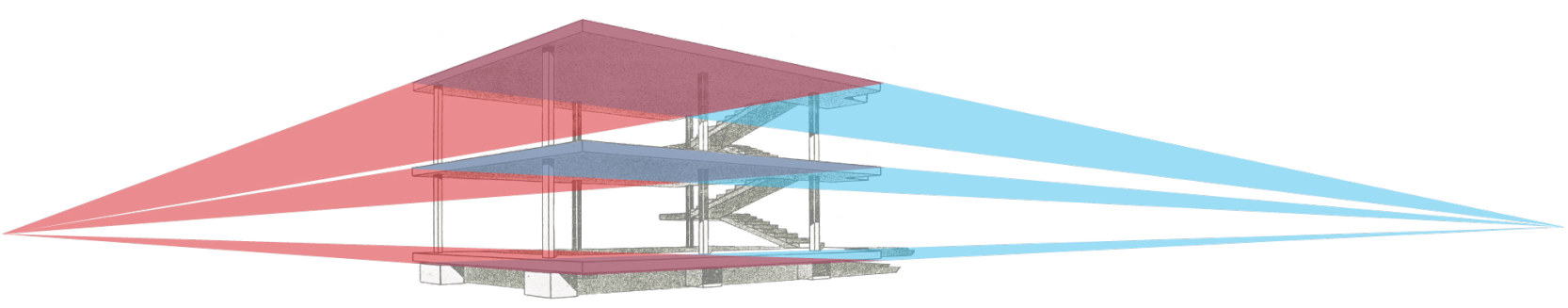

fig.1-11 Aspects of Dom-ino: 'a new object-man relationship'

fig.1-12 Aspects of Dom-ino: 'a new object-man relationship'

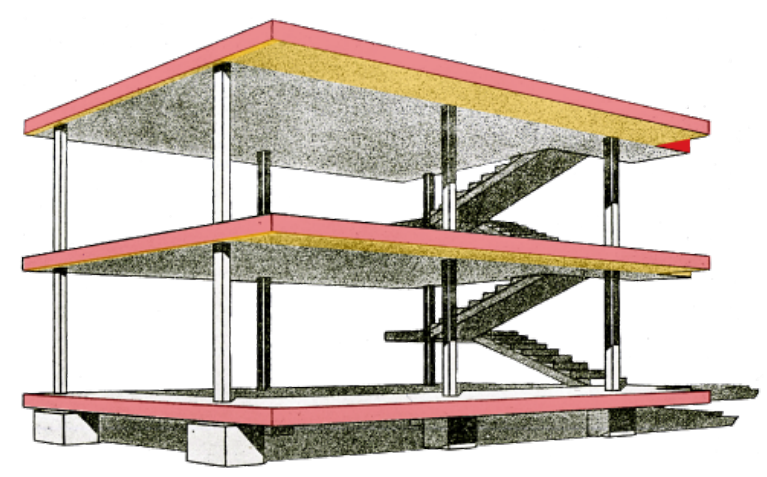

Second, for Eisenman, the "horizontal datum"22 of the "Dom-ino diagram [...] differs from the classical conception of frontality and datum" where "man" was "required to walk around the building to understand the object." Instead, Dom-ino, with its emphasis on "horizontal as opposed to the vertical datum," ${ }^{23}$ is a "Modernist" ${ }^{24}$ condition that signals a "conception [that] is from a single static position." Furthermore, the "sandwich-like character" 25 of the "horizontal planes," which is achieved by "setting the column grid back," suggests "the possibility [...] of horizontal extension of the slab on the long axis." A proposition that implies that the "horizontal plane becomes a datum carrying the idea of both an infinite extension of space in longitudinal vectors and the denial of the same proposition in lateral vectors." Therefore, the "horizontal datum of Dom-ino speaks only of its own physical condition. It is a sign of that condition and nothing more. In a sense, it is self-referential." As a result, Dom-ino "exists [only] as a mark of its own condition" that "begins to alter the conception and definition of architecture." 
a.

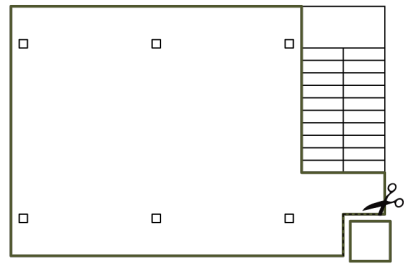

$b$.

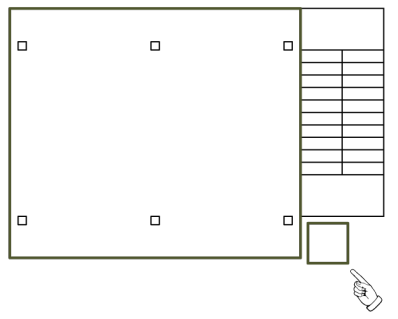

C.

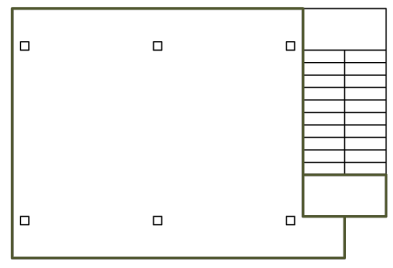

fig.1-13 Aspects of Dom-ino: how the staircase attaches to the slab

Third, "the particular location of the staircase with respect to the slab"26 Dom-ino can offer another "kind of interpretation" and its "self-referential notation." For Eisenman, there are "three interpretations" of the possibilities for how the slabs and the staircase can connect to each other: (a) slab is an extension of the edge of the staircase = the void on the top slab becomes a cut-out, (b) the slab is ended at the edge of the staircase = top of the stair is an appendage to the slab and (c) the stair case and slab are commingling $=$ meeting each other half-way.

Fourth, "the six square base elements in relationship to the first horizontal slab" ${ }^{27}$ which, for Eisenman, "their size, shape, and location suggest something more than support." Again, there are "other configurations" which could have suggested adequate support for such a structure. Nevertheless, in Dom-ino, their "shape, size and location" imply an intention that exceeds mere "structural support." As a result, these "footings" make Dom-ino a 'self-referential sign' as "they function, but at the same time they overcome their function."

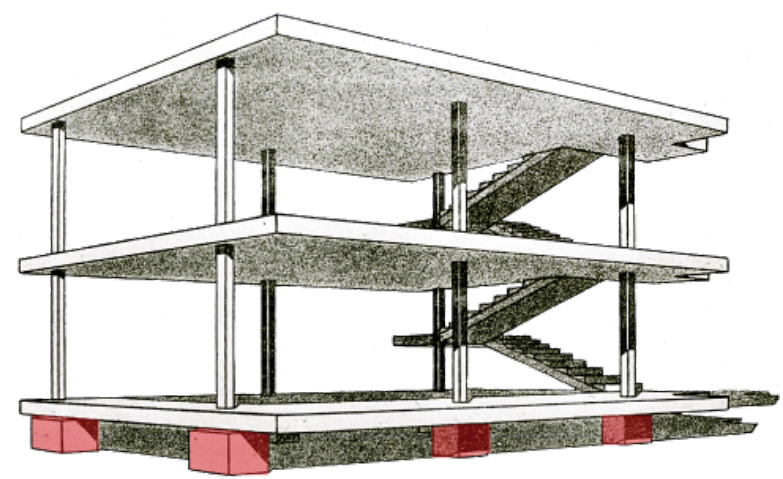

fig.1-14 Aspects of Dom-ino: a 'primitive condition' 
Eisenman's attempt to re-read Dom-ino as a 'self-referential sign', has been questioned by later critiques. Paolo Vittorio Aureli, considered Eisenman's process as "a rather idiosyncratic study of Le Corbusier's prototype. ${ }^{28}$ Another critic, Stanford Anderson questions the criticality of Eisenman's approach to Dom-ino and writes: “Eisenman's respect for Le Corbusier and the renown of the Maison Dom-ino diagram is such that he unquestioningly assumes that there must be formal intentionality in the given configuration of the Maison Dom-ino."29 Both Aureli and Anderson criticize Eisenman for neglecting the larger external forces that had shaped Dom-ino and its impact on the history of the discipline ${ }^{30}$ most notably the use of reinforced concrete and its implications for housing.

At the time of the publication of "Aspects of Modernism" in the introduction to the essay, Kenneth Frampton criticizes Eisenman and writes:

the boundaries between a late Humanist volumetric culture and a modernist process oriented conception of the world seem to become curiously conflated, the former category invading the latter and vice-versa. And yet to claim that the marking alone is the sine qua non of modernism-a minimalist recording of data and nothing more - and at the same time to attach a priority to 'wallness,' ['doorness'] and 'planeness,' is surely to return, despite the 'antiilluminist' jargon, to some of the self-same essences which were an intrinsic part of the Renaissance.

\subsubsection{THE 'THRESHOLD' (1)}

The word threshold can be interpreted as three different things: (1) threshold, the English word, (2) the threshold, an element of construction and (3) the 'threshold', a metaphor.

The first use of the word threshold in English language dates to "before 900." ${ }^{31}$ It is related to the word thresh which, in agriculture, is the act of separating "the grain or seeds" from the rest of a plant like wheat. It can also mean 'beating' something or "to deliver blows as if with a flail."

The threshold (the ELEMENT OF CONSTRUCTION) is a sill, ${ }^{32}$ a beam that can be structural or non-structural, which supports the doorframe. It can also be called a 'doorsill'. It prevents dust, dirt, pests (or even noise) from passing under the door. Essentially, the threshold is a strip of material at the bottom of a doorframe which the inhabitants must cross every time they pass through a doorway.

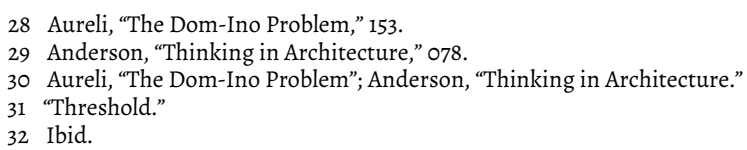


The 'threshold' (the metaphor) is a 'place', a 'space' and a state of mind. It can be "the entrance to a house or building"33 or "any place or point of entering or beginning." It can also relate to the concept of 'limen' which is "the point at which a stimulus is of sufficient intensity to begin to produce an effect." In a sense, 'threshold' (a metaphor) is something that is recognized in our mind. It is a proverbial line-in-the-sand.

$$
* * *
$$

According to George Teyssot, the metaphorical threshold- the 'threshold'- "entered the vocabulary of architecture" 34 in the 2oth century through the writing of the "theologian and philosopher Martin Buber," and the publication of his book I and Thou in 1936. Buber's ideas proved to be influential with "architects and town planners"-like Aldo van Eyck, among others - who responded to his "humanist plea" and "the task to build for human contact, to build an environment which invites human meetings and centers which give these meetings meaning and render them productive'." The concept became influential among many of the "Team 10 members" (which van Eyck was a prominent member) and was labeled as "the 'threshold' [,] 'doorstep' [,] the 'meeting place' or the 'shape of the in-between'."

In the 1959, CIAM meetings at Otterlo Netherlands, Aldo van Eyck "quoted Buber"36 when explaining his "theory of the threshold." ${ }^{\text {" For van }}$ Eyck, his theory was a proposal "on the need for architecture to reconcile spatial polarities such as inside-outside" which he demonstrated through various "keywords and leitmotivs, such as [...] 'the realm of the in-between' or $[. .$.$] 'the greater reality of the doorstep'."$

At the same CIAM meeting, Aldo van Eyck presented a "two-circle diagram" 38 to demonstrate his theories. The three images in the "circle" on the left represent the "three great traditions" that provided the foundation for van Eyck's ideas: (1) "Parthenon" represents "the classical" tradition with its "immutability and rest'," (2) the "counter-construction of van Doesburg" represents "the modern" tradition that characterizes "change and movement" and (3) the "Pueblo village" represents "the archaic" and "'the vernacular of the heart'." Therefore, van Eyck posited that "these three traditions should not be considered mutually exclusive but should be reconciled to develop an architecture with a formal and structural potential sufficiently rich to meet the complex reality of contemporary life."

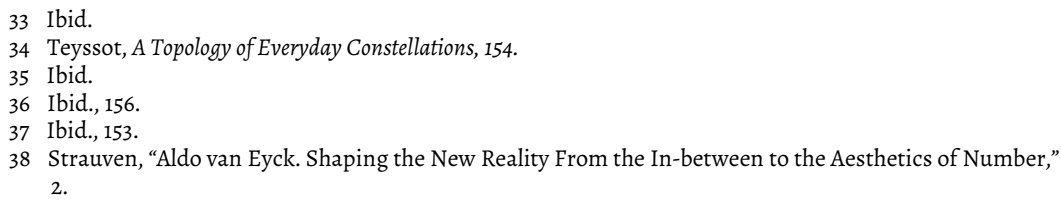


fig.1-15 Aldo van Eyck, Otterlo Circles, 1959-62

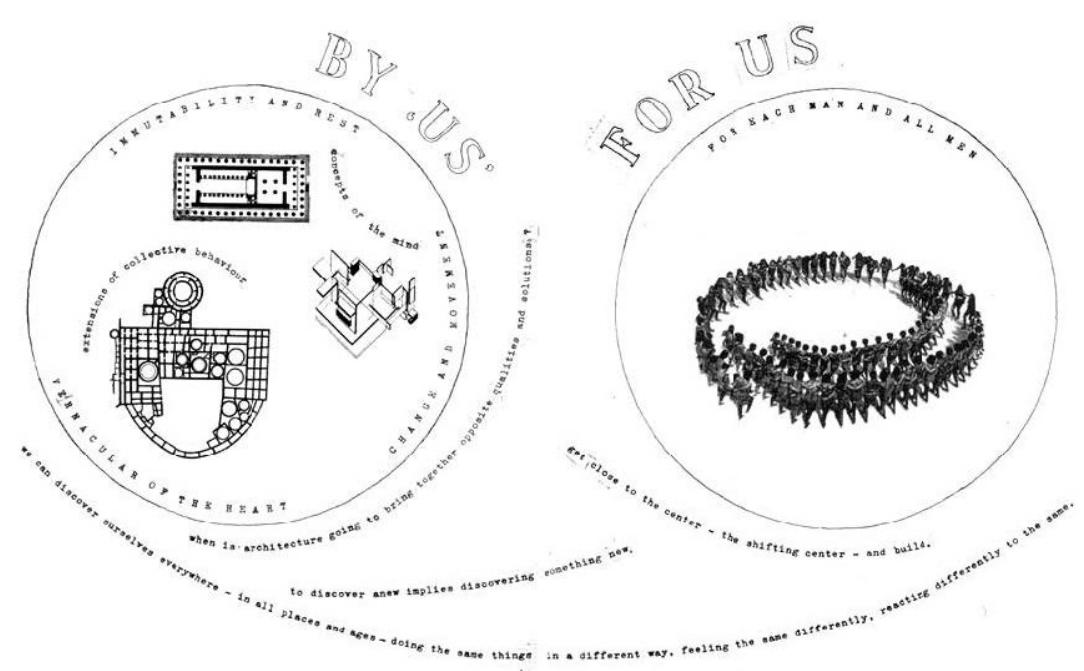

The "circle" 39 on the right represents "the realm of architecture" where "the paradigms of the three traditions are united." There is an image of "dancing Kayapó Indians" gathering "around an open centre" that "spirals" to open or close. This movement denotes architecture's role as a responder to the "constant and constantly changing' human reality, i.e. not only with what is different from the past, but also with what has remained the same."

$$
* * *
$$

The way the HINGED-DOOR-LEAF (the door) came to be associated with the 'threshold' (the metaphor) as a 'sufficient condition' for its architectural importance relates to how van Eyck and other "post war"40 architects "rehabilitated the door as a site for architectural invention." This notion was a direct response to "International Style" and its desire to preserve "the continuity of space" that had eliminated any notion of the door as a separate place from the rest of the architecture; limiting it to an "abstract plane."

For Aldo van Eyck (as Pierre von Meiss remarks) a 'threshold' is a 'place' or a 'space' of "transition" ${ }^{\text {"1 }}$ which "reveals the nature of the limit" of any 'space'. Therefore, as a 'threshold', a door cannot be architecture by itself, since the "functional" 42 aspects of a door "is not enough to describe this place where the world reverses itself." In this conception, the door only "reveals the wall" and "its presence and its thickness" while, the 'threshold' differentiates "between an interior and exterior." 
Like Eisenman, for van Eyck (as expressed by Pierre von Meiss) architecture also happens in the mind since "the means of building an architectural place are always physical, but alone, they are not enough." ${ }^{43}$ Therefore, the "architectural form" cannot "derive" its 'meaning' from "aesthetic principles, utility or geometric and constructional rules." [see 3.3]

Despite the 'humanistic' aspiration and critical view of 'The International Style', later critics were divided on the success of van Eyck's theory. On the one hand, "Charles Jencks saw him as an important representative of the 'idealistic' tradition that he viewed as the mainstream of the Modern Movement." ${ }^{44}$ On the other hand, "Kenneth Frampton stressed the radical critique he exerted on the modern movement, and paid special attention to the unorthodox position he occupied in relation to his contemporaries within Team 10." 


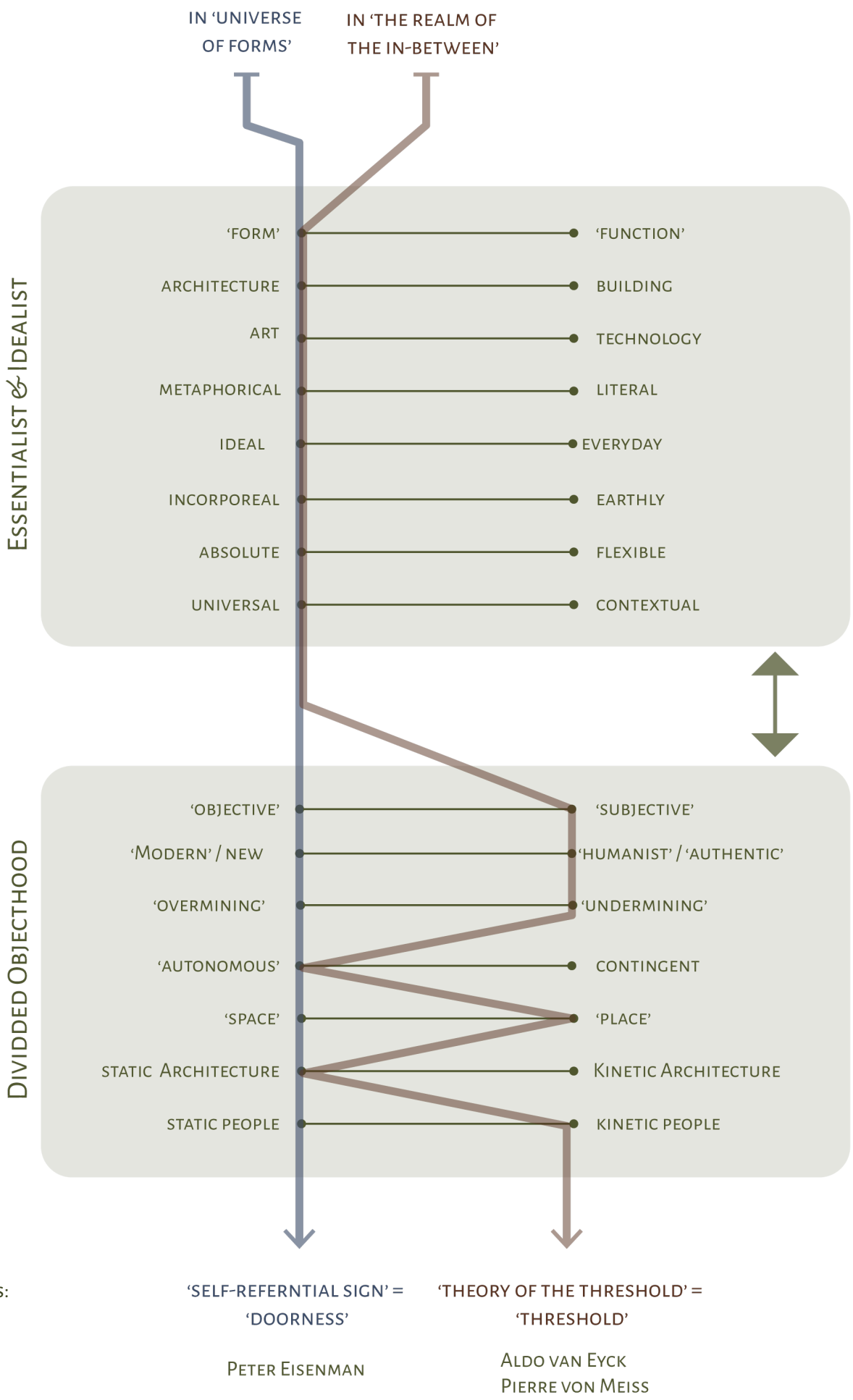

fig. 1-16 theories in SHORT REAL: two contrasting theories: similar sets of binary oppositions

Pierre von Meiss 


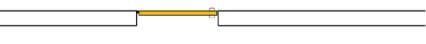

Door: $0^{\circ}$

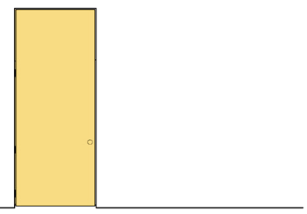

6/6 Door

o/6 Doorway

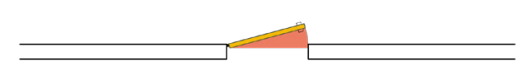

Door: $15^{\circ}$

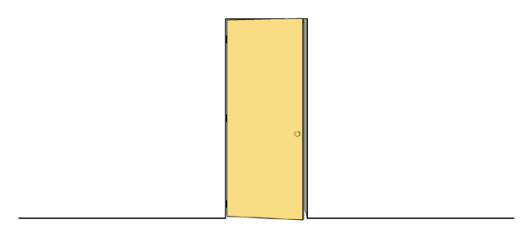

5/6 Door

1/6 Doorway

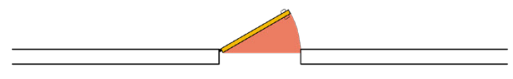

Door: $30^{\circ}$

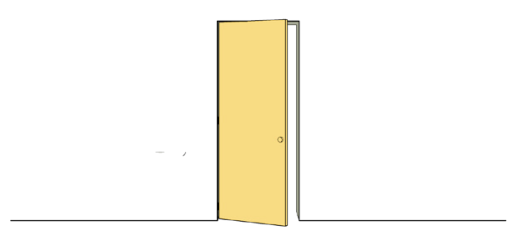

4/6 Door

2/6 Doorway

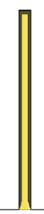

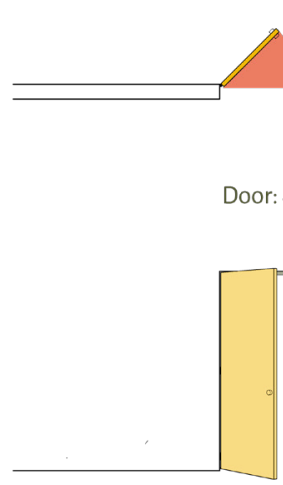

3/6 Door

3/6 Door 


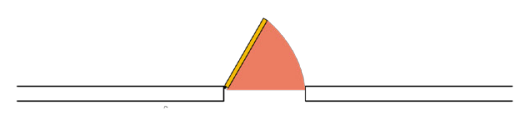

Door: $60^{\circ}$

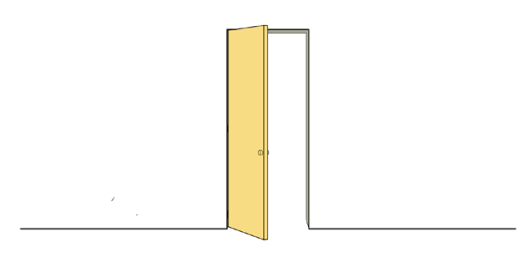

2/6 Door

4/6 Doorway

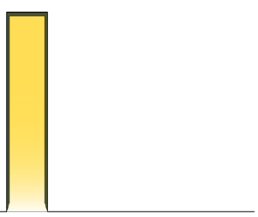

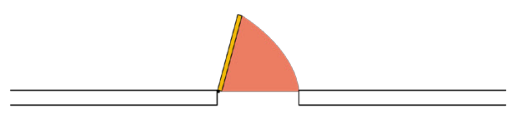

Door: $75^{\circ}$

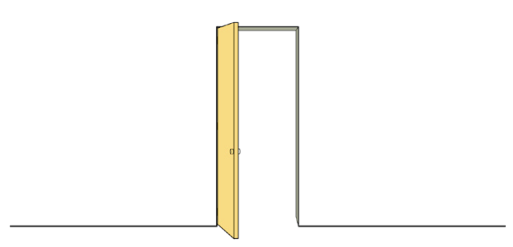

1/6 Door

5/6 Doorway

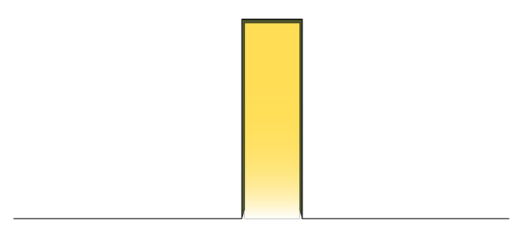

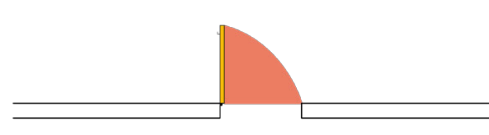

Door: $90^{\circ}$

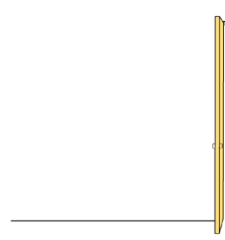

o/6 Door

6/6 Doorway

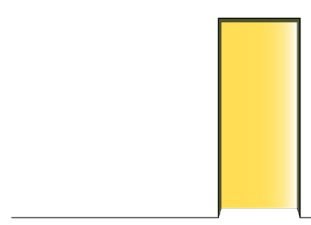

When the HINGED-DOOR-LEAF (THE DOOR) is paired with 'threshold', it becomes a switch for a binary opposition: the door is open, the wall is open, the 'threshold' is 'on'; or, the door is closed, the wall is closed, the 'threshold' is off.

What happens when the door is half-open or half-closed? 


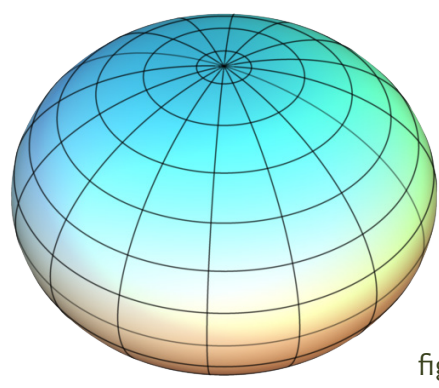

fig. 2-1 It's an onion, not a ball.

In most people's mind, the earth is a sphere, but the earth is an oblate spheroid $^{1}$ (oblate: Flattened or depressed at the poles). The flattening happens by rotating a sphere along its shorter axis. The imaginary earth and the real earth differ in their shape. Although it might be a slight difference, the implication is clear. The sphere is the fixed image of earth. As a shape, it never changes. It was made that way and will stay that way. On the other hand, the real Earth is an oblate spheroid because as an object in the universe it is always in a state of becoming. Its form, surface, and atmosphere change. Its relationship to other celestial bodies is in constant flux. 
fig. 2-2 Buster Keaton, One Week, 1920

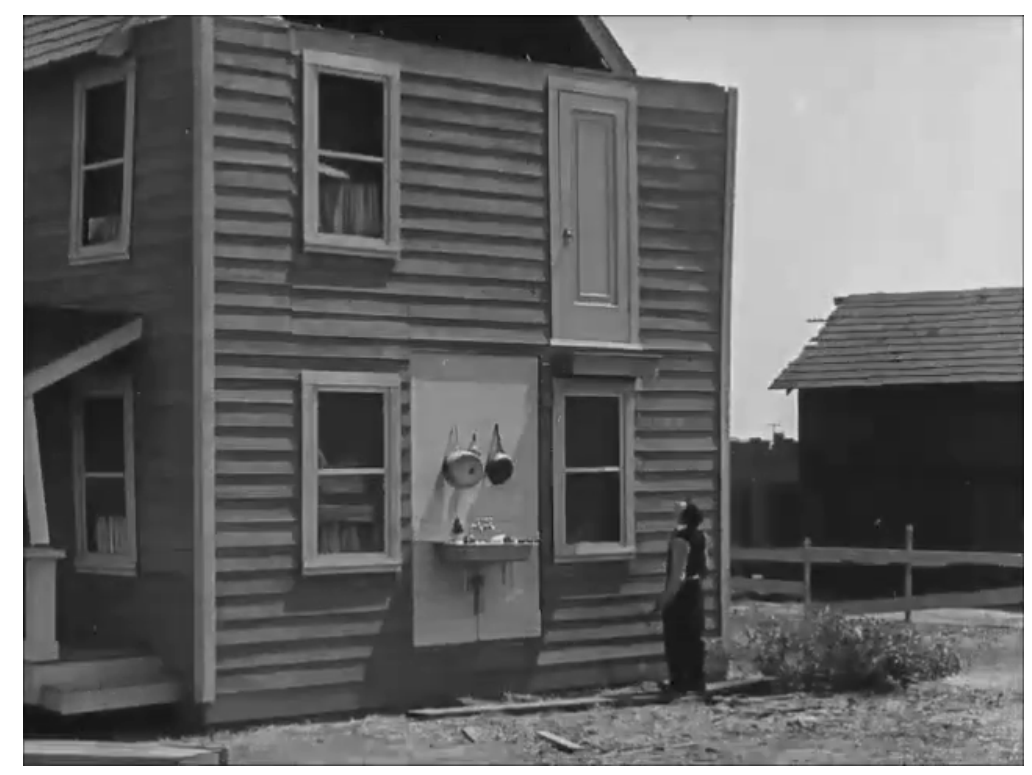

"an unexamined [architecture] is not worth [designing]."

—Socrates, 2017 
"All the rooms in this house are in one room."

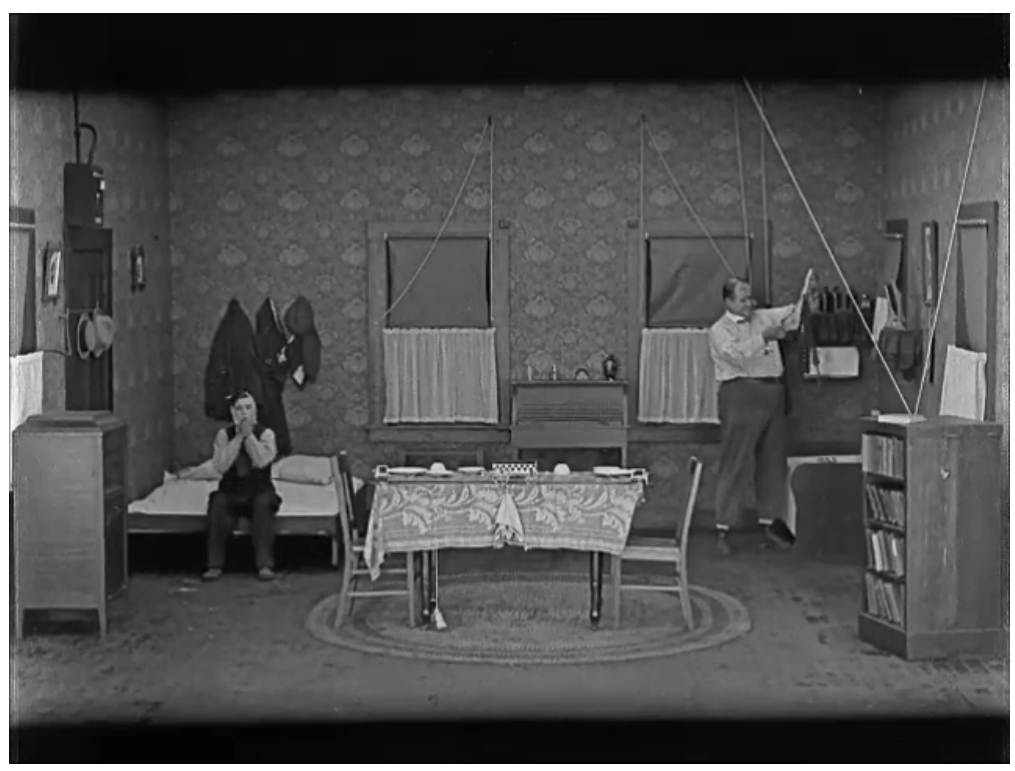

fig. 2-3 Buster Keaton, The Scarecrow, 1920

"Buster's World is flat [...] a lot of the gags are about human movement in the flat world."

- Tony Zhou 


\section{FLAT WORLD}

THIS CHAPTER INTRODUCES FLAT WORLD AS THE TERRITORY CREATED BY THIS THESIS TO NECOTIATE THE CONSPIRACIES OF SHORT REAL.

HERE, THE THEORETICAL AND DISCURSIVE UNDERPINNING OF FLAT WORLD IS DISCUSSED BY DRAWING ON THE CENERAL THEORIES OF SURREALISM, THE NOTION OF 'POINT SUPREME' AND THE PARANOIDCRITICAL METHOd (PCM)—AS DESCRIBED by SALVAdor Dalí AND ReM KOOLHAAS.

LASTLY, THE 'TACTICS' EMPLOYED BY THIS THESIS TO NECOTIATE THE CONSPIRACIES OF SHORT REAL ARE REVEALED. 


\subsection{NEGOTIATIONS}

Conventional thinking sees binary oppositions as two ends of a linear spectrum. It offers the illusion of a real difference between the two poles while they are essentially the same 'strategies' deployed in different idealistic-packaging. This black-and-white thinking is not suitable for architectural design. Therefore, this thesis constantly refers to NEGOTIATION.

Notions like negation, subversion approach binary oppositions with a no-fail attitude. Likes of Eisenman and van Eyck accept that the two poles of a binary opposition are the only features of any critical territory. They seek to either oppose, contest or unify these binary oppositions; which, in return only strengthens their position. On the other hand, NECOTIATION means approaching a problem with-fail. Accepting that the territory for exploration is wide open and Flat and, although the poles of the binary opposition are present, they are not the only features. By negating, subverting binary oppositions the relationship between the poles are always symmetrical: they are always opposite each other and one is defined as the negative-image of the other. Through NECOTIATION, FLAT WORLD proposes that the most effective way to avoid the reductive workings of binary oppositions is to understand that the process must be asymmetrical. Therefore, negotiations are always asymmetrical.

\subsubsection{ELEMENTS OF CONSTRUCTION (1)}

FLAT WORLD is possible through the understanding that, in architecture as a discipline with a paradoxical GENIUS, there is always a middle ground where the speculations of the two poles of any binary opposition must materialize through the ELEMENTS OF CONSTRUCTION (like the door, the window, the wall, and many more). Even at the theoretical level, a 'conceptual' design must reflect a capacity for materialization. IN FLAT WORLD, architecture is its doors, windows, walls and roofs, etc.

Here, binary oppositions are present, but they are powerless to sway the direction of explorations towards themselves. The power of the poles of any binary opposition are not greater than any other ELEMENT OF CONSTRUCTION. Because, architecture is not just speculations and not just materialized realities: Architecture is speculation made material.
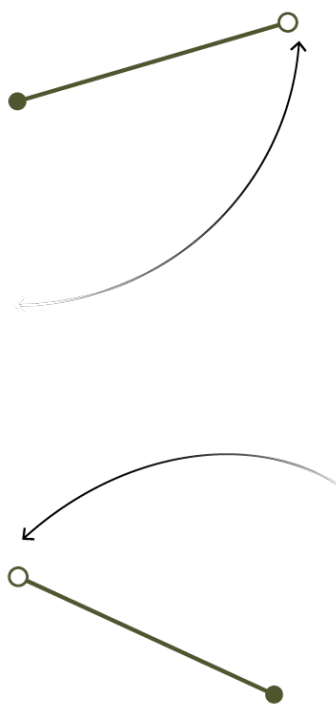

fig. 2-4 In SHORT REAL, negations and subversion are affected by the power of binary oppositions. 

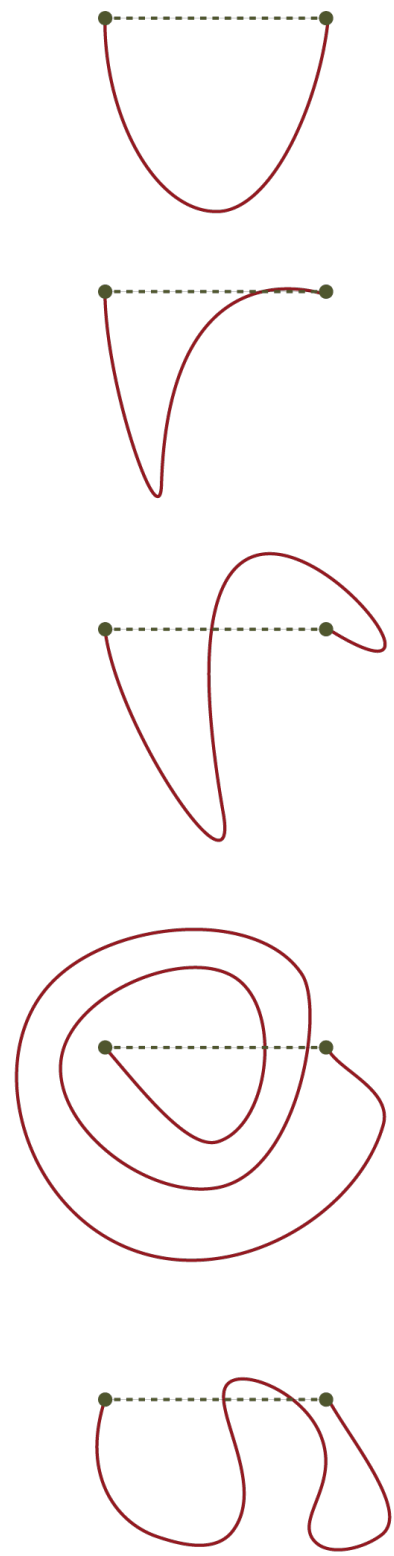

In FLAT WORLD, through NECOTIATIONS, oppositions inform other elements and are in-formed by them in return. The poles of the binary oppositions stay where they are and, instead, the means that are employed by the discourse to materialize them are NECOTIATED.

\subsubsection{ALLEGORIES}

In FLAT WORLD, ELEMENTS OF CONSTRUCTION become allegories that tell the story of "abstract concepts, qualities or situations" that have empowered the conventional thinking of architecture. Their paradoxical workings stand in for the contradictory workings of architecture. In rediscovering their GENIUS, they reveal that genius of architecture that ultimately "changes the very frame through which we perceive the world and engage in it." ${ }^{2}$

Allegory, literally, means "speaking otherwise than one seems to speak."3 The most known allegorical technique is "personification,"4 exemplified in English language in phrases like Love is Blind, or Time Flies. ${ }^{5}$ In the Western tradition, at least, visual allegory was considered more potent than any allegories in written words. In the middle ages, "even poets (...) agreed that images could be more striking and more memorable than words." The power of the 'visual allegory' was in its inability to be specific like language, which as a "noticeable ambiguity" was regarded its main advantage.

fig. 2-5 In FLAT WORLD, the binary oppositions are present but have as much power as any other element. Negotiations play with the means of materializing ideas and not the ideas themselves.

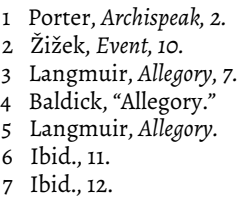




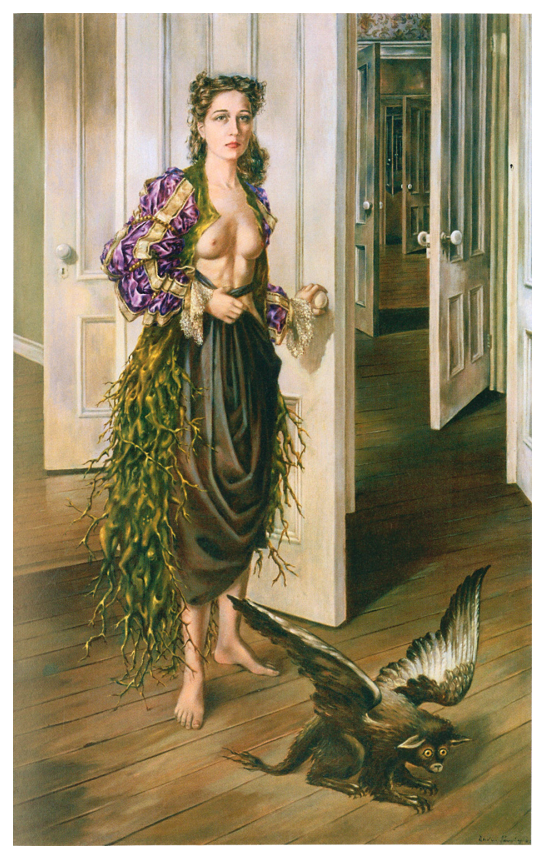

fig. 2-6 Dorothy Tanning, Birthday, 1942

"I had been struck, one day, by a fascinating array of doorshall, kitchen, bathroom, studio - crowded together, soliciting my attention with their antic planes, light, shadows, imminent openings and shutting's. From there it was an easy leap to a dream of countless doors. Oh, there was perspective, trapped in my own room!"’

—Dorothy Tanning, Between Lives

This "self-portrait" depicts a "modern-day" version of the Greek myth of Daphne as Tanning's body is undergoing "a visual metamorphosis." Also, the "'countless doors" that fill the background, like a "mental 'labyrinth'," speak to "her complicated psychological journey as an artist." 

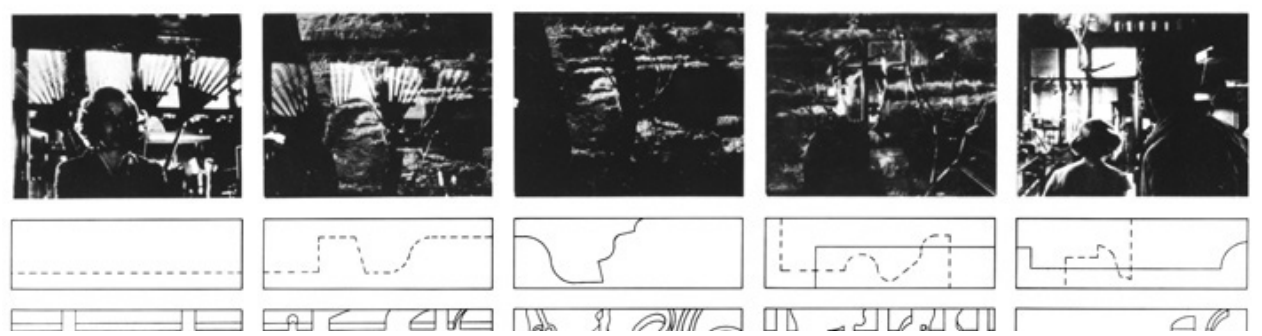

fig. 2-7 Bernard Tschumi, Manhattan Transcripts, 1976-1981
In Manhattan Transcripts (Transcripts), Bernard Tschumi draws on photographic and cinematic techniques to construct a 'visual allegory" of architecture. The overall narrative is set "parallel to the most common formula plot: the archetype of murder."10 In the allegorical fiction that fuels the Transcripts, architecture is a story "about love and death." Set in a real/fictional place, the events and the characters of the transcript come to personify Tschumi's architectural ambitions - a "different way of reading architecture." 


\subsubsection{SURREALISM \& FLAT WORLD}

The aspirations of FLAT WORLD as a distorted reflection of SHORT REAL parallel's the Surrealist ambition "to transform the world and to change life." ${ }^{11}$ Krzysztof Fijalkowski and Michael Richardson elaborate on the conventional misunderstanding of Surrealism and comment that it "must be recognized as addressing a coherent, if perpetually renegotiated and sometimes paradoxical, philosophical engagement." ${ }^{12}$

Dalibor Veseley clarifies that what most people view as a Surrealist "doctrine," ${ }^{13}$ was only the "public face of Surrealism" that had developed in "response to repeated attacks and criticism." It is simplistic to view Surrealism as just another artistic movement. Rather, its mode of operation must be regarded as "a subterranean world of the whole of modern culture." As Veseley holds, Surrealism is more than a "preoccupation [with] marvellous and extraordinary experience" such as "dreams, hallucinations, objective chance and madness." Instead, Surrealism was about an "attempt to reconstruct the qualitative universe" by excavating a world that is "buried behind the positivistic world of quantities." ${ }^{14}$ Veseley distinguishes between Dada and Surrealism and writes:

unlike Dada exploited the result of negation for its own positive goals, developing and cultivating the technique of surprise and bewilderment [...] towards more imaginative ways of disrupting the given, conventional reality until it collapses. ${ }^{15}$

\subsection{4 'POINT SUPREME'}

Dalibor Veseley asserts that the common misunderstanding of Surrealism has hidden its "primary goals." Unlike popular perceptions which "reduce Surrealism to a set of principles and goals-such as automatism, objective chance, transformation of the world and of life," its main motif was "to reach an absolute point of reconciliation of dream and reality ${ }^{16}$ through poetry.

As Veseley remarks: "the task of poetry in Surrealism was not to substitute the existing reality" but "to transform" the world "through the alchemy of words and images." ${ }^{17}$ Similar to "a ritual or magic act in which reality is transformed always in full corporeality," the poet creates "a world not unlike an earthly paradise." ${ }^{18}$ In this world, "the poet" has "the power to revolt against the oppressive hegemony of hyperlogical reality, and [...] is able to create a world which has its own logic.” All of

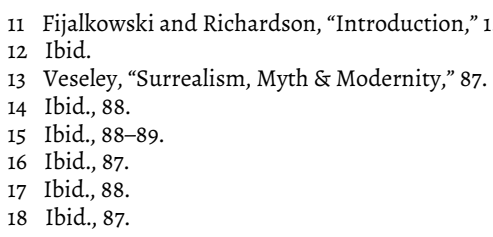


these "reveal the primiary goal of the movment" (that is often ignored): a "supreme point of all contradictions" where "a completely new realitysurreality" is created.

Like "all surrealist activity", ${ }^{19}$ NECOTIATIONS in FLAT WORLD are "directed toward the determination" of 'point supreme'- "the supreme point,"2o "the sublime point."

As the "motive point of surrealism," ${ }^{21}$ the concept of 'point supreme' was defined by Andre Breton in the second Surrealist manifesto as the point where "life and death, the real and imagined, past and future, the communicable and the incommunicable, high and low, cease to be perceived as contradictions." ${ }^{22}$ According to Michael Richardson and Krzysztof Fijalkowski, 'point supreme' is not "metaphoric." ${ }^{23}$ It is not "any sort of aesthetic or poetic gesture" or "an effort to go beyond or bring into question binary oppositions, thus creating a collapse of traditional classifications." Instead, 'point supreme' is constructed around the "very oppositions" ${ }^{24}$ that it addresses.

'Point supreme' is a not an idealistic notion of an "unattainable" ${ }^{25}$ goal at the top of a "mountain peak." ${ }^{6}$ It is a vantage point that offers "a 'panorama' from which to look out." It allows us to transform binary oppositions by determining "the secret that is hidden within their apparent opposition." The paradoxical WORKINCS of 'point supreme' acknowledges that there is a risk of undermining, the very foundation that holds up any "edifice," that leads to the collapse of "reality itself." ${ }^{27}$ It "is a brilliance that may blind us instead of liberate us at the moment of illumination."

fig. 2-8 Giorgio de Chirico, Melancholia, date 1916, painted ca. 1940

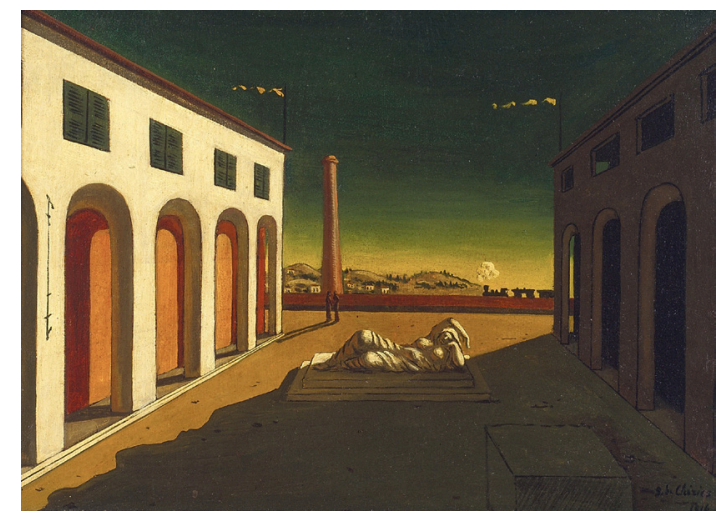

\footnotetext{
19 Richardson and Fijalkowski, "The Supreme Point," 248.

20 Ibid.

21 Ibid.

22 Richardson and Fijalkowski, "The Supreme Point."

23 Ibid., 248.

24 Richardson and Fijalkowski, "The Supreme Point."

25 Ibid., 249.

26 Ibid.

27 Ibid., 248.
} 


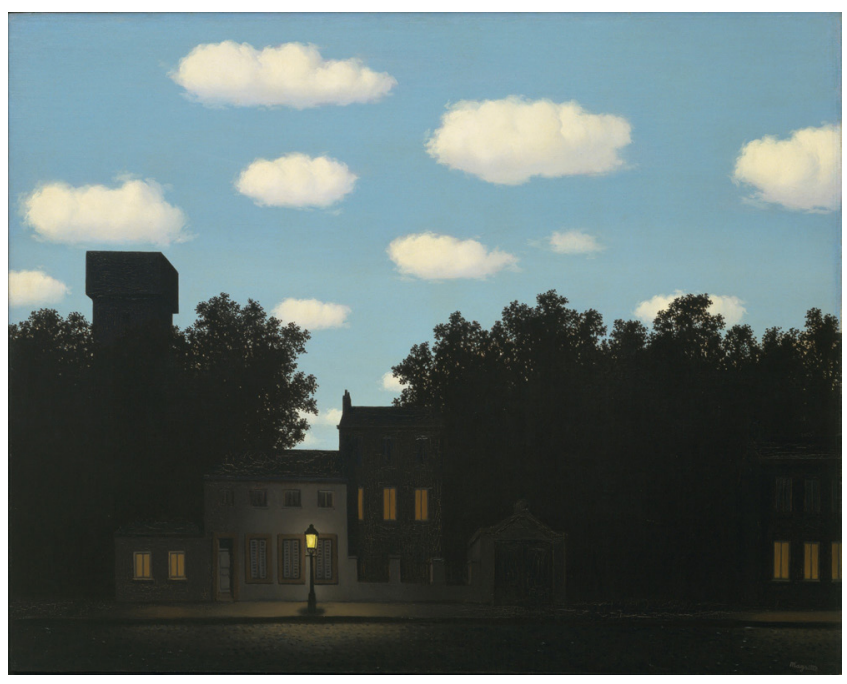

This image by Magritte is paradoxical in two ways: (1) two natural oppositions-night and day-existing at the same time without a conflict and (2) because in today's world with automated, timed and scheduled lighting this scene is an everyday occurrence at certain times of the day. Is it possible to assume that the first instance is Surreal while the second one is a 'Reality Shortage'? Or, does this image signal a new way of negotiating oppositions? fig. 2-9 René Magritte, Empire of Light, II 1950 


\subsection{5 'REALITY SHORTAGE'}

As previously mentioned, SHORT REAL is also a play on words on the concept of "Reality Shortage"28 which Rem Koolhaas discusses in Delirious New York as part of his account of Dalís travels to New York in 1930s and the theorizing of the Paranoid-critical Method (PCM).

According to Koolhaas, "Reality Shortage,"29 is brought on by the "higher density" of our lives as we become more "metropolitan" and engage in a rapid "consumption of the reality of nature and artifacts" which 'depletes' our sources of 'reality' faster than we can replenish them. In "the 2oth century," ${ }^{\circ}$ this "process intensifies" as "all facts, ingredients, phenomena, etc., of the world have been categorized and catalogued." As a result, in this world an "anxiety" overtakes the population since "everything" that "is known, including that which is still unknown" is accounted for and systematized.

As Koolhaas explains, paradoxically, the Paranoid-critical Method (PCM) "is both the product and the remedy against [the] anxiety" ${ }^{31}$ of 'Reality Shortage.' In this world, PCM "promises" to start anew from old stock-to 'recharge' and 'enrich' our 'reality' "through conceptual recycling." Here, "the worn, consumed contents of the world" fuel "new generations of false [alternative] facts and fabricated evidences [that] can be generated through the act of interpretation." Therefore, PcM "proposes to destroy, or at least upset, the definitive catalogue, to short-circuit all existing categorizations, to make a fresh start-as if the world can be reshuffled like a pack of cards whose original sequence is a disappointment." ${ }^{32}$

The concept of 'Reality Shortage' is like the notion of "collective starvation" ${ }^{33}$ as described by Salvador Dalí in his writing on the Paranoid-critical Method (PCM). The difference between Koolhaas and Dalí is how Dalí used PcM to "radically confuse the real" ${ }^{34}$ while Koolhaas used it to "produce the real." Dalí's agenda for PCM was to use it as "as an instrument in the service of visual trickery" 35 and "as a faculty of perception" while Koolhaas sharpens its critical aspect. Nevertheless, for the most parts, their account for the method remains the same.

\subsubsection{PCM (1)}

Salvador Dalí theorized about the Paranoid Critical Method (PCM) in his writings in the early 1930s. Dalí describes PCM as a "spontaneous method of irrational knowledge based on the interpretive critical association of

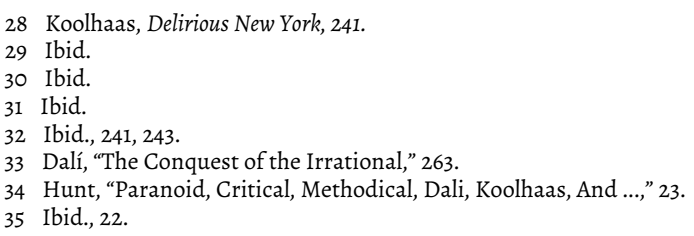


delirious phenomena." ${ }^{36}$ In PCM, the critical activity appears simultaneously with a form of 'synthetic paranoia' and "intervenes uniquely as a liquid developer of images, associations, coherences, and finesses." ${ }^{37}$ In PCM, even small details or unnoticed relations become part of a larger catalogue of reality that is swiftly and undeniably woven together to resemble our own world.

What Koolhaas terms as 'Reality Shortage' is what Dalí refers to as "collective starvation"38 - "the irrational hunger of our contemporaries" ${ }^{39}$ who are

placed before a cultural dining table on which are found only, on the one hand, the cold and insubstantial leftovers of art and literature, and, on the other, the blazing analytical precision of the particular sciences, which are incapable, for the moment, of a nutritive synthesis because of their immoderate extension and specialization. ${ }^{40}$

A society that suffers from "collective starvation" 41 is a society "cretinized by mechanism and by an architecture of self-punishment." ${ }^{42}$

\subsection{7 'CONCRETE IRRATIONALITIES'}

Through PcM, Dalí sought to invade our world with 'concrete irrationalities' that as, uncanny versions of our own objects and images, undermine it from the inside as they replace the conventional 'reality' known to us. They seek to materialize and replace the physical reality itself. As Dali write that

Contrary to the remembrance of dreaming and the virtual and impossible images of purely receptive states, 'that one could only relate,' there are the physical facts of 'objective' irrationality with which one already can injure oneself. ${ }^{43}$

For Dalí, images of 'concrete irrationality' are simulacrums with imperialistic ambitions. 'Concrete Irrationalities' will "pass tangibly to the level of reality," ${ }^{44}$ become the "double image [...] of an object [...] without the slightest physical or anatomical change" 45 and as contagious spies take over the world from the inside without any detection. They will "intervene [and] get into extensive and daily classes with life's other objects, in the broad daylight of reality." ${ }^{\prime 6}$ Their strength or effectiveness is dependent on the strength of the host that they infect. Therefore, the success or

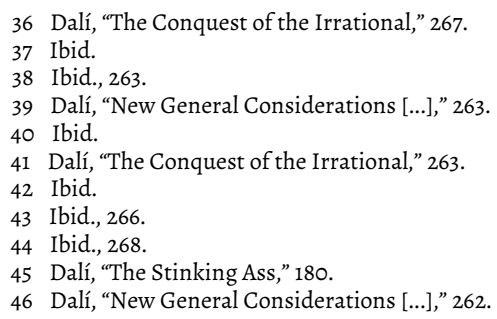


fig. 2-10 Salvador Dali, Diagram of the workings of the Paranoid-critical Method [text added by author] failure of any 'concrete irrationality' is contingent on the qualities of their host because 'concrete irrationalities' are dependent on what already exists in the world.

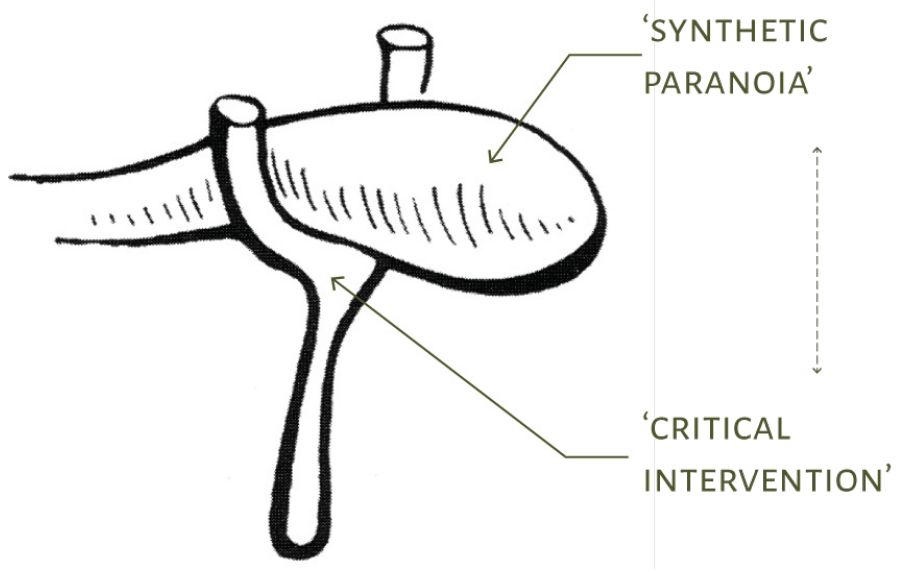

In Delirious New York, Rem Koolhaas explains the workings of the Paranoid-critical Method:

a sequence of two consecutive but discrete operations: [1] Synthetic reproduction of the paranoiac's way of seeing the world in a new light — with its rich harvest of unsuspected correspondences, analogies and patterns. [2] Compression of these gaseous speculations to a critical point where they achieve the density of fact: the critical part of the method consists of fabrication of objectifying 'souvenirs' of those excursions back to the rest of mankind, ideally in forms as obvious and undeniable as snapshots. ${ }^{47}$ 


\subsubsection{A POETIC DIMENSION}

Dalí saw PcM as the next evolutionary step for Surrealism. One of the reasons for this emphasis for PcM striving for physical possibility was Dalí's discontent with automatism, and other passive techniques of the Surrealists. In fact, he saw PCM as a solution for achieving the Surrealist goal of transforming reality ${ }^{48}$ by affecting the objects of the world. If the Surrealists wanted to 'surrender' to their subconscious, Dalí sought to tame the subconscious and transform the reality of the world through its workings.

Dalí saw PcM as a method that could affect any discipline and any form of phenomena. In the opening lines of The Conquest of the Irrational, Dali explains how current scientific methods have cast aside the notion of "logical intuition"49; which had in the past helped particular sciences stride forward, this is what he attributes to the process of 'collective starvation'.

$$
* * *
$$

The design projects of this thesis become CONSPIRACIES at the level of 'poetic images' and 'concrete irrationalities' that assist with harnessing the paradoxical WORKINCS of architecture. Unlike scientifically quantifiable outcomes and artistic expressions of aesthetics, architecture is not all qualitative speculations and (imaginations) and it is not all quantitative empiricism of the materialized world. ARCHITECTURE IS SPECULATION MADE MATERIAL. like a 'poetic image', an element of construction like the HINGED-DOOR-LEAF has "an entity and a dynamism of its own." ${ }^{50}$ It is "independent of causality." In a sense, the HINGED-DOOR-LEAF is an "affect that seemingly exceeds its causes." ${ }^{51}$

$$
* * *
$$

In the case of the door, where the 'poetic image' of Gaston Bachelard is most helpful is in the critique of the "phenomenological" ${ }_{22}$ approaches, like the 'threshold', that deny the everyday realities of the door. For Bachelard, the notion of "poetic creation" goes beyond the typical "imitation-invention' opposition. His view on 'imagination' was unlike "Plato and many medieval phosphors" who viewed it as "copying" or "Kant and the romantics" who "hailed" it "as a productive force in its own right." For Bachelard, the 'poetic imagination' "resisted" the conventional "extremes." Instead, Bachelard viewed 'imagination' "at once receptive and creative" in a territory where oppositions "were inseparable." In his view, "the world itself dreams, and we help give it voice." Bachelard "celebrated imagination's power to realize the unrealized potential of the world"

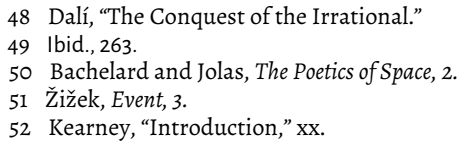


unlike "German Idealists or externalists like Sartre" who viewed it as a tool for "a radical negation of things."

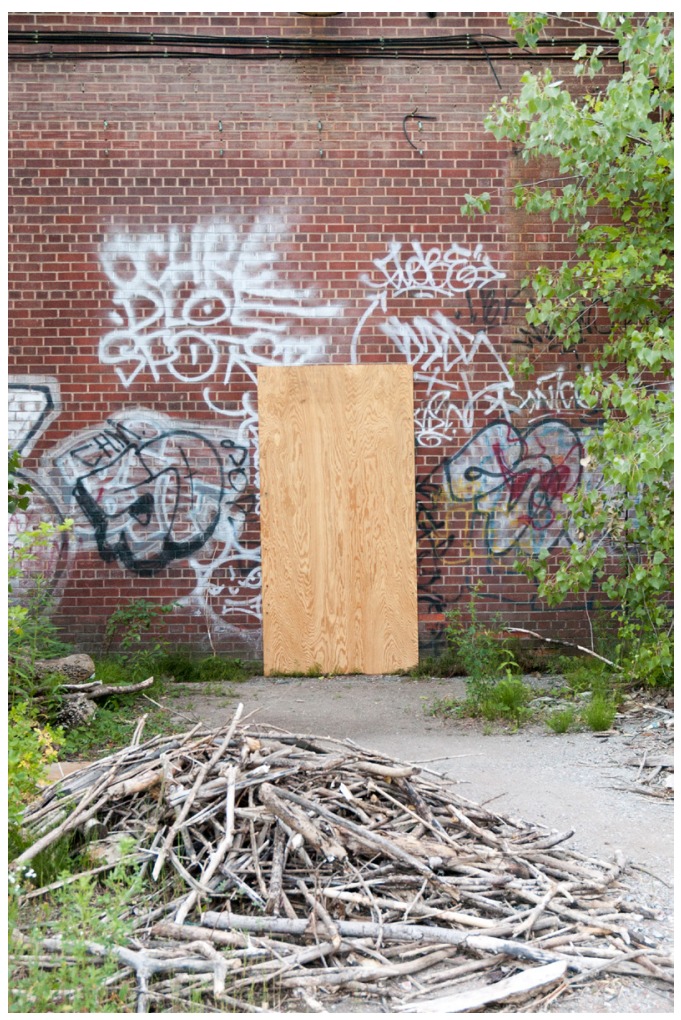

fig. 2-11 A plywood board fastened to a brick wall: a door is a 'concrete irrationality of a wall. 


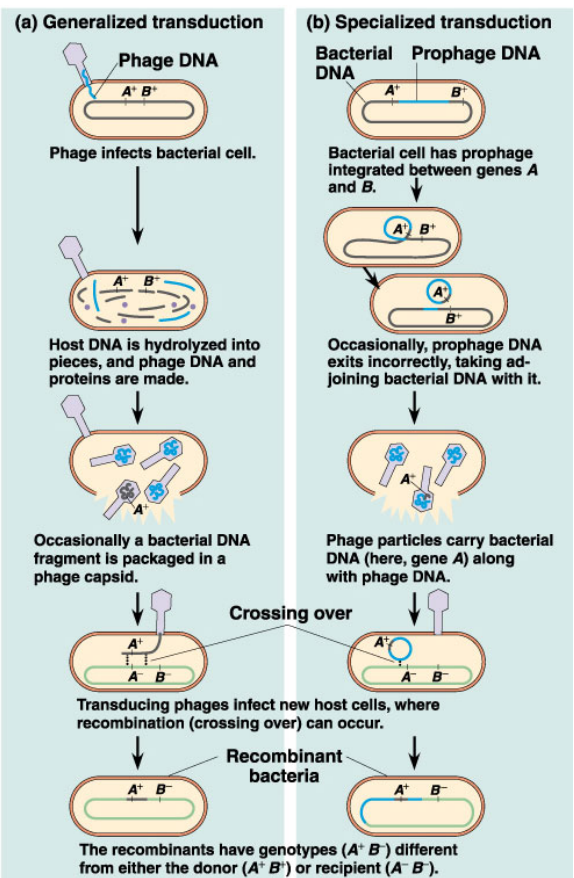

According to Deane Simpson, Delirious Nerw York,

operates predominately in an inductive mode. [...] If the modernist manifesto was intended to be read according to a logic of rationalist deduction, then the reversal of this procedure (induction) corresponds to the retroactive manifesto. In a genetic context, a third term, transduction, refers to the transfer of coded material from one bacterium to another. ${ }^{53}$

\section{Encyclopedia Britannica defines 'transduction as}

process of genetic recombination in bacteria in which genes from a host cell (a bacterium) are incorporated into the genome of a bacterial virus (bacteriophage) and then carried to another host cell when the bacteriophage initiates another cycle of infection. In general transduction, any of the genes of the host cell may be involved in the process; in special transduction, however, only a few specific genes are transduced. It has been exploited as a remarkable molecular biological technique for altering the genetic construction of bacteria, for locating bacterial genes, and for many other genetic experiments. ${ }^{54}$ fig. 2-12 Genetic process of transduction

53 Simpson, "Performative Modernities: Rem Koolhaas's Delirious New York as Inductive Research," 12.

54 "Transduction | Microbiology | Britannica.Com." 
fig. 2-13 Madelon Vriesendorp, Freud Unlimited

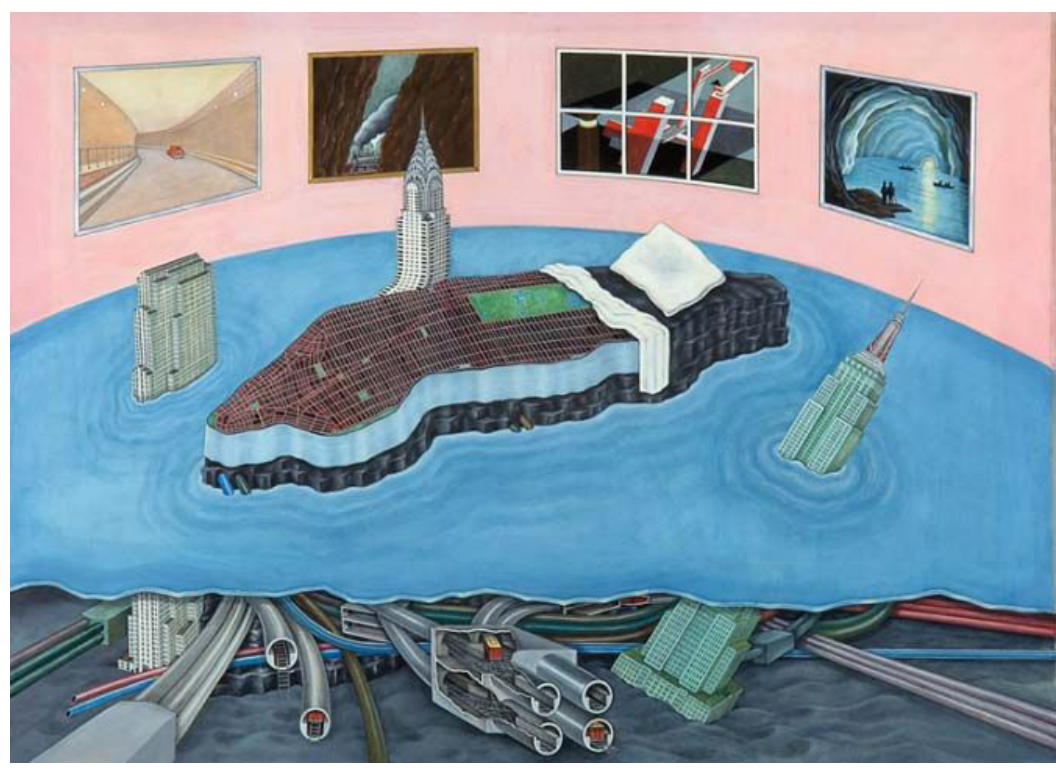

In the Introduction to Delirious New York, Rem Koolhaas explains that a retroactive manifesto was the result of investigating Manhattan as a "mountain range of evidence" 55 . This is contrary to the typical modernist approach to manifestos where no evidence is provided. They are often based on empty promises and idealized personal visions. So, Koolhaas attempts to both reinterpret the notion of manifesto in architecture, and give a framework to a city like Manhattan. At first, Koolhaas declares himself as the "ghost writer"56 for Manhattan, but he uses Manhattan as a justification for projects that he had done before the book; using them to forge a fictional conclusion for his protagonist, 'Manhattanism'. He presents New York and its Manhattanism as irrationalities that when critically assessed are made real, believable and didactic. 


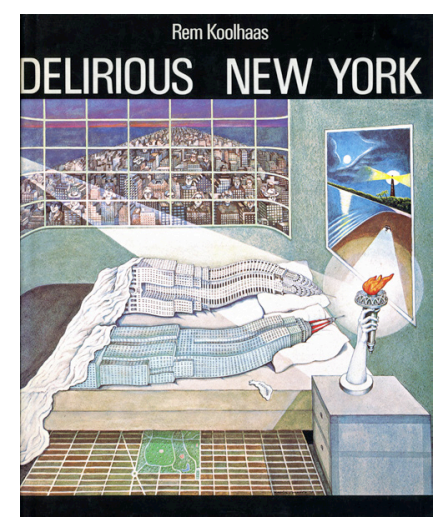

In Delirious New York, 'Manhattanism' uses new technologies (elevators, electricity, plumbing, telephones, etc.) and new materials (steel, flexible wood, etc.) to manufacture alternative realities or fantasies within its buildings. It adapts a made-to-order attitude: borrowing, stealing, and reiterating any form of architecture from any era, collapsing and Flattening time and space. By building vertically, 'Manhattanism' multiplies the virgin land of each block and creates skyscrapers that replicate that piece of land many times. It mutates the time-honoured tradition of harmony between programs in the interior and their representation on the façade by performing an "architectural lobotomy." ${ }^{57}$ It rejects Beaux-art axial planning, at least on the surface, and creates a series of separate blocks, each standing as an island within the island of Manhattan. These blocks absorb the skyscraper into a base that spans the whole block. In return, they create private spaces that are open to public making each citizen into extended house guests.

The spirit of 'Manhattanism' allows its inhabitant to soar to the top of the skyscraper to become self-conscious of the finitude of their island which paradoxically feeds into their need to build higher. ${ }^{58}$ It develops a habit of 'cannibalizing' its own architectural creations as a way of remembering them, immortalizing them through constant reiterations. Manhattanism was a collective experiment, where the architecture was fed by the public's need for pleasure and a place of refuge from everyday life. 'Manhattanism' was both the cause and solution to 'reality shortage' of living on an island with finite boundaries that was laid out to an iron grid. And, Koolhaas presents the whole thing as a carefully crafted movie, with multiple plots, intriguing characters, exquisite mise-en-scene and shrewd montage. ${ }^{59}$ fig. 2-14 cover, Delirious New York 


\subsubsection{SURRATIONALISM}

In an approach to a "critical architecture," 60 Paul Lewis, Marc Tsurumaki, and David j. Lewis adopt "Surrationalism" ${ }^{61}$ as a way "to challenge the familiar, [...] the conventions and norms." Surrationalism was proposed by Gaston Bachelard as a form of "intellectual reform." By using Surrationalism as their "tactic," ${ }^{62}$ Lewis, Tsurumaki and Lewis create a situation where a "what-if...' question" claims an "alternative [...] logic" for their "given object of study" and highlights the "logic that sustains the norm." Then, a second operation - "the speculation"-"sets into motion a sequence that is used to produce the project." Their aim is to reveal the "Snafus" ${ }^{3}$ behind each 'convention' and to logically "exacerbate the logic of the given situation."

\subsubsection{SNAFUS}

Snafu, as defined by a dictionary and understood by the general population, means a state of utter chaos, a mess, and a confused state of affairs. However, as originally used by American Soldiers, SNAFU was an acronym for the phrase: "situation normal all fucked up" ${ }^{64}$ and described a condition were "disorder" was "created by an excess of conflicting Army rules and regulations." Today, snafu simply means "computer glitches, traffic jams," Wi-Fi overloads, or messy line-ups at Christmas sales. Snafus are "anathema to progress and production," and undermine our collective strive for "efficiency, speed, and information exchange." Unlike our contemporary usage of the term Snafu, the original phrase used by the soldiers poignantly described the internal tension of a system-that a system can be normal and fouled up simultaneously. This state is "ironic and paradoxical." ${ }^{65}$ Therefore, despite appearances of order Snafus admit that there is chaos brewing under the surface of an orderly system. As Lewis, Tsurumaki, and Lewis explain the original phrase points to the "seemingly incompatible conditions occurring simultaneously." ${ }^{66}$ This situation "arises not from the insertion of a foreign agent into the system, but as the result of the very structures of the system itself."

In short, Snafus indicate a situation where we are aware of the internal tension of the system; that, underneath the facade of "normal or the familiar," resides another form of it that is "strange and unfamiliar." Therefore, the 'Snafu' of each convention is the strange part that is already part of the system but is not accepted, valued or taken for granted. Therefore, through "conscious, and rational" projects, objects emancipate "rationality from the encrusted habits of convention."

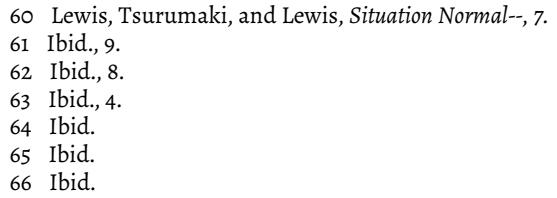




\subsubsection{THE WALL (1)}

When two elements of construction, like the wall with a door, are analyzed together through conventions, they are often labeled as a 'threshold', a 'doorway', or a means of egress. On the other hand, if examined only through their WORKINCS, a wall with a door can be analyzed as the series of relationships between ELEMENTS OF CONSTRUCTION: a wall and a door always go together, and a door always opens away from the wall. In this instance, it is possible to rethink the structure of the system of architecture to rethink the relationship between ELEMENTS OF CONSTRUCTION without succumbing to conventional dogma.

SINCE DOOR AND WALL GO TOGETHER, AND AT SOME POINT, THEY BOTH REST ON THE SAME PLANE, WOULD IT NOT BE POSSIBLE THAT, INSTEAD OF THE DOOR, IT COULD BE THE WALL THAT ROTATES AWAY FROM THIS FLAT PLANE?

\subsubsection{4 'TACTICS' \&'STRATEGIES'}

To reclaim the objecthood of the door and its importance both as an architectural object and architects' greatest invention, this thesis employs certain 'tactics' to challenge, expose and negotiate the CONSPIRACIES of SHORT REAL. Beforehand, it is important to distinguish the difference between 'tactics' and 'strategies'.

$$
* * *
$$

According to Michel de Certeau "strategies demand location of power, require competition," 69 "define legitimate modes of research," "establish the boundaries of acceptable practice" and "are the institutional processes that set norms and conventions." Conversely, "tactics [...] lack a specific location, survive through improvisation, and use the advantage of the weak against the strong." They "are the modes of creative opportunity that operate within the gaps and slips of conventional thought and the patterns of everyday life."

For de Carteau, 'tactics' work "within the constraints of a given order, bringing about 'manipulations within a system' based on an 'absence of power', a 'non-lieu' (non-place) [...] like Freudian Jokes." ${ }^{11}$ In this definition, de Carteau also draws on "the Greek concept of mètis, "ᄁz as "a from of practical intelligence that enables a weaker party to get the better of a stronger [...] by exploiting blind spots in the operation of superior power." Therefore, mètis works as "a series of context-specific operations-polys, scams [...] that rejig the balance of forces." However, unlike 'strategies' that can transform into indoctrinated and rigid "world views," 'mètis' remain open and flexible.

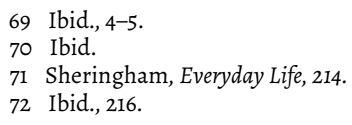



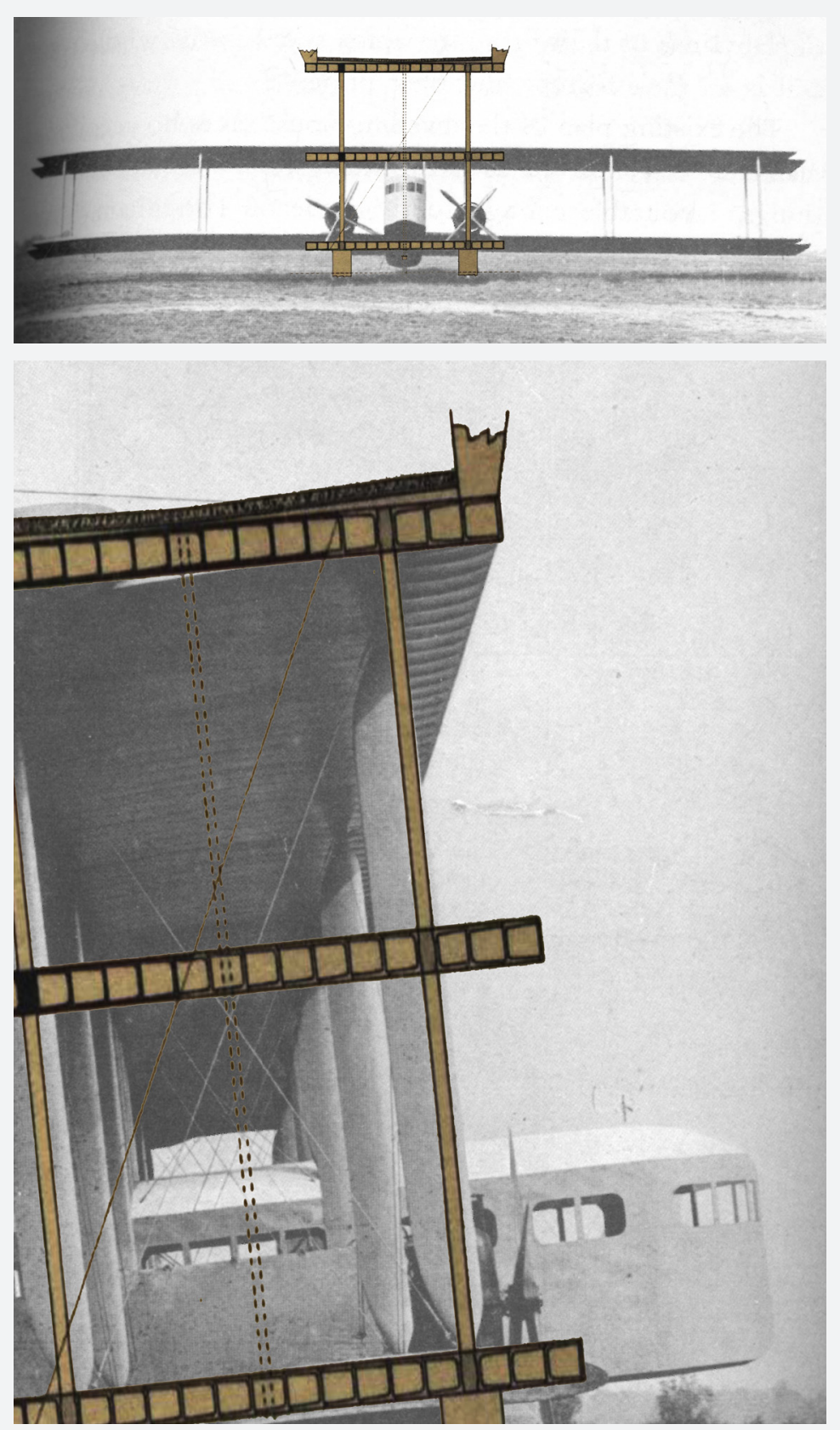

When I was going through Le Corbusier's book Towards a New fig. 2-16 Plane Dom-ino Architecture (1931), I came across many images of airplanes. What I was looking for was a section or detail of Dom-ino. And I saw it in the structure of the airplanes.

Dom-ino is a PcM activity. It makes us wonder if a plane is a flying house or if Dom-ino is a concrete plane. 


\section{2 'TACTICS' OF DESIGN-CONSPIRACIES}

DESICN-CONSPIRACIES OF THE FLAT WORLD AIM TO REINSTATE THE GENIUS OF ARCHITECTURE THROUGH THE GENIUS OF THE HINGED-DOOR-LEAF (THE DOOR). THEY RELY ON THREE INTERCONNECTED 'TACTICS' OF FLATTENING, HYPOTHETICAL QUESTION AND SECTIONING.

In the spirit of PCM, the 'tactics' of this thesis correspond to the two operations of the Paranoid-critical Method. Here, the first 'operation'"synthetic [...] reproduction of the paranoiac's way of seeing the world in a new light" operation - "the critical part of the method"- is achieved through FLATTENING and SECTIONINC which become "objectified a posteriori by the critical intervention." ${ }^{74}$

These techniques enable the projects of this thesis to reveal the possibilities that lie behind the FLATNESS of the conventional perceptions of architecture and the HINGED-DOOR-LEAF.
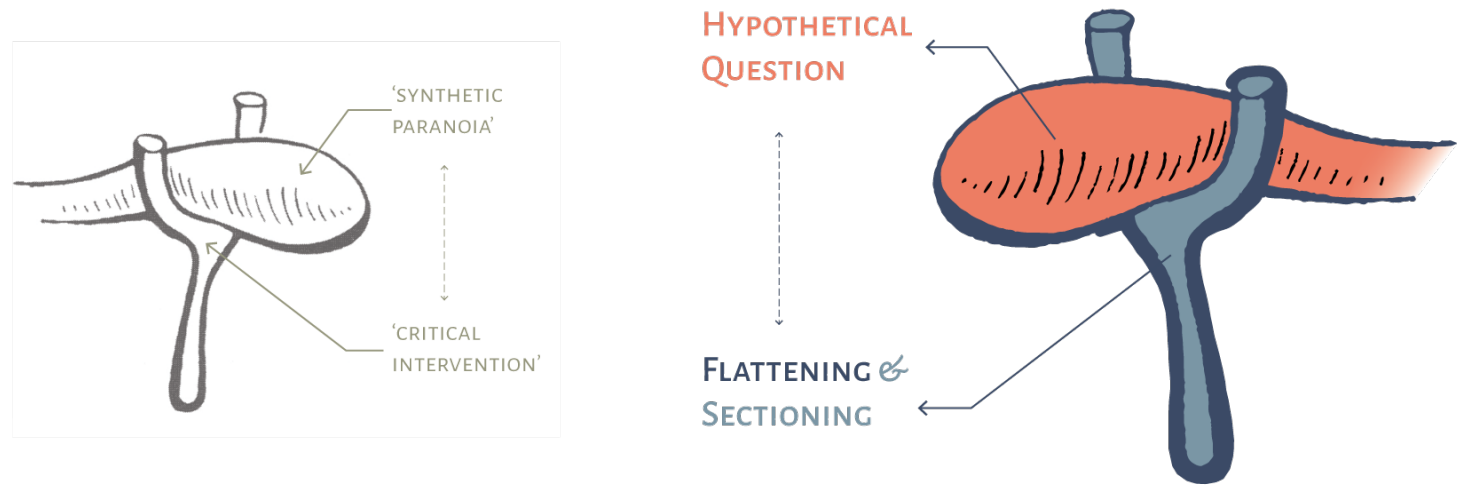

fig. 2-17 how the 'tactics' of this thesis relate to PcM 


\subsubsection{HYPOTHETICAL QUESTION}

A HYPOTHETICAL QUESTION sets up a condition/situation where design must respond to an illogical problem. Through FLATTENING and SECTIONING, each design must respond to the question as if the condition were real. Therefore, each HYPOTHETICAL QUESTION must be pursued with material realities of architecture in mind.

\subsubsection{Flattening}

In Flat World, FLATTENING is engaged as a device for both interpretation and design. FLATTENING is a 'tactic' of this thesis that allows any design or interpretive exercise to begin from a leveled field. It FLATTENS of all differences that might privilege one concept, object or perception over others when approaching a subject.

FLATTENING is a conscious and critical oblivion (disregard, naivete, ignorance) for all the conventional perceptions (hierarchies, perceptions, scale, size, material specificity, assembly sequences, disciplinary specific knowledge and many others) that influence our understanding of the ubiquitous objects in the everyday world.

FLATTENING denotes an understanding that when the world is FLATTENED (hence, FLAT WORLD) even the smallest bits (the repressed, the ignored or the seemingly invaluable) can become that basis for transformation. Because of FLATTENINC, in FLAT WORLD, nothing is sacred and nothing is taken for granted.

NOW, THE TITLE OF THIS THESIS COULD ALSO MEAN: WHEN THE WORLD IS FLATTENED, EVEN THE SHORTEST FORMS OF REALITY CAN BECOME THE STARTING POINT FOR TRANSFORMING THE EVERYDAY REALITIES OF ARCHITECTURE.

\subsubsection{SECTIONING}

The DESICN-CONSPIRACIES that correspond to the conditions of the HYPOTHETICAL QUESTIONS draw on the findings of the FlatTENINC of conventions. If FLATTENING takes always all the conventional axioms about an element, then in response to the HYPOTHETICAL QUESTIONS, SECTIONING highlights some aspects of architecture that is often ignored in conventional design.

By responding to a HYPOTHETICAL QUESTION through design, SECTIONING reveals the hidden possibilities of ELEMENTS OF CONSTRUCTION.

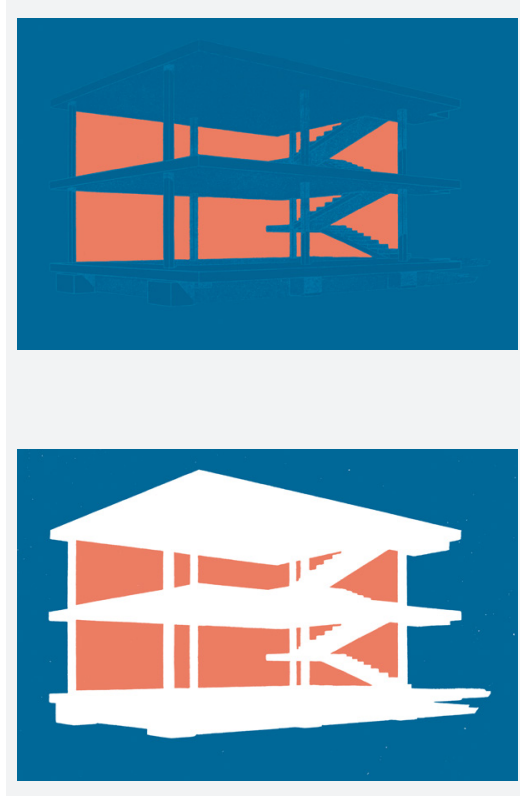

fig. 2-18 Dom-ino Flattened 


\subsubsection{INTERACTION OF 'TACTICS'}

The interaction of these three 'tactics' is not linear.

There are times when a design begins with a HYPOTHETICAL QUESTION. There are times that the HYPOTHETICAL QUESTION become evident at the end of each design.

Also, FlATtening and SeCtiONING are always at work but they do not necessarily follow each other. A FLATTENINC from a previous project can inform the SECTIONINC of another. And, the SECTIONINC of one project can start FLATTENINC of other projects.

The 'tactics' of the projects presented here do not follow a logical (or conventional) path. Instead, as it is the case with humans, they behave idiosyncratically: they feed on whatever that is useful to their cause (even cannibalize each other). They infect other projects retroactively or host other explorations that have not become started.

In short: A HYPOTHETICAL QUESTION sets up an irrational logic for a DESICNCONSPIRACY. The FLATTENING is a conceptual abstraction of all the conventional thinking about a certain topic. during SECTIONINC, the materialized responses to the HYPOTHETICAL QUESTION and FLATTENING reveal other possibilities, that would have remained unexplored. Since architecture is speculation made material, if the question was only evaluated as a purely conceptual construct.

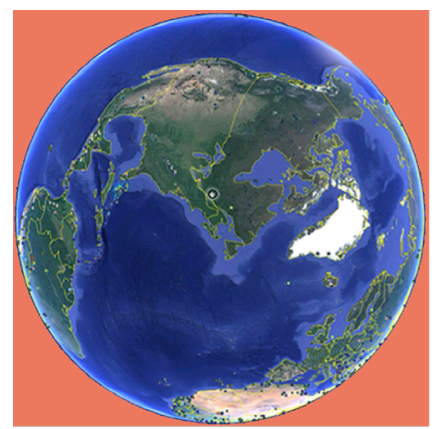

"Not to Scale"

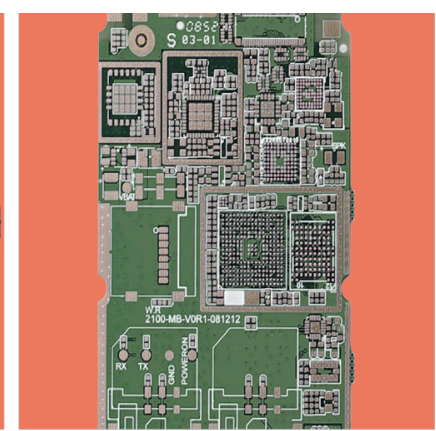

"Not to Scale"

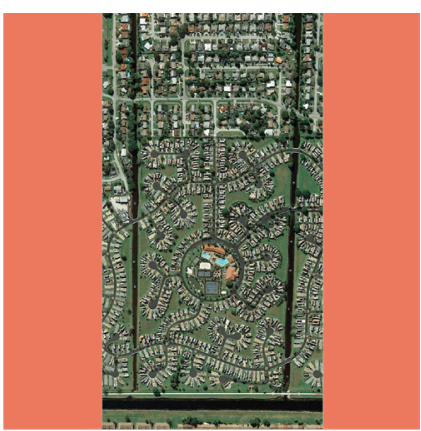

"Not to Scale"

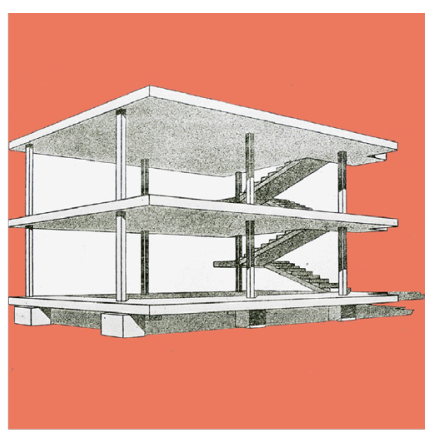

"Not to Scale"

fig. 2-19 Scale of objects FLATTENED 

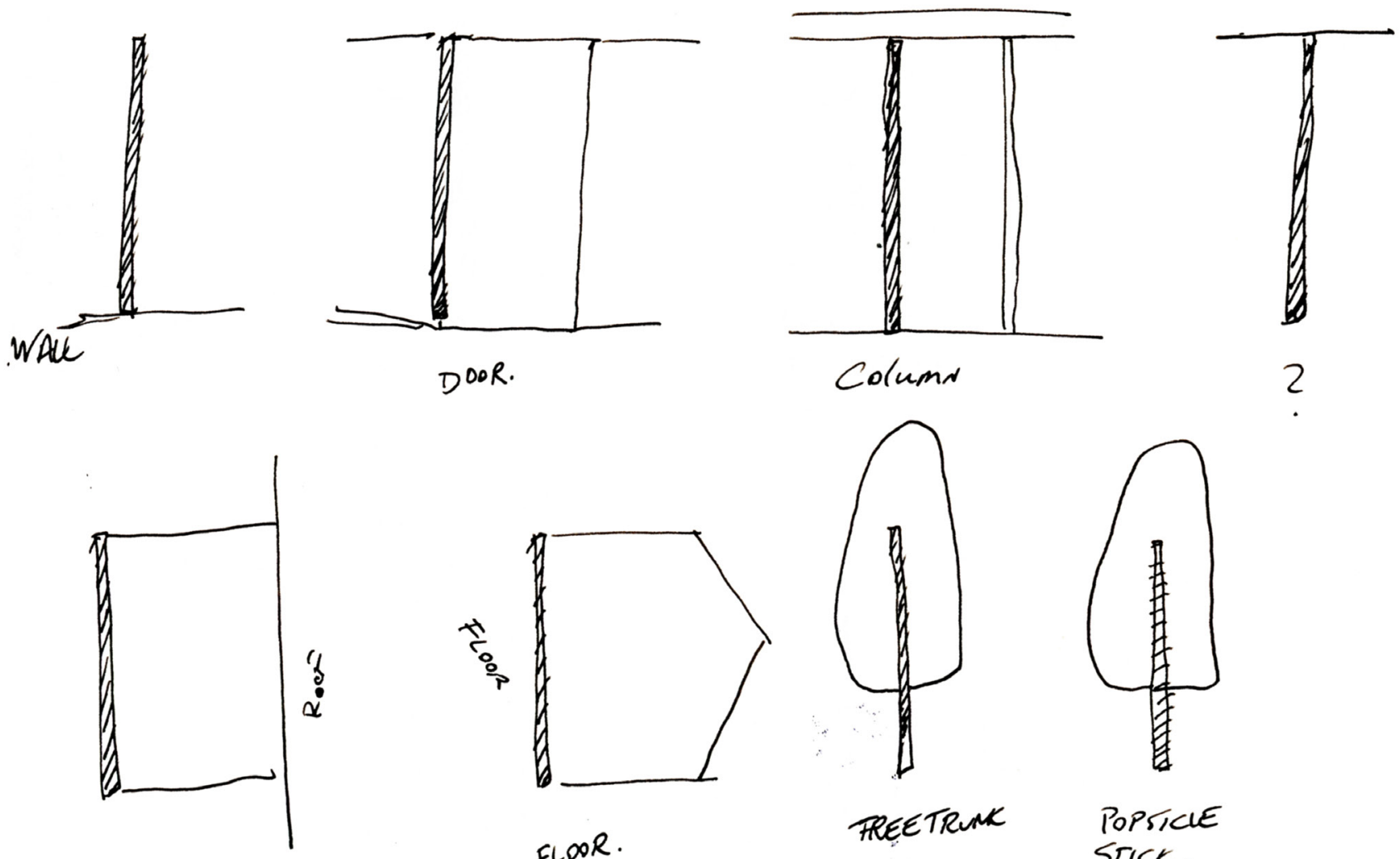

Roof.
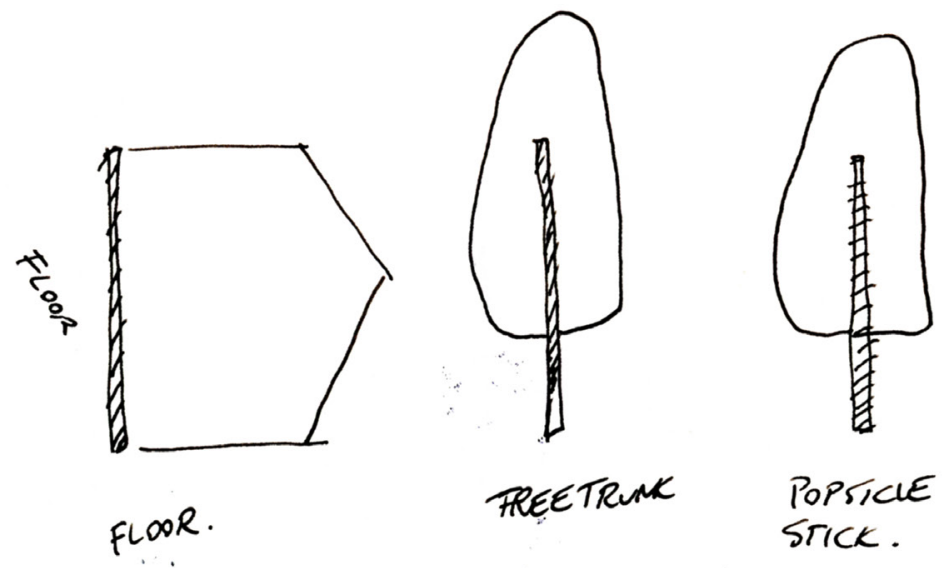

fig. 2-20 differences and perceptions between everyday things and ELEMENTS OF CONSTRUCTIONS FLATTENED, sketch

\subsubsection{FLAT}

The terms Flat World, FLATTENING or FlatNess that are used by this thesis were inspired by the concept of 'flat ontology." ${ }^{75}$ Flat Ontology opposes to structure a discipline in hierarchical orders. In Flat Ontology objects might differ in spatio-temporal scale, but they are at equal level in relationships to each other in their ontological status. 


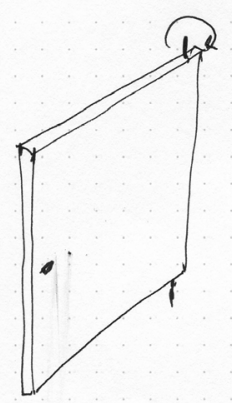

PIVOT DOOR
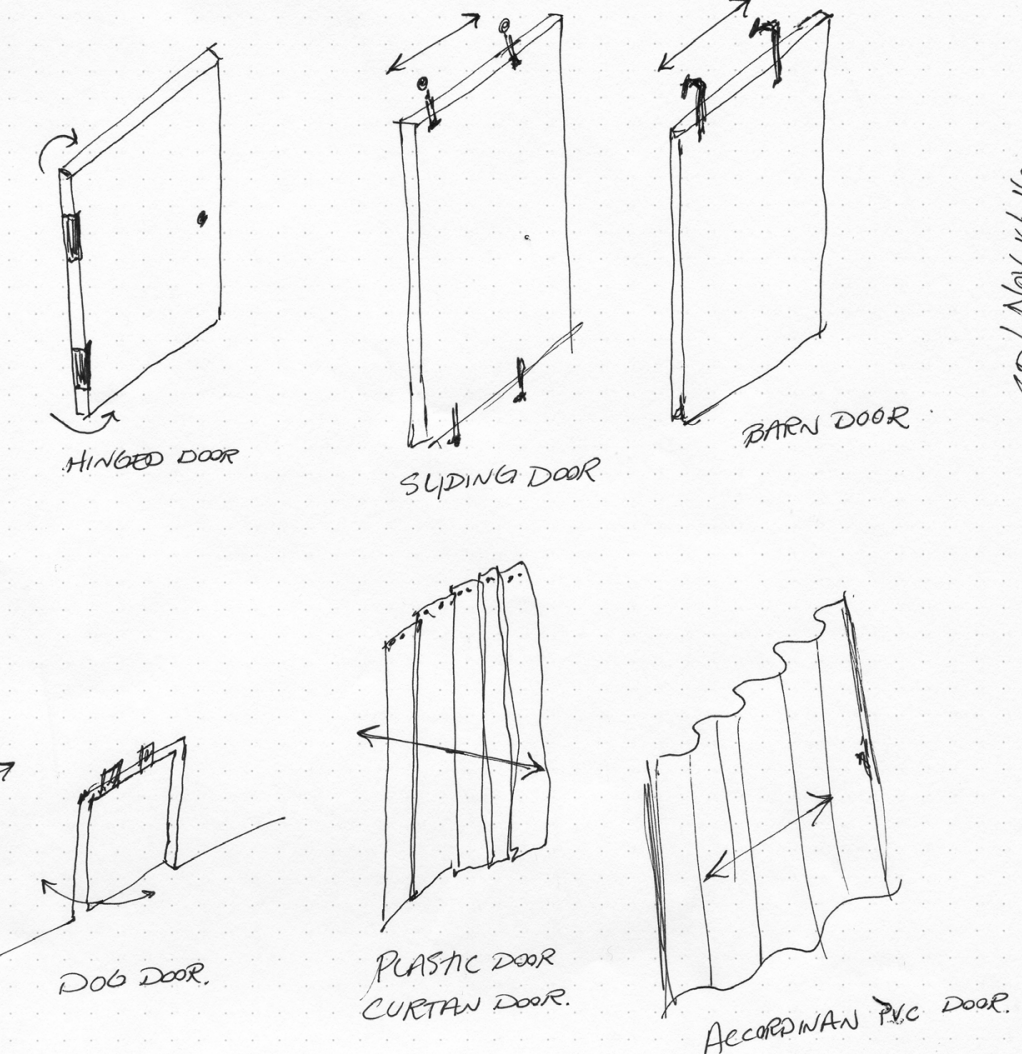

$\frac{2}{2}$

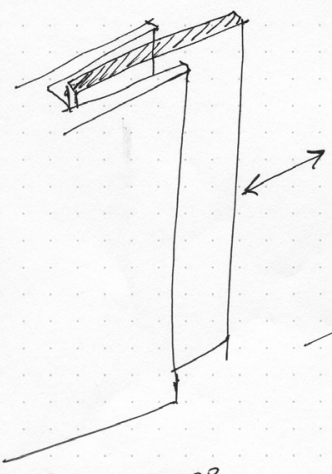

POCKET DOOR.
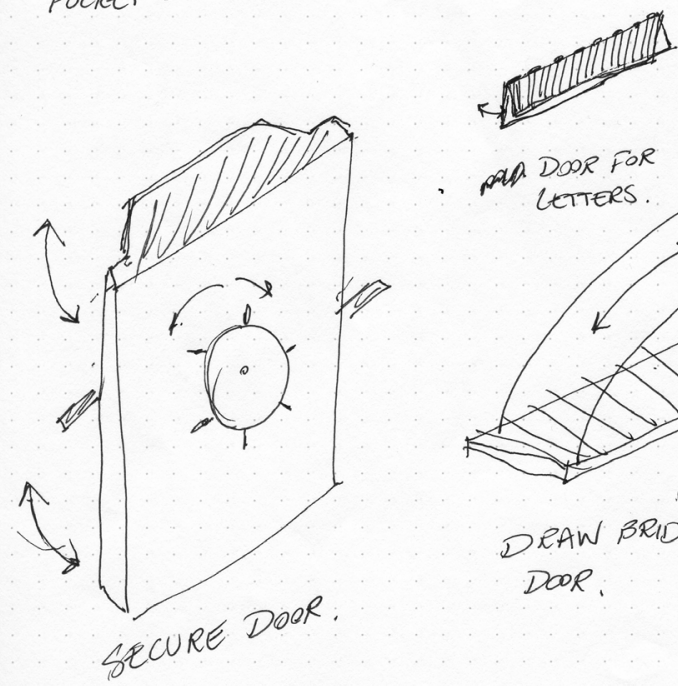

fig. 2-21 Few different types of doors, sketch 


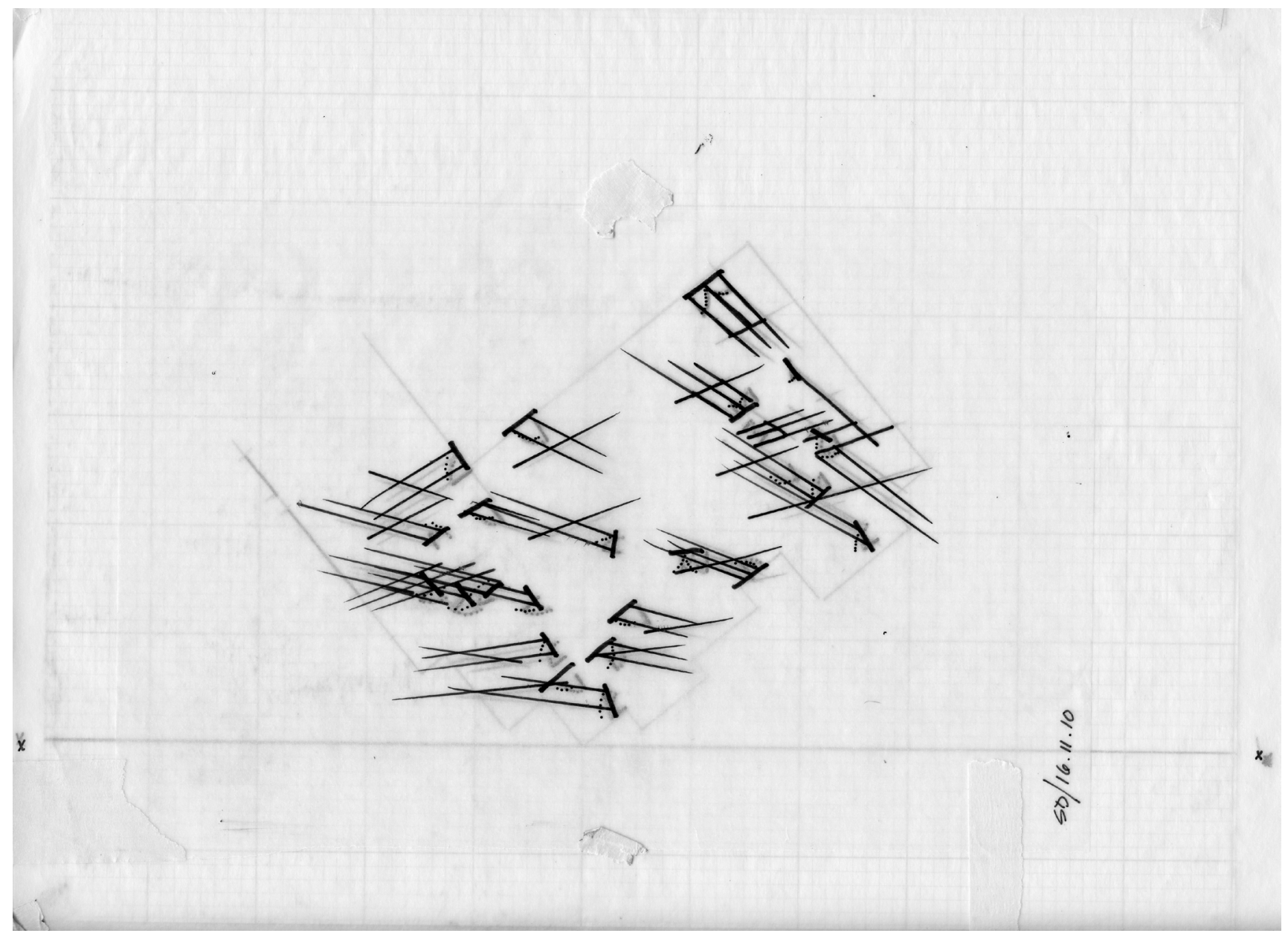

fig. 2-22 perspectives of all the doors of a house Flattened 


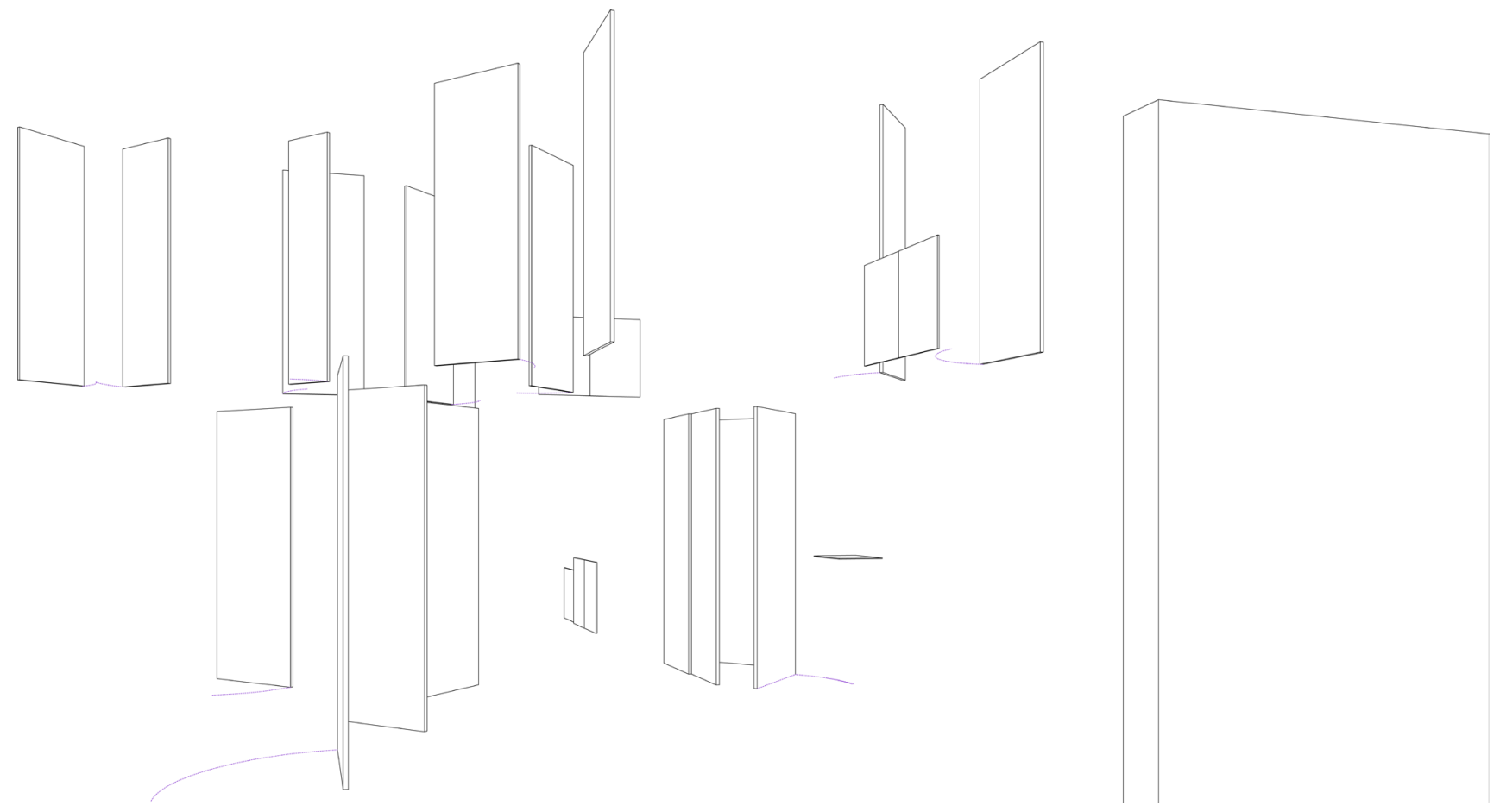

fig. 2-23 a suburban house through all its doors, perspective

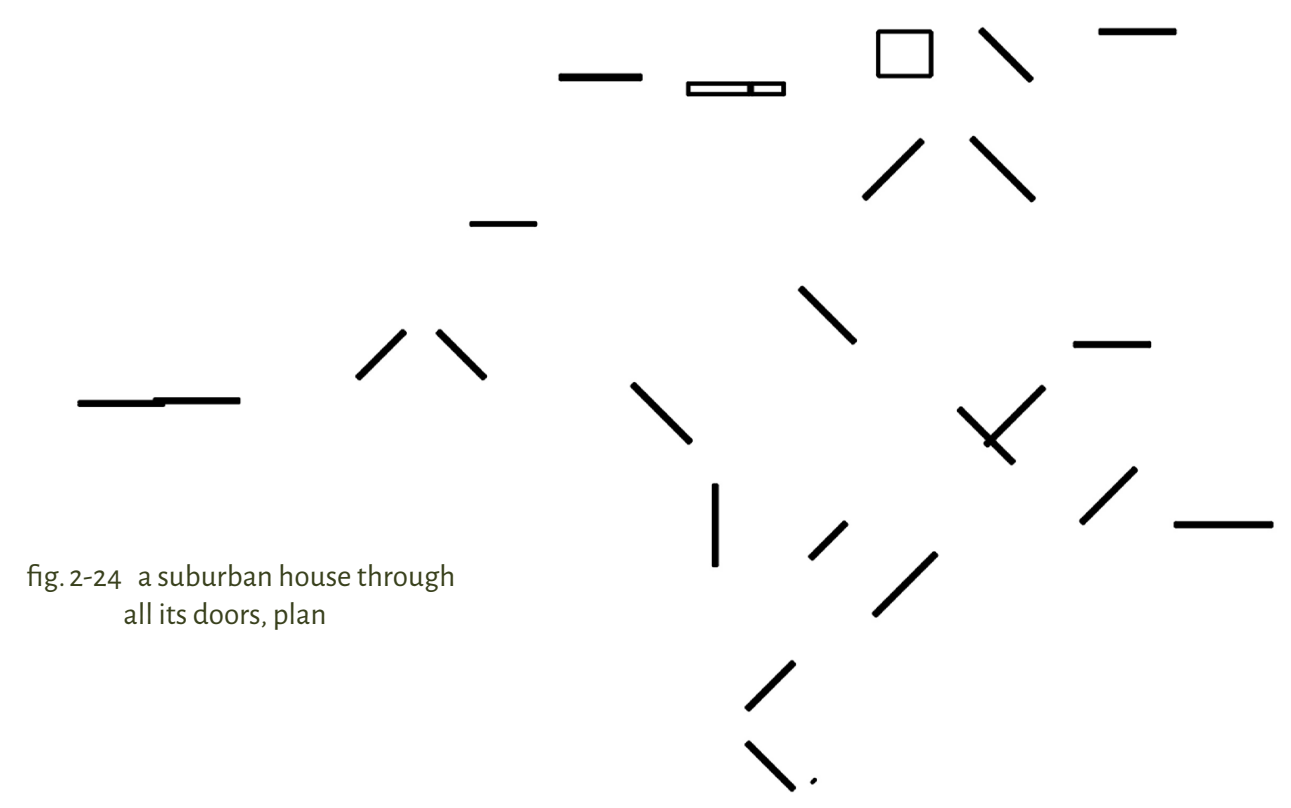




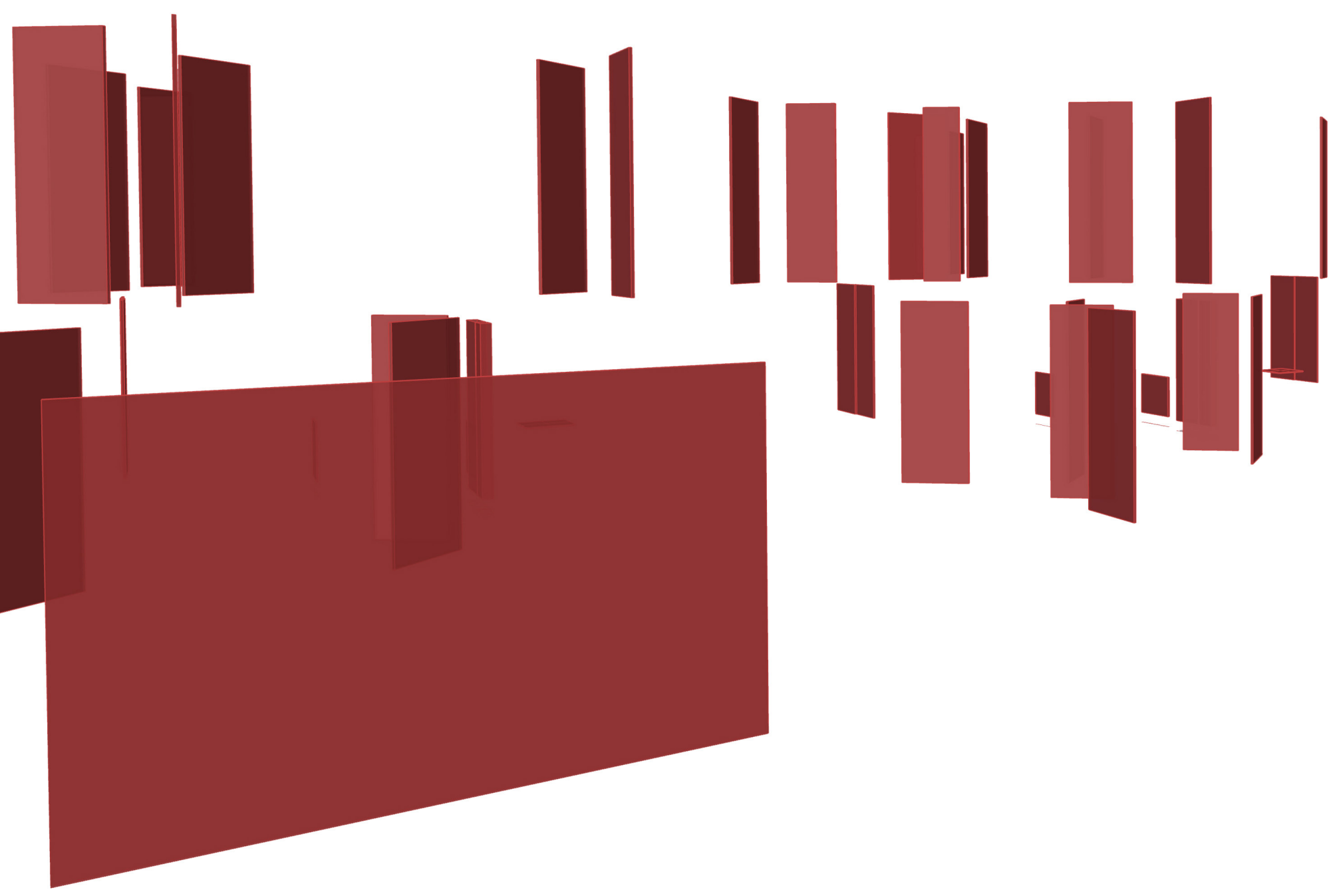

fig. 2-25 A suburb through all its doors, perspective [top image]

fig. 2-26 A suburb through all its doors, plan [opposite page] 
"There are critical movements ... that attempt to introduce dynamism into [an] static structure ... in the more general context, the introduction of an exterior to the system."

— Kojin Karatani

"As we are contingent beings, and therefore destined to die, we desperately need to think there is something to fasten onto that will not perish, in other words, an Absolute."

-Umberto Eco
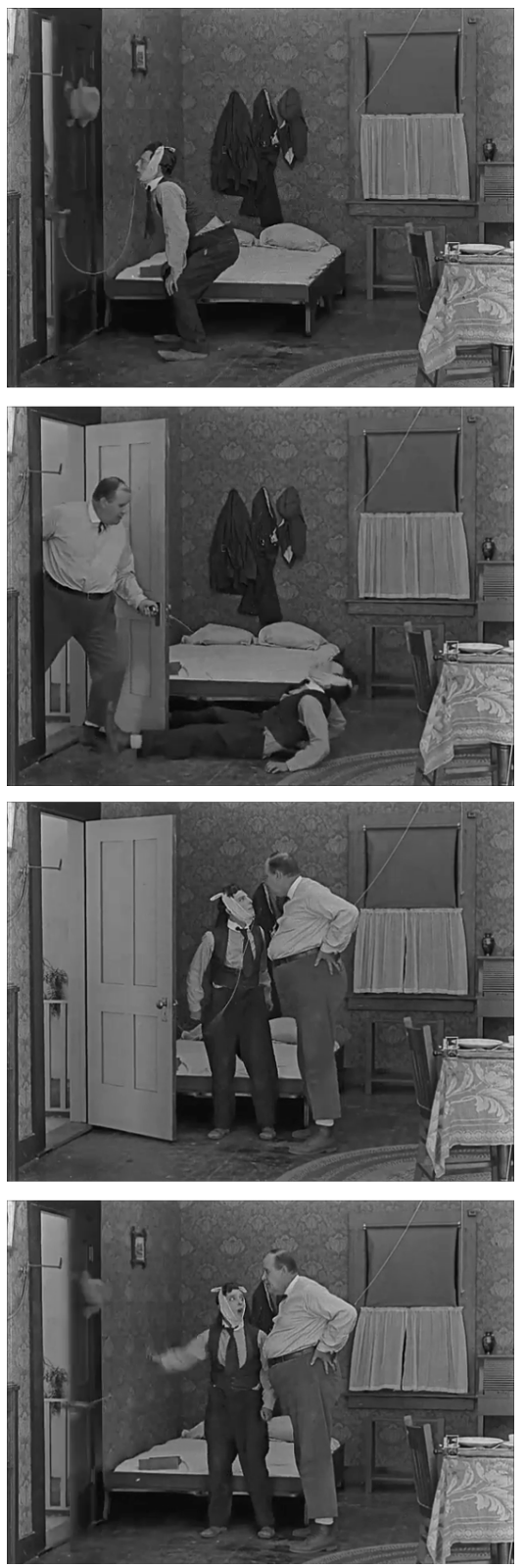

fig. 3-1 Buster Keaton, The Scarecrow, 1920

1 Kōjin Karatani, Architecture as Metaphor: Language, Number, Money, ed. Michael Speaks, trans. Sabu Kohso, Writing Architecture (Cambridge, Mass: MIT Press, 1995), 73.

2 Umberto Eco and Richard Dixon, Inventing the Enemy and Other Occasional Writings, $2013,23$. 


\section{A STRING OF CONSPIRACIES}

THIS CHAPTER ESTABLISHES THIS THESIS'S OBJECTIVE THAT ARCHITECTURE IS 'DECEPTIVE', PARADOXICAL AND CONTINGENT THROUGH A COMPARISON OF WHY ARCHITECTURE IS DIFFERENT FROM OTHER DISCIPLINES. THROUGH AN EXAMINATION OF PROBLEMS WITH BORROWING FROM PHILOSOPHY AND LINCUISTICS, THIS CHAPTER CRITIQUES BOTH Peter Eisenman and Aldo van Eyck and demonstrates the GENERAL PROBLEM THROUGH THE INTERDISCIPLINARY EXAMPLE OF WitTGEnstein HOUSE. 


\subsection{CONSPIRACY OF SYMMETRY}

\subsubsection{TWO DISCIPLINES}

In SHORT REAL, the assumption is that architecture (as a discipline) is analogous to other disciplines and their workings. This short-sightedness can create many problems when designing with elements of construction. While, there is nothing wrong with borrowing terms or concepts from other disciplines, when the transaction happens between two disciplines such as philosophy and architecture, with two vastly different workings, one must be vigilant not to undermine either of the disciplines. In SHORT REAL, theories of architecture (like Eisenman and van Eyck) assume that the WORKINGS of architecture and philosophy as two distinct disciplines are symmetrical to each other.

Philosophy has specific qualities that are at odds with the genius of architecture. There are three problems that must be considered when architects establish an inter-disciplinary relationship with philosophy, without due diligence:

1) philosophy's prime medium is language while architecture is a multi-media ${ }^{3}$ discipline. This problem is most evident in the use of philosophical categories as metaphors in architecture.

2) Philosophy has an idealized (and divided) relationship with materialized objects ${ }^{4}$ while architecture is about negotiating the 'form-matter opposition'. ${ }^{5}$ This difference appears in the way philosophers either dismiss or idealize the inherent value of objects.

3) Philosophy is about 'absolutes' ${ }^{\prime}$ while architecture is about contingency. ${ }^{7}$ This difference is most evident in the way philosophical concepts, like 'form', 'space' or 'place', are used as absolute binary oppositions that force architect to take side on an imaginary spectrum of oppositions.

3 Adrian Forty, “The Empire of Language," Thesis // Bauhaus-Universität <Weimar> Heft 3 (2003): 23-26.

4 Graham Harman, The Quadruple Object, epub (Winchester, U.K.: Zero Books, 2011).

5 [based on what Vilem Flusser terms as "the original opposition 'matter-form"'] Vilém Flusser, "Form and Material," in The Shape of Things: A Philosophy of Design, trans. Anthony Mathews (London: Reaktion, 1999), 24.

6 Todd McGowan, "We Are Already Dwelling: Hegel and the Transcendence of Place," in The Missed Encounter of Radical Philosophy with Architecture, ed. Nadir Lahiji (A\&C Black, 2014), 55-68.

7 Karatani, Architecture as Metaphor; Jeremy Till, "Architecture and Contingency," Field 1, no. 1 (2007): 120-135. 


\subsection{METAPHORS \& $\mathrm{f}$ ARCHTECTURE}

\subsubsection{METAPHORS}

Architecture is a multi-media discipline and architects make use of at least three mediums in its practice: "Drawing, Language (both spoken and written), and Building." ${ }^{8}$ Metaphors, as a linguistic device of "analogy," bridges the communication barrier between architects and those who are not part of its discipline. As Charles Jencks posits, "metaphor plays a predominant role in the public's acceptance or rejection of buildings." ${ }^{\circ}$ Nevertheless, as Paul-Alan Johnson posits, this understanding should "in no way" be employed for "designing" and writes that

The attempt here has been to reposition metaphor at the conceptual end of the spectrum, as architects do when they offer up retrospective dictums in the form 'Architecture is ...' for others to latch on to while designing.

Johnson further explains that "Metaphor is a technique of transferring or transporting a name or description to something as if it were that thing but clearly is not." ${ }^{\prime 2}$ Also, as Adrian Forty posits,

Metaphors are never more than partial descriptions of the phenomena they seek to describe, they are always incomplete. Indeed, were they to succeed in total reproduction, they would cease to be metaphors, which subsist through likenesses drawn between inherently unlike things. ${ }^{13}$

The problem of metaphors in the discourse (Short Real) comes from the "all-or-nothing attitude"14 of the discourse when using them. Adrian Forty criticizes this attitude that demands architects to "subscribe" to "metaphors" not for their conditional usefulness but as an "allegiance to a full-blown system" 15 that impacts the design and making of architecture.

8 Forty, "The Empire of Language," 17

9 Garry L. Hagberg, "Metaphor," in The Routledge Companion to Aesthetics, ed. Berys Nigel Gaut and Dominic Lopes (London; New York: Routledge, 2001), 285, http://site.ebrary.com/id/2002431.

10 Gernot Böhme, "Metaphors in Architecture - a Metaphor?," in Metaphors in Architecture and Urbanism: An Introduction, ed. Andri Gerber and Brent Patterson, Architecture 19 (Bielefeld: Transcript-Verl, 2013), 47.

11 Paul-Alan Johnson, The Theory of Architecture: Concepts, Themes \& Practices (New York: Van Nostrand Reinhold, 1994), 431.

12 Ibid., 428.

13 Adrian Forty, Words and Buildings: A Vocabulary of Modern Architecture, 1st paperbacked (New York, NY: Thames \& Hudson, 2004), 84

14 Ibid.

15 Ibid., 85. 
As Paul-Alan Johnson holds, in the discourse of architecture, "the understanding of architecture is metaphoric in that it is rarely known for itself."16 For the most parts, architecture is always understood as something that 'stands' in for something else. This sentiment is mirrored by Gernot Böhme who posits that "The understanding of architecture through the metaphors of another art/discipline [...] arises because of the quite strange, but at the same time classic embarrassment to state what architecture should be as discipline in its own terms. ${ }^{17}$ As Böhme explains, the allure of metaphors is their capacity to "allow for an initially diffuse amount of data to be theorized," ${ }^{18}$ which approximates the scientific methods. In "the Western tradition," architecture "is understood either as 'standing for' something else by virtue of interpreting meaning." In contrast, in the "Eastern tradition," it is understood "in the relation effected between it and the participant or observer." Johnson concludes that "in short, Western architecture is primarily accessed through and currently obsessed with metaphor."

\subsubsection{THE DOOR (2)}

No wonder that Gaston Bachelard warns us that "we are obliged to supervise the use of fossilized metaphors. For instance, when open and closed are to play a metaphorical role, shall we harden or soften the metaphor? Shall we repeat with the logicians that a door must be [either] open or closed?"2o

\subsection{3 'MONODIC' (1)}

"This metaphor provides the system's form in every area where it appears. Which results in the repression of anything resembling play, exteriority, or alterity. The system tends to be monodic: it has only one voice, the other voice is not heard there." ${ }^{21}$

-Dennis Hollier

Historically, philosophers have borrowed terms from the vocabulary of architecture to represent their ideas, which is part of the genius of architecture. The name of the Elements of construction, like the threshold or the door, might be communicated through different sounds in different languages but what they represent is rather universal. All that is needed to imply that there should be a door somewhere is to translate the word. Everything else, the way it works and the way people engage with it is universal. 
That is why, according to Denis Hollier, architecture as a "system of systems"22 Allows "various fields of ideological production" to find a common tongue through its terms. However, as Hollier holds, the metaphors of architecture can become problematic when they muddle the discipline's understanding of itself. For example, to define a term like architecture itself, the metaphors of 'architecture' in other disciplines distort the territory to an extent that deciphering "the proper meaning"23 becomes a challenge. In this case, architecture becomes "a compulsory loan burdening all of ideology, mortgaging all its differences from the outset." The prevalence of architectural terms like "keystone," "structure," "foundation," or "pillar" in philosophy and theology is a testament to this argument.

According to Kojin Karatani, "in the Occident, since Plato, philosophers have figuratively likened themselves to architects, namely, the archeof-techne (head of knowledge), although they made little of architects in practice, since they were handicraftsmen." ${ }^{25}$ In the metaphor of architecture, Plato found the perfect instrument to resist or withstand all 'becoming's' by reconstructing them as 'makings', "26 which contradicts the material reality of architecture. The metaphoric architecture of Plato is 'monodic' and happens in the mind which is "Unlike the substantial materiality of architecture" that "belongs to the realm of what we might call 'semi-becoming."

\subsubsection{THE 'THRESHOLD' (2)}

Threshold, the element of construction, was borrowed by philosophers and anthropologists who used it to represent very specific ideologies. By most accounts, the association of the door with the 'threshold' (the metaphor) is traced to the writings of anthropologist Arnold van Gennep. In his "1909 work The Rite of Passage, "27 Gennep developed a thesis around "various ceremonies that mark the successive stages of human life." For Gennep, "The door is a boundary between the foreign and domestic worlds in the case of an ordinary dwelling." ${ }^{28}$ Also, the door separates "the profane and sacred worlds in the case of a temple." Gennep's work "influenced" 29 many thinkers at the time. For instance, Walter Benjamin observes that our daily life has become devoid of "rites" that can enrich our life. He asserted that in our modern life, "we have grown very poor in threshold experiences" and attaches the term "threshold magic" to "porches, doorways and vestibule" as they can manifest "magical effect" as we pass through them. However, the anthological views that were the

25 Kōjin Karatani, "Architecture and Association," Thesis // Bauhaus-Universität<Weimar> Heft 3 (2003): 23. 26 Karatani, Architecture as Metaphor, xxxi.

27 Georges Teyssot, A Topology of Everyday Constellations, Writing Architecture (Cambridge, US: The MIT Press, 2013), 87 .

28 Ibid., 162.

29 Ibid., 87.
} 
basis for his ideas where drawing on "a biased manipulation of French and German historians during the late nineteenth century."

\subsubsection{MONADIC (2)}

The 'threshold' operates as a metaphor that aims to scientifically generalize a set of common human everyday operations into a universal set of moral values. Its conception was nothing more than a 'temporal fallacy'similar things happening at the same time, but for different reasonsthat worked for philosophy but fails to be as useful in architecture.

Any interaction with the concept of 'threshold' requires a reciprocity that only emerges from pre-selected 'values' and 'histories'. When architects approach the door with only conventions and conspiracies to guide them, they passively play the Surrealist game of Exquisite Corpse, where the cultural and disciplinary dogmas feed into our understanding of the discipline of architecture.

\subsection{6 $\operatorname{PCM}(3)$}

In Delirious New York, Rem Koolhaas holds that Paranoid-critical activities have always been present in the human history. In a sense, a PcM activity mimics the "process of colonization-the graft of a particular culture onto an alien site." ${ }^{31}$

Therefore, it is possible to see how the prevalent and uncritical use of metaphors in the discourse is like 'grafting' of one culture into another. In SHORT REAL, metaphors (and binary opposition) are the weapon of choice of it conspiracies. Therefore, in FLAT WORLD, and through its PCM-inspired 'tactics', one PCM activity-metaphors- is critique through another PcM activity-design conspiracies.

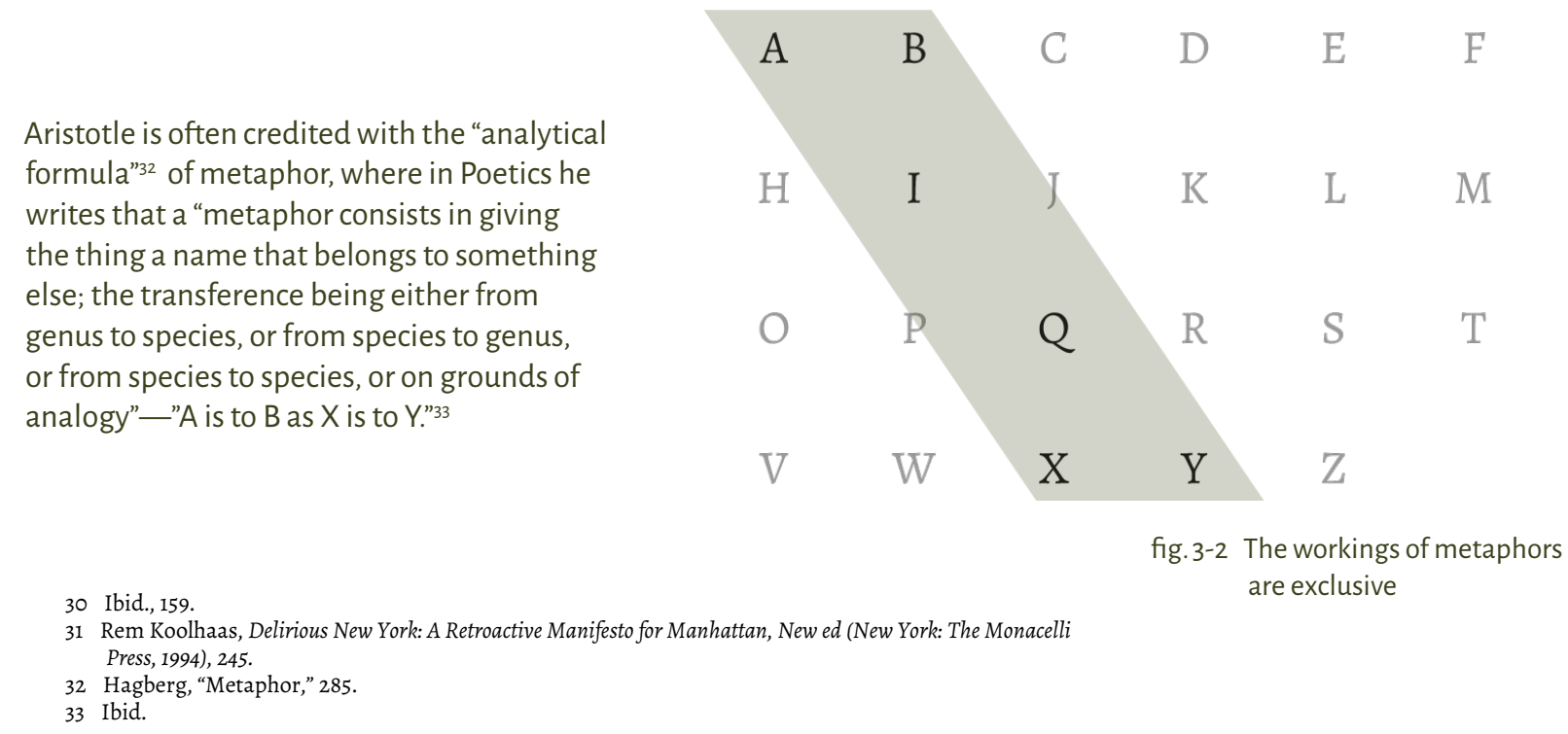




\title{
3.3 CONSPIRACY OF 'FORM'
}

\author{
"Sufficient conditions are what is enough for something to be the case. \\ Necessary conditions are what is required for something to be the \\ case." ${ }^{34}$
}

Even though Kojin Karatani posits that Plato's metaphoric architecture did not affect the way architecture was built at the time, ${ }^{35}$ it is not hard to see how it has affected the way architects theorize about architecture in recent histories. Consequently, Denis Hollier warns that "no metaphor is innocent"36 because those who borrow terms from architecture often profess "monodic" ideologies. In universality of architectural terms, others often find the "vocabulary" to "[repress] anything resembling play, exteriority, or alterity." ${ }^{37}$

\subsubsection{IDEALISM (1)}

The main premise for Eisenman and van Eyck is that the everyday and earthly realities of ELEMENT OF CONSTRUCTION (as architectural objects that are 'required' to make a building) are not 'enough' to make them architecture. By referring to the concept of 'form' and the effect of metaphor on 'architecture' in the philosophy of Plato, this argument becomes clearer. According to Richard Weston, "in Western thought, and indeed in architecture," 38 Plato's Idealism "has led to an attempt to represent things in an ideal form, as they out to be rather than as they are." In the Platonic sense, "form" ${ }^{39}$ meant "idea or essence."

Adrian Forty writes that "within Western thought" the concept of 'forms' acted as "the solution to a wide variety of philosophical problems." 40 Especially for Plato, who used "forms"' to address "a complex of problems" such as "the nature of substances, the process of physical change, and the perception of things." Therefore, for Plato, the concept of 'form' "distinguishes between 'that which always is and never becomes' and 'that which is always becoming but never is'." ${ }^{41}$

As "Plato argues," 42 in his 'metaphoric architecture', "forms were always superior to things made in their resemblance." Therefore, "in making

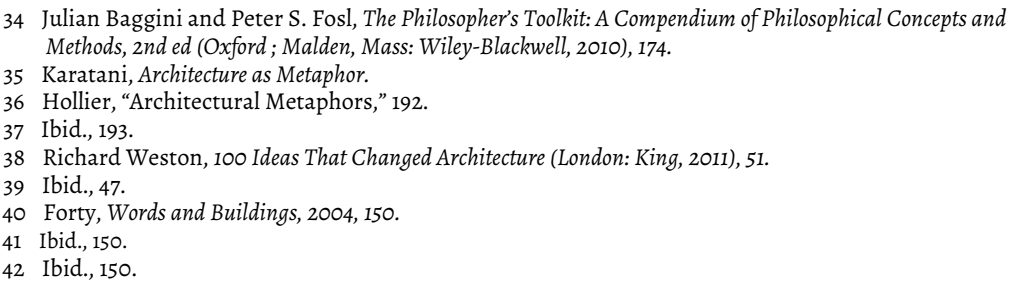


anything [...] the maker follows the 'form', not things already existing." 43 The implication of Platonic Idealism for architecture, as Kojin Karatani explains, has been 'the impossibility of the 'being' of the 'ideal' and yet, at the same time, it repeatedly invokes the 'will to architecture' by asserting that the impossible, the 'being' of the 'ideal', to be realized." ${ }^{44}$ Furthremore,Plato distrusted "artists and technicians" 45 and viewed them as "traitors to Ideas." Plato thought that they were "tricksters" who "cunningly seduced people into perceiving distorted ideas." ${ }^{46} \mathrm{He}$ also dismissed "art and technology" 47 because "they betray and distort theoretically intelligible forms ('Ideas')" by transferring them "into the material world."

\subsection{2 'MONODIC' (3)}

In architecture, as Adrian Forty posits, “There is in 'form' an inherent ambiguity between its meaning 'shape' on the one hand, and on the other 'idea' or 'essence': one describes the property of things as they are known to the senses, the other as they are known to the mind." ${ }^{48}$ Forty questions the value of a concept of 'form' in architectural thinking despite its ubiquitous use in the discourse which "is precisely what should make us suspicious of it." ${ }^{49}$ For Forty, the philosophical concept of 'form' is nothing more than "a device for thought-it is neither a thing, nor a substance." Therefore, in architecture, it is possible to hold that 'form' is a concept that has outlived its usefulness." ${ }^{50}$

Forty holds that 'In modernism, use of terms like 'form', 'space' and 'order' "were generally presented as absolutes, concepts that embraced the entirety of their categories, that subsumed their 'other'." ${ }^{51}$ In modernism, even the term 'design' came to be associated with the Ideals of 'form' as an instrument of differentiation between what happens in the mind and what happens in the world. As Adrian Forty writes:

Design fulfilled modernism's need for a term that enabled one to distinguish between a work of architecture in its materiality, as an object of experience, and a work of architecture as the representation of an underlying 'form' or idea. If 'form' was to be a primary category of architecture, then 'design' was its necessary accomplice, for 'design' is the activity which realizes form, and brings it into the world. ${ }^{52}$

43 Karatani, Architecture as Metaphor, 150.

44 Ibid., xxxv.

45 Vilém Flusser, "About the Word Design," in The Shape of Things: A Philosophy of Design, trans. Anthony Mathews (London: Reaktion, 1999), 18. 46 Ibid.

47 Ibid.

48 Forty, Words and Buildings, 2004, 149.

49 Ibid., 150.

50 Ibid., 172.

51 Ibid., 61.

52 Ibid., 137. 
Which is probably why in his 1994 book, The Theory of Architecture, Paul-Alan Johnson commented that "architecture is the last stronghold of Platonism. ${ }^{53}$

\subsection{3 'SUFFICIENT CONDITIONS'}

As early as Renaissance, as a "member of the Platonic Academy," ${ }^{44}$ Leon Batista Alberti made a distinction between "the line in the mind of the architecture and matter in architecture." In his treatise On the Art of Building, Alberti expresses his belief that "architecture is the projection of the idea onto the material." Alberti was not alone in his perception of a "incorporeal Idea." ${ }^{55}$ Essentially, the whole of modernist architecture was chasing the Platonic Ideal of 'form' that is conjured in the mind of a creator and is then projected onto the world. For instance, in his 1923 book, Vers une architecture, Le Corbusier compared the effect of "Engineer's Aesthetic" ${ }^{56}$ to an works that result in "Platonic grandeur."

Therefore, as Eisenman explains, the 'function' of a door always needs an "intention" 57 that "overcomes" its 'function' [something that 'happens in the mind'?]. Similarly, for Aldo van Eyck (and Pierre van Meiss), a door as a "functional" 88 element is not "enough" to be "architecture." The functional, economical and formal quality of a door is only "required" to make it a building, but is not "sufficient" to make it "architecture" as an "art" at the "service" of humans. However, the 'functionalism' that both Eisenman and van Eyck oppose, (as a way to negate modern architecture) is nothing more than a construct of 2oth century architectural critics and their idealistic perceptions of architecture as art.

$$
* * *
$$

In "The International Style," 59 Philip Johnson and Henry Russell Hiscock forged "a fictitious category of 'functionalist' architecture" ${ }^{60}$ as a way to "discard" the "political content" of "European modernism," frame it "as a purely stylistic phenomenon" and exclude any "work with reformist or communist tendencies." In a 1982 interview, Philip Johnson explains that they had an active position to assert that "architecture was still an art; that it was something you could look at." ${ }^{11}$ Therefore, against the initial aspirations of the modern movement in Europe, Johnson and Hitchcock implied that "architects should not be worried about the social implications, but about whether the work looked good or not."

\footnotetext{
53 Johnson, The Theory of Architecture, 244.

54 John Shannon Hendrix, The Contradiction Between Form and Function in Architecture. (Hoboken: Taylor and Francis, 2013), 63, http://public.eblib.com/choice/publicfullrecord.aspx? $p=1128265$.

55 Ibid. (from: Alberti's Commentary on Plato's Symposium on Love

56 Weston, 100 Ideas That Changed Architecture, 51.

57 Peter Eisenman, "Aspects of Modernism: Maison Dom-Ino and the Self-Referential Sign," ed. Kenneth Frampton, Oppositions: Le Corbusier 1905-1933 15/16 (Winter/Spring 1979): 126.

58 Pierre von Meiss and Theo Hakola, Elements of Architecture: From Form to Place + Tectonics, 2nd edition (London: Routledge, 2013), 215.

59 Forty, Words and Buildings, 2004, 187

60 Ibid.

61 Beatriz Colomina, Privacy and Publicity: Modern Architecture as Mass Media (MIT Press, 1994), 203.
} 


\title{
3.4 LANGUACE CONSPIRACY
}

\author{
"Strictly speaking, semiotics and structuralism propose language not as \\ a metaphor for architecture, but rather that architecture is a \\ language. ${ }^{\prime 62}$ \\ - Adrian Forty
}

\subsection{1 'MONODIC' (4)}

As Adrian Forty remarks, central to the "form-function"63 conspiracy is "the assumption of a relationship between buildings and the members of the society inhibiting them." In Short Real, this distinction leaves architects with two different questions to answer: is it "the action of the social environment" that shapes "the form of the building?" or, is it "the action of the buildings" that affects the "society?"

For some critiques, like Georg Simmel and Adolf Behne, in early 2oth century, the concept of 'form' was "an eminently social matter." 65 However, another development based on the "linguistic theories of Ferdinand de Saussure" 66 comes to overshadow this perception. Saussure argued "that language is a form and not a substance" ${ }^{\prime 67}$ and, in architecture, Saussure's conception of 'form' provided a "far-reaching" ideal that has informed the critical positions later taken by both Eisenman and van Eyck.

\subsubsection{A CATEGORICAL ERROR}

In 1960s, Eisenman explored Noam Chomsky's theories of “deep structure" 68 of syntax and posited that, like language, "forms in architecture presented themselves both in a 'surface' aspect-texture, colour, shape-recognized by the senses, and also in a 'deep' aspect as relationships of frontality, obliqueness, recession, etc., recognized in the mind." ${ }^{69}$ Similarly, van Eyck cited "the writings of Franz Boas, one

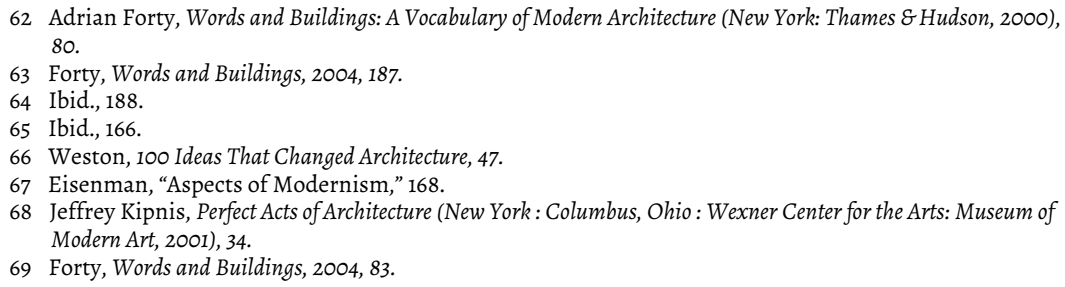


fig. 3-3 When architecture is a language $=$ a categorical error

\section{when 'architecture is a language':}

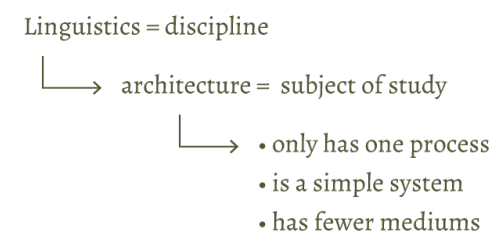

of the first ethnolinguists who focused on the unconscious nature of cultural phenomena;"70 which, like Eisenman positions the theory of the threshold" in "the realm of language." "11

A major categorical error for both Eisenman and van Eyck is the assumption that architectonic implications of design are analogous to linguistic concepts. Therefore, in their lofty ambitions, they diminish the opportunity for a 'transdisciplinary' dialogue between architecture and other disciplines.

As Forty remarks, "Strictly speaking, semiotics and structuralism propose language not as a metaphor for architecture, but rather that architecture is a language." ${ }^{72}$ These formalists posited that architecture was a language and linguistic or semiotics concept could apply to the study of architecture. What is assumed is that architecture is a language. ${ }^{73}$ It's elements are like words, and the rules that combine them are like its grammar. In a sense, this attitude both diminishes the possibility of learning some useful method from another discipline and places architecture under the disciplinary guidelines of another discipline.

\subsection{3 'TRANSDISCIPLINARY'}

The borrowing from other disciplines should entail a 'transdisciplinary' approach which endorses the "exchange of concepts and techniques between established disciplines in terms of translation and transference." It contrasts "interdisciplinarity" that promotes "the crossing of disciplines to establish shared methods or concepts." As Homi Bhabha elaborates (quoted by Mark Linder), "transdisciplinary work [...] happens at the edge or limit" of any given discipline, but is aware of that discipline's limits and desires. As a result, "transdisciplinary work continues to use properly disciplinary techniques, concepts, and vocabularies but is open to the alternations that emerge when they appear in or are applied to other disciplines."

70 Teyssot, A Topology of Everyday Constellations, 153-54.

71 Ibid., 154.

72 Forty, Words and Buildings, 2000, 80.

73 Forty, Words and Buildings, 2000.

74 Mark Linder, Nothing Less than Literal: Architecture after Minimalism (Cambridge, Mass: MIT Press, 2004$), 2$. 


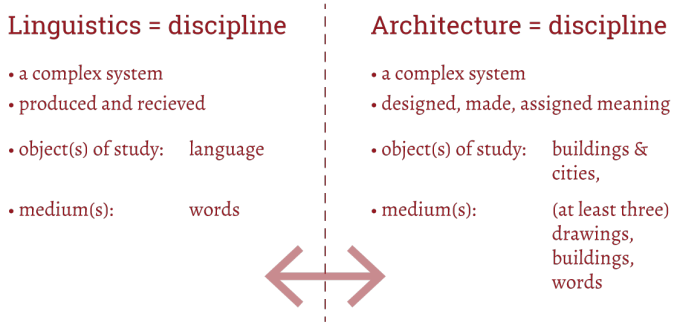

\subsubsection{MORPHOSYNTAX}

For example, in contemporary linguistics, language is not studied as a single system, but is understood as something that "incorporates a number of subsystems which, while being part of language, also seems to function outside of language." 75 Since, the main objective of any language is communication, the major sub-system of a language addresses its semantics or "the meaning behind" what is said. Another subsystem, grammar, deals with the rules that ensure mutual understanding of meanings between producers and receivers of messages in a particular language. In return, grammar is also divided into two sub-systems: morphology and syntax. Each one of these sub-systems operates at a different scale. "Morphology" looks at "how words are internally constructed;" while "syntax" studies "how words combine into utterances [sentences]."

As a result, Linguists sometimes use an alternative term, "morphosyntax," to address the concept of grammar more comprehensively. This replacement acknowledges "the important relationship between syntax and morphology." Thus, linguists are better equipped to study various languages with the knowledge that "something which may be expressed syntactically in some languages may be expressed morphologically in others."

Basically, MorphoSyntax addresses the issue that an utterance that is made meaningful in a language through play with the external through the play of the internal form and structure of the words themselves. The correct borrowing from linguistics should be the underlying concept and not the direct metaphor. If we were to borrow how the concept of morphosyntax operates at two scales in linguistics, it is possible to say that ELEMENTS OF CONSTRUCTION should also be looked at different scales. That, something that is made possible in one condition through the structure or hierarchy of one element can be made possible in another context through its materiality. 


\subsection{A DIVIDED OB]ECTHOOD}

One major difference between the 'doorness' and the 'threshold' is their views of the HINGE-DOOR-LEAF (the door) as an architectural object. As 'doorness' presents an objective approach and "a change in the conception of the relation of man and his object world." "77 While, the 'threshold', sees the door 'subjectively and as an instrument in the "production of place"78 to reassert the "timelessness of man'."

\subsubsection{THE 'DOORNESS' (2)}

For Eisenman, the 'doorness' exists in "an unarticulated universe of form," ${ }^{79}$ removed from our everyday lives and grasp, and is waiting to be "excavated." In a sense, the 'doorness' presents a Platonic Ideal of things that already exist in a world beyond ours. Nevertheless, for Eisenman, the 'intentionality' of the 'self-referential sign' presents itself as a break from the "humanist [and] anthropocentric" conceptions of architecture that "viewed man as an all-powerful, all-rational being at the centre of his physical world." Therefore, in a truly Modernist world "Man" is just a "peer" and not "the determiner" of the objects.

\subsubsection{THE 'THRESHOLD' (3)}

For van Eyck (and others) the door as a 'threshold' is purely subjective as it is perceived by humans in the service of their 'rituals' and 'occasions'. Therefore, they also engage in an "anthropomorphic pairing" 80 that treats "a building" as analogous to "the human being;" like, Saint Thomas Aquinas who had said: "what the architects it to the building he erects, God is to the world he creates." Consequently, as George Teyssot posits, in and Aldo van Eyck's 'theory of threshold', 'Man' is "distanced [...] from the anonymous world of things" and becomes the "locus" of all operations.

\subsubsection{ARCHITECTURAL OBJECTS}

This divided view on the importance of the door as an architectural object in the human world stems from the philosophical underpinning of both 'doorness' and the 'threshold' (as theorized by Eisenman and van Eyck)

77 Eisenman, "Aspects of Modernism," 119

78 Kenneth Frampton, “On Reading Heidegger," in Oppositions Reader: Selected Essays 1973-1984, ed. K. Michael Hays, I edition (New York: Princeton Archit.Press, 1999), 4.

79 Forty, Words and Buildings, 2004, 169.

80 Teyssot, A Topology of Everyday Constellations, 160. 
that corresponds to a fundamental difference between the two disciplines of philosophy and architecture.

In philosophy, according to Graham Harman, two contradictory positions dominate how philosophers approach Objects. At one side, Objects are perceived as "too specific to deserve" ${ }^{\text {"1 }}$ any consideration for having any "ultimate reality" in their earthly existence. Philosophers who take this position often "dream up some deeper indeterminate basis" to examine Objects; which is the process that Harman terms "undermining." ${ }^{\prime 2}$ On the other side, philosophers who feel Objects have value in themselves tend to assign them with a "deep" ${ }^{83}$ meaning that transcends their worldly existence. This is what Harman calls "overmining." Both perceptions, despite their difference, are reductive in their attempt to understand Objects for what they are.

\subsubsection{ELEMENTS OF CONSTRUCTION (2)}

When it comes to elements of construction as architectural objects the discourse of architecture is also reductive, and operates in seemingly contradictory fashions. For the 'self-referential sign' objects are too 'deep' to be understood by humans as they reside "in the universe of form" waiting to be 'excavated'. Nevertheless, they need an intermediate Ideal, like the notion of a 'self-referential sign', to make them palpable to humans. On the other hand, for 'threshold,' a door and its geometric, physical and functional aspects are too 'shallow' to be architecture by themselves. Therefore, an object like the door will need a human value attached to it so it can be elevated to the level of something understandable as 'architecture'. In short, the 'doorness' engages in 'overming' the door while the 'threshold' resorts to 'undermining' it.

Like architecture itself, the door or any other ELEMENT OF CONSTRUCTION, are "part of a complex process of transformational relations." ${ }^{84}$ They form a mega-system that operates paradoxically through negotiation of various interconnected relationships. The black-and-white philosophical convention that Graham Harman refers to is nothing but an idealistic perception that ignores the everyday realities of our lives, its objects and the ELEMENTS OF CONSTRUCTION. It might be valuable in philosophy but it is not as valuable in architecture. 


\subsubsection{THE 'ACTOR-NETWORK'}

There are instances that philosophers attempt to address this problem with the door ${ }^{85}$ (not surprisingly) becoming central to some of these arguments. For instance, in the "actor network approach," ${ }^{86}$ as described by Bruno Latour, there is an acceptance of the fact that "sociotechnical systems" originate from "negotiations between people, institutions, and organizations." However, to feature the complexity of these relationships in full, one must also accept that "artifacts are part of these negotiations as well."

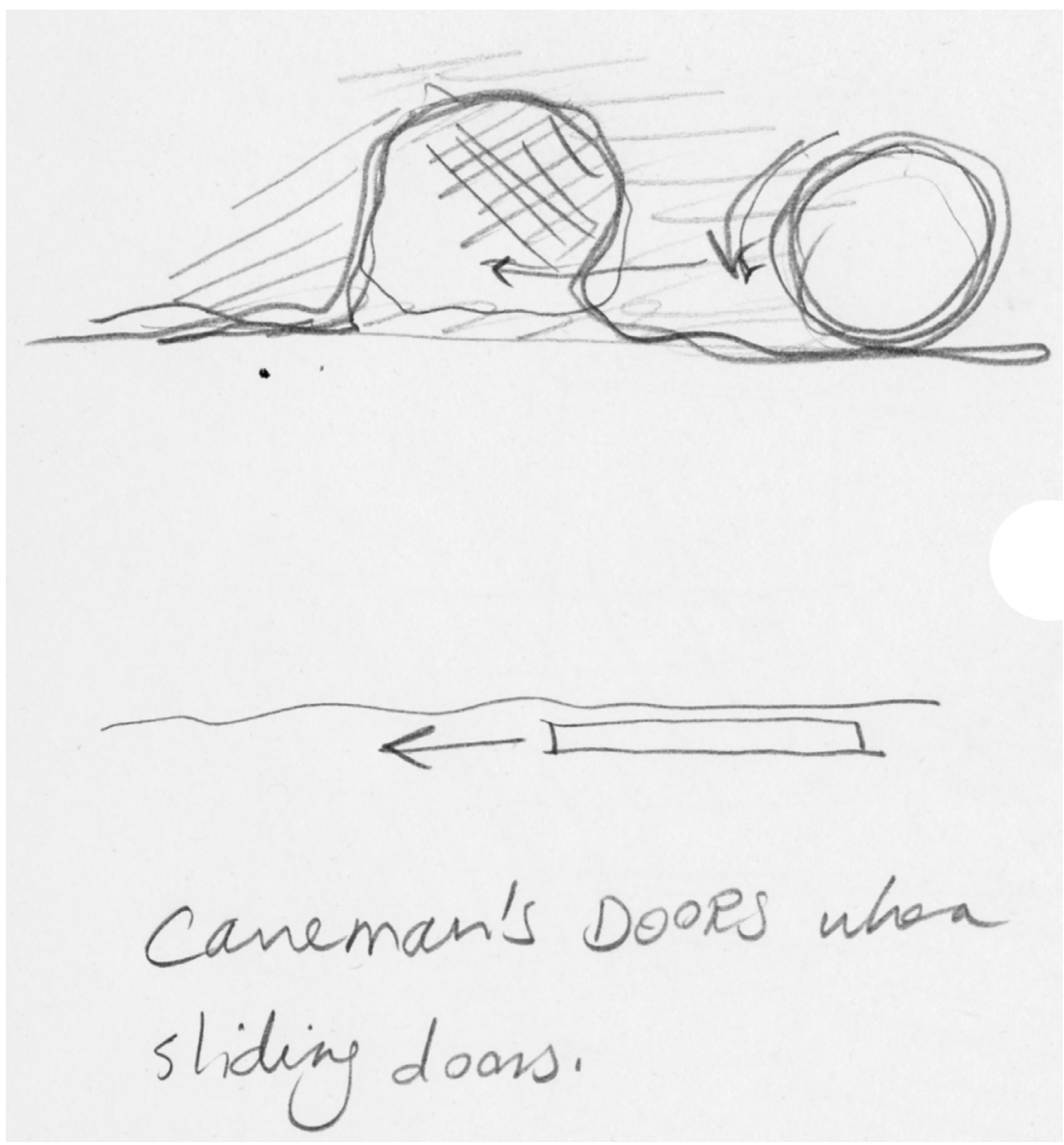

85 Bruno Latour, "Where Are the Missing Masses, Sociology of a Few Mundane Artefacts," in Technology and Society, Building Our Sociotechnical Future, ed. Deborah J. Johnson and Jameson M Wetmore (Cambridge, Mass.: MIT Press, 2008), 151-80.

86 Deborah G. Johnson and Jameson M. Wetmore, eds., Technology and Society: Building Our Sociotechnical Future, Inside Technology (Cambridge, Mass: MIT Press, 2009), 151. 


\subsection{THE DOOR (3)}

In SHORT REAL, and through the 'doorness' and the 'threshold', the objecthood of the HINGED-DOOR-LEAF (the door) is diminished. However, the divide in their views-the 'doorness'= 'overmining' and the 'threshold'= 'undermining'-is where this thesis aims to exploit the conspiracies of Short Real through its own design-conspiracies that operate in FLAT WORLD.

When it comes to the door, this task is relatively easy. Despite what the 'doorness' and the 'threshold' imply, the HINGED-DOOR-LEAF (the door) has a life of its own. There are countless metaphors, puns and imagery that draw on the rich and colourful life that the door leads in our world. As Gaston Bachelard notes: "If one were to give an account for all the doors open has closed and opened, for all the doors one would like to re-open, one would have to tell the story of one's entire life." ${ }^{87}$ Like humans, the door is a "half-open being." 88

$$
* * *
$$

The door-THE HINGED-DOOR-LEAF -is the most influential element of construction. It is the architects' greatest invention. It is the building block of any architecture. Without a door, there is no 'space' that is properly demarcated by the wall and has repeated access to other 'spaces'. Without the door, any building is a grave: a lump of material piling somewhere. It is with the door that architecture finds it audience.

The door-THE HINGED-DOOR-LEAF-is the original kinetic structure. It is the embodiment of a flexible space but not in the conventional connotation of the term 'space'. Every time a door opens or closes, it creates a flexible field where its material and 'form' move from one location to another. Unlike conventional perception, the flexibility of a door is not a philosophical ideal (like a 'void' or a 'volume ${ }^{89}$ ) or a lack of material, rather it is directly related to the movement of matter.

The flexible field of any door is a prediction and speculation on the clearances, tolerances, meeting points and leeway. Therefore, the wORKINCS of any door always create a territory for negotiations.

87 Gaston Bachelard and M. Jolas, The Poetics of Space, New edition, Penguin Classics (New York, New York: Penguin Books, 2014), 239.

88 Ibid., 237.

89 Forty, Words and Buildings, 2004. 

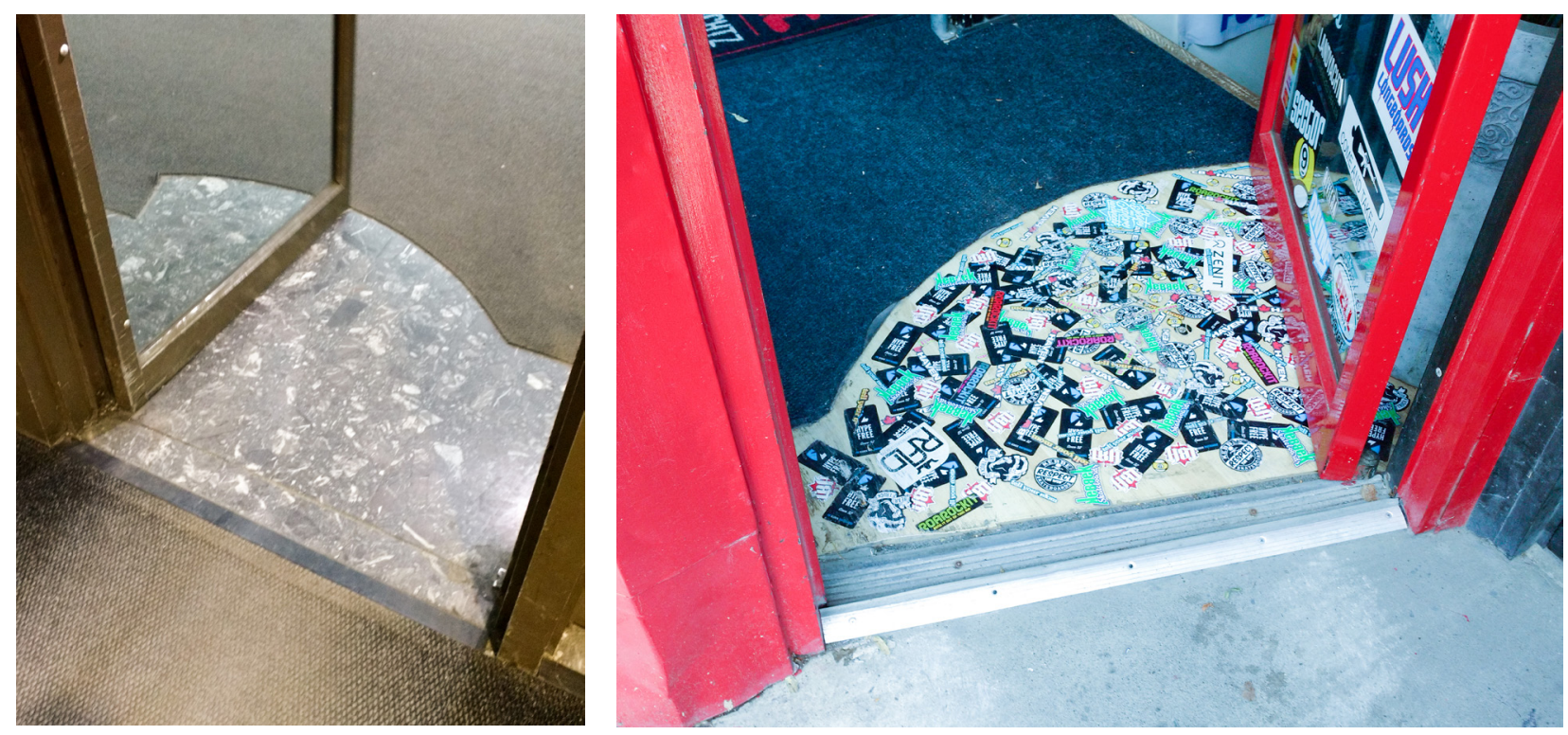

fig. 3-6 flexible space/field of a HINGED-DOOR-LEAF (the door) $=$ where matter moves from one location to another, photographs

fig. 3-7 flexible space/field of a HINGED-DOOR-LEAF (the door) $=$ where matter moves from one location to another, diagram 
Any door is a friendly wall and a not-so-friendly aperture. It is a universal metaphor. Each door reveals or hides our desires. It communicates our feelings. It sees our past and foresees our future. Doors can stand in for a building, for an abstract idea or even for complex notions like government [fig.3-7].

The door is ambiguous and paradoxical. The door is not incorporeal. It is one of us. it is always in a state of 'semi-becoming. ${ }^{90}$ It is changed every day as it engages with peoples: touched, knocked, kicked and screamed at; or, when it is shut in a hurry, kept open for too long by a brick; or, it is locked and made to witness unspeakable horror.

\subsubsection{A FRAUD AND A TEASE}

When it comes to the HINGED-DOOR-LEAF (the door), 'doorness' asks us to 'form' the 'matter' in the image of an 'idea'. At first, the process seems symmetrical, with an analogous possibility to translate an 'idea' into an element of construction. However, the 'doorness' is an Platonic Ideal that lives in the "unarticulated universe of form which remains to be excavated'." ${ }^{\prime 1}$ As such, it always "distinguishes between 'that which always is and never becomes' and 'that which is always becoming but never is'." That is why, 'doorness' cannot accept that any door that is made in its image can ever reach its level of perfection. Therefore, as an "incorporeal Idea," "93 'doorness' is a tease.

$$
* * *
$$

Also, those who attempt to make the door into a 'threshold'- as a 'place' that is universal and symmetrically understood-forget that not every two person perceives the world the same way. The following story by Edward T. Hall can illuminate this argument:

[In America, if] one is standing on the 'threshold' holding the door open and talking to someone inside, [or] 'pokes his head in the door' of an office, [or just] holding on to the doorjamb when one's body is inside the room still means a person has one foot 'on base' as it were so that he is not quite inside the other fellow's territory. None of these American spatial definitions is valid in northern Germany. In every instance where the American would consider himself outside he has already entered the German's territory and would become involved with him. ${ }^{94}$

Any attempt to build a universal 'threshold' is like proclaiming that everyone will like the same kind of sandwich while, in everyday world, all

90 Karatani, Architecture as Metaphor, xxxii ("Unlike the substantial materiality of architecture, which belongs to the realm of what we might call 'semi-becoming,' Platonic architecture is metaphorical.").

91 Eisenman, "Aspects of Modernism," 168.

92 Forty, Words and Buildings, 2004, 150.

93 Ibid. (from: Alberti's Commentary on Plato's Symposium on Love

94 Hall, The Hidden Dimension, 133.

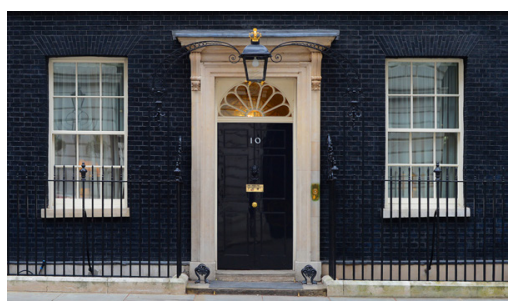

fig. 3-8 10 Downing Street 


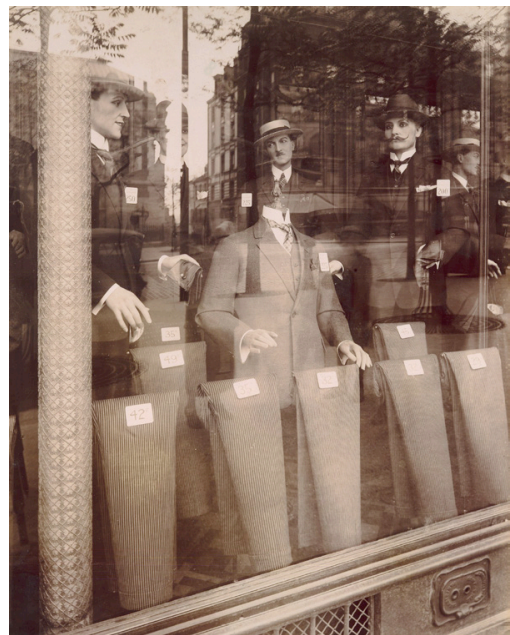

fig. 3-9 Eugene Atget, Avenue des Gobelins, 1927 they can assume is that some people might like sandwiches. In everyday world, the 'threshold' is a lie because it can only be universal and symmetrical in the minds of those who know its rules. Therefore, the 'threshold' is a fraud. It is like that the 'doorness' dangles a carrot in front of the door and tells it that it can never be architecture. While, the 'threshold' dangles an imaginary carrot in front of the door and tells it is has already become architecture only if it was immaterial. Whenever 'doorness' (a tease) and 'threshold' (a fraud) want to sell us a door, there is ample reason to suspects that neither of them know anything about it.

\subsection{2 'THE UNCANNY'}

Both the 'doorness' and the 'threshold' seek grand definitions for architecture. They are only after "feelings of positive kind." 95 For van Eyck, for example, a door as a 'threshold' is never a 'place' for an unhappy 'event' because we must "make each door a welcome and give a face to each window. Make each one a place." 96

When we engage with the HINGED-DOOR-LEAF (the door) through philosophical metaphors, like the 'threshold', we give into philosophy's desire for only absoluteness.

For example, no one ever mentions that a bathroom stall that is overflowing is also a 'threshold'. Because, conventionally, the pungent smell of shit that alerts all our six senses, and separates us, can never be a 'threshold' - “'meeting place' or [a] 'shape of the in-between'." ${ }^{97}$ Only things that are 'eternal' and unifying can be 'thresholds'. In addition, although 'threshold' is always defined in relation to 'human rituals'98-it only seeks certain 'rituals' that reciprocate its idealistic aspirations. For instance, an entrance to a museum is a 'threshold', but the vestibule at a Walmart is not. For the 'threshold', it does not matter that no one ever mentions that entering Walmart is a ritual for most people who have never heard of a 'threshold'. Essentially, by accepting the 'threshold', or any 'monodic' metaphor, it is easy for the discourse of architecture to operate in exclusive terms.

$$
* * *
$$

This insistence on 'happy', 'grand' and reciprocal instances that give conspiracies like the 'threshold' or 'doorness' their exclusive approach to architecture, corresponds to Sigmund Freud and his criticism of aesthetics.

In "The Uncanny", Freud argues that the topic belongs to "a particular area of aesthetics"99 while "on this topic we find virtually nothing in the

\footnotetext{
95 Sigmund Freud, “The Uncanny," in The Uncanny, trans. David Mclintock (London, U.K.: Penguin Books, 2003), 123.

96 Meiss and Hakola, Elements of Architecture, 191.

97 Teyssot, A Topology of Everyday Constellations, 153.

98 Meiss and Hakola, Elements of Architecture.

99 Freud, "The Uncanny," 123.
} 
detailed accounts of aesthetics, which on the whole prefer to concern themselves with our feelings for the beautiful, the grandiose and the attractive." Freud defines "the uncanny" ${ }^{100}$ as "species of the frightening that goes back to what was once well know and had long been familiar." Another definition for 'the uncanny' can be as "the sense of the return of something archaic [... and] a kind of eruption of the non-living in the midst of life: a return of the living dead." ${ }^{101}$ For Freud, 'the uncanny' is "what [...] was meant to remain secret and hidden and has come into the open."102

Freud refers to the study of E. Jentsch who describes the experience of encountering 'the uncanny' as "doubt as to whether an apparently animate object really is alive and, conversely, whether a lifeless object might not perhaps be animate." ${ }^{\prime 03}$ The examples that Jentsch provides are encountering "waxwork figures,"104 "dolls" or "automata." Furthermore, according to Jentsch "manifestations of insanity" are also encounters with the uncanny since they "arouse in the onlooker vague notions of automatic-mechanical-processes that may lie hidden behind the familiar image of a living person." For Freud, 'the uncanny' also denotes the realization of the inevitable meeting of two opposites. In the case of the notion of 'homely' Freud writes that "the notion of the hidden and the dangerous [...] undergoes a further development so that 'heimilich' [homely] acquires the sense that otherwise belongs to 'unheimilich'[unhomely]."

\subsubsection{THE DOOR (4)}

That is why a hinged door-leaf is the best element of construction to start a new conspiracy about architecture: it is never prefect, it "works-only if it fails"106 and it is "not to be trusted." 107 That is why it is very risky to leave any door half-open.

There is a whole social structure-systems of social contracts-that ensures the door is never left ajar. As Claus Seligman notes:

the half-open position is necessarily the most ambiguous of all. It indicates an exquisitely balanced equivocation between the poles of total privacy and of total gregariousness. The

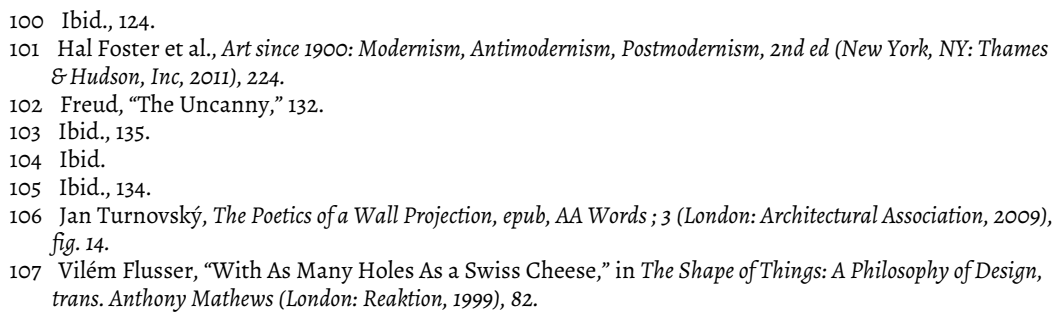


potential for misunderstanding is very high; a well-structured social context is required to offset the inherent risk. ${ }^{108}$

$$
* * *
$$

Vilém Flusser, in tracing the term 'design' observes that, “The words design, machine, technology, ars and art are closely related to one another, one term being unthinkable without the others, and they all derive from the same existential view of the world." ${ }^{109}$ Yet, 'modern bourgeois', divided culture into two branches: "one scientific, quantifiable and 'hard', the other aesthetic, evaluative and 'soft'." This distinction created "a gap" that the "word design" bridged.

If the Platonic view of architecture is to 'project' an ideal 'form' onto 'matter', then we are bound to dismiss the value of both 'form' and 'matter'. By referring to making a wooden chair, Vilém Flusser dissects the problem as follow: "The tragedy here is that in so doing they not only in-form wood (impose the table form on it) but also deform the idea of the table (distort it in the wood). The tragedy is therefore that it is impossible to make an ideal table." Later, Flusser remarks: "the appearance of material is form." "110 Similarly, as Elizabeth Diller holds, "Design needs no alibi but, undoubtedly, technology is indispensable to it." "111 Diller Holds that often "technology" is associated with "applied sciences" while "architecture itself can be thought of in a broader definition as a technology that involves many inseparable soft systems."

$$
* * *
$$

Architecture is a complicated design discipline and tired classification of the "modern bourgeois" 112 cannot apprehend its genius. Perhaps, that is why architects always talk about the door as a 'threshold' or through its 'doorness'. They cannot accept that in architecture the 'hard' or 'soft' are not absolute designations. And, like the door, architecture is flexible. For the conspiracy of Short Real to work, it must always define the door in binary oppositions. If the door is 'hard', materialized and quantifiable, then it is 'technology'. And, if it is 'soft', 'qualitative' and incorporeal, then it is 'architecture'.

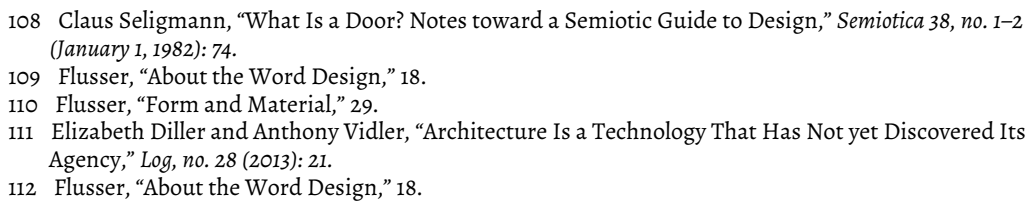




\subsection{A 'WALL PROJECTION'}

The following example of philosopher Ludwig Wittgenstein and his attempt to construct a "symmetrical window"113 will illuminate the argument that architecture and philosophy are not necessarily analogous and what works in philosophy (or linguistic conceptually) will not work the same way in the conception of any architecture.

Between 1926 and 1928, ${ }^{114}$ philosopher Ludwig Wittgenstein engaged in construction of a house for sister in Vienna; alongside the architect of the house Paul Engelmann. The experience left such an impression on Wittgenstein that he came to refer to it as "My architecture." 115

$$
* * *
$$

In analyzing the house in The Poetics of a Wall Projection, Jan Turnovský discusses an "architectural fragment"116 that was an architectonic solution to a philosophical problem. This 'fragment', or 'Wall Projection (Mauervorsprung) ${ }^{{ }_{117}}$ as termed by Turnovský, was the result of a failed attempt to construct a window that was symmetrical from both inside and outside. In the assessment of the problem, Turnovský writes: "the desire for a symmetrical window position turns out to be abstract ideal that, on account of being empirically unsubstantiated, encounters the massive resistance of the architectural syntax." ${ }^{118}$ Turnovský also speculates that the "perfect (yet absurd) solution to the problem [of a symmetrical window] would be to insert a thick 'exterior wall' where no boundary wall is necessary." Instead, for Wittgenstein the problem is solved through an illusion of such 'thickness'.

The 'wall projection', as the remedy for the impossibility of a symmetrical window within the larger context of the house, "divides the front interior wall surface [thus] creating [a] symmetrical wall and a residual surface that corresponds exactly to the thinness of an imagined 'exterior' wall."119 Thus, the architectural solution for a philosophical problem becomes nothing more than "a formal response" that acts as "the embodiment of a sub-concept-an ad-hoc measure that attempts to sustain a conceptual

113 Turnovský, The Poetics of a Wall Projection, chap. 3. On the Wittgenstein House.

114 "Wittgenstein House," VIENNA - Now. Forever, accessed September 1, 2017, https://www.wien.info/en/sightseeing/sights/from-s-to-z/wittgenstein-house.

115 Karatani, Architecture as Metaphor, 125.

116 Ken Kleinman, "Introduction," in The Poetics of a Wall Projection, epub, AA Words ; 3 (London: Architectural Association, 2009), sec. Poetics.

117 Turnovský, The Poetics of a Wall Projection, Introduction

118 Ibid., figs. 11-12.

119 Ibid., figs. 12-13. 


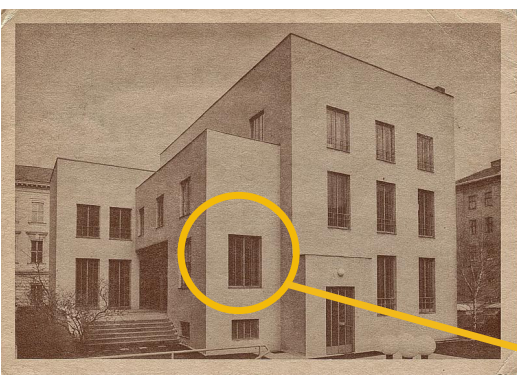

fig. 3-10 Wittgenstein House, Vienna

fig. 3-11 Wittgenstein House, intermediate-level plan, building permit drawing
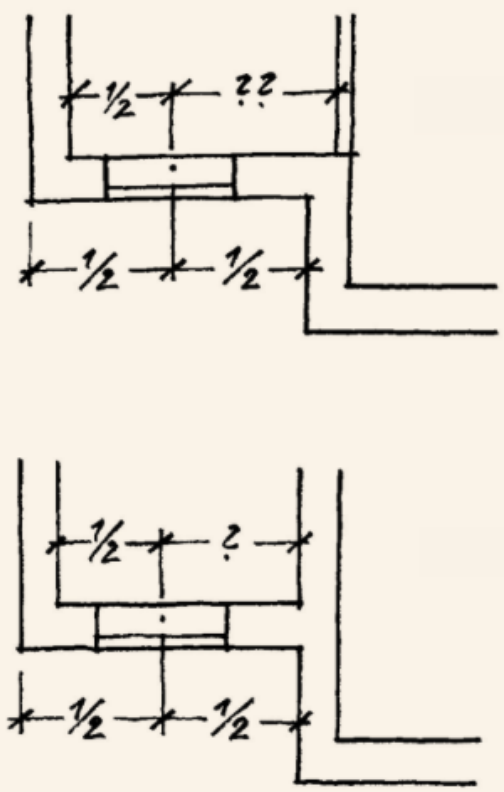

fig. 3-12 Jan Turnovský, Fig.14 The Nature of Syntax: 'works only if it fails'!

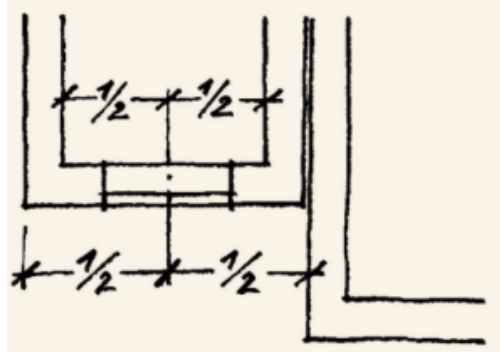

This still doesn't work

This works - only if it fails 
impulse in the face of 'material' opposition. In fact, it becomes an opposition of the particular [...] problem" it aimed to solve.

\subsubsection{THE WINDOW (1)}

"Communication is usually understood as a model in which a ideal speaker and an ideal listener exchange message by means of a common code." ${ }^{120}$

- Kojin Karatani

Wittgenstein placed the metaphor of a 'symmetrical window', its 'idea' over the realities of the construction of an everyday window or a new type of window (a window-wall?).

BUT, WHY?

Considering Wittgenstein's relationship with some of the most prominent Viennese architects of the time, ${ }^{121}$ it is possible to conclude that he approaches the problem with a Platonic vision that parallels the Modernist paradigm of projected 'form' onto 'matter'. There is also another speculation that could answer his unsubstantiated desire for a 'symmetrical window'. That relates to the specific connotations of his first philosophy.

Chronologically, the "Wittgenstein-Stoneborough House" falls between the two philosophies of Wittgenstein. As one of the most influential philosophers of the $20^{\text {th }}$ century, Wittgenstein is known for two completely different philosophies: (1)"picture theory of meaning"122 of Tractatus Logico-Philosophicus (1921) and (2) "tool conception theory of meaning"123 and "Language games" of Philosophical Investigations (1953).

Wittgenstein's first philosophy- "picture theory of meaning"124 probably has more to do with Wittgenstein's desire for a 'symmetrical window'-one that looks symmetrical from both inside and outside. As philosopher John Searle in a conversation with Bryan Magee explains, 'picture theory of meaning' implies that a "sentence is like a picture of a possible fact [...] sentences contain names which correspond to objects in the world, and the arrangement of names in the sentence corresponds to a possible arrangement of objects in the world." 125

In so many words, the 'picture theory of meaning' implies that there is a symmetrical relationship between the structure of the language and 'the state of affairs' of the objects in the world. However, as communicative

120 Karatani, Architecture as Metaphor, 73

121 Turnovský, The Poetics of a Wall Projection.

122 Bryan Magee, "Wittgenstein: Dialogue with John Searle," in The Great Philosophers: An Introduction to Western Philosophy (Oxford; New York: Oxford University Press, 1988), 323.

123 Ibid., 326.

124 Ibid., 323.

125 Ibid. 
properties of any language are concerned, this notion relies upon the symmetrical understanding of a message by both its producer and its intended receiver. Considering the implication of Wittgenstein and his philosophy of 'picture theory of meaning' it is possible to speculate that he wanted a 'symmetrical window' because of the metaphoric implications of the window.

$$
* * *
$$

Windows provide any space with "light and fresh air"126 but also act as the "eyes for the building." Through "framing our experience of the wider world," windows, "perhaps more than any other architectural elements," provide "character" to any "building." According to Richard Weston, "True to modernity's other face-a fascination with the primitive and an urge to return to origins-some of the most memorable modern windows sprang from the desire to recapture the primal act of making a hole in a wall." ${ }^{127}$

Georges Teyssot holds, "like any other instrument (including language), the window is an apparatus that separates and unites." ${ }^{128}$ By tracing the "etymology" of the English word window, which "derives from wind and eye," Teyssot posits that "window aperture is a complex instrument that both admits light and ventilation to an interior and enables the eye." So, "if the window can be an 'eye,' then the eye can be a window." With this analogy, "to let the gaze enter a house is correspondent to an act of violence. [...] is like opening up the house as if it were a body." ${ }^{\prime 29}$ However, "the onlooker's gaze is asymmetrical, because he sees without being seen." 130 This asymmetry, or remaining "hidden from the Other's gaze" is the origin of "the Latin intimus, the superlative of interior." In fact, "Intimate is a stronger notion than private. Privacy was (and still is) mainly ruled and circumscribed by law."

So, it is possible to assume that what Wittgenstein desired was to architecturally represent a philosophical ideal of a window. He wanted to show that what happens in our mind is symmetrical to what happens in the world, that the relationship between the inside and outside are symmetrical in the message they communicate. 


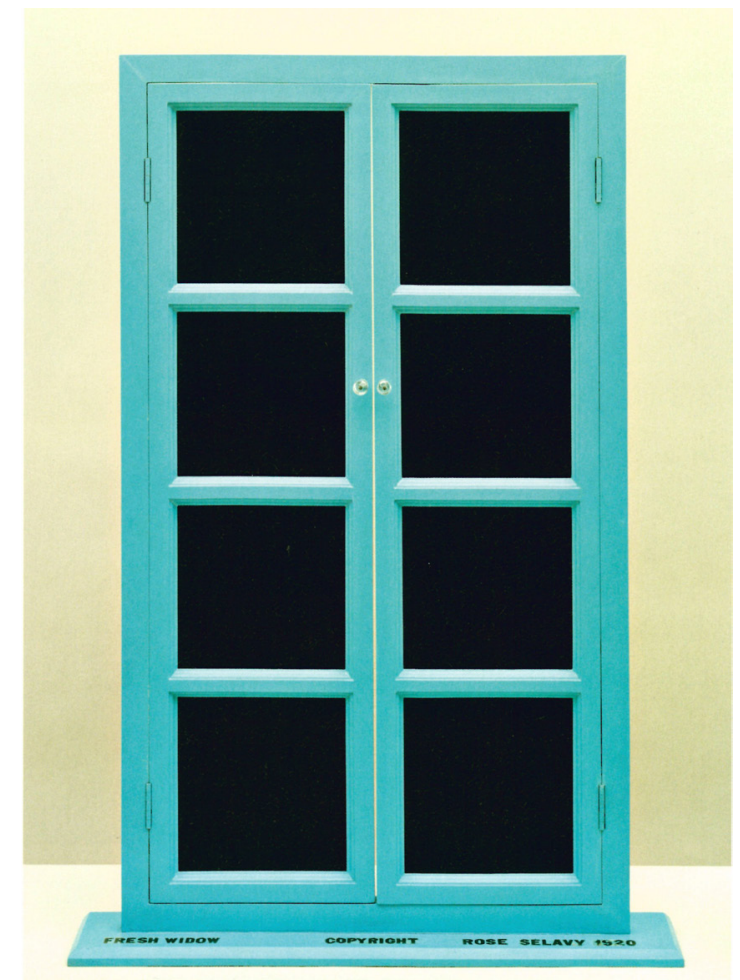

"Fresh Window" was "the first work to be designed by Duchamp's female alter ego Rose Selavy."131 For the most parts, it is a "miniature replica of a typical French window." However, instead of the panes of glass, each opening is "covered in black leather." The lack of transparency where it is expected, the blacked-out panes force us to "linger on the window itself, which has ceased to be a gateway to the outside." With this work, Duchamp attempts to rejected "the traditional view of painting as a 'window onto the world'." fig. 3-13 Marcel Duchamp, Fresh Window, 1920, replica 1964

131 Jane Alison, "The Surreal House," in The Surreal House, ed. Jane Alison, Mary Ann Caws, and Barbican Art Gallery (London: New Haven, CT: Barbican Art Gallery; In association with Yale University Press, 2010), 298. 


\subsubsection{BINARY OPPOSITIONS}

Wittgenstein fails to achieve a truly symmetrical window and contents himself to an illusion of it that becomes 'Wall Projection'. This experience could have been one reason for Wittgenstein abandoning his first philosophy. As Jan Turnovský clarifies:

When Wittgenstein realized that he had based the Tractatus on faulty premises, he discarded it. Indeed, he abandoned the project of a conceptually oriented philosophy entirely as he became convinced that philosophical theories-as products of imagination -offered only simplified, superficially profound constructs that obscured the actual diversity of reality. ${ }^{132}$

$$
* * *
$$

However, it is admissible to assume that Wittgenstein did not respond to his failure in an architectural way.

In his second philosophy-Philosophical Investigation-Wittgenstein instead focuses on "Tool conception of meaning." "33 Again, John Searle sums up the later philosophy of Wittgenstein: "he abandoned the picture theory of meaning in favour of use or tool conception of meaning...the meaning of a word is its use in the language."

$$
* * *
$$

Like the conspirators of SHORT REAL, Wittgenstein shifts from one extreme end of the spectrum to the other. His two philosophies differ from one another because each corresponds to two contradictory poles of a binary opposition that although in architecture are harmless, create a problem for philosophy.

\subsection{3 'TWO MODALITIES'}

In philosophy, "one must always arrive at the position of the absolute."134 Todd McGowan explains that in "each domain of thought" in philosophy" exists "an absolute perspective from which we must think if we are not to disfigure and misrepresent this domain." For example, "The history of philosophy must attain the absolute philosophy, the philosophy of religion must discover the absolute religion and the philosophy of aesthetics must find the absolute form of each art." ${ }^{135}$

$$
* * *
$$

\footnotetext{
132 Turnovský, The Poetics of a Wall Projection, Chapter 1.

133 Magee, "Wittgenstein: Diaglogue with John Searle," 326.

134 McGowan, "We Are Already Dwelling: Hegel and the Transcendence of Place," 57.

135 Ibid., 58.
} 
Probably, that is why philosophers are attracted to architecture. In the workings of architecture, like Plato, they find a way to represent an absolute position. What works in philosophy is not necessarily or sufficiently architectural because these two disciplines have very different geniuses. Unlike philosophy, architecture is about contingency. Architecture is simultaneously a system of paradoxes and a paradoxical system. That is probably why the discourse has grappled with various outside disciplinary ideas to curb some of the idiosyncratic qualities that defines the genius of architecture.

$$
* * *
$$

As Jan Turnovský explains that: "Viewed in the broadest terms, architecture encompasses two contrasting domains, one associated with the term 'conceptual', the other with empiricism'." Turnovský further explains that the two 'modalities' of architecture "never appear in their pure form; architecture is always more a matter of a dominant tendency or priorities." ${ }^{136}$ At one pole, architecture can begin with "an abstract concept" 137 that "is defined by a categorical, compositional will-to-order." On the opposite pole, architecture is "committed to concrete existing conditions related to construction, us or site, compositional intentions and rules." Since, these two poles are both present in each work of architecture, usually what curbs the conceptual modality and informs the empiricism is the "resistance of the empirical material," which is "extraordinarily unwieldy, idiosyncratic and stubborn."

\subsection{4 'EVENT'}

Unlike philosophy, in architecture, as a design discipline, an absolute approach is meaningless. According to Wolfgang Jonas: "Expertise in design is the art of dealing with scientific and non-scientific knowledge, with fuzzy knowledge, with outdated knowledge and with no knowledge at all to achieve these value-laden fits. In other words: the art of muddling through." ${ }^{138}$ Furthermore, as Kojin Karatani explains:

Design is similar to Wittgenstein's 'game', where, as he says, 'we play and-make up rules as we go along'. [...] Architecture is an event part excellence in the sense that it is a making or a becoming that exceeds the makers' control. ${ }^{139}$ [...] Because architecture is an event, it is always contingent." ${ }^{140}$

$$
* * *
$$

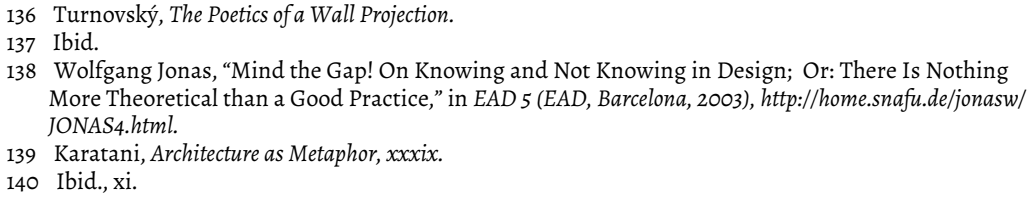


According to Slavoj Žižek, an 'event' is "something that occurs within the world, but it is a change of the very frame through which we perceive the world and engage in it." ${ }^{\prime 41}$ Thus an 'event' is "the effect that seems to exceed its causes." ${ }^{142}$

The distinction between an 'event' and a Platonic Ideal like the concept of 'form' or 'threshold' is that although 'events' do not occur in the material world, their effect on our perception changes the way we relate to objects in the world. An 'event' is a rupture in our lives that can change our relationship to reality. ${ }^{143}$ Event can also denote a moment of enlightenment, where we set ourselves free from the illusions of the world around us. Most importantly, an 'event' is understood retroactively. ${ }^{144} \mathrm{We}$ can never wait for an 'event' to happen, or act to make an 'event' emerge since we can never know when it will come. It is rather after its occurrence, only retroactively, that we comprehend it as an 'event'.

For idealists like Plato or Buber, the concept of 'event' is non-existent, since nothing can change the relationships between 'forms' as they are 'eternal' and 'immutable'. While, in material world, in our everyday world, an 'event' can ruptures/change the relationship between entities, through changing our frame of mind. ${ }^{145}$ As Žižek explains, "In the textbook version of Plato's Idealism, the only true reality is the immutable eternal order of Ideas, while the every-changing material reality is just its frail shadow." ${ }^{146}$ In making of the 'threshold' and 'form' we must engage the 'immutable' relationship of 'eternal Ideas' through the contingent relationship of materials, which is an impossibility. In 'Ideal world', "unstable material reality" ${ }^{147}$ is of no concern because relationship between objects and things never change and "nothing happens." Trying to make a door in the image of 'doorness' of 'threshold' will only result in a tragic outcome.

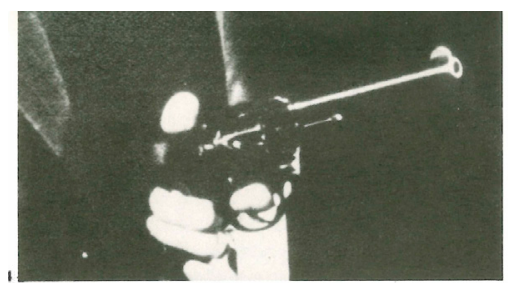

fig. 3-14 an 'event'
Bernard Tschumi defines event as: "an incident, an occurrence; a particular item in a programme. Events can encompass particular uses, singular functions or isolated activities. They include moments of passion, acts of love and the instant of death. Events have an independent existence. Rarely are they purely the consequence of their surroundings. In literature, they belong to the category of the narrative (as opposed to the descriptive)." ${ }^{148}$

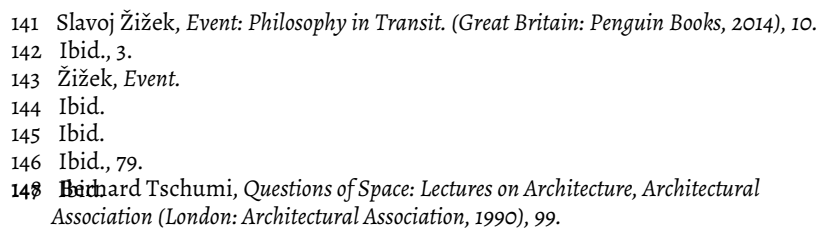




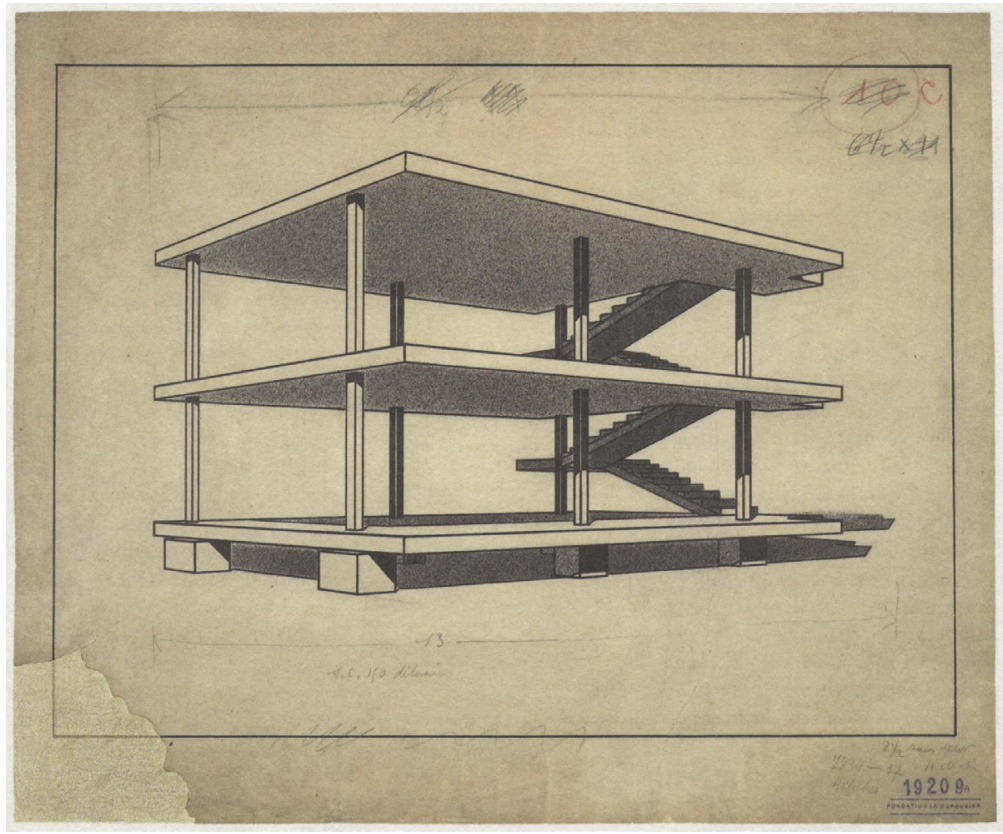

fig. 4-1 Le Corbusier, Maison Dom-ino perspective, 1914-15

"The overall appearance of the perspectival view is more technological and precise, like the representation of an engine by a professional draughtsman. [At the same time,] Dom-ino image $[\ldots]$ blends two seemingly incompatible orientations: a concern for matter-of-factness, or objectivity, and illusionistic rendering techniques." ${ }^{1}$

-Antoine Picon 


\section{DOM-INO CONSPIRACIES}

THIS CHAPTER EXPLORES SOME OF THE METAPHORS, BINARY OPPOSITIONS AND IDEOLOCIES THAT EMPOWER THE 'STRATECIES' OF CONSPIRACIES OF SHORT REAL IN RELATION TO THE "MAISON DOM-INO" (DOM-INO) PROJECT BY LE CORBUSIER. IN THIS CONTEXT, DOM-INO IS USED AS A VEHICLE FOR BOTH CRITICAL INQUIRY INTO THE DISCOURSE OF ARCHITECTURE AND DESICN-CONSPIRACIES, REFLECTIVE OF THE WORKINCS OF FLAT WORLD AS A TERRITORY FOR CRITICAL INTERPRETATION OF ARCHITECTURE. 


\section{1 'DOORNESS' (3): AN 'OTHERNESS'}

In his 1979 essay "Aspects of Modernism," Peter Eisenman reproduces the perspective drawing of Le Corbusier's 1915 project "Maison Dom-ino" (Dom-ino) as a series of axonometric drawings. The decision to 'translate' "an iconic drawing from one style of projection to another" affords Eisenman the opportunity to explore "new interpretations" of Dom-ino. The translation of one style of representation to another reflects Eisenman's intent to find "an other condition of representation, an other significance, an other realm" ${ }^{2}$ within Dom-ino that "exists simultaneously with the accepted interpretation." It is possible to assume that like the 'doorness' that makes the door 'architecture', it is the "otherness"' of Eisenman's reconstruction of Dom-ino that finds its 'Dom-ino-ness' and provides "a Modernist context for Dom-ino" to become 'architecture'.

According to Hayles and Gannon, by reconstructing Dom-ino as 3D axonometric drawings, Eisenman "uses an abstract drawing technique"3 which "produces a series of spare interpretations of Le Corbusier's already stripped down original." In a sense, Eisenman's reconstruction resembles the photographic process where realities are "multiplied in film and made infinitely malleable with digital technologies." Therefore, the reconstruction of Dom-ino in a different projective representation can also represent its industrial and modular beginnings that, in the hands of Eisenman, is turned into a device for fostering "new forms of architectural thinking." 
fig. 4-2 Dom-ino like a domino!

\section{DOMINO}

(1) aris

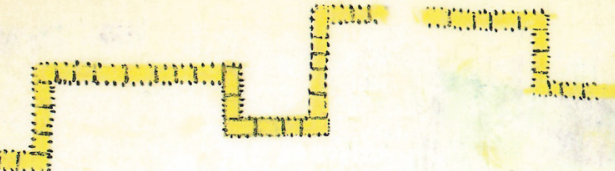

(2)

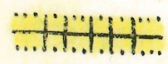
$\cdots$ infifit. $\cdots$ $\cdots$

This drawing by Le Corbusier shows "Maison Dom-ino" project workings like the domino game: pieces attaching to each other and growing in the landscape. In a sense, looking at this image, it is possible to see how there was a playful and rather unconscious dimension to the workings of Dom-ino's design both as a drawing and as a system of housing. It is like playing the Surrealist game of Exquisite Corpse.

Surrealists were interested in surrendering to their subconscious, exploring all the way they could lose themselves in chance and indeterminate situations. The game started as a word play in the parlours of $19^{\text {th }}$ century, was later adapted by Surrealists and expanded to include "drawing and collage games." As Jean La Marche explains,4

the parlour game version was a verbal game in which people would write down a few words or phrases, fold the piece of paper until only one or two of the words were showing, and pass it on for additional contributions by everyone else in the game. The final verbal construction usually made little or no sense at all.

The name the game, as La Marche explain, came "from the Surrealist experiment with the game, the first result of which was "le cadavre eques boira le vain nouveau' (the exquisite corpse will drink the young wine)." The game was an important development in the surrealist movement. As Michael Sorkin posits (quoted by La Marche), the Exquisite Corpse is "the greatest ... metaphor for modern culture ever... [and] a perfect image of the city: our greatest, most out of control collective artifact." 


\subsection{RGB DOM-INO}

In FLAT WORLD, conventions and objects of Short Real are negotiated and sent back as their 'concrete irrationalities'. Dom-ino is an sketch of an idea, and an image of a process. It represents a negotiation of form, function, matter, and economy. As an object for the machine age, it was meant to be reproduced ad infinitum. Therefore, is it possible to use the same technological method that inspired Domino to negotiate its image?

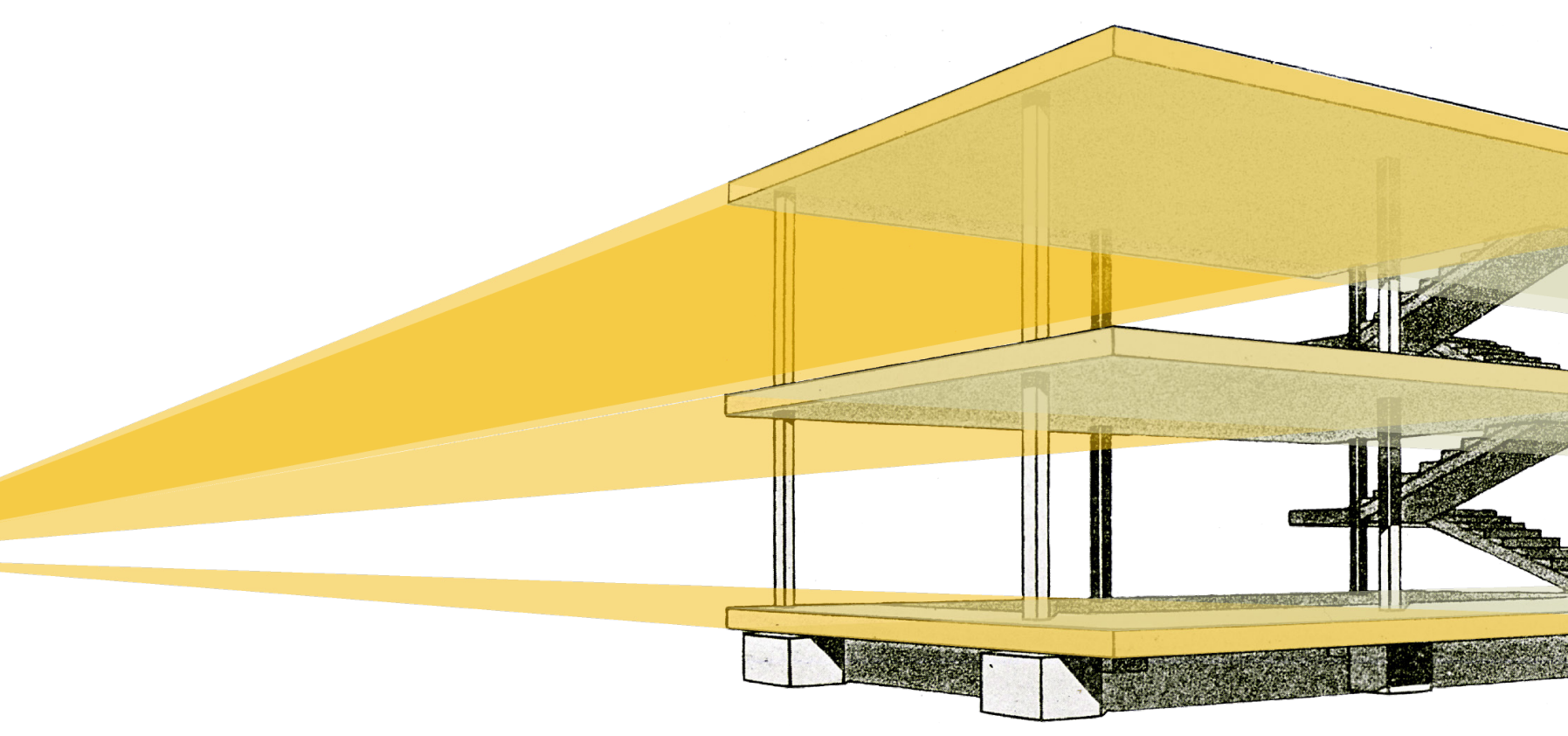


Dom-ino perspective is a $2 \mathrm{D}$ construction of an speculation. It is both materialized, as it responds to real-life techniques, and is a speculation, because it is hard to build it as it is imagined.

To reduce it to a 3D model (like Eisenman) or a physical model (like "one-to-one domino" meant stripping it of it embedded disciplinary memory. As a building constructed in perspective, Dom-ino accumulates 500 years of architectural representation. It is both inspiring and a superb piece of architectural propaganda.

The strength of any concrete irrationality is dependent on the strength of the original subject that it consumes. So, to change the perspective of Dom-ino would have reduced its impact.

Today, the bare structure of Dom-ino is no longer revolutionary and can resemble many things. It is a convention that can be found in many different types of building. 


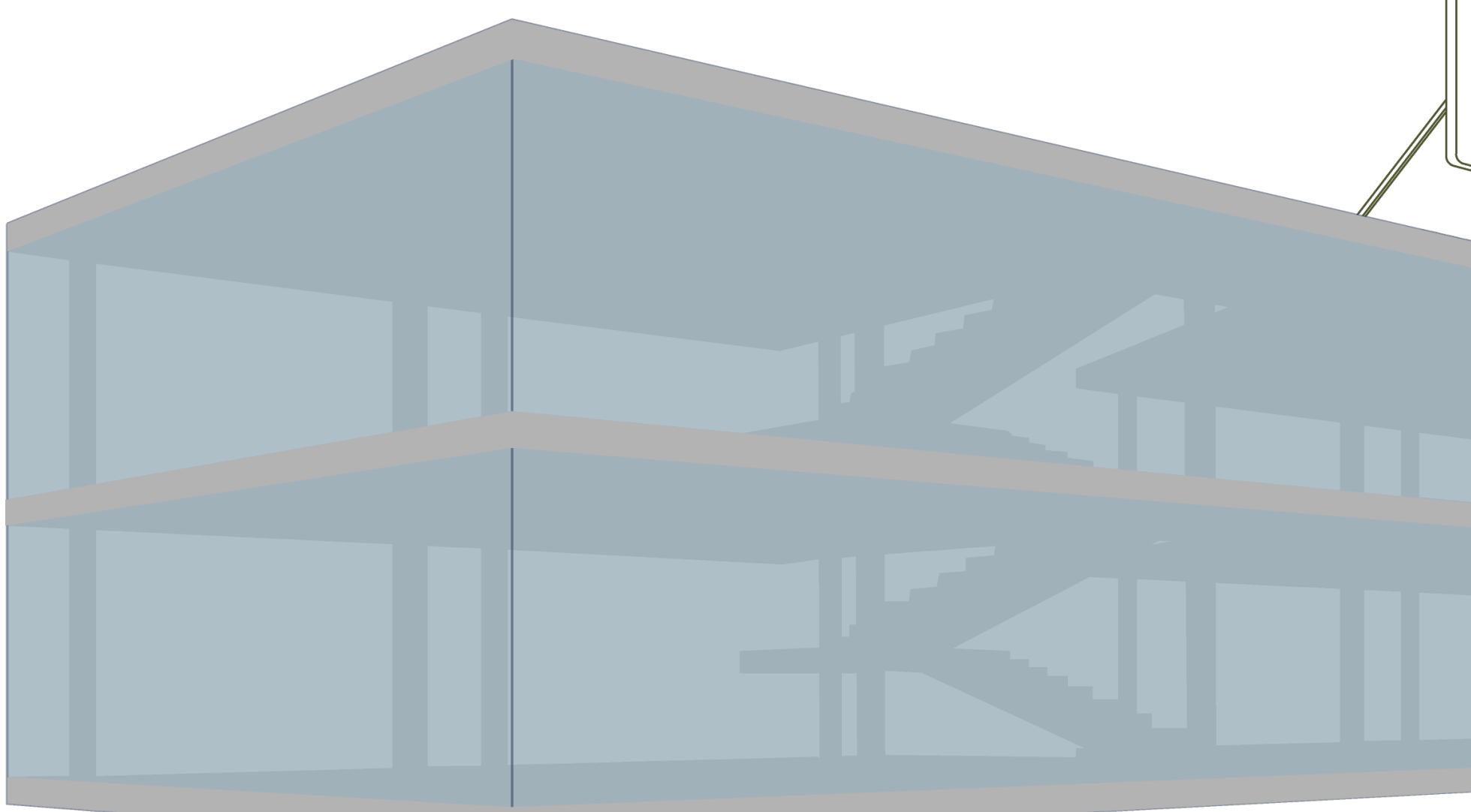

fig. 4-4 Dom-ino Mall 
What Eisenman presumes as the 'horizontality' of Dom-ino that made it a 'self-referential sign' and, therefore, architecture can also be the basis for a mundane building like a shopping mall.

Also, what Eisenman deems as Dom-ino's 'break' from the verticality of representation techniques before it, can be seen in all the ways that Dom-ino has been replicated vertically in our office towers and condos.

IS IT POSSIBLE TO REREAD THE DOM-INO SKETCH WITHOUT RELYING ON CONVENTIONS OF ARCHITECTURAL REPRESENTATION? 


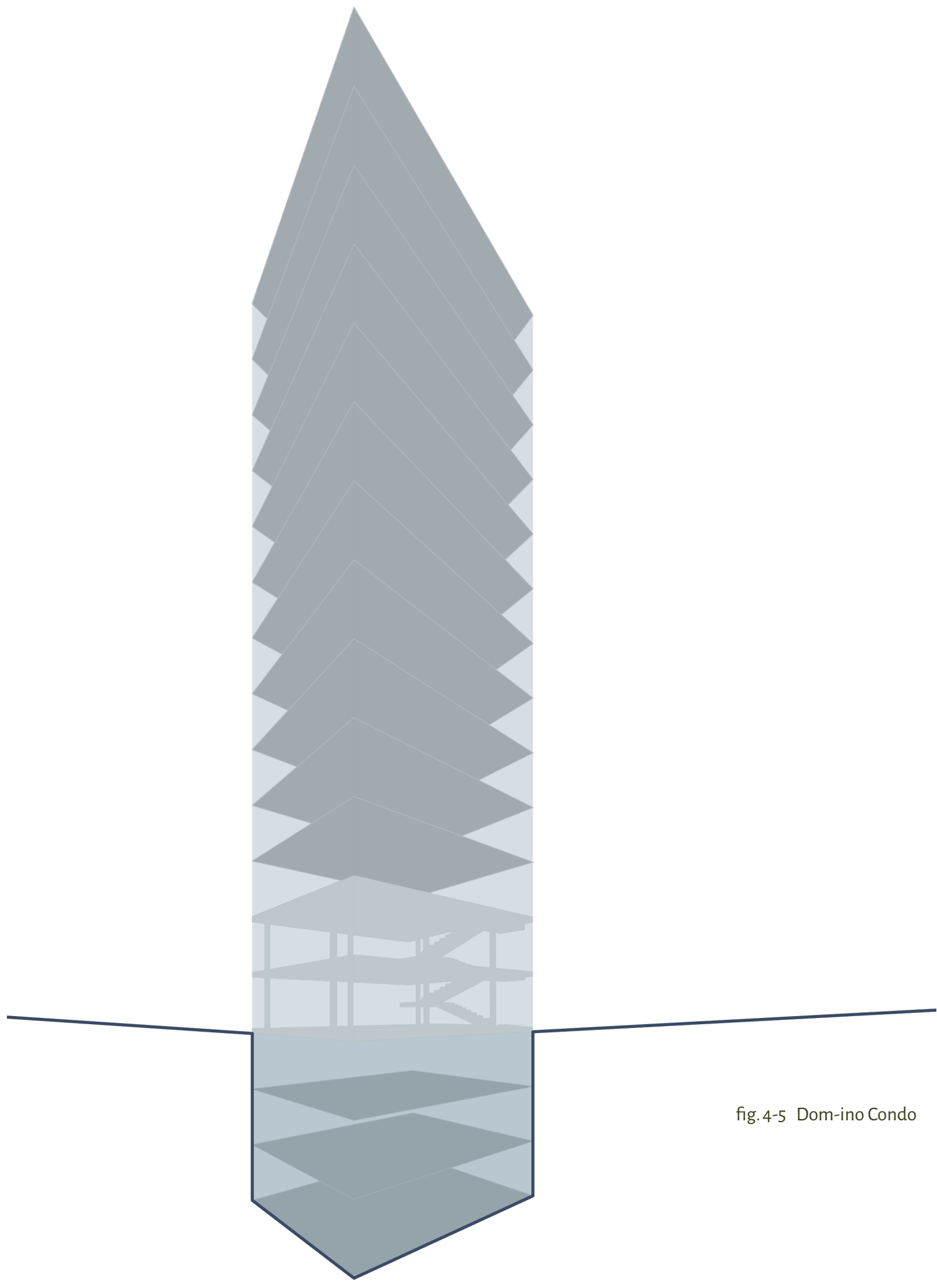


What Eisenman declares as the 'wallness' or the 'beamness' of a 'plane' is nothing more than historical conventions that define elements of construction. However, this separation does not depend on what they are but lies in our way of approaching them. What we see as their effect is what we perceive as their difference. Their difference is only dependant on how we (humans) experience gravity.

Dom-ino is a 2D construction with a very specific set of disciplinary attributes, that Eisenman remakes in axonometric. Therefore, if "one-to-one dom-ino" was a 3D replica in corporeality, Eisenman's axonometric drawings are 3D replicas of Dom-ino in the incorporeal world. As a 'virtual' reconstruction, Eisenman is not interested in the materiality of Dom-ino either. His only interest is the way its 'form' is represented as 'volumes' that seem to have very intentional relationships.

fig. 4-6 Dom-ino: constructed with shadows

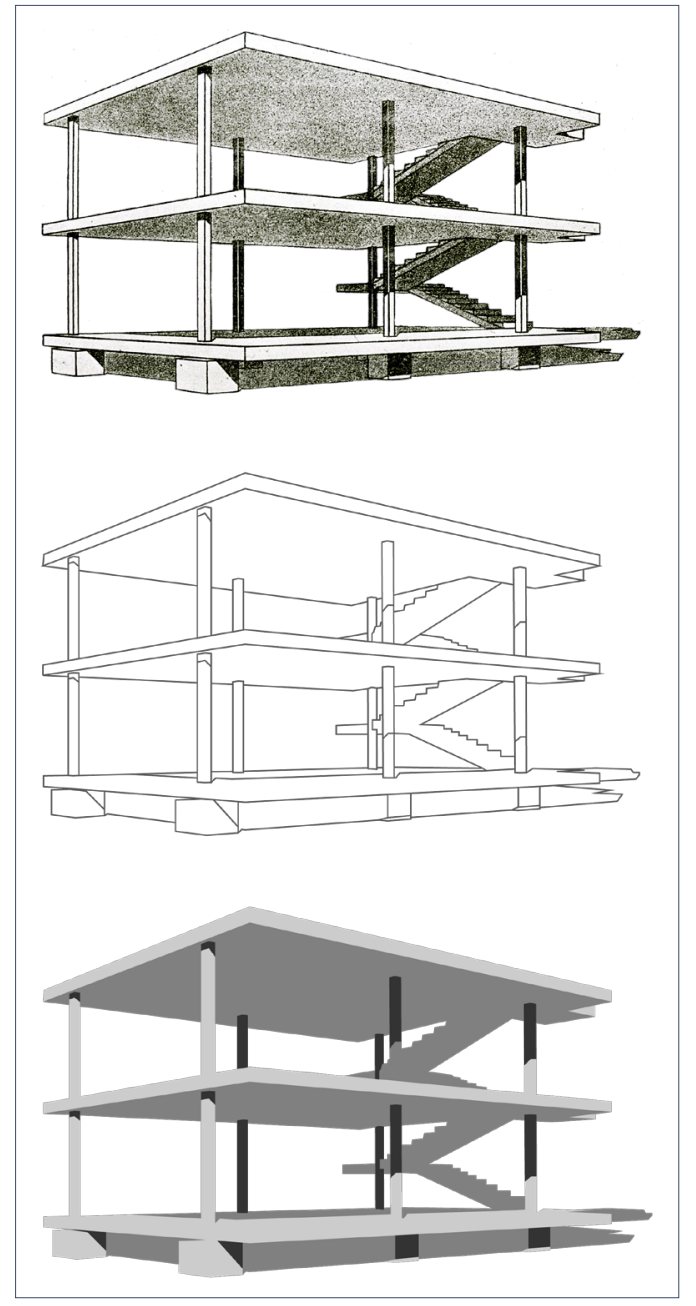




\subsubsection{DECONSTRUCTION}

Any exploration of Dom-ino must take into consideration the power of its image. So, to produce, or reproduce, new images of it, we must first break it down to its components. To do so, instead of taking for granted conventions that say: "this is a wall" or "this is a slab" (like Eisenman), we can approach the drawing with a disciplinary naiveté. In short, it is possible to see different elements and components in Dom-ino when its famous perspective is read as an image.

To begin this project, the elements of Dom-ino were deconstructed, not based on their assumed structural role, but as through their brightness of the component of its image (the drawn plans and lines).

A building in the everyday world is held up by its structural components (like walls, doors, etc.). When constructing a building, its components are read from an image that has recorded the intent of the architect through very specific disciplinary conventions of architectural representation. However, an image also has other components that are not necessarily architectural, but are informed and inform the architectonic information. At its simplest form, the structural components of an image are lightness, shadow, and colour of its planes.

IN THE SPIRIT OF DICITAL TECHNOLOCY, WHICH IS THE WAY MOST OF US WILL BE VIEWINC THIS VERSION OF DOM-INO, THE THREE DIFFERENT SHADES PRESENT IN DOM-INO WERE GIVEN THREE DIFFERENT COLOURS: RED= THE LICHTEST, BLUE= THE MIDDLE AND GREEN=THE DARKEST.

NOW, IT IS POSSIBLE TO SEE HOW COMPONENTS OF DOM-INO, AS AN IMACE, CAN BE DECONSTRUCTED AND RECONSTRUCTED IN THE FLAT SPACE OF PAPER.

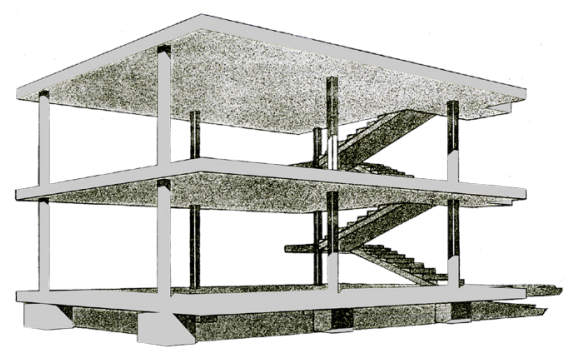

fig. 4-7 R Dom-ino

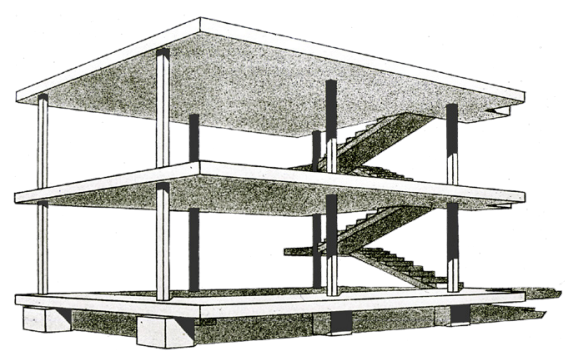

fig. 4-8 G Dom-ino

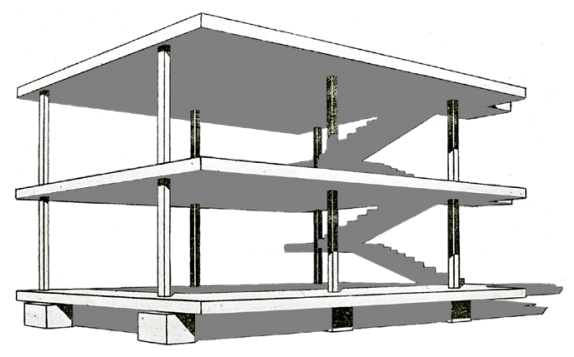

fig. 4-9 B Dom-ino

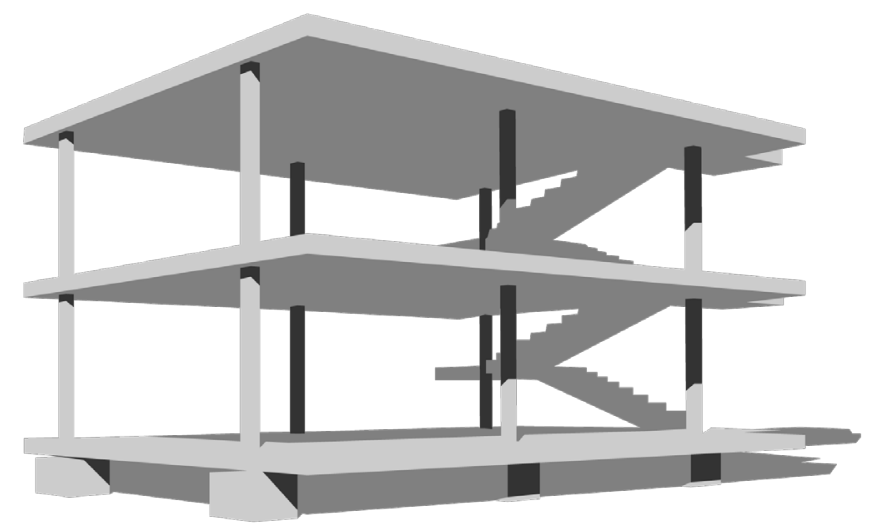

fig. 4-10 Grey Dom-ino 

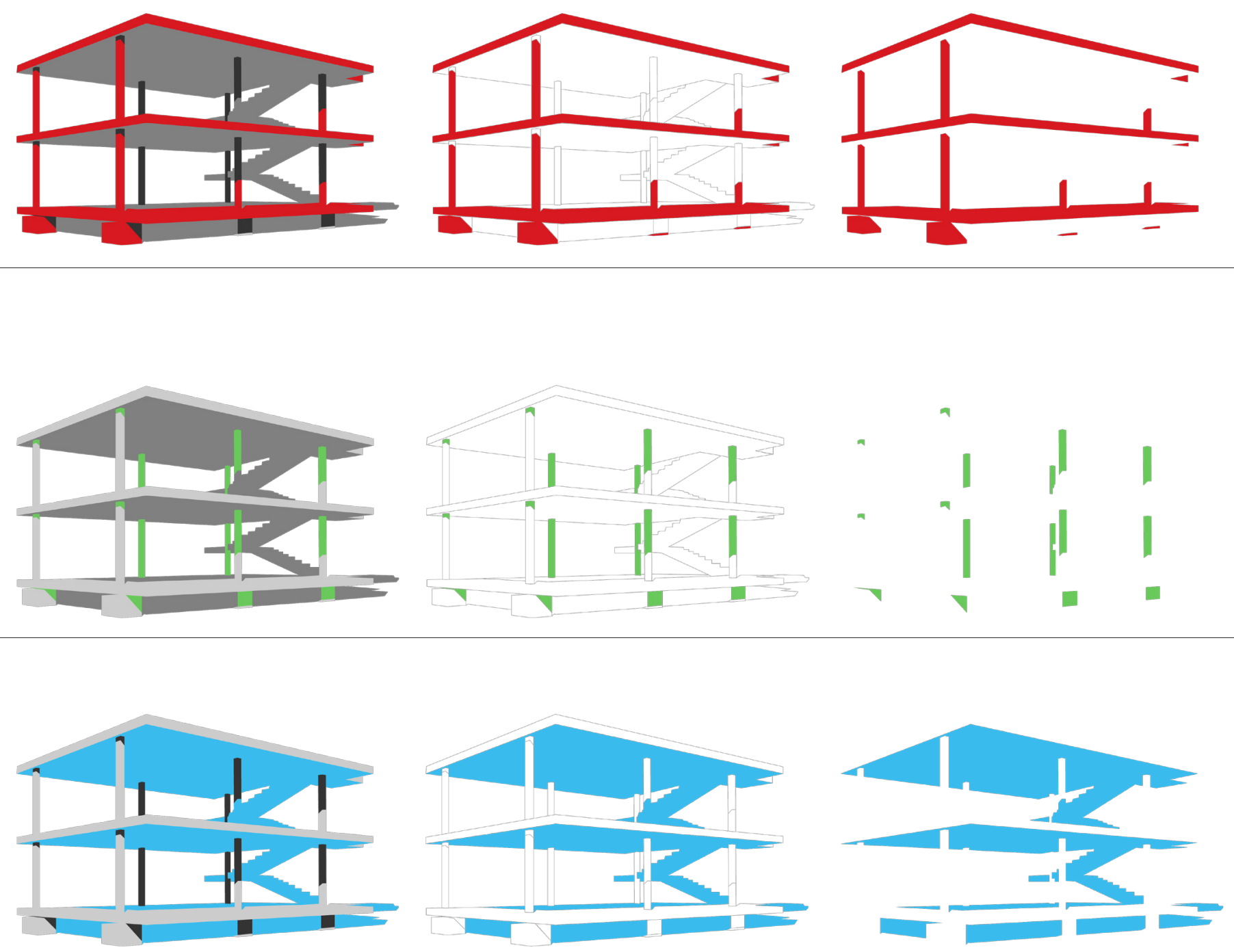

fig. 4-11 RGB Dom-ino

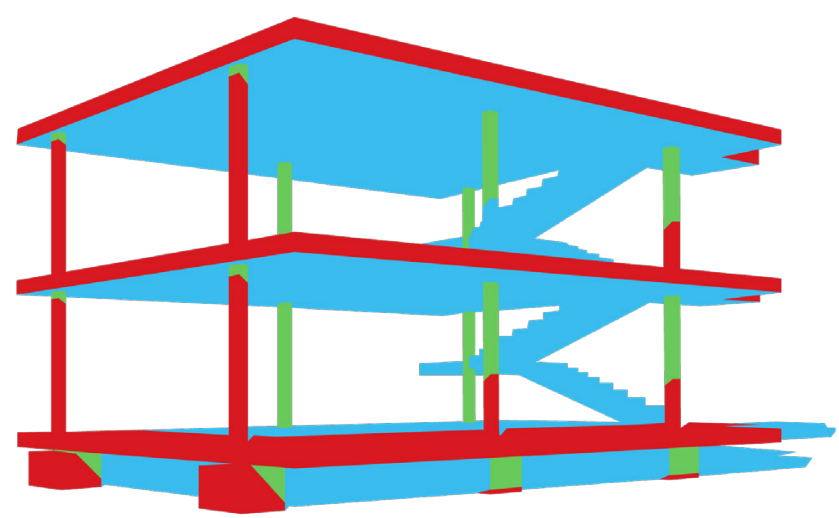




\subsubsection{COOPERATION}

Dom-ino perspective was an image of a prototype. It was intended to be replicated ad infinitum. However, when built, each Dom-ino would have looked different as the walls were intended to be built from the rubble of demolished houses and by the inhabitants. ${ }^{6}$ Therefore, no two Dom-ino would have looked the same.

To replicate this effect this project included a cooperative stage. Here, the three R-G-B components of Dom-ino were given to a professional printer with three constraints: (1) each sheet of paper must have $1 \times R, 1 X C$ and $1 X B$, (2) they should not have the same sequence (meaning not all papers can be printed in the R-G-B order) and each sheet must be moved slightly so an overlap of the 'planes' of Dom-ino are visible. This project was silk-screened with a photocopier. It was a game of Exquisite Corpse with a machine.

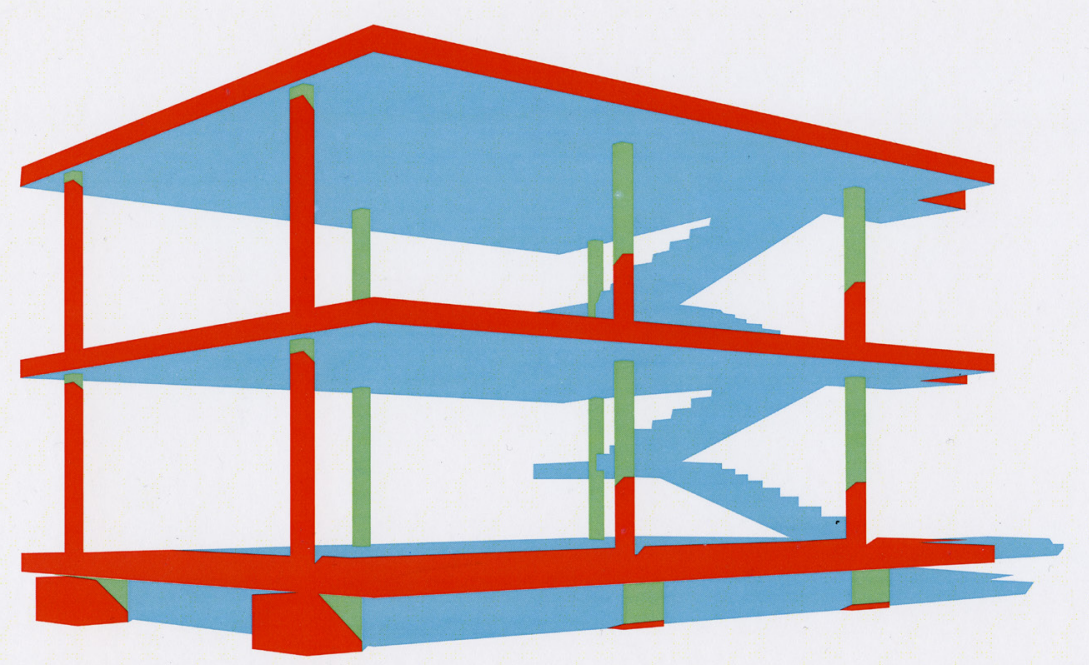




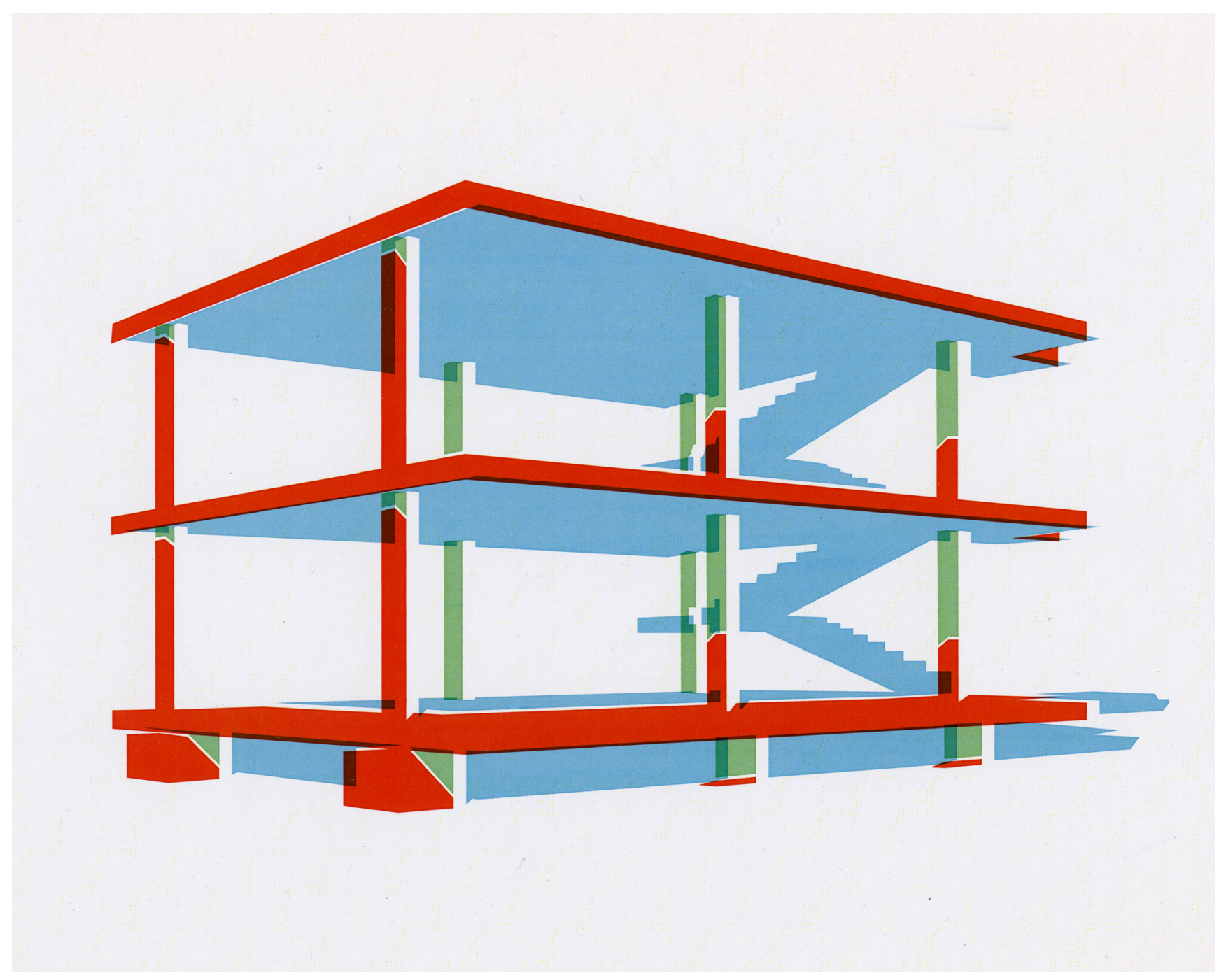

fig. 4-13 RGB Dom-ino: cooperation 


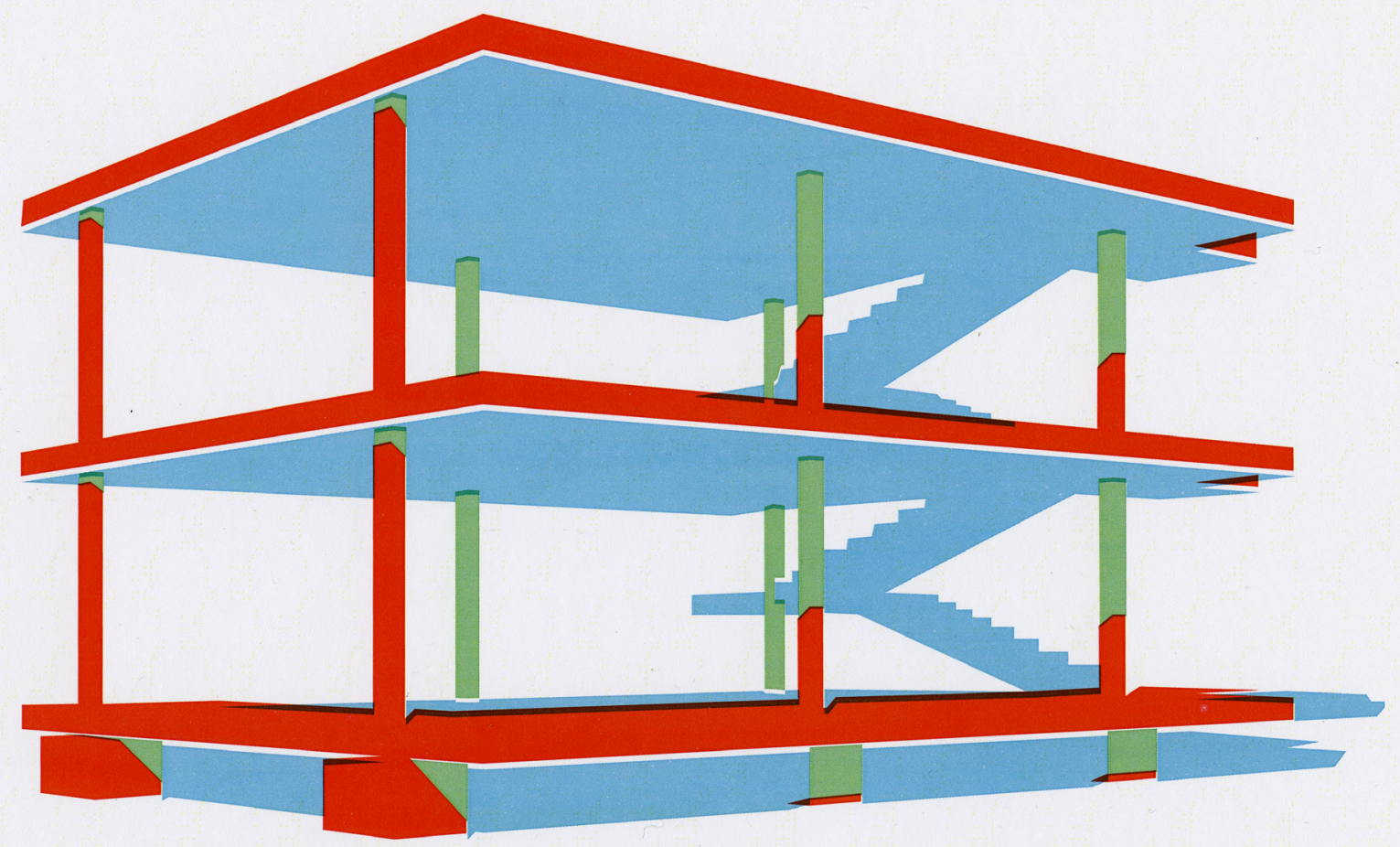

fig. 4-14 RGB Dom-ino: cooperation 


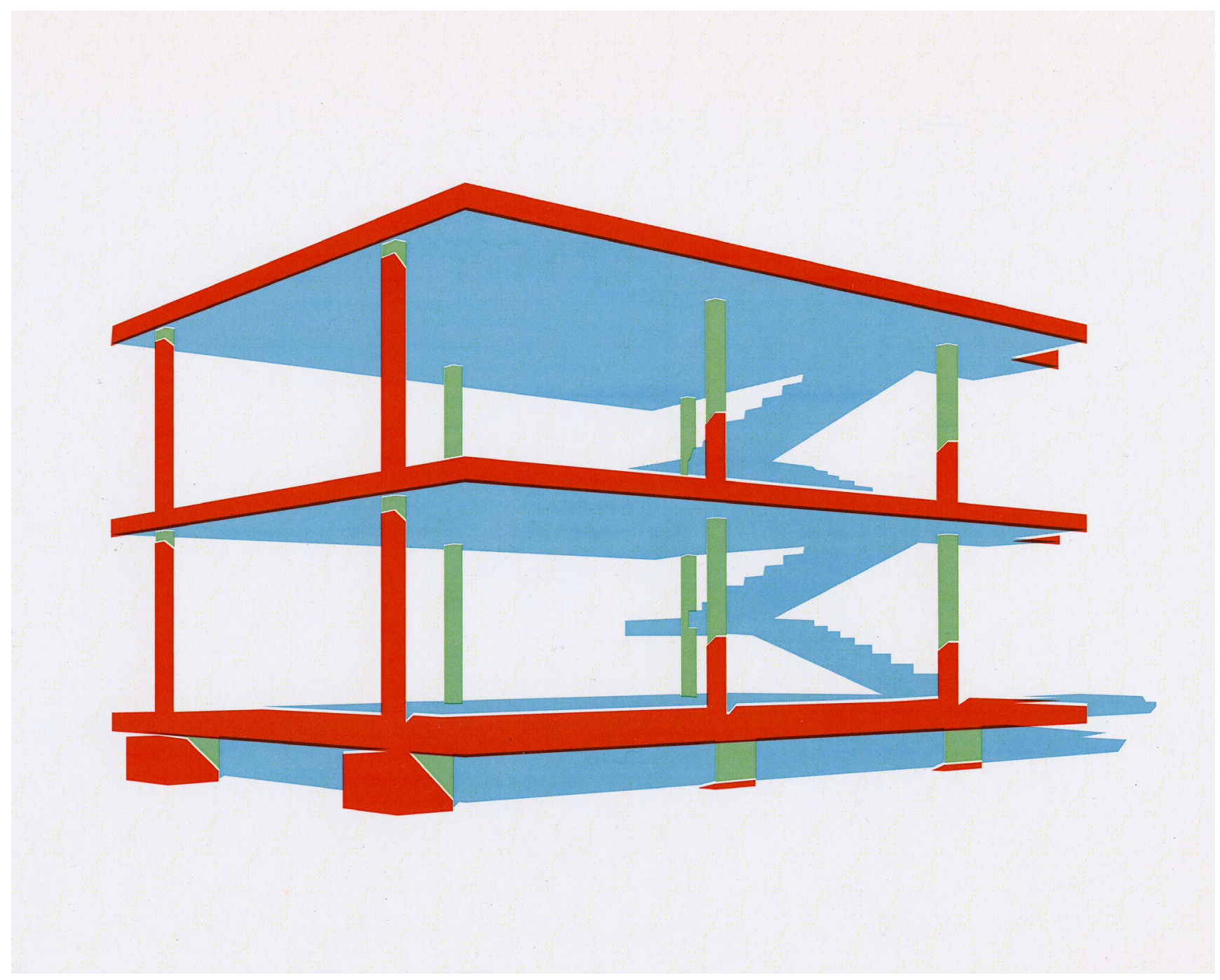

fig. 4-15 RGB Dom-ino: cooperation 


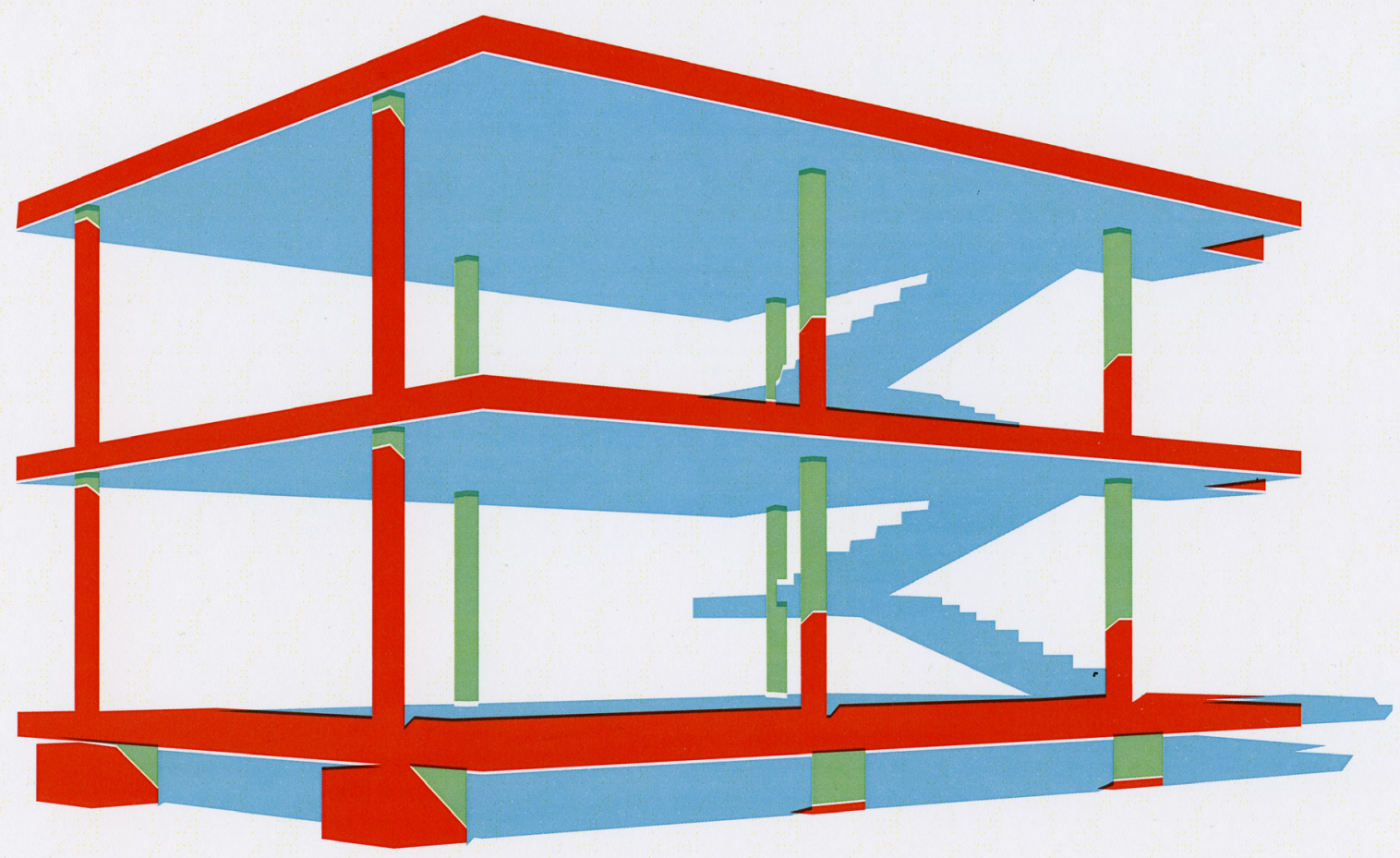

fig. 4-16 RGB Dom-ino: cooperation 


\subsubsection{INTERPRETATIONS/SYNTHESIS}

When made into a building with the help of construction firms and inhabitants, a new Dom-ion image would have emerged. Every iteration would become a simulacrum of the original Dom-ino drawing. These exercises are about creating those simulacrums. By cannibalizing Dom-ino, I am preserving its lost cENIUS through countless repetition.
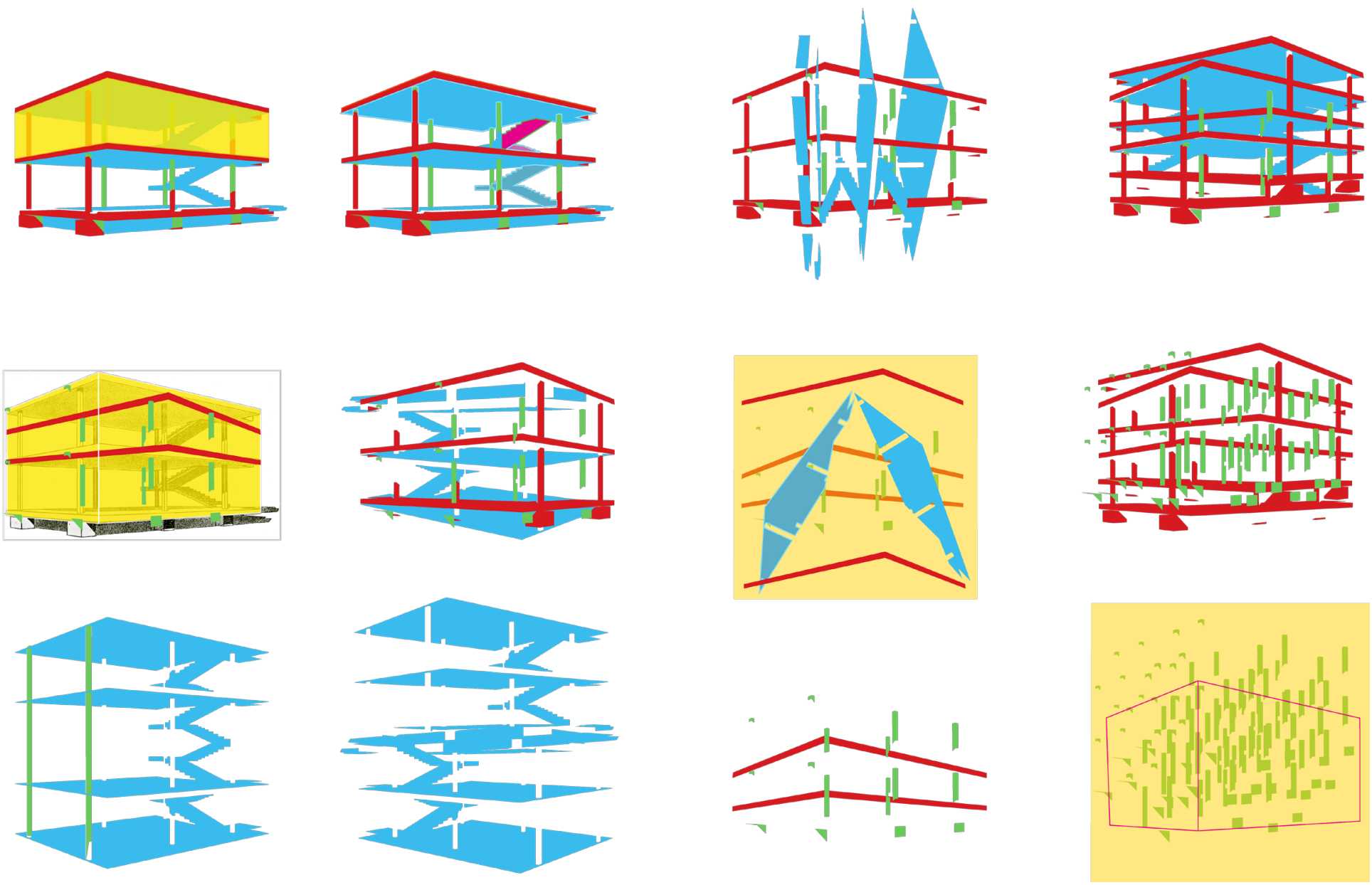

fig. 4-17 RGB Dom-ino: synthesis 


\subsection{A WOODEN DOM-INO}

\subsection{1 'ONE-TO-ONE'}

After 100 years, the famous unbuilt 1914-15 project by Le Corbusier Maison Dom-ino (Dom-ino) was finally constructed at the 2014 Venice Architecture Biennale. Called "one-to-one dom-ino,"? and built by Architecture Association (AA), the structure was described as a "1:1 replica" of the unbuilt Dom-ino. There were a couple of stated reasons for constructing this 'replica': (1) that year coincided with 10oth birthday of Dom-ino and was celebrated by a year-long series of events called "Happy Birthday Dom-ino" and (2) AA wanted to acknowledge Dom-ino's importance to architecture as "a project [that] distills modern architecture to a set of guiding, abstract, and idealized principles." Since "the 'afterlife' of Dom-ino can still be seen and felt today, a hundred years later."

Le Corbusier's 1914-15 design was a reinforced concrete structure that was the result of his many years of explorations that accumulated in Dom-ino as a 'transmutation' of 'the concrete skeleton developed by the engineer into a means of architectonic expression." However, "one-to-one dom-ino" was a replica of Dom-ino in "engineered timber."

The decision to switch the material might have had something to do with the temporary nature of the Biennale that would not permit a concrete skeleton in the middle of its garden. But, the team responsible posit that this change reflects their intention to "upgrade and update"10 Dom-ino from its early 20 th century construction method to a more contemporary choice of materials and techniques that address contemporary issues.

\subsection{2 'MONODIC' (5)}

When it comes to Dom-ino, the term 'replica' is too ambiguous to be a convincing description. Looking at photos of "one-to-one dom-ino," the question remains: what exactly is 'replicated' here? Is "one-to-one" a replica of the 'image' of Dom-ino (its now famous perspective)? Is "one-to-one" a replica of the 'intent' behind Dom-ino? its 'form'? its 'material'? its 'system'? its 'design'? or its 'architecture'? Also, what is it that "one-to-one dom-ino" celebrates? Is it Dom-ino's social agenda? Its

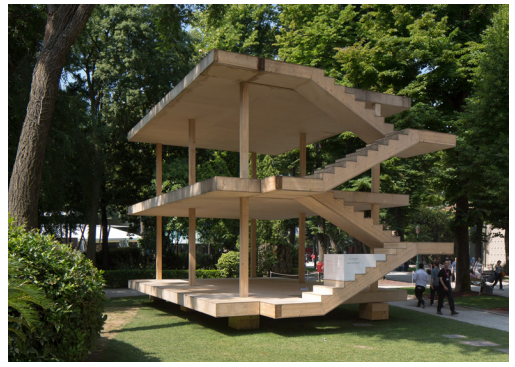

fig. 4-18 "one-to-one dom-ino" at 2014 Venice Biennale 
economic agenda? Its conceptual qualities? Its empirical qualities? Its autonomy? Its contingency? Its speculative qualities?

These strings of questions are not directed at "one-to-one dom-ino" or Dom-ino. They are directed at the dialogue that arises when the two Dom-inos are compared and pertain to the fundamental issues that apply to the 'form-matter opposition' of the modernist discourse of architecture. Then, why keep the 'form' and change the material? Is material that interchangeable? Is 'form' so much more important, that even when the materials in the world change, the architectural 'form' remains immutable?

$$
* * *
$$

It is conventionally believed that 'form' precedes 'matter', and 'form' is inherently more architectural than 'matter'. The design of Dom-ino was not a purely conceptual construction that Le Corbusier then decided to make in reinforced concrete because it was new and fashionable. Rather, Le Corbusier studied a great deal of precedents of both engineering methods and vernacular technique to arrive at Dom-ino; as a project that informs his Five Points more than a decade later. ${ }^{11}$ Therefore, "one-to-one dom-ino" is not an upgrade. It is a recession back into the modernist mentality of 'form' above 'matter' that has persisted in the discourse of architecture since the Renaissance.

\subsubsection{POSSIBILITIES OF A WOODEN DOM-INO}

If AA wanted to update the material of Dom-ino by making it out of wood, they might have considered that a wooden version of Dom-ino already existed. In fact, as Pierre Vittorio Aureli states, Dom-ino's clean slab-plan-less-can be compared to the invention of "balloon frame,"12 which also features a plan-less form of architecture where the space is constructed by erecting the perimeter walls, leaving the interior space open for future configurations. However, unlike 'balloon framing' were a family could put together their own house, Dom-ino relies on construction companies to deliver technology and "standardized"13 doors and windows.

Dom-ino as an subversive act destroys the traditional spatial properties, but is then turned around during modernism to harbour the capitalist 
restructuring of domestic space. The open plan is marketed under the disguise of "flexibility and adaptability."14 Aureli warns that "in capitalism, flexibility is never an innocent attribute," which is why Aurelie maintains that "The Dom-ino idea can be understood as the ultimate example of how economy has conquered architectural form."15 Aureli writes that:

In the case of domestic space, this means the possibility of subversion of all the patterns that have supported the mastery of the domestic as the locus of such fundamental economic categories as home ownership, gender roles, and security. [...] Here form is no longer just an object or, worse, a style but process through which we can constantly reinvent the world within our daily praxis. ${ }^{16}$

In Space, Time and Architecture, Siegfried Giedion describes the intention of Balloon Framing as an invention that was "closely connected with the level of industrialization which had been reached in America." ${ }^{17}$ Similarly, according to Spiro Kostoff, the development of balloon framing directly responded to the technological, economic and industrial development of its day: (1) "mass production of dimensioned lumber,"18 (2) "machinemade nails" and (3) "prompt distribution by rail."

At the time, 'balloon framing' was hailed as the "most important contribution to our domestic architecture."19 One of the reasons, besides the simplicity of this method, was the loose 'modularity' of the system. Giedion quotes a comment from Great Industries of the United States where the rapid settlement of the West was directly attributed to this method of construction and the industrial processes behind it:

with the application of machinery, the labor of house building has been greatly lessened, and the western prairies are dotted over with houses which have been shipped there all made, and various pieces numbered. ${ }^{20}$

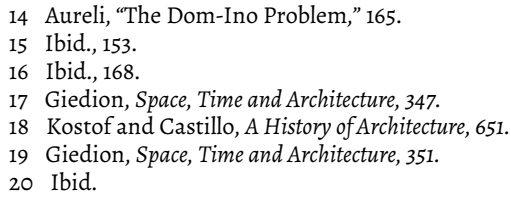


fig. 4-19 Blueline B7088-16S sheet:

\subsubsection{THE GRID (1)}

For modernism, the 'grid' becomes the 'eternal' plan projected from above onto earth. A 'grid' is "prediction" ${ }^{21}$ by 'design' and not by chance. The grid represents the economy (efficiency) of flow of information. When on Grid, everything can be located through two numbers that correspond to its two axis of $\mathrm{X}$ and $\mathrm{Y}$. Grid provides a way that we can move entities from one location to another location with certainty and assurance. A 'grid' is a bottom-line. It is equal no matter where it lays or who it located. Everyone and everything on a 'grid' are equally ordered.

$$
* * *
$$

"The Grid is [...] a conceptual speculation [...] it claims the superiority of mental construction over reality."22

\section{- Rem Koolhaas}

the accountant's grid

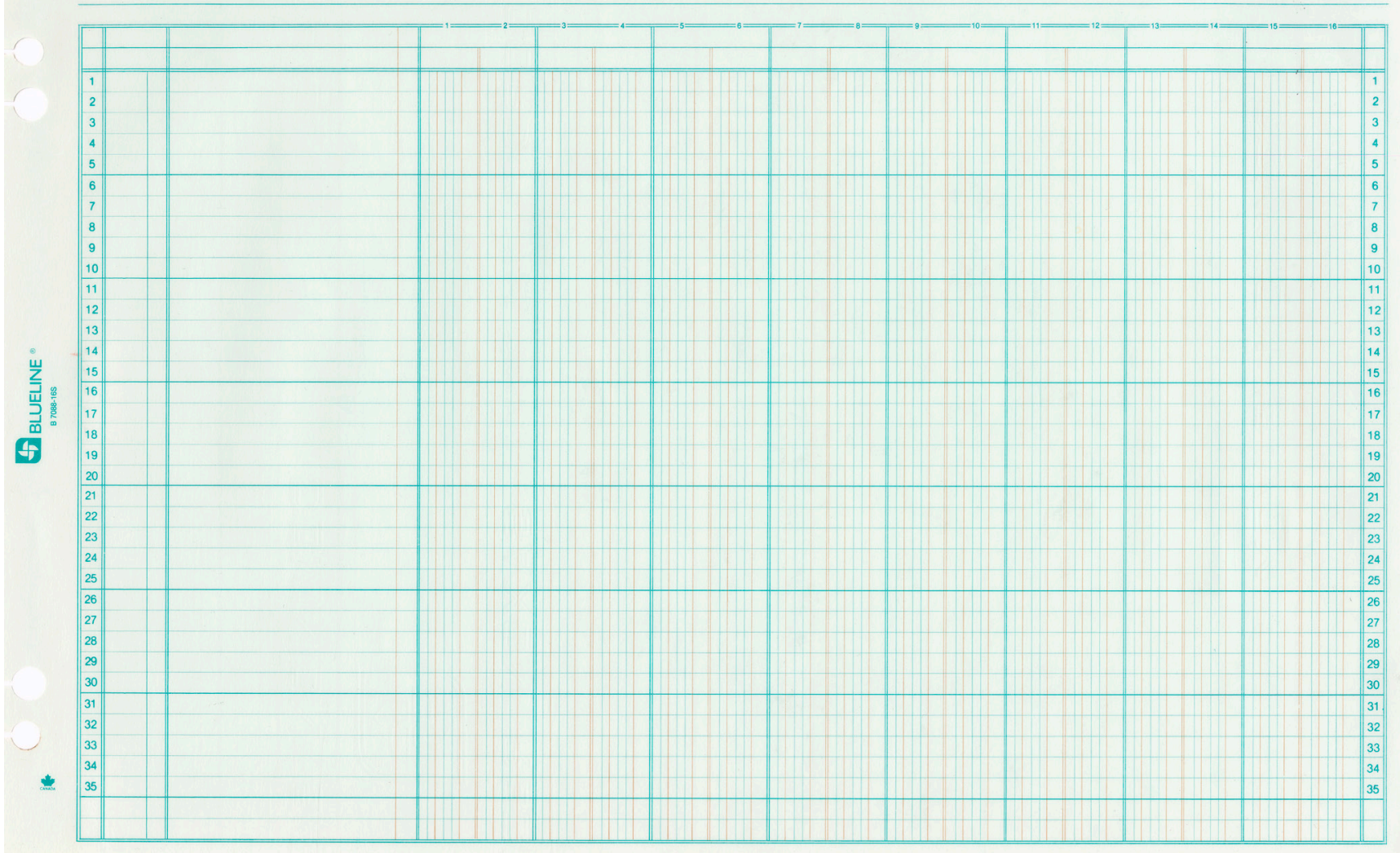




\subsubsection{BLUELIne Manhattan}

"150 years later $[\ldots]$ the grid in viewed as a "negative symbol of the short-sightedness of commercial interest. [...] in fact, it is the most courageous act of prediction in Western civilization." ${ }^{23}$

— Rem Koolhaas

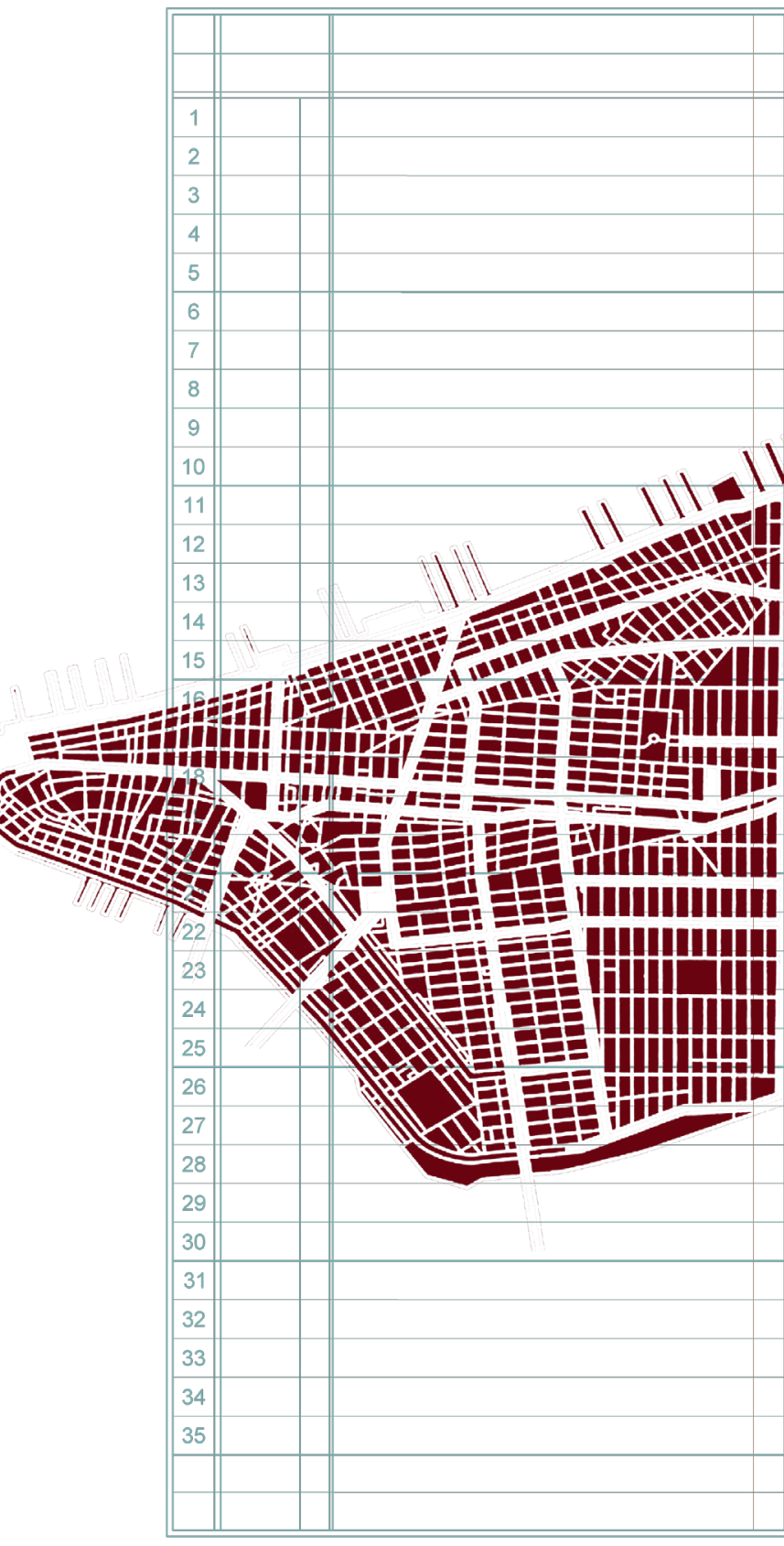




\subsection{ECONOMY}

The original development of Dom-ino was in response to the destruction of French housing during the First World War. Therefore, Dom-ino was designed as a "system" 24 that "exploited standardized components for its structural elements." The name of the system Dom-ino was a "reference to the Latin domus (house) plus innovation." Also, as some of the sketches of Dom-ino show, there was a clear reference to the game dom-ino [fig. 4-2]. Each house was meant to act like pieces of dom-ino that attach to each other and string across a field. There was also commercial interest in the project. It was a joint venture as a collaboration between Max Du Bois, Juste Schneider and Le Corbusier. ${ }^{25}$ They had filed a "patent application"26 for the Dom-ino system as a "low-cost, modular concrete structures" in 1916.

According to Aureli, the century old fascination with Dom-ino sketch is the result of its "ambiguity" 27 because Dom-ino is "one image" that communicate "two opposing conditions for architecture." It represents how Le Corbusier appropriates a construction method that was explored by Albert Kahn in America for constructing of "warehouses and factories," to producing of housing. For Aureli, "the idea for Dom-ino comes not from the study of a specific building typology, but from the appropriation of a specific building technique: in this case reinforced concrete."

This two-fold ambiguity opens Dom-ino to a different reading than what Eisenman explored. Instead of looking at the relationships between the elements, and treating Dom-ino in a bubble separate from the world, Aureli investigates it as an outcome and response to larger social changes that have changed the architecture of domestic space -

The Dom-ino idea can be understood as the ultimate example of how economy has conquered architectural form. ${ }^{28}$

\subsubsection{FALSE-FRONT}

The comparison to 'balloon framing' and the assumption of economy's conquest of the 'architectural form' can be seen in the development of the 'commercial false front' in the frontier towns of the late $19^{\text {th }}$ century

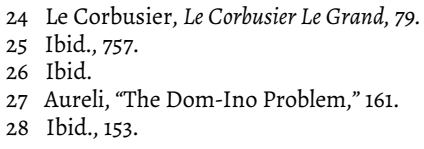


America. According to Kingston WM. Heath, the "commercial false front evolved as a central factor in the development of community life on the 'urban' frontier." 29 The application of the 'false-front' was to provide an illusion of urbanity in places where no such life was present. In frontier towns buildings were "hurriedly constructed to accommodate the miners and the reality of 'city'." In this context, everything is a make-believe game, where the 'front' is an illusion of what lies behind it. As Heath writes,

"the buildings were false in material pretense (wood feigning masonry), structural pretense (log party walls supporting a balloon frame front wall for greater light and display area) and formal pretense (a rectilinear façade hiding a gable or shed roof)." ${ }^{30}$

The speed with which these towns were built meant that buildings of various programs had to adapt to the architecture of the 'false front'. Therefore, all that distinguished between a bank or a brothel was the "lettering paints on the face of the building." ${ }^{31}$ And, "In essence, these buildings were little more than surfaces for the distribution of signage." Like Las Vegas, where the signs were the primary identifiers of the function of the building that lay behind them. ${ }^{32}$

In the frontier towns, the 'false front' was more than a signage board for individual business. They directly reflected to the prosperity or economical success of the town as a speculative endeavour. What would begin as a tent community would transform to a town of 'false fronts'. If the town further prospered, the materiality of the 'false fronts' would change or they would be replaced with more durable and more expensive materials in the form of permanent building. However, if the town would fail and was abandoned, the 'false fronts' would remain as banners of "defeat." ${ }_{33}$

\subsubsection{LОВОтОМҮ}

The correlation between the forces of economy and success or failure of speculative aspects of architecture in the form of a pretend game is very much like what Rem Koolhaas in Delirious New York describes as "the 

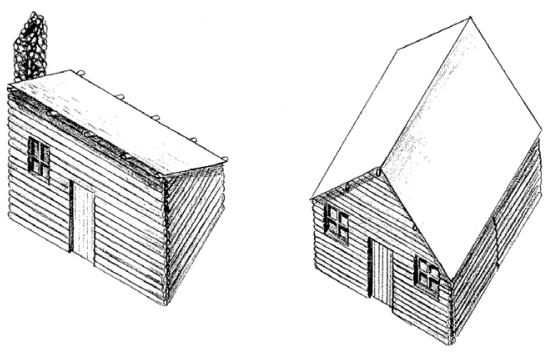

Type 1. Shed roof, log-facade store form.

Type 2. Gable-ended log store/house form.

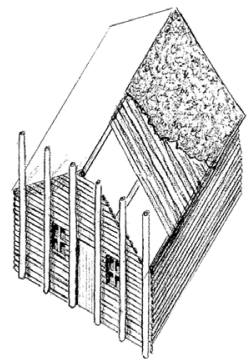

Transition Phase: Adaption of $\log$ store/house form to facade. (construction diagram)

fig. 4-21 evolution of the commercial false front

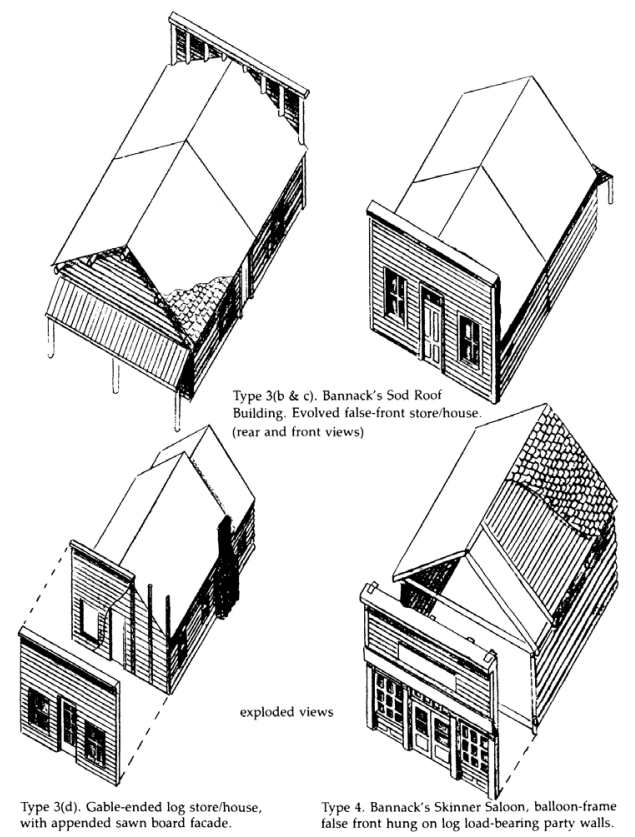

fig. 4-23 evolution of the commercial false front

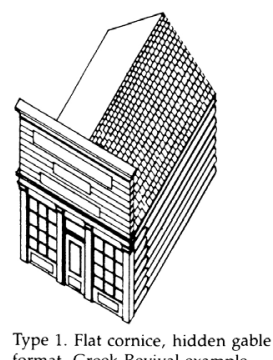

fype 1. Hect comice, hidden gable
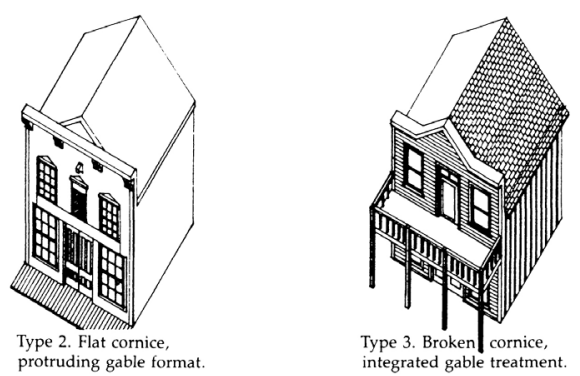

fig. 4-22 evolution of the commercial false front

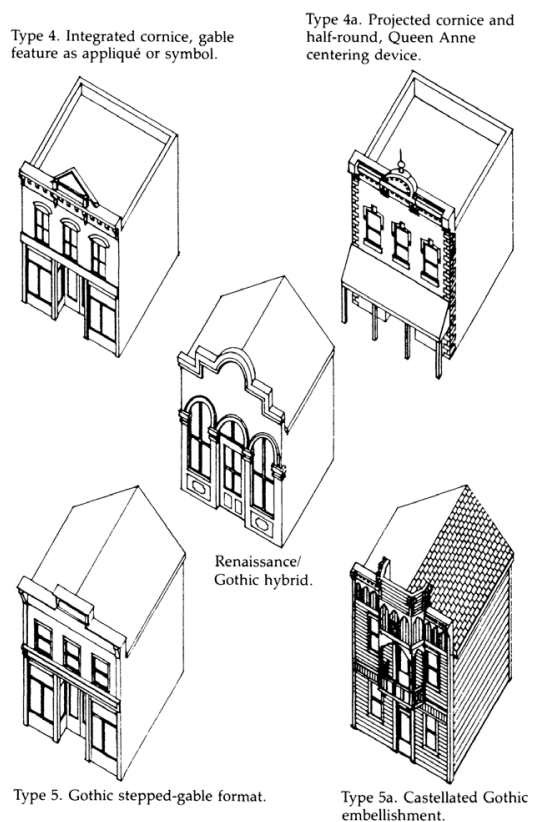

fig. 4-24 evolution of the commercial false front 
architectural equivalent of a lobotomy," ${ }^{34}$ where the "exterior and interior architecture" ${ }^{35}$ are surgically separated.

In Delirious New York, Skyscrapers are concrete irrationalities. They multiply the piece of earth that they took many times over, granting each floor an autonomous life behind the lobotomised skin of the building. From outside, each skyscraper looks the same, but behind the façade they are incubators of a dizzying number of functions.

In a reverse of the 'commercial false front', the lobotomized architecture of New York, would allow for a uniform front that never changed, while the inside was constantly updated or refurbished. Ironically, what was a sign of 'defeat' in the frontier town, became a device for prosperity through 'cannibalization'36 of architecture itself.

\subsubsection{A BALLOON-FRAMED CONSPIRACY}

The history of 'balloon framing' is not without its own conspiracies. In fact, Freud's criticism of aesthetics [also see, 3.5.9] , it is possible to see how the discourse of architecture has come to "supress a long and complex evolution of light wood framing techniques and their meanings within American culture," ${ }^{37}$ in favour of the "myth of the balloon frame" as the defining technology of an "ideal American" architecture. As David Monteye explains, the nostalgia of the virtues of the balloon frame has eclipsed other light wood framing techniques; most notably "the platform frame." ${ }^{38}$ Monteye posits that "since World War II, almost all houses in the United States have been built with [...] Platform framing [and] if houses are the most common building type by sheer number, then platform framing is by far the most common method of construction in use today."

The initial development of "light wood frame construction had no definitive form in the nineteenth century." ${ }^{39}$ Unlike the account of the invention of balloon frame that is given by "the Geidion school." Due to various "traditions," "environmental conditions" and "development of communication networks" balloon frame "did not spring forth as a resolved design to settle the frontier."

Geidion believed that the 'balloon framing' indicated the point in time that "housing" ${ }^{40}$ was directly affected by "industrialization." Like any other area of the industrial society, in housing the "skilled carpenter" was now replaced by "unskilled laborer." 'Balloon frame' replaced the traditional "mortise and tenoned joints," that were complex and costly to

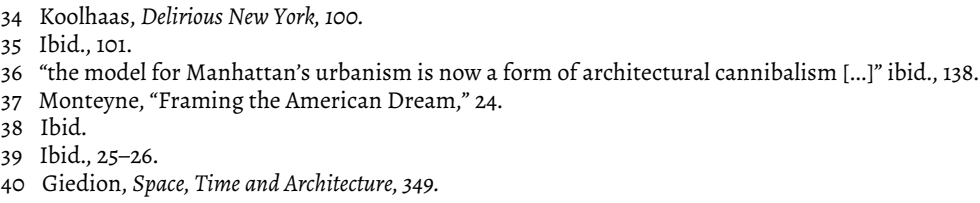


construct, with a light system that would allow anyone to "put together a house like a box, using only nails." ${ }^{41}$ However, as Monteyne argues, the direct relationship between housing and industrialization resulted in platform frame and not balloon frame. ${ }^{42}$

According to Monteyne, unlike what the 'Giedion school' would have us believe as "the romantic concept of the self-sufficient homesteader and his boy readily balloon framing their own house," 43 construction of 'balloon frame' required "an experienced carpenter [...] to integrate and plumb the complex relationships between individual pieces of lumber." Indeed, a close reading of some of the accounts of what is presumed to be a description of the use of balloon frame in "Midwest" 4 could be seen as a "critique of the method of balloon frame" in favour of the "platform frame."

The platform frame as the "most common method of construction in use today" ${ }^{45}$ has been 'codified' and 'standardized' since the mid-nineteenth century due to various industrial and economic developments. Firstly, the "mail-order industry" ${ }^{46}$ that sold and shipped "packaged and readycut houses" triggered many "lumber mills" to standardize the building components (such as joists) that these companies needed. Secondly, in the "late 1920 " 47 and 1930s, the "lumber industry" had experimented with "engineered products" made from wood particles held together with adhesives. These developments lead to the invention of "plywood" after the development of "waterproof glues" in mid-1930s.

The extensive use of plywood by the "Army Corps of Engineers" 48 in the World War II, and the subsequent return of the soldiers who were now familiar with the material, lead to a "very rapid construction of the platform and sheathing of the wall units." In post war housing construction plywood became the "basic material in platform systems." Together, the use of plywood, with the desire for "onsite construction" and "the increasing rarity and expense of longer studs," lead the platform frame to become the dominant method in housing construction.

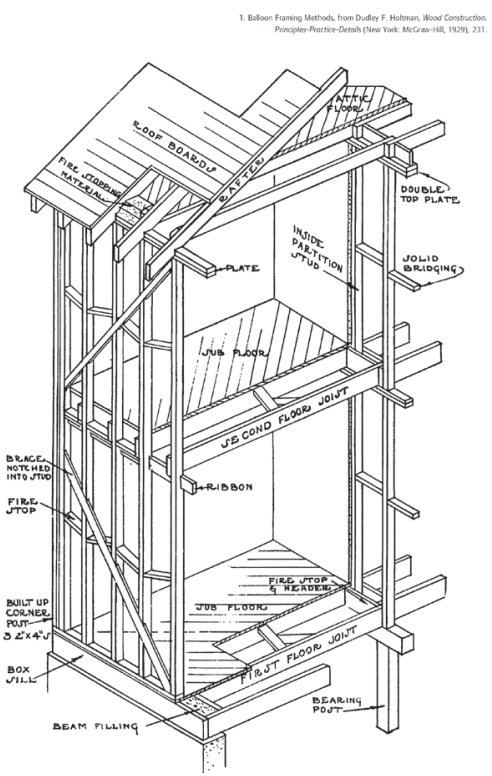

fig. 4-25 balloon frame

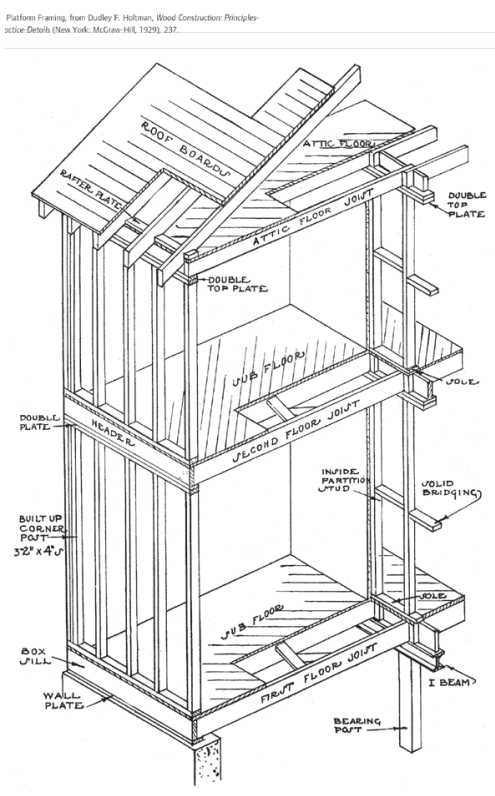

fig. 4-26 platform frame 
fig. 4-27 Subfloor: balloon frame and platform frame
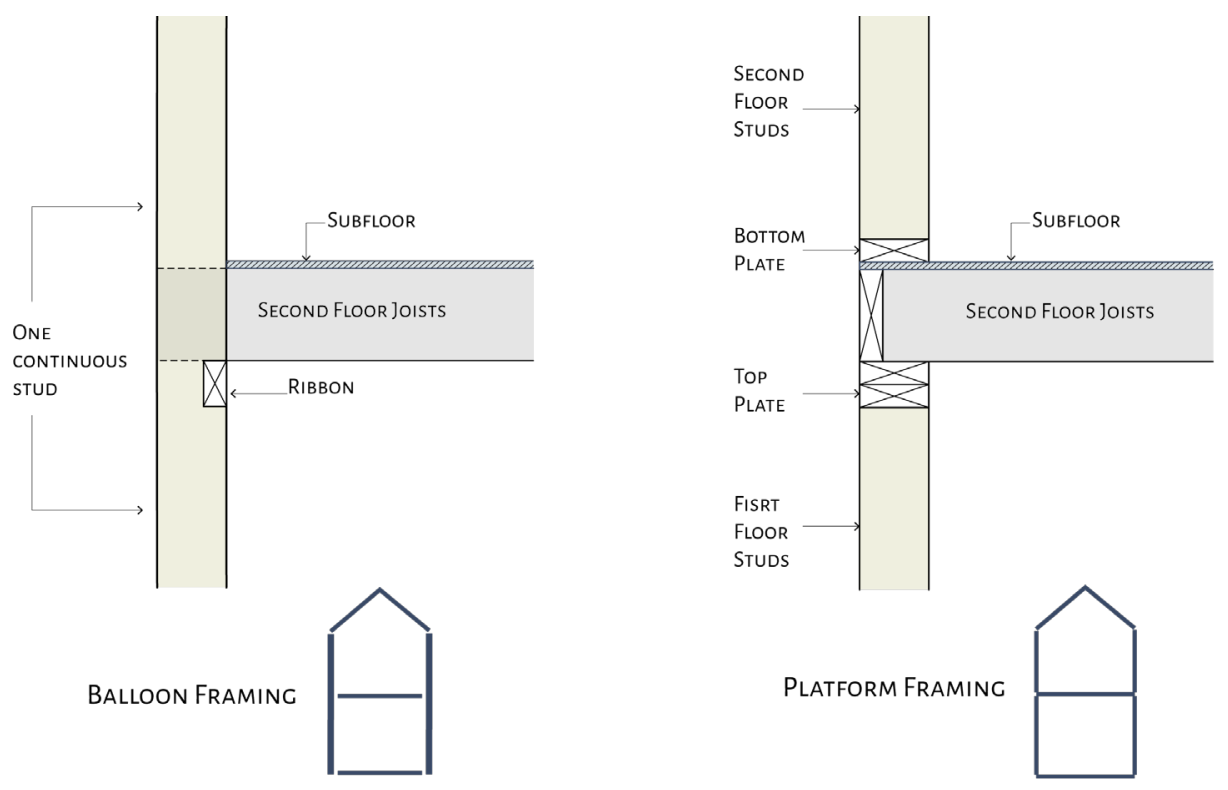

What differentiates the 'balloon frame' and 'platform frame' is the "construction of the sills, the length of the studs and connection between floors, and the order of erection." ${ }^{49}$ In constructing a 'balloon frame' house, the final height of the construction must be known as the exterior "walls must go up before anything can be done." Conversely, "in platform framing, [...] each story is erected as a separate unit."

$$
* * *
$$

Placement of the subfloor is important. It is what gives the system its initial rigidity. Also, the surface of a subfloor resembles a slab.

In balloon framing the subfloor sits on the joist. The construction of the stud wall is independent of the subfloor and precedes it in the sequence of construction.

In platform framing, the subfloor is placed first and then the studs are raised on its surface (with a bottom plate). Without the subfloor, which is made of plywood, the platform frame would not be possible.

Subfloor has the plane-ness of the slab. 
"Fere's your house!"

\section{PORTABLE HOUSE COMPANY}

\section{DIRECTIONS:}

1 To give this house a snappy appearance put it up according to the numbers on the boxes.
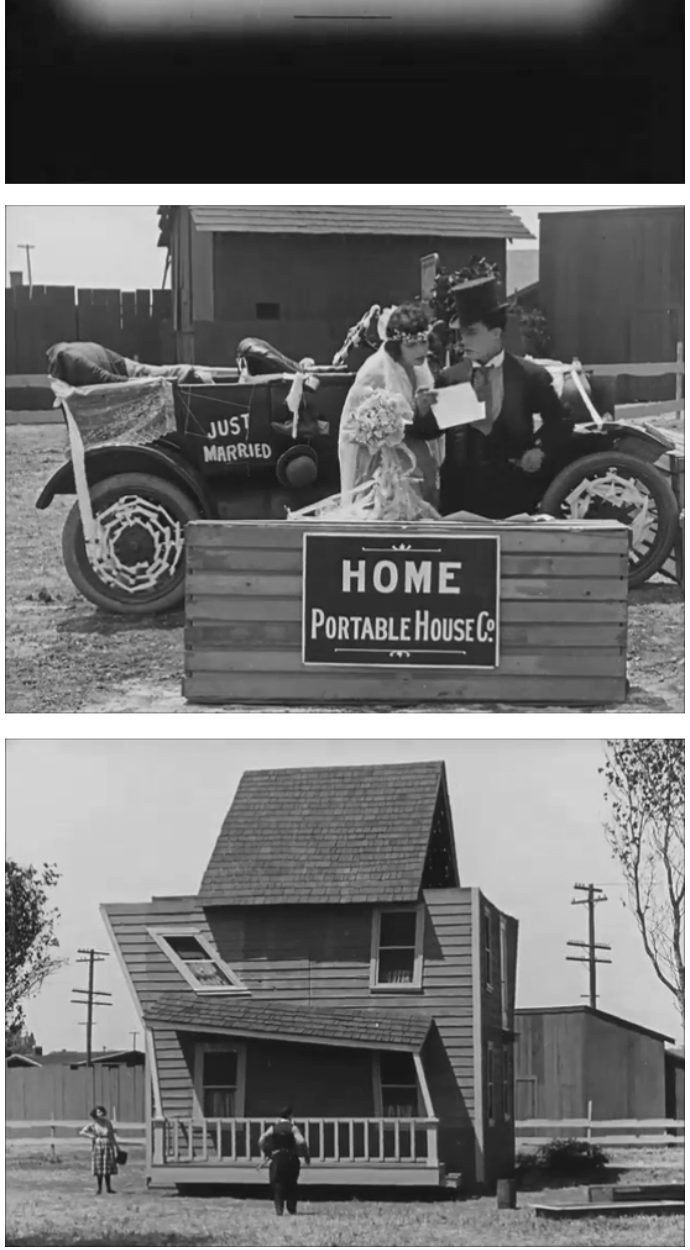

fig. 4-28 Buster Keaton, One Week, 1920 


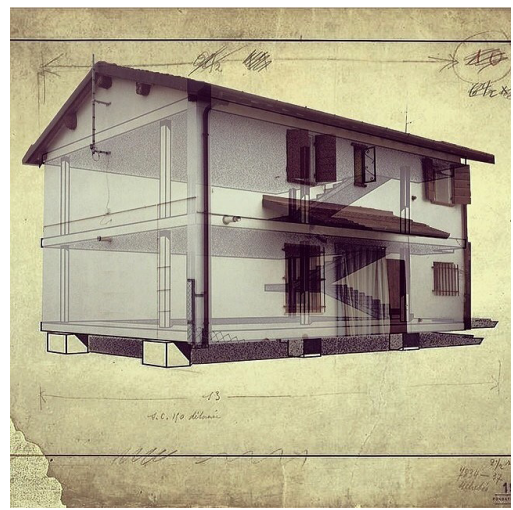

fig. 4-29 Space Caviar (Joseph Grima), 99 Dom-Ino, at 2014 Venice Architecture Biennale

\subsubsection{PLYWOOD DOM-INO}

Today, standard woodstuds (2x4 family) and plywood are also used in forming concrete. The formwork for concrete always leaves its impression on the surface of slab. It is almost like colonization: the act of grafting one culture into another. ${ }^{50}$

SO, WHY IS IT THAT THE FAMOUS PERSPECTIVE OF DOM-INO DOES NOT SHOW ANY MARKINCS OF ITS FORMWORK?

With Dom-ino and its "one-to-one" version, this grafting happens twice. First time, in 1914, the reinforced concrete is grafted in place of the plywood formwork. In that process, the plywood creates an outline of an invisible structure, a hollowed-out form that is then filled and replaced with concrete. The second time, in 2014, the temporary building of 1914, the hollowed-out plywood building is now solid all by itself. There is no room for concrete in this version, but the image still reminds of the original concrete structure.

COMPARING THE TWO, ONE CAN ASK: IS DOM-INO AN IMAGE OF A WOODEN HOUSE ENVISIONED BY LE CORBUSIER AS A CONCRETE MADE FROM PLYWOOD IN 2014?

\subsubsection{D PRINTED DOM-INO?}

In what follows, Le Corbusier expands on how he imagined the construction process of Dom-ino houses. The process he describes makes it a conceptual project even by today's standards:

Here you see that solution of 1914 called 'the Dom-Ino houses.' I study the famous old houses of the architecture of Flanders; I draw them schematically; I discover that they are glass houses ... Then I imagine this: a construction firm will pour without framework but by means of ingenious site machinery, the framework of a house: six columns, three floor slabs, and the stair case. The dimensions: 6x9 meters. Standard columns at a standard span of 4 meters; on either side, on cantilevered ribs, as overhang of $4: 4=1$ meter. ... I tried innumerable combinations of plans within these structural frameworks. Everything was possible. ${ }^{51}$

The reinforced concrete system that was "established in 1890 s by Francois Hennebique" 52 was not embraced by all architects. For instance, "in Britain it was initially considered a 'pagan' material, lacking a 'nature' of its own." Even an architect like Frank Lloyd Wright, who eventually makes use of concrete in his later work, "initially declared that concrete had 'neither song nor story.'

50 Koolhaas, Delirious New York.

51 Aureli, "The Dom-Ino Problem," 153.

52 Weston, 100 Ideas That Changed Architecture, 107. 


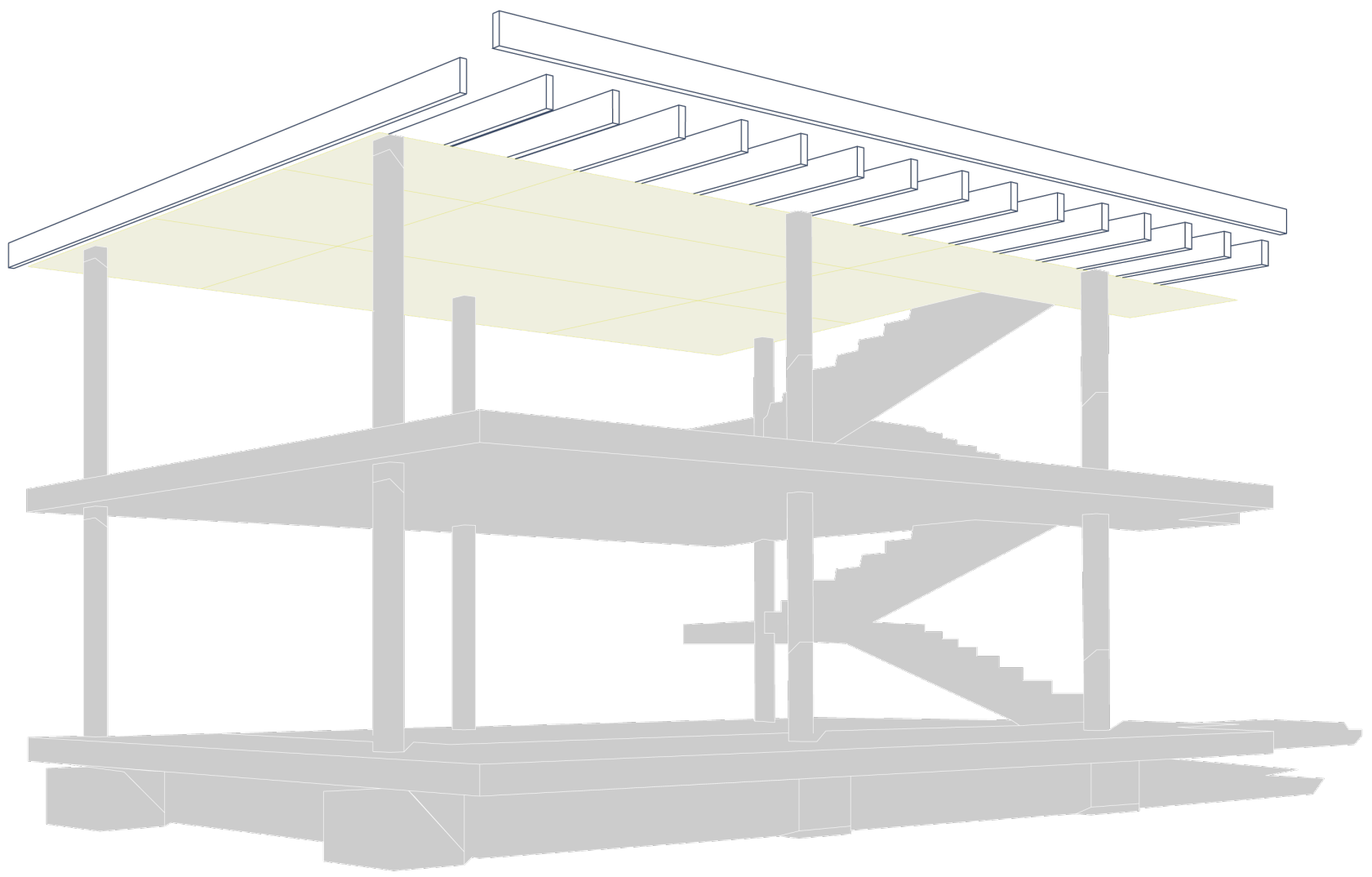

fig. 4-30 Platform Dom-ino

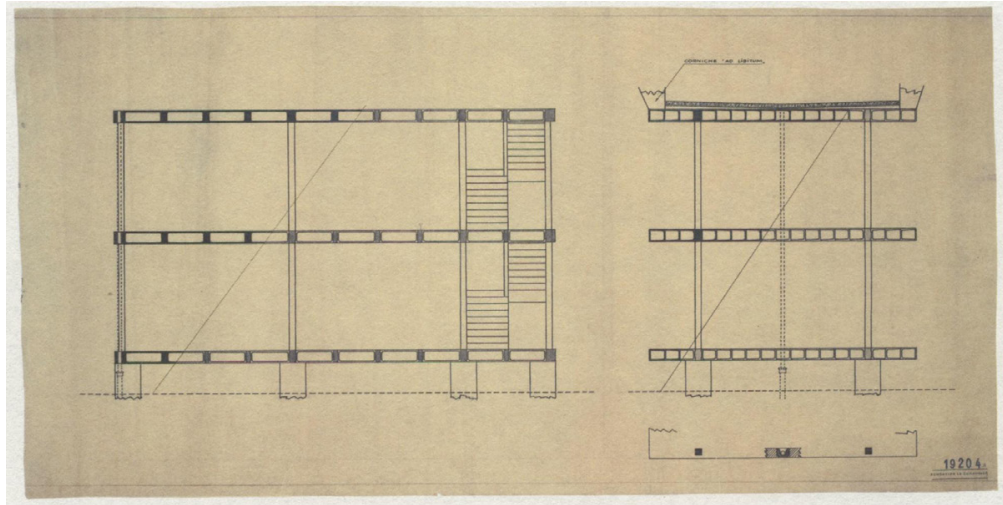

fig. 4-31 Le Corbusier, Maison Dom-ino, Sections 
fig. 4-32 interior view of "one-to-one dom-ino" at 2014 Venice Architecture Biennale

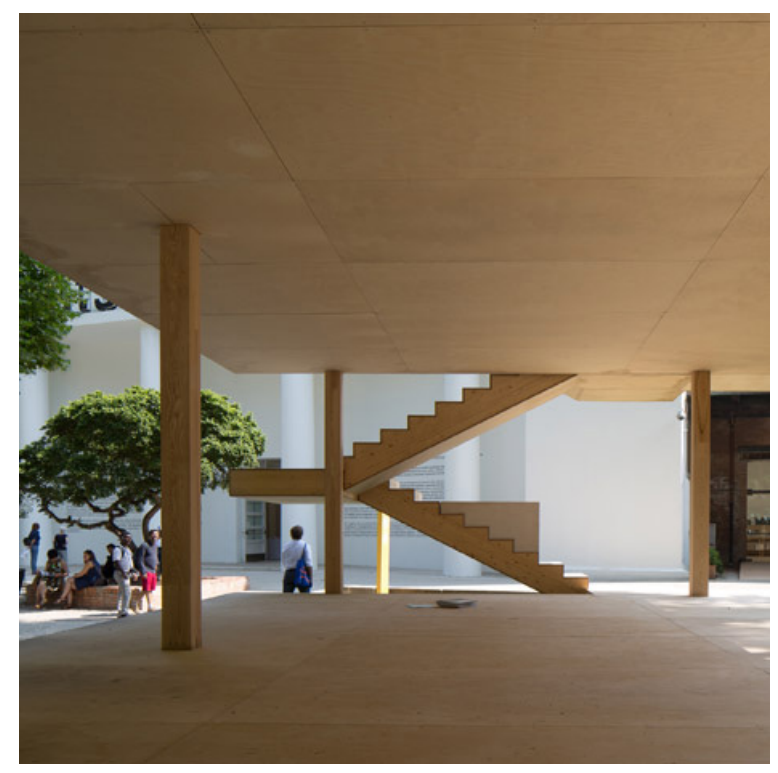

On the other hand, Le Corbusier, was one of the architects who recognized the importance of concrete as a material, and as Siegfried Geidion writes, made it "the instrument for the expression in architecture of his ideas." ${ }^{3}$

The critical failure of "one-to-one dom-ino" was the separation of the material reality of Dom-ino from its 'form'. Meaning, instead of honouring Dom-ino for its achievement as a work of design that architecturally negotiates the opposition of 'form' and 'matter in the discourse of architecture, they decided to instead privilege its 'form'. Maybe to honour Dom-ino and its revolutionary achievement the AA should have built Dom-ino using 3D printers.

\subsubsection{SPECULATIVE}

Most of us do not regard Dom-ino as a hypothetical project or a conceptual vision for futuristic methods of construction. However, Le Corbusier's description maintains it as a very conceptual project. In an excerpt from Precisions, where Le Corbusier bombastically explains his intentions:

at a moment when ... current architectural aesthetics sought a precarious renovation in traditional construction methods, I imagined something entirely new, something that was conceived whole, functioned socially, industrially, and aesthetically, and already proposed, in their totality. ${ }^{54}$ 
Interestingly, this highly conceptual, speculative project, was based on a very simple, yet powerful syntactic play of ELEMENTS OF CONSTRUCTION that would address the semantic dimension of architecture. Furthermore, he expands to include all the other construction elements that are not shown in the sketch. He could have been post-rationalizing, riding on the fame of Dom-ino when he wrote Precisions. Nevertheless, his description of the process highlights the speculative nature of the project:

Future perspective appeared: once the skeleton was poured by a construction firm, the bombed-out inhabitant, with the burnt materials of the original, would finish his house in accordance with his own ideas. He would buy from a parent construction company standard combinable windows, wardrobes, combinable drawers, doors. Everywhere, modular dimensions would allow innumerable combinations..$^{55}$ And this would be quite new: the doors and window would not be set into holes in the masonry. No, the doors, the windows, the wardrobes, which the standard height of the floors and spans of the columns made easy to do, would be set in first. These elements place, the wall would be built around them, that is to say, filled in. ${ }^{56}$ fig. 4-33 changing view of the door: elevation to section and back to elevation
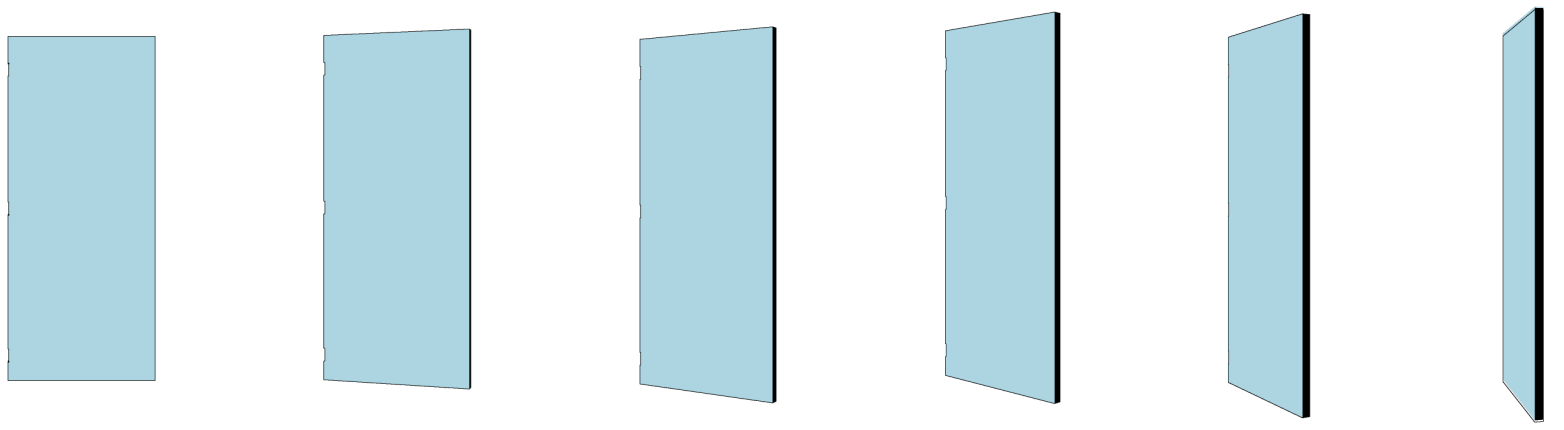


\subsection{Oblique Dom-INo}

\subsubsection{THE DOOR (5)}

In FLAT WORLD, it is possible to examine Dom-ino and its history through the WORKINGS of the HINGED-DOOR-LEAF (the door).

Unlike the 'doorness' and the 'threshold' that are fixed concepts and often take on a static and immutable 'form', the door constantly shifts our perception. The door, as the only kinetic ELEMENT OF CONSTRUCTION in a family of static elements, reveals various 'forms', 'shapes', and views as it is operated on a daily basis.

In a sense, in its everyday life, the door constantly moves from a front elevation view to a section when opened 90-degrees, and from a section to a back elevation when opened completely.

By engaging Dom-ino through the genius of hinged-door-leaf (the door) is it possible to reveal the hidden histories behind its image?
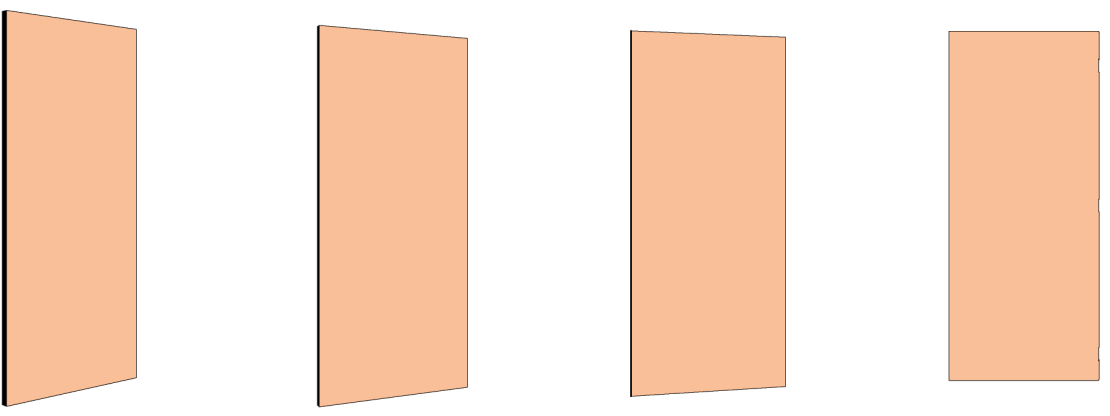
What is important about Dom-ino is that it is a perspective. It is constructed according to very specific disciplinary rules that are unique to architecture. To construct it as a physical model or in the virtual space proved to be an impossible task. As a result, Dom-ino is a construction of architecture in a 2-dimensional space. Everything happens from a fixed view and on a flat plane.

However, what if this convention was negotiated.

What if the perspective was a veil?

What if this perspective was a flat plane covering another form behind it?

Alternatively, what if our fixed view remained, but the 2D construction was to move around?

Is it possible that there is another form hiding behind Dom-ino?

These ideas make Dom-ino look like a facade of a frontier town. In the front, it is robust and permanent, but once it rotates the form changes, with every rotation something new occurs.

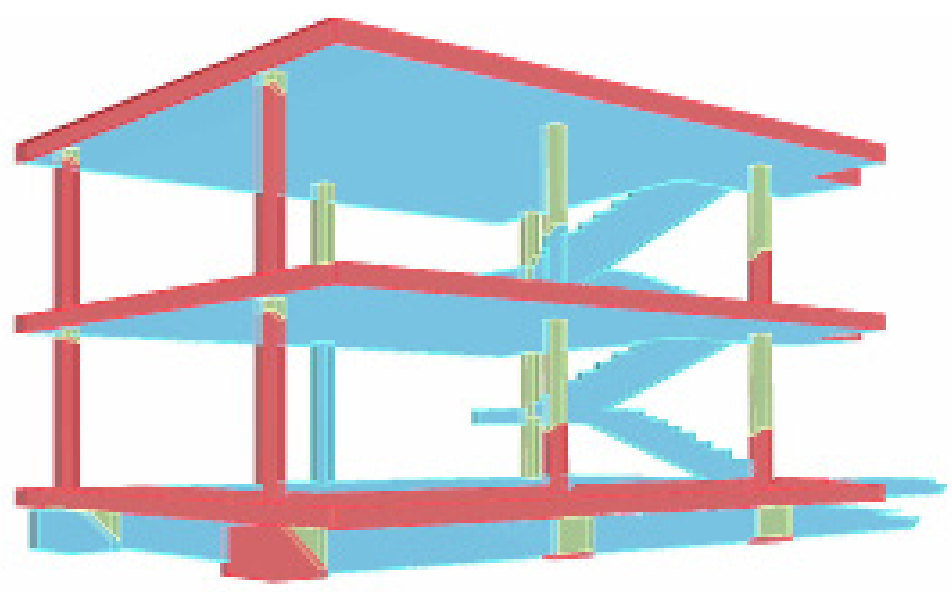

fig. 4-34 Oblique Dom-ino, animation 

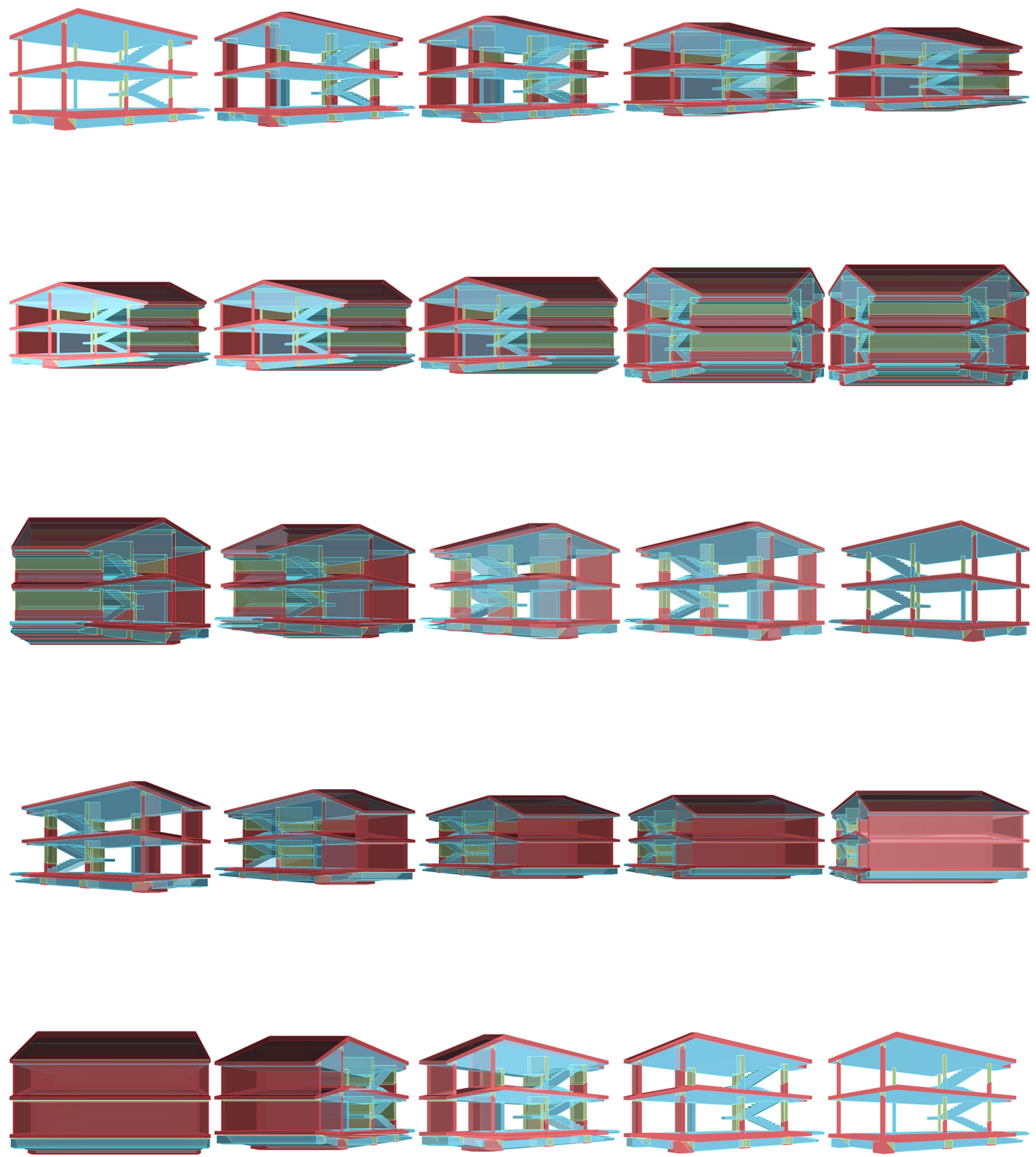

fig. 4-35 frames from Oblique

Dom-ino animation 


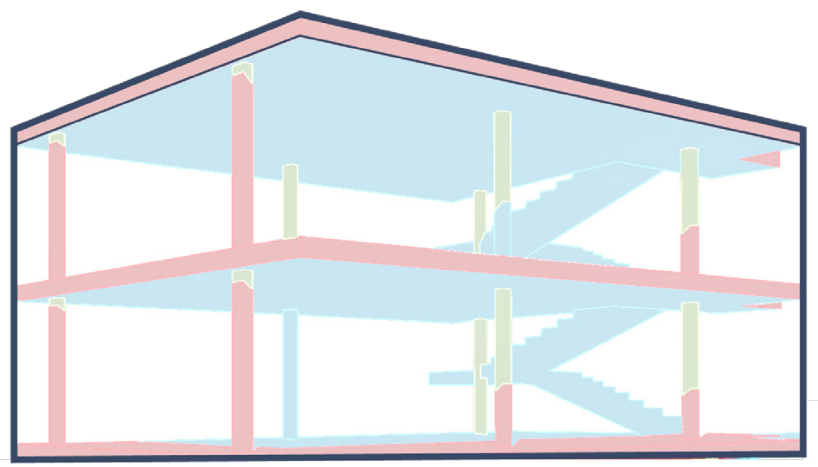

fig. 4-36 a familar form?

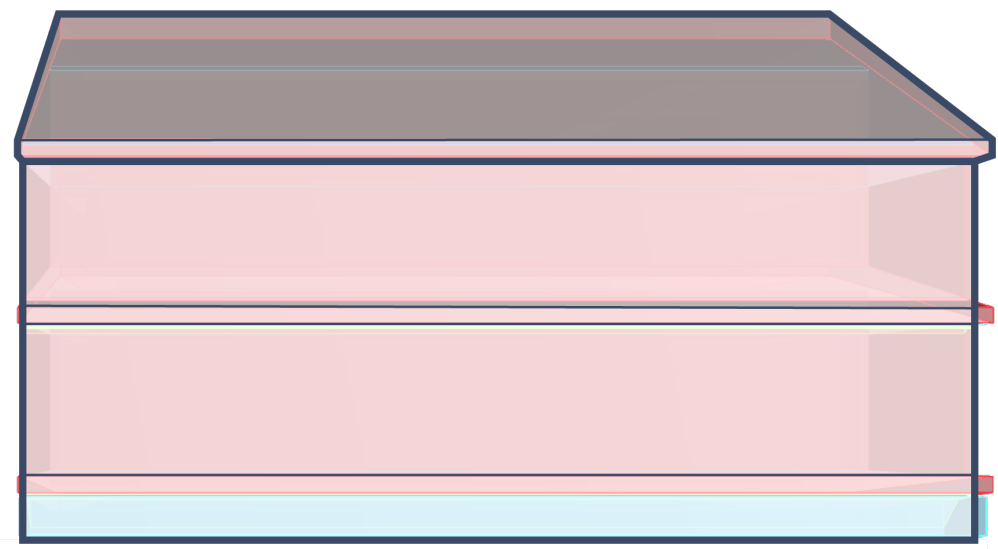

fig. 4-37 back of Oblique Dom-ino looks like a suburban house!

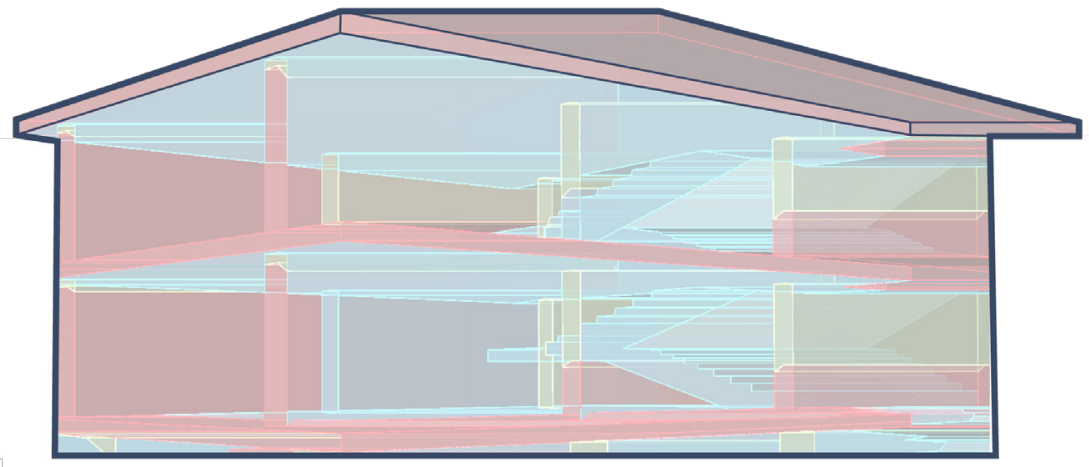

fig. 4-38 the pitched roof embedded in Oblique Dom-ino 


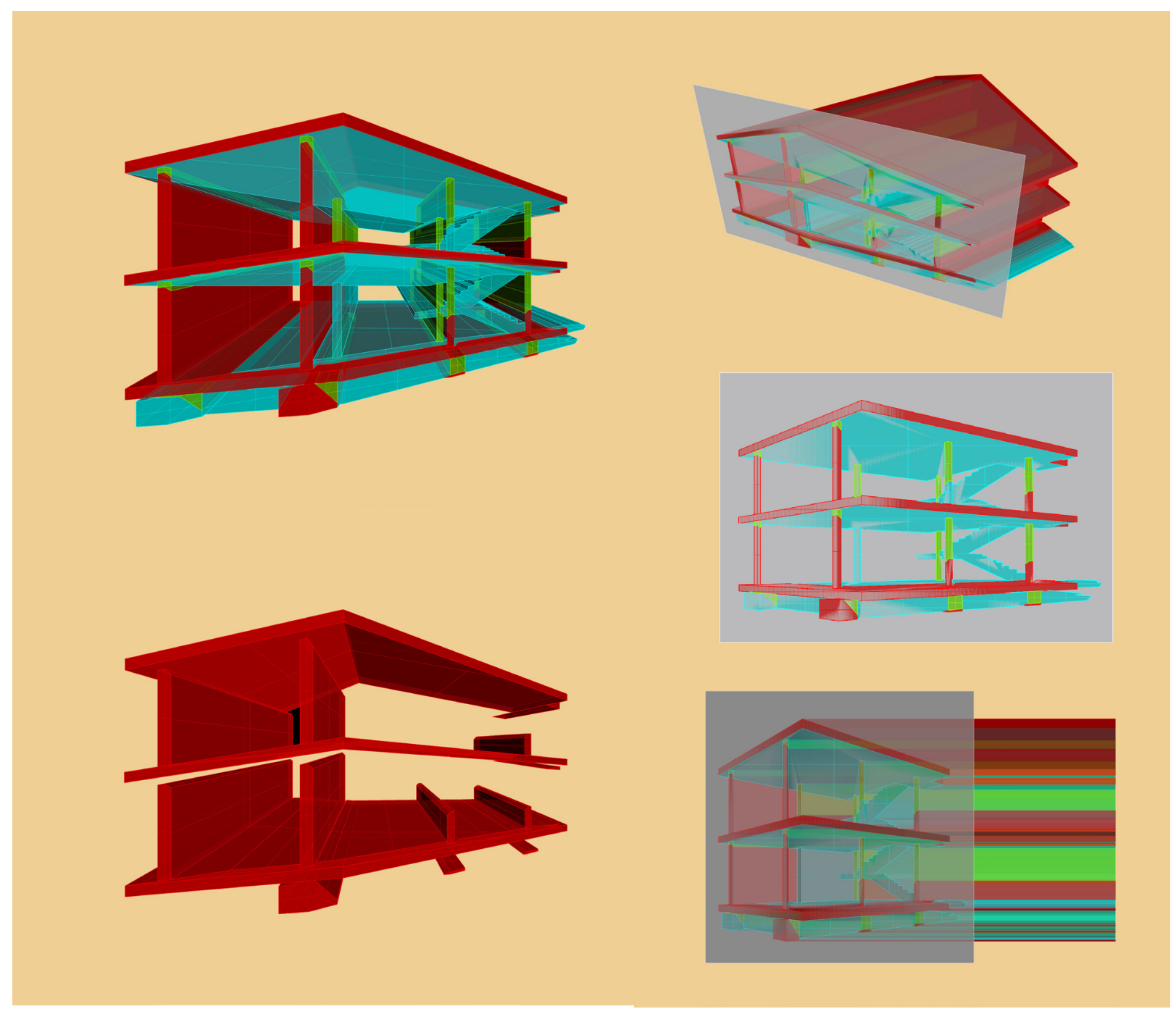

fig. 4-39 behind Oblique Dom-ino 
The title of Marshall McLuhan's famous book is Medium Is the Message, but the cover reads: "Medium Is the Massage."

It was a typesetting error. McLuhan responded, "Leave it alone! It's great, and right on target!"

\section{$* * *$}

If someone made a similar error when typesetting Wittgenstein's On Certainty, it could have read "No Certainty," instead.

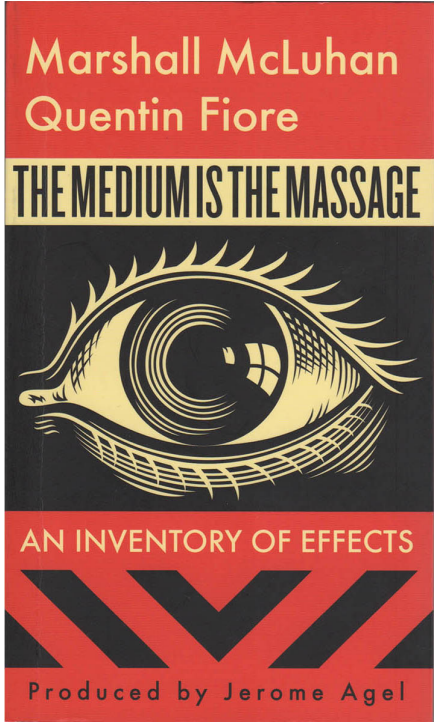

fig. 5-1 cover image, Medium is the Massage

"architecture $=$ the imposition on the world of structures it never asked for and that existed only as clouds of conjectures in the minds of their creators." ${ }_{2}$

-Rem Koolhaas

"If you're purely after facts, please buy yourself the phone directory of Manhattan. It has four million times correct facts."

-Werner Herzog 


\section{THE CONSPIRATORS}

IN THE FIRST PART OF THIS CHAPTER THE FOCUS IS ON THE RELATIONSHIP BETWEEN ELEMENTS OF CONSTRUCTION THAT MAKE THE HINGEDDOOR-LEAF (THE DOOR) THE ARCHITECT'S GREATEST INVENTION. IN THE SECOND PART, A HYPOTHETICAL QUESTION STARTS A SERIES OF EXPLORATIONS THROUGH THE GENIUS OF THE DOOR THAT RETHINKS MULTIPLICITIES OF OTHER RELATIONSHIPS BETWEEN ELEMENTS OF CONSTRUCTION. 


\subsection{THE DOOR (6)}

To rediscover the GENIUS of architecture through the everyday reality of its ELEMENTS OF CONSTRUCTION, this thesis asks a question that is rarely asked: What is the genius of the door?

$$
* * *
$$

When a building is made, walls enclose its boundaries. A wall creates a barrier from outside in the horizontal direction and gives the roof support in the vertical direction. We like the wall to be rigid and impenetrable. However, in an ironic turn of events, after building a wall, there is also an need to get to the spaces that are on the other side of the wall. Because, "Walls are a nice invention, but if there were no holes in them there would be no way to get in or out-they would be mausoleums or tombs."

So, for connectedness, convenience, and supporting life the wall is inflicted with an idea that is contradictory to its initial purpose: an aperture. Now, wall is defective and sick. To remedy the sick wall, we 'graft' it with a mobile version of itself: a HINGED-DOOR-LEAF- "a miracle of technology." 5

To make the wall ready for its door, and to stop the wall from crumbling on itself and turning into a grave, a beam-a lintel- is placed equal to the required opening for the door off the ground in the hole in the wall. On the opposite end, on the same vertical plane, a sill-a threshold—is placed on the ground. The threshold helps with the integrity of the door, the floor, the wall, the doorframe and the doorway. More importantly, the threshold prevents dirt, pests and other things from passing from under the door when it is closed.

Doors debunk the conventional myths that separate architecture from everything else. Doors refuse to be defined as binary oppositions of 'technology-architecture', 'construction-design', 'mechanic-static', 'kinetic-building', 'form-matter' or 'literal-metaphoric'. Doors resist the Modernist attempt to dematerialize architecture into glass and limitless Walls. That is why the discourse is fearful of doors.

The door-THE HINGED-DOOR-LEAF- is an allegory. It is architecture 'personified.' Its story tells the story of "abstract concepts, qualities or

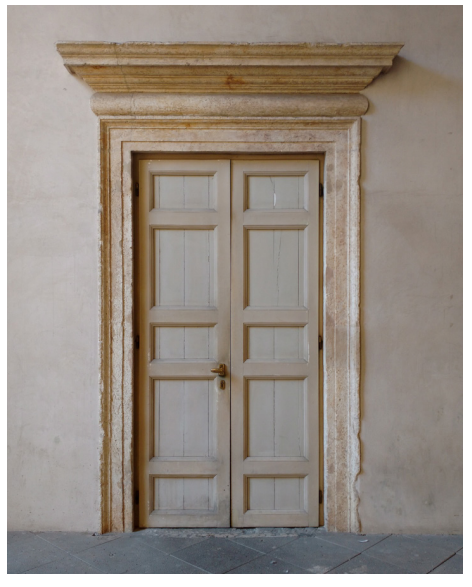

fig. 5-2 a door at Palladio Museum in Vicenza, Italy 

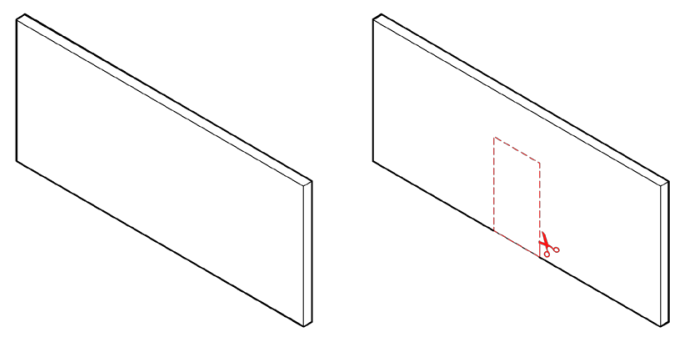
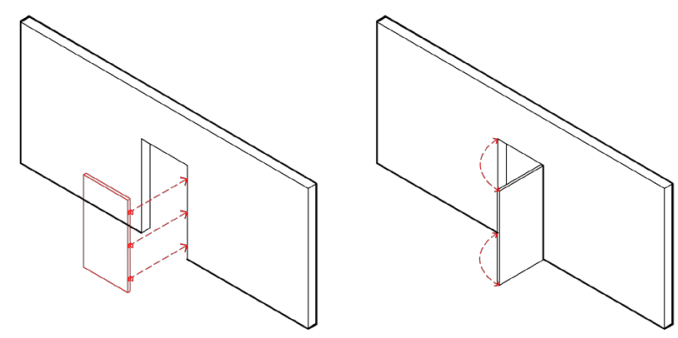

fig. 5-3 the door remedies the 'sick wall'.

situations"s that have empowered the conventional thinking of architecture. It is architecture 'personified': the ambiguity of the door stands in for the ambiguity of architecture. It "changes the very frame through which we perceive the world and engage in it." It is "the effect that seems to exceed its causes."

The door is the black sheep of the family. When a house is broken, its door is blamed. When a city is invaded, its door is blamed. When wall fails, we point the finger at the door not being locked.

We entrust the door to close a corrupted a wall (a sick wall) and it fails at that on a daily basis. The door NECOTIATES the wall, but it also 'betrays' it because the door is the wall's 'concrete irrationality.' As such, the door fools us as it passes "tangibly to the level of reality" of the wall. Doors with Locks are especially duplicitous. They become the "double image" ${ }^{10}$ of a wall "without the slightest physical or anatomical change." That is how a door diminishes any wall's ability to protect. Even in the case of a locked door, the man with a key can undo what a wall was built to do.

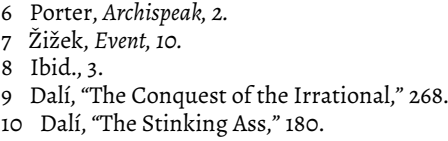




\subsection{THE UNDERDOG}

"Lenny, you think you're the hinge, but you're the door."

- Cardinal Spencer

It is the doorframe that helps the door to connect to the wall. But, what makes the door a 'miracle of technology' is not the doorframe, the wall or the threshold. It is the hinge.

If a wall with a hole-a defective wall-is the door's 'sick muse, ${ }^{12}$ then in the hinge the door finds its better muse. If the door is a mobile version of the immobile wall, then the hinge is an even more agile version of the door. The hinge is the door's companion and its confidant.

The hinge looks small, but it is unyielding. In some places, it is more durable than the wall and the door. It is the hinge that makes the door flexible. It is the hinge that does not allow the door to succumb to 'doorness' and the 'threshold' and their 'monodic' aspirations.

In the saga of reality and Idealism, the opposition between the door, 'doorness' and the 'threshold', the hinge is the underdog- "That the small be made stronger than the large is a very moral story indeed (think of David and Goliath)."13

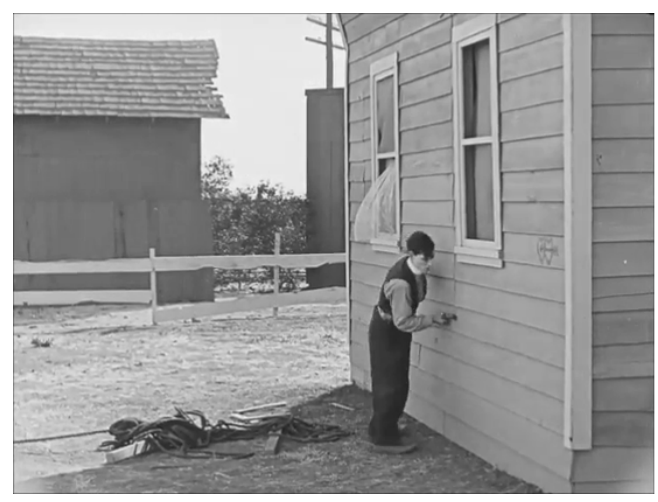
1920

11 Sorrentino, "The Young Pope."

12 "La Muse Malade (The Sick Muse) by Charles Baudelaire," v. 1: "My poor Muse, alas! what ails you today?”.

13 Latour, "Where Are the Missing Masses, Sociology of a Few Mundane Artefacts," 155.

fig. 5-4 Buster Keaton, One Week,

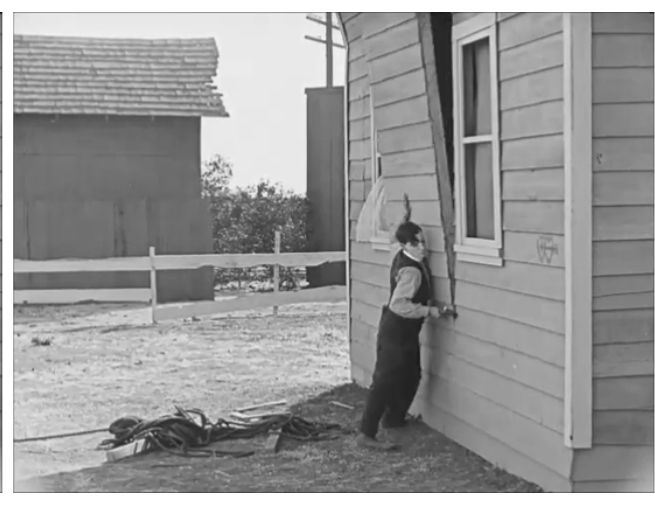


Since antiquity, even the most Platonic of architects appreciated the material reality of the hinge. In Seven Books on the Art of Building: Ornament to Sacred Buildings, Leon Battista Alberti writes about the joy of operating a heavy door that is facilitated by a well-designed hinge:

'I much prefer temple doors that are easy to open and close.' The silence and the easiness of closing and opening depends upon good technology. The bottom end of a pivot should therefore sit in a socket made of copper mixed with tin...and may contain between an iron ball, perfectly round and smooth... and around the axle there should also be a free moving iron washer, polished smooth on all sides. ${ }^{14}$
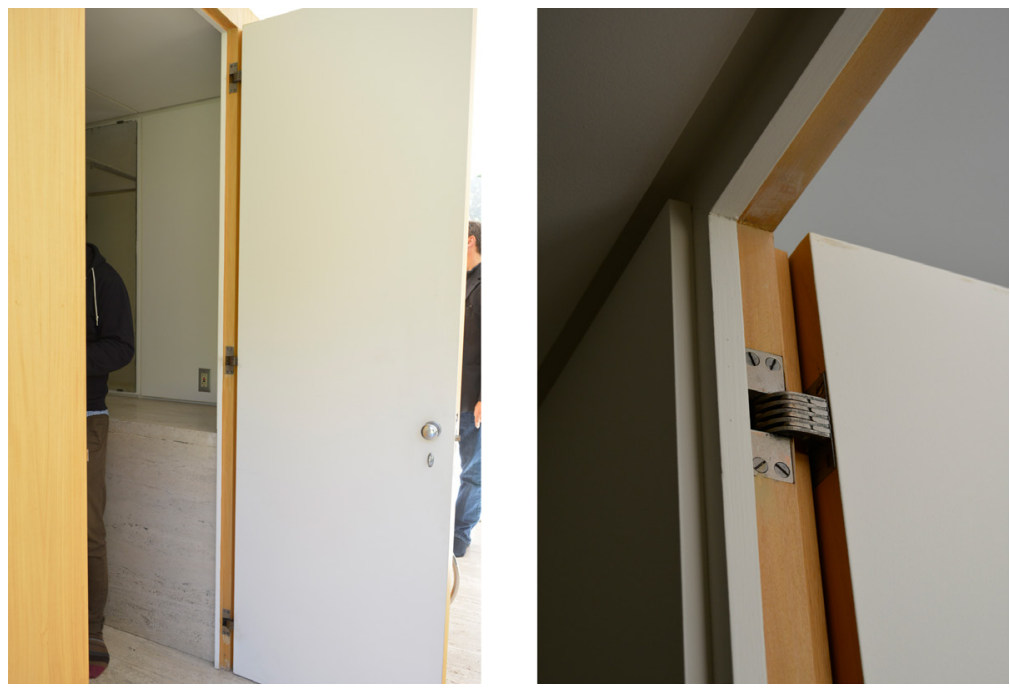

fig. 5-6 Hinges at Farnsworth House

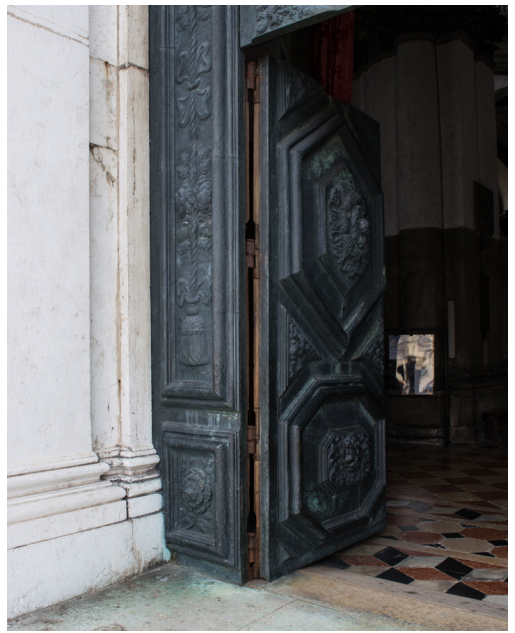

fig. 5-5 a temple door

Even a modernist like Mies van der Rohe, whose 'conceptual' work preceded his built work, as an architect whose early fame depended on 'images' and not building, paid attention to the hinge. In Farnsworth House, a house with few Walls, Mies employs a special Hinge for the bathroom door. However, in the modernist tradition of "dematerializing" door" he tries hard to hide it. 
fig. 5-7 Hinges of Carlo Scarpa at Fondazione Querini Stampalia, Venice, Italy
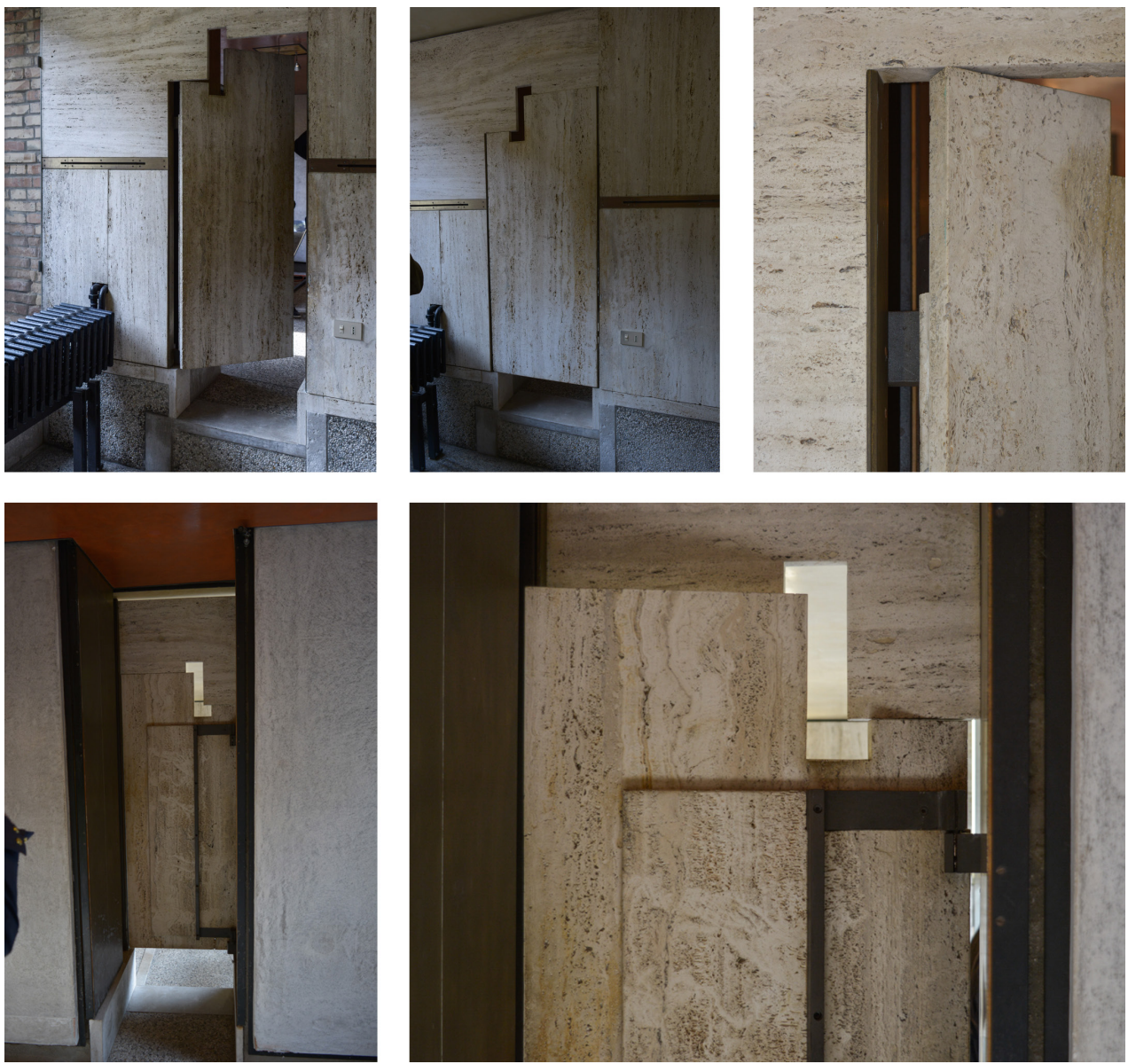

One of the most satisfying uses of the hinge is in the architecture of Carlos Scarpa. He took a keen interest in the operation of hinges which is present in many of his well-known buildings. He often designed one of a kind hinges for his doors. In Scarpa's buildings, doors are often made up of what covers the wall. The face of the wall becomes the structure of the door. He also separates the door from the wall. Either with a gap or another material. In Scarpa's buildings, the hinge is prominent and visible. The WORKINCS of the hinge is tactile. 


\subsection{THE WINDOW (2)}

If certainty is what the 'threshold' seeks, it might be easier to see the window as a true 'threshold' rather than the door. Like the door, the window begins its journey as a remedy for the aperture in the wall (the sick wall). This time, the doorsill is replaced with the windowsill.

Windows allow light, fresh air and sounds to pass from the outside surface of the wall and reach us on the inside. The window also allows our eyes to extend beyond the limits of the wall. The window, in this sense, offers us a luxury that the cavemen did not have.

The window negates the door. The DOOR-LIKE WORKINCS of any door allow our bodies to transgress both sides of each wall (the inside and outside). On the other hand, the window-like workings of a window allow our senses to transgress the inside surface of our walls while holding our bodies back. Therefore, what constitutes a window is not related to the size of the opening in the wall, or to the apparatus that fixes the wall, what separates the door and the window is their wORKINCS and how they mediate our inside and outside in relation to our bodies. With the door, we can act on what we find, but with the window we must only covet it.

Window is about the 'projected' image of the world into our house. Window is like a one-framed eye, it has a fixed view and a fixed aperture. Even changes in the size of the window of changes in its frame (with curtains or shutters, for example) do not remedy the fact that a windowview is always the same flat plane; like a wall. A WINDOW-LIKE operation is flat while the door is like a motion picture, it changes our frame and view with every angle of its WORKINCS which is facilitated by the HINCE-LIKE WORKINGS of its hinge.

Therefore, a symmetrically constructed window might as well be a wall, since it must cover the whole expanse of any space. Nevertheless, the WORKINCS of the window and the wall are very similar. They both hold our bodies in, protect us against outside forces and demarcate our boundaries. Today, with all the glass walls in our buildings, the windows have WALL-LIKE WORKINCS while all the walls have WINDOW-LIKE WORKINGS. Sadly, while we are offered a great view of other people's outside wall, we are still unable to see the 'outside' of our own walls from the inside.

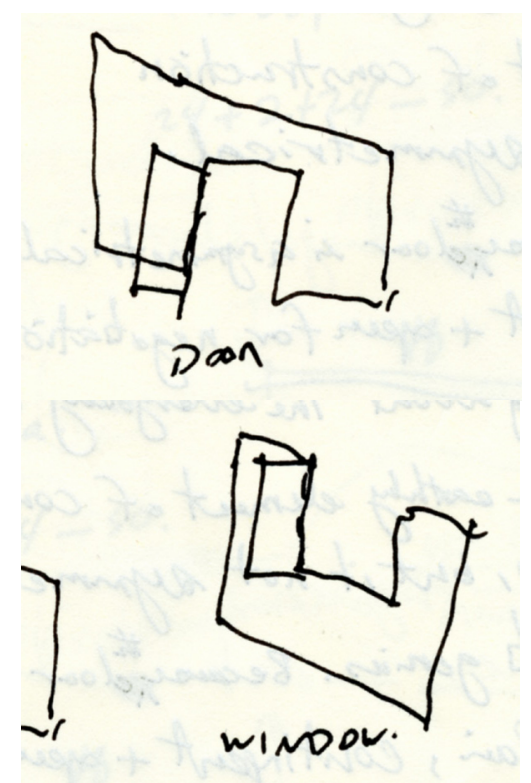

fig. 5-8 The window negates the door! 


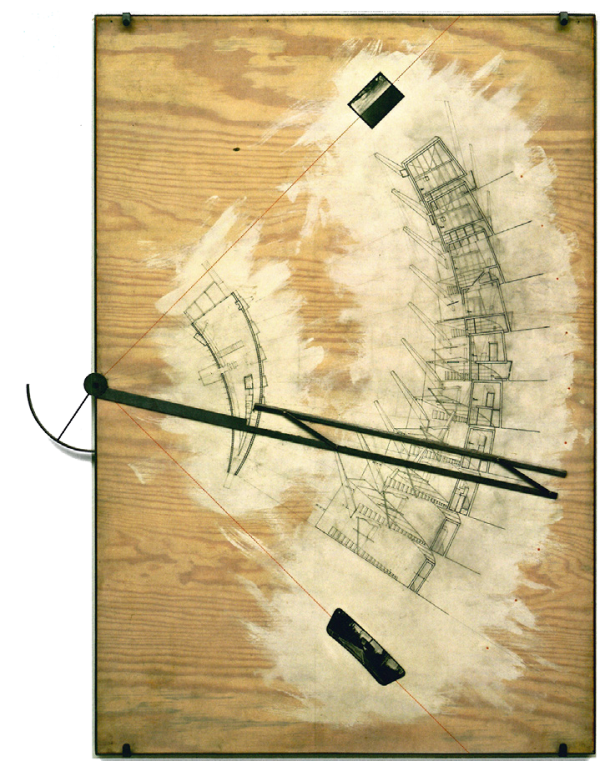

The Slow House project by Diller + Scofidio was a proposal for "a holiday retreat for an art collector"15 and "was conceived as a passageway." In its design, Diller + Scofidio "employ a range of devices which fetishizes the view, making it more desirable: the transverse sections emphasize and traces the journey from car to ocean view; and a curved passageway-a common cinematic suspense device-denies instant access to the object of desire." At the moment of reaching the large window, one comes to realizations that what is presumed to be a window showing "a 'real' view" is nothing more than a "recorded version of the same view on a large video monitor."

$$
* * *
$$

"In [this] project we asked, which is the higher technology, the video of the view of the sea or the framed window's view of the sea? Both are equally mediated and that is not a bad thing." ${ }^{\prime 16}$

— Elizabeth Diller fig. 5-9 Diller + Scofidio, Slow House Project, 1989 (left)

fig. 5-10 Diller + Scofidio, Slow House, 1991 (right) 


\subsection{WHAT IF...}

Through, Flattening, Hypothetical Question and Sectioning, FLAT WORLD PRODUCES THE DESIGN-CONSPIRACIES THAT NEGOTIATE THE CONSPIRACIES OF SHORT REAL.

A HINGED DOOR-LEAF (the door) is the best ELEMENT OF CONSTRUCTION to start a new CONSPIRACY about architecture: it is never prefect, it "worksonly if it fails" ${ }^{17}$ and it is not "to be trusted." ${ }^{18}$ As Gaston Bachelard reverses the ajar door:

for the door is an entire cosmos of the half-open. [...] The door schematizes two strong possibilities, which sharply classify two types of daydream. At times, it is closed, bolted, padlocked. At others, it is open, that is to say, wide open. But then come the hours of greater imagining sensibility. On May nights, when so many doors are closed, there is one that is just barely ajar. We have only to give it a very slight push! The hinges have been well oiled. And our fate becomes visible. ${ }^{19}$

$$
* * *
$$

The duplicity of a door is an asset when making DESIGN-CONSPIRACIES.

A HYPOTHETICAL QUESTION can start the process:

WHAT-IF INSTEAD OF THE DOOR, IT WAS

THE HOUSE THAT SWUNG OPEN?

The question goes to the core of architecture and its construction of spaces:

what is a wall?

What is a door?

What is a hinge?

What is a building or a house?

This requires FLATTENING all the conventions and perceptions about architecture and ELEMENTS OF CONSTRUCTION. 


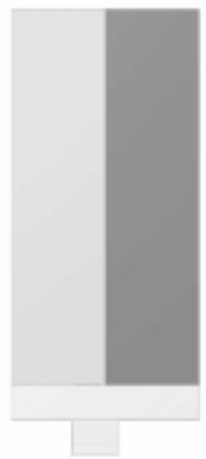

This animation is available online: https://vimeo.

FIC. 5-11 HOUSE-THAT-SWINGS-

OPEN-1, animation 

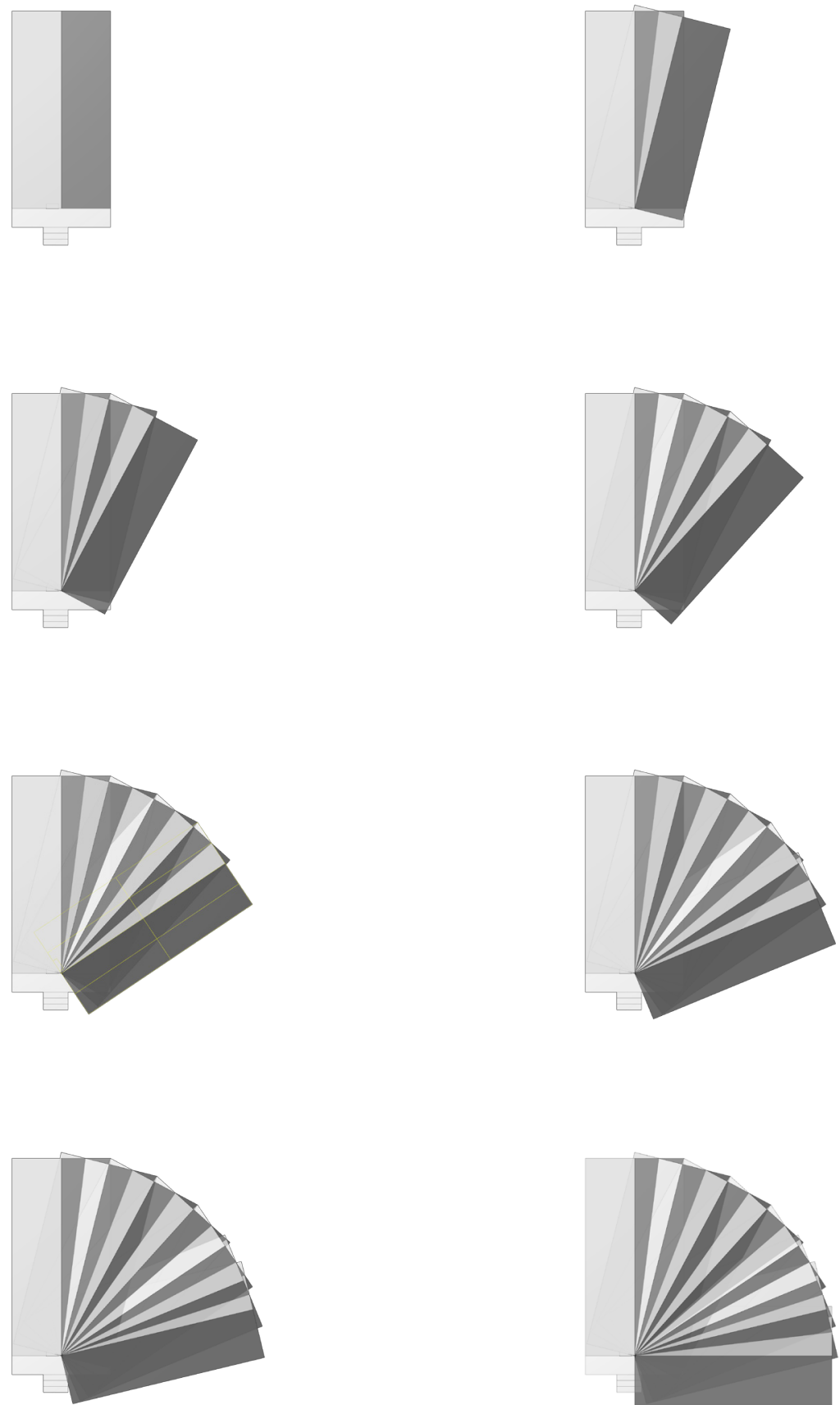

fig. 5-12 stills from the animation of HOUSE-THAT-SWINCS-OPEN-1 


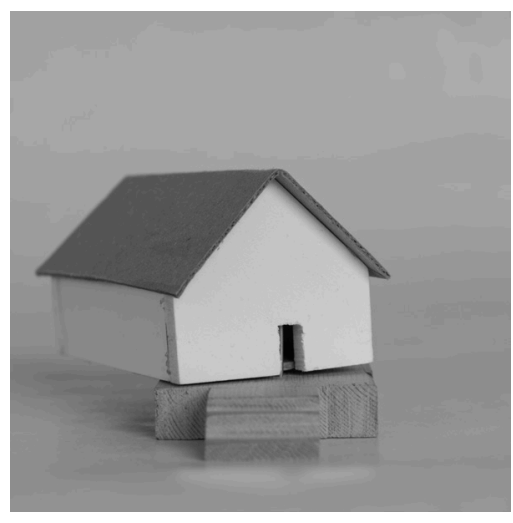

FIC. 5-14 HOUSE-THAT-SWINGSOPEN-1, first functioning

\subsection{A HOUSE THAT SWINGS OPEN}

In FLAT WORLD, where it is the house that swings open, the 2D representation of the house looks like the $2 \mathrm{D}$ representation of a house from SHORT REAL but there is something different about it.

In SHORT REAL, the house sits on the ground and it is the door that is off the ground. When it is the house that swings open, in FLAT WORLD, the house is now off the ground and is hovering above the earth. As it opens and closes it moves parallel to the ground.

When it is the house that swings open, the door stops the house from turning. In a conventional house, it is the doorframe or the wall that often stops the door from going too far.

\subsubsection{CONSTRUCTING A HOUSE THAT SWINGS OPEN}

The HYPOTHETICAL QUESTION of this project does not attempt to reverse the role of the door with the house. Instead, it was an illogical assumption about the relationship between the ELEMENTS OF CONSTRUCTION and the conventions that define their WORKINCS.

The important thing here is that now the hinge, the door and the wall are FLATTENED. As the trio that defines the conventional WORKINCS of a door that swings open, they are now FLATTENED to allow the house to swing open.

By SECTIONING, meaning to design this condition and responding to the material realities of the HYPOTHETICAL QUESTION, it is possible to discover other possibilities within this seemingly irrational system of relationships.

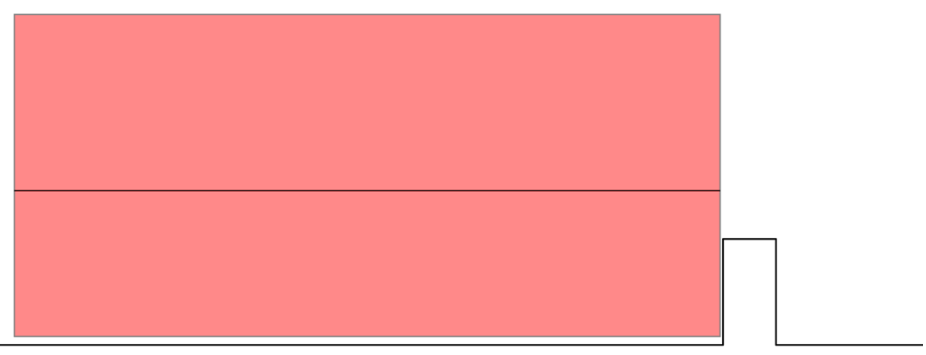



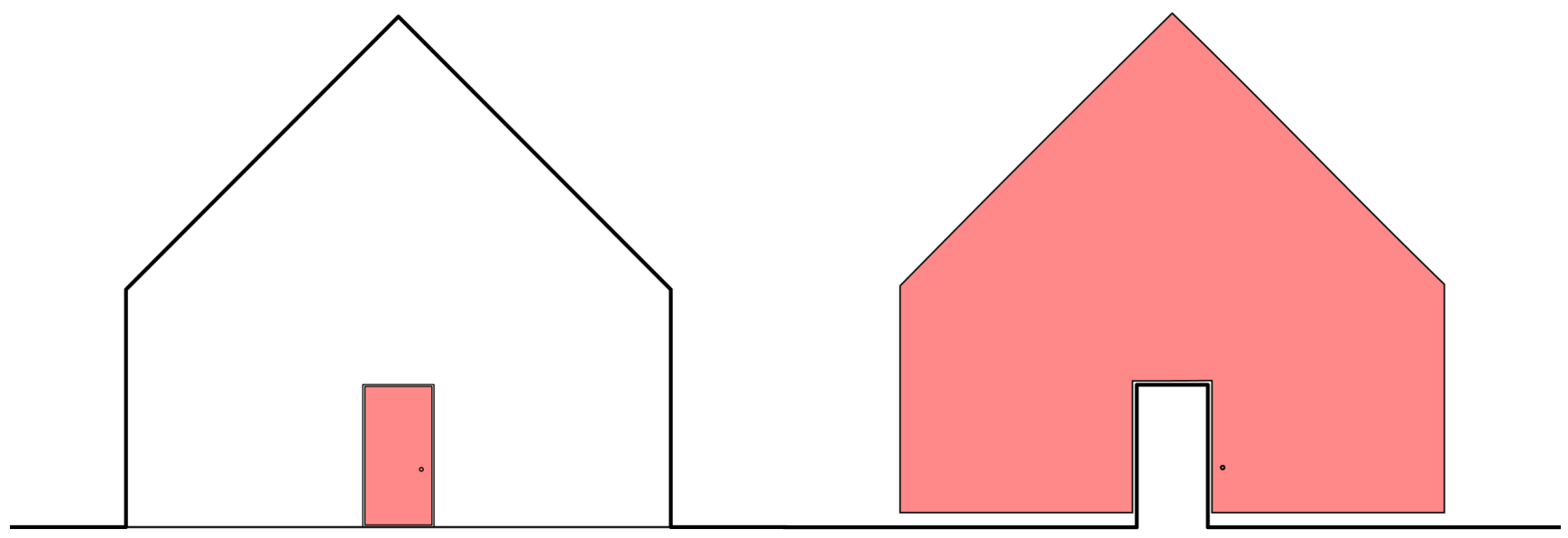

FIC. 5-16 HOUSE-THAT-SWINCSOPEN-1: diagram
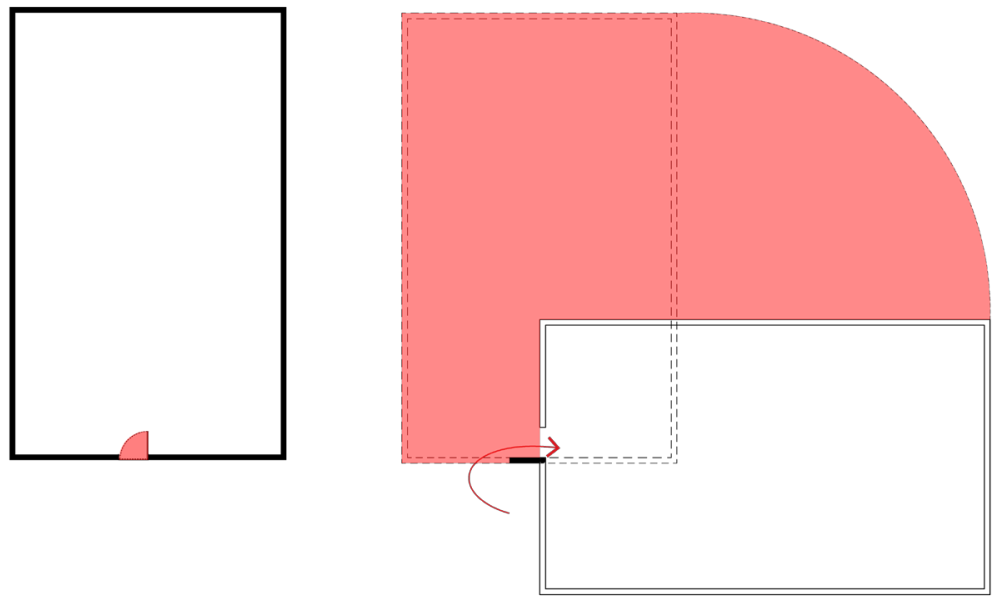

FIC. 5-15 HOUSE-THAT-SWINCSOPEN-1, plan/diagram 
fig. 5-18 relationship between the door, the hinge and the wall

fig. 5-17 various possibilities for the shape of the door for a house that swings open
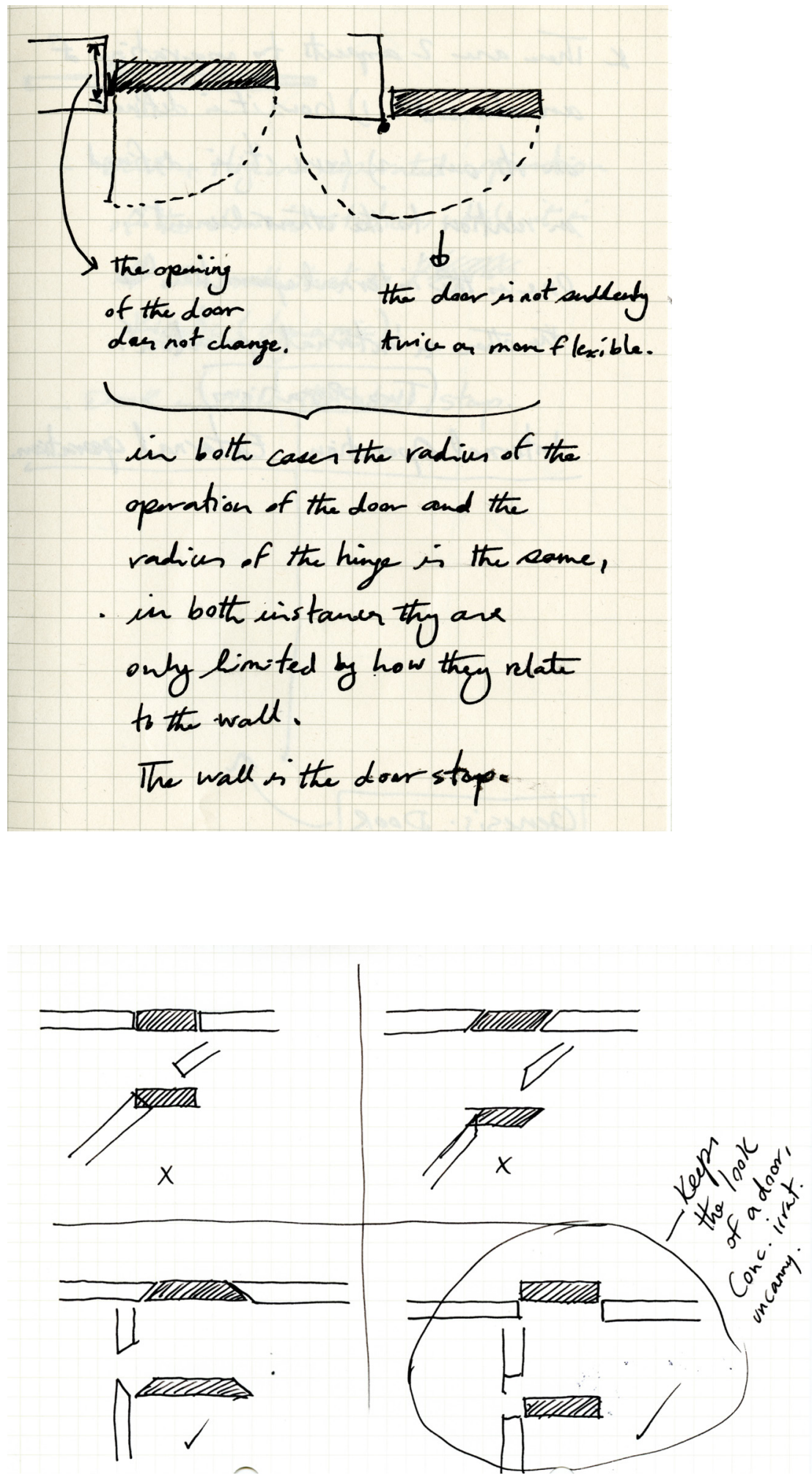


\subsubsection{HINGE (1)}

The hinge is one of the ELEMENTS OF CONSTRUCTION that is often neglected in SHORT REAL. When talking about the door, no one mentions the hinge. Now, it is the most prominent member. In FLAT WORLD, through HYPOTHETICAL QUESTION, FLATTENING and SECTIONINC, the hinge becomes the most important competent of the house that swings open.

In the $2^{\text {nd }}$ functioning model of the HOUSE-THAT-SWINGS-OPEN-1, the hinge is the most prominent structural element in the house. Its strength allows the rest of the house to hover over the foundation piece.

When it is the house that swings open, the hinge is a hinge, a beam and a column. More accurately, it has HINGE-LIKE, BEAM-LIKE and COLUMN-LIKE WORKINCS. It has the persona of the hinge but also assumes other WORKINCS. The hinge is now HINCE.

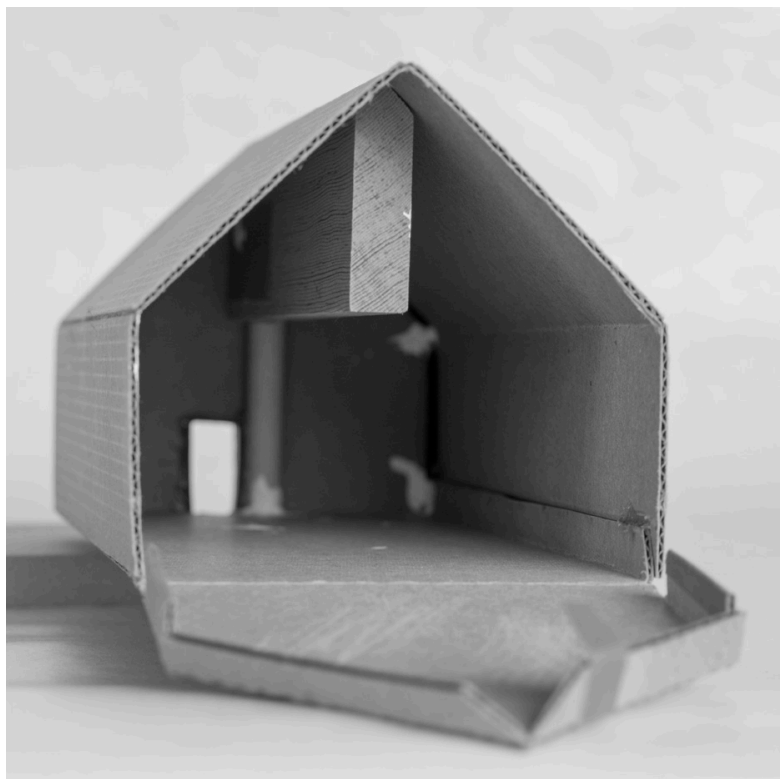

fig. 5-19 [opposite page, top] conventional perception of the relationship between the three elements of construction (the door, the hinge and the wall) responsible for making the door swing open

fig. 5-21 [opposite page, middle] the relationship between the door, the hinge and the wall when they are Flattened so the house can swing open.

FIC. 5-20 HOUSE-THAT-SWINCSOPEN-1 (second functioning model): the hinge is as the most important component 
$\theta$
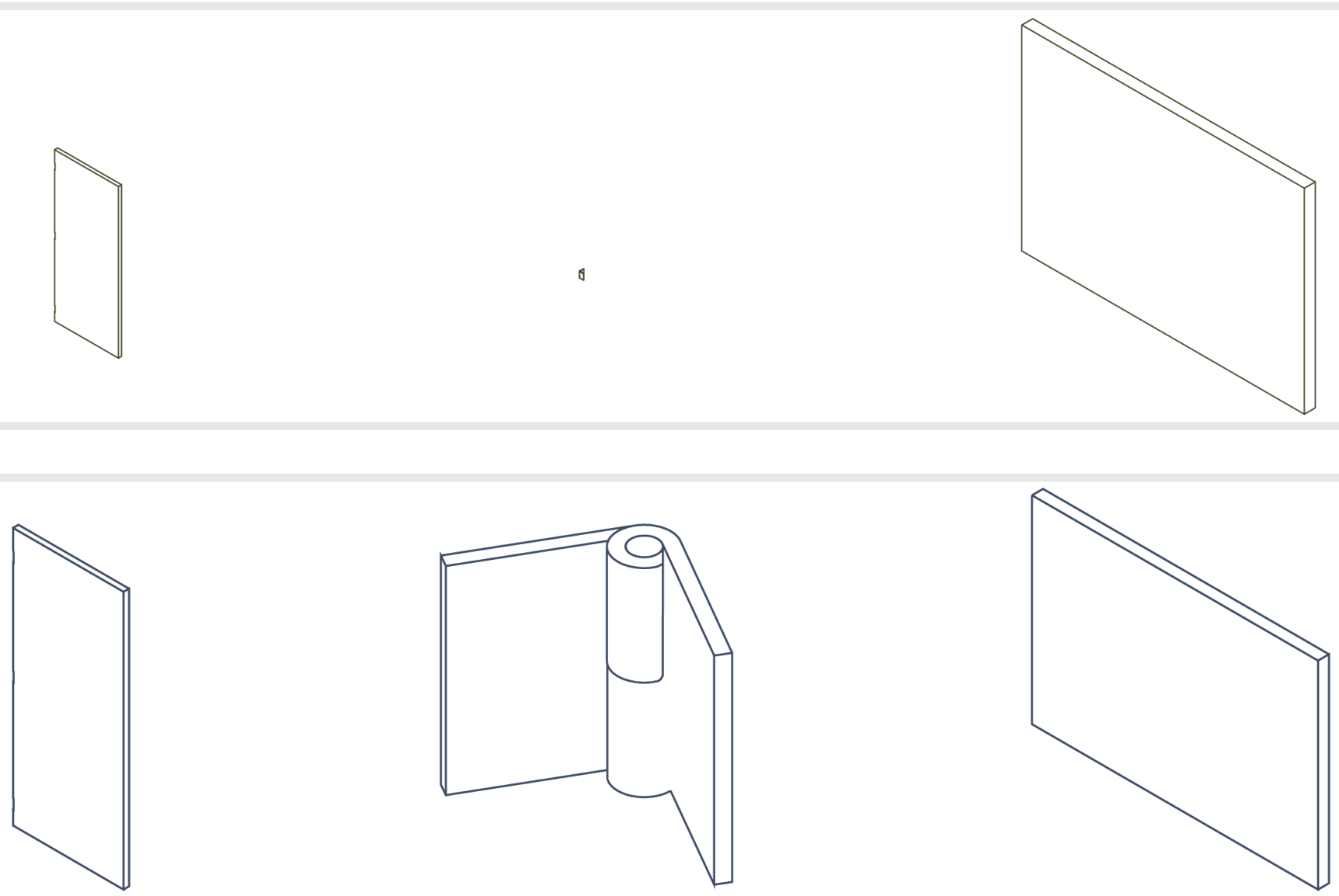

FIC. 5-22 HOUSE-THAT-SWINCS-

OPEN-1 (first digital model): the hinge has BEAM-LIKE and COLUMN-LIKE WORKINCS

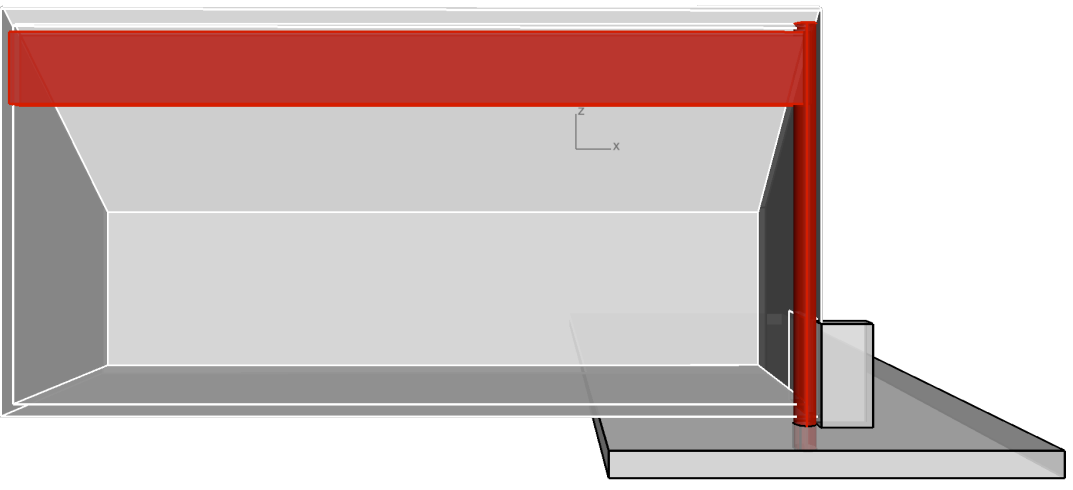




\subsubsection{APPROACHING A HOUSE THAT SWINGS OPEN}

When it is the house that swings open, the door is like a wall. Unlike a conventional house where the change of the angle in the door does not change our direction toward the house, when it is the house that swings open, anyone approaching the house must adjust their course according to the angle of the opening of the house and its relationship to the door.

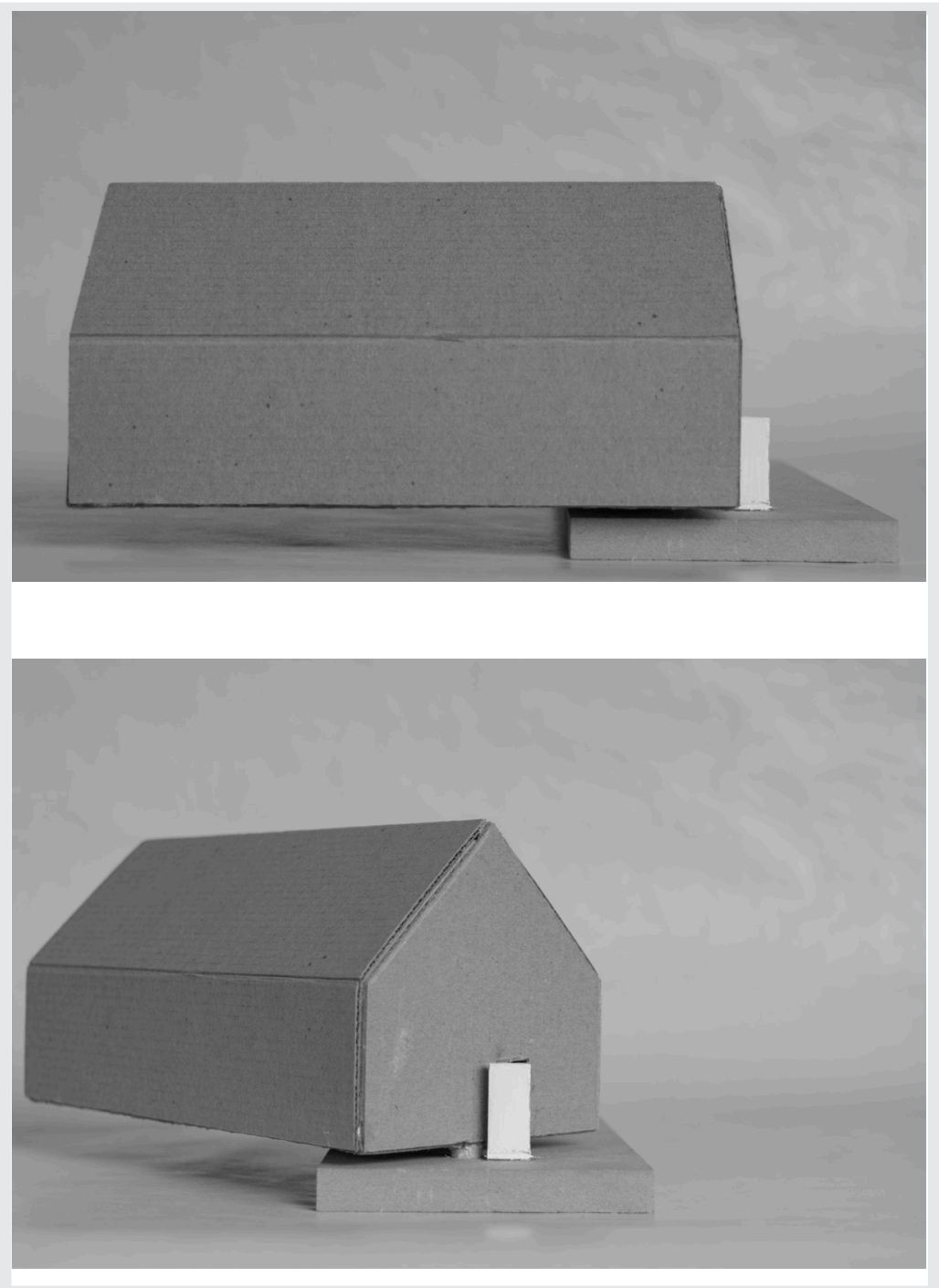

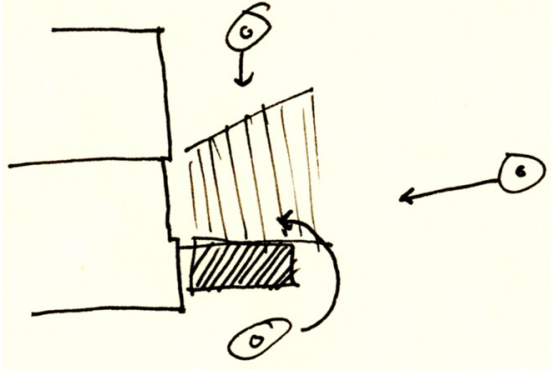

fig. 5-24 direction of approach to the house that swings open

FIC. 5-23 HOUSE-THAT-SWINGSOPEN-1 (second functioning model): in motion to open 

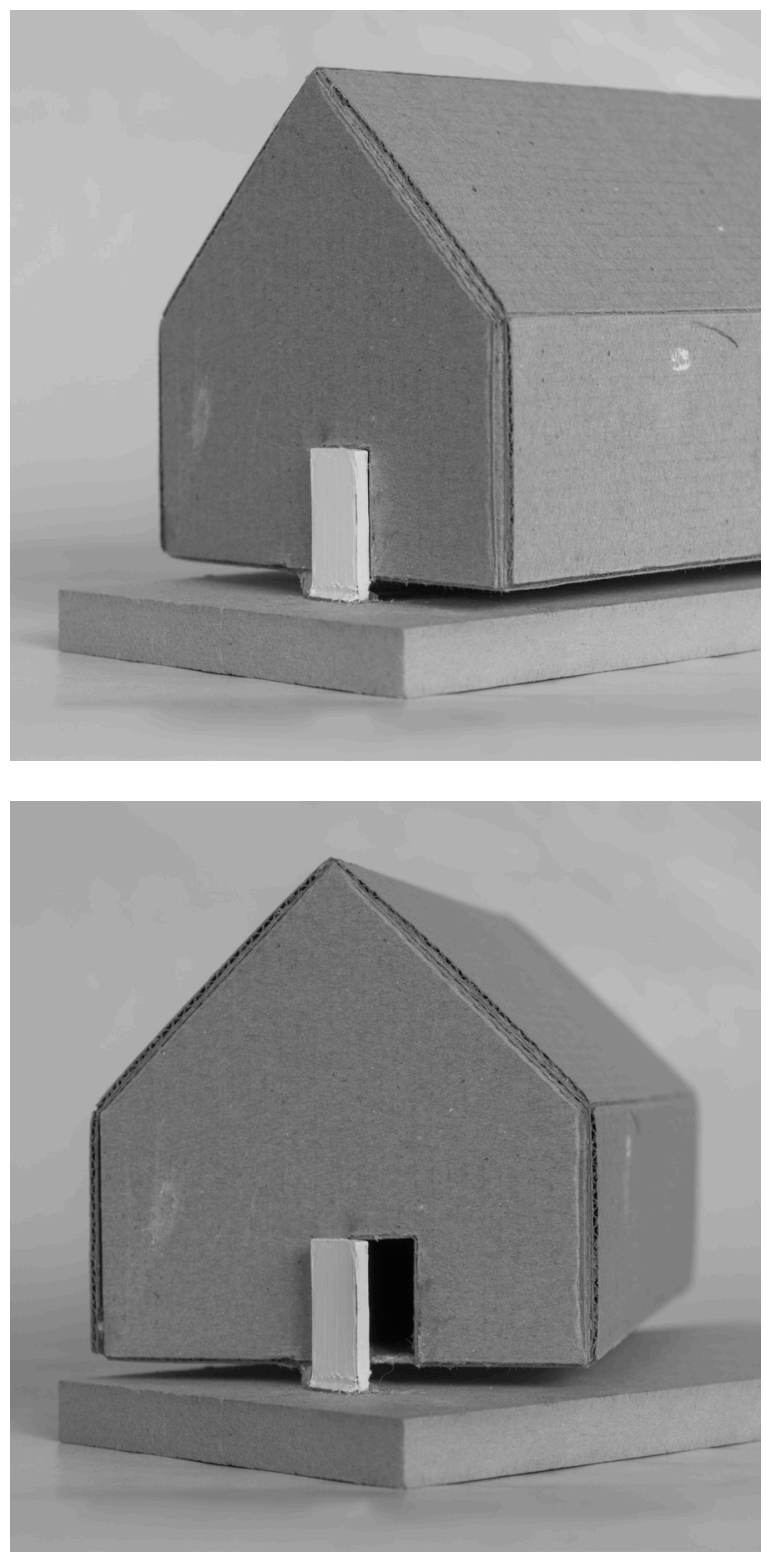

FIC. 5-25 HOUSE-THAT-SWINGS-

OPEN-1 (second functioning

model): in motion to open
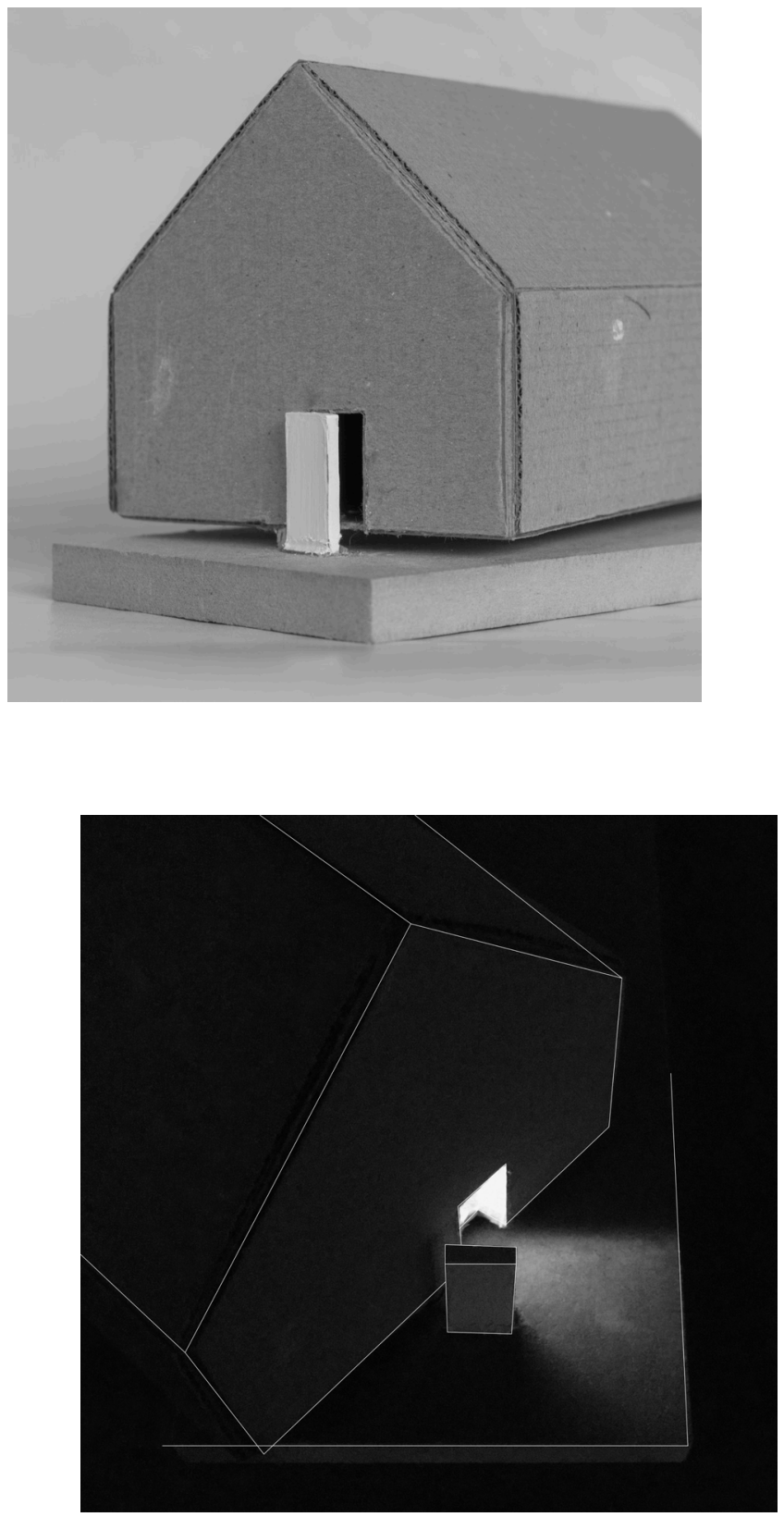

FIG. 5-26 HOUSE-THAT-SWINCS-

OPEN-1 (second functioning model: how light is emitted 


\subsubsection{THE LIGHT}

When it is the house that swings open, the light that is emitted from the house changes with the change in the opening of the house. This is unlike our experiences approaching a conventional house.

With a conventional house, the source of the light (say, a lamp) is within the house, and that house is static. When it is the house that swings open, the source of the light moves with the house, like a lighthouse.
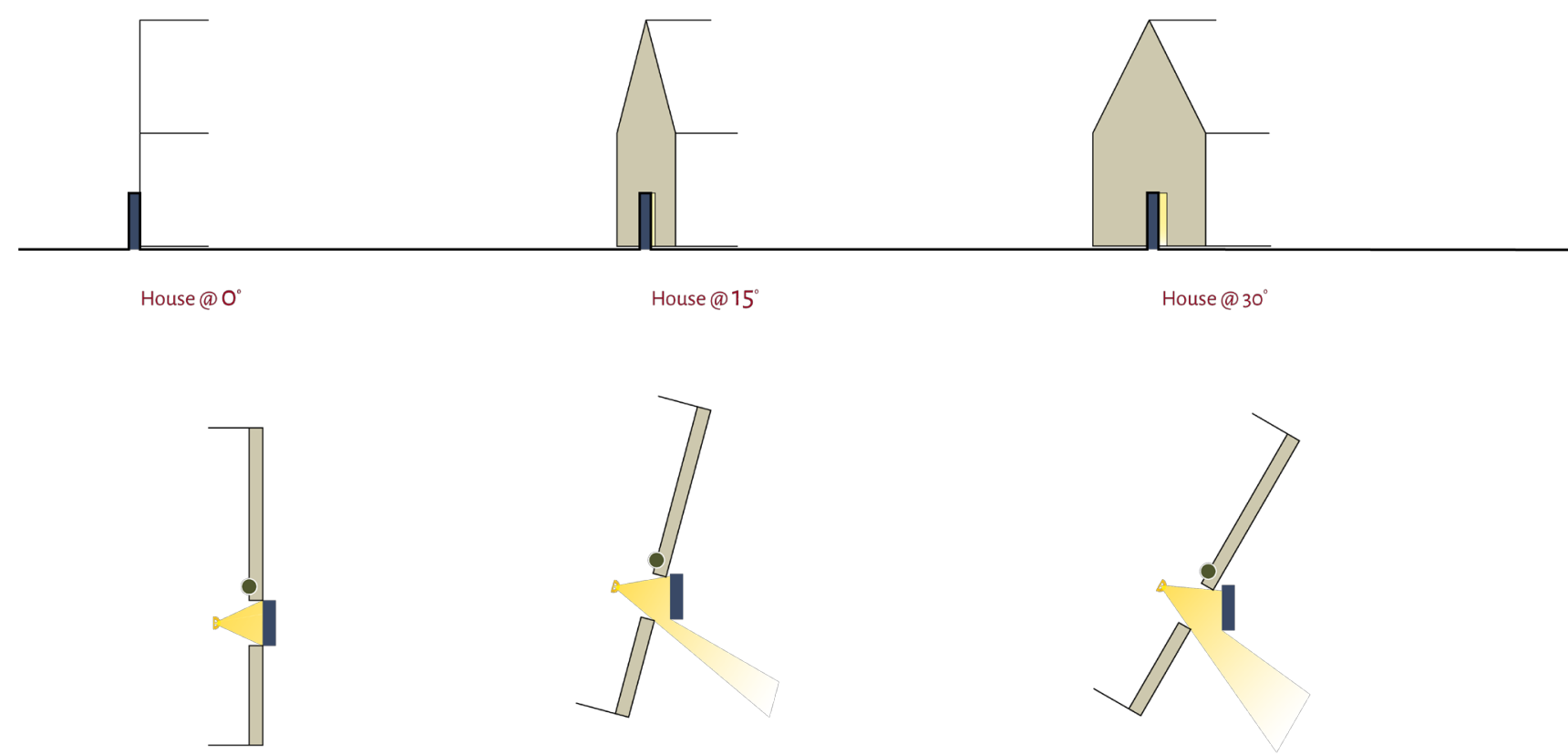

FIC. 5-27 HOUSE-THAT-SWINGSOPEN-1 (second functioning model: how light is emitted, diagram 


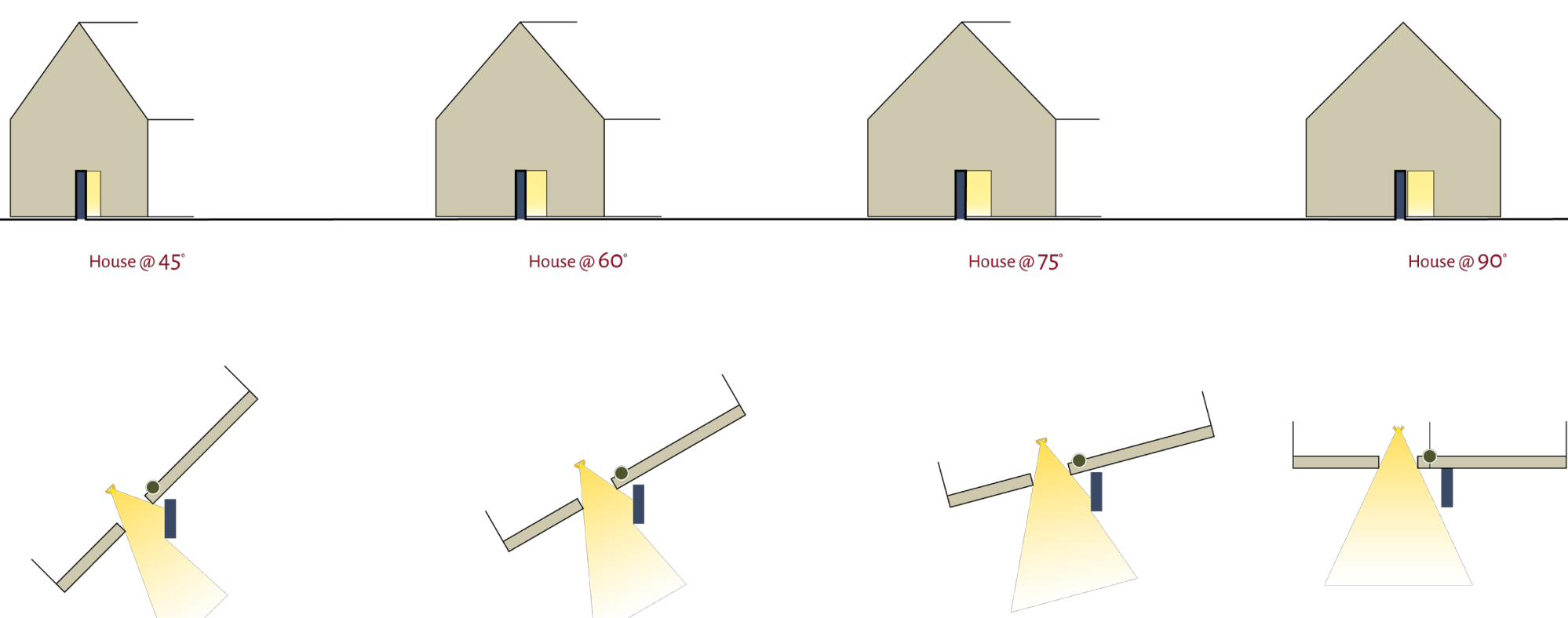




\subsection{WHEN IT IS THE HOUSE THAT SWINCS OPEN...}

\subsubsection{WALL: A PARACHUTE WALL}

For the house to swing around its door, it is hung from the roof. This 'shift' started a chain reaction that revised the role and materiality of every other element of construction: the roof is now carrying the walls. Walls were now supporting the floors, which was now off the ground. The door became a wall. And, the hinge was so prominent that the whole system depended on its internal structure.

To build such a house, we need the hinge first, so that the other elements can attach to it. We also need to make sure that there is a door nearby to close the space. The materiality of the walls also become important.

The front wall which connects to the hinge is solid so as to provide stability to the whole house. The other walls, the roof and every other enclosing element can be made from any other materials. In this case, a fabric wall makes every other wall a parachute.

When it is the house that swings around its door, the walls become a parachute. The door becomes a tombstone. The hinge is now a beam-column. The wall is now a persona: WALL.

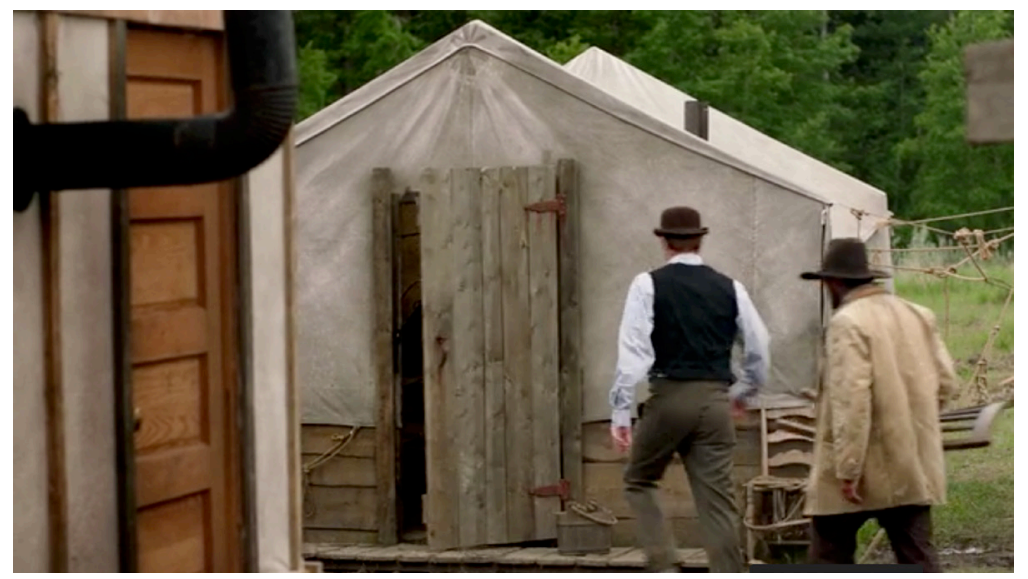

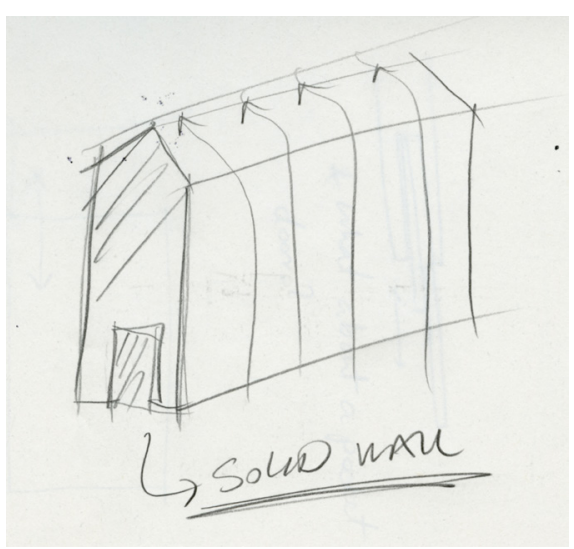

fig. 5-28 the PARACHUTE WALL CONDITION, sketch

fig. 5-29 screenshot from Hell on Wheels 
fig. 5-30 sketch, the window roller house, when it is the house that swings open and the wall is a parachute.

FIC. 5-31 HOUSE-THAT-SWINCSOPEN-2: first functioning model

\subsubsection{WINDOW : A ROLLER WINDOW}

When it is the house that swings open, the wall is a parachute and the whole structure is supported by the hinge that has COLUMNLIKE and BEAM-LIKE WORKINGS, it is possible to imagine the wall on a roller. The windows can move up and down to close and open or to adjust to the angle of the sun. The window is not a persona: WINDOW.
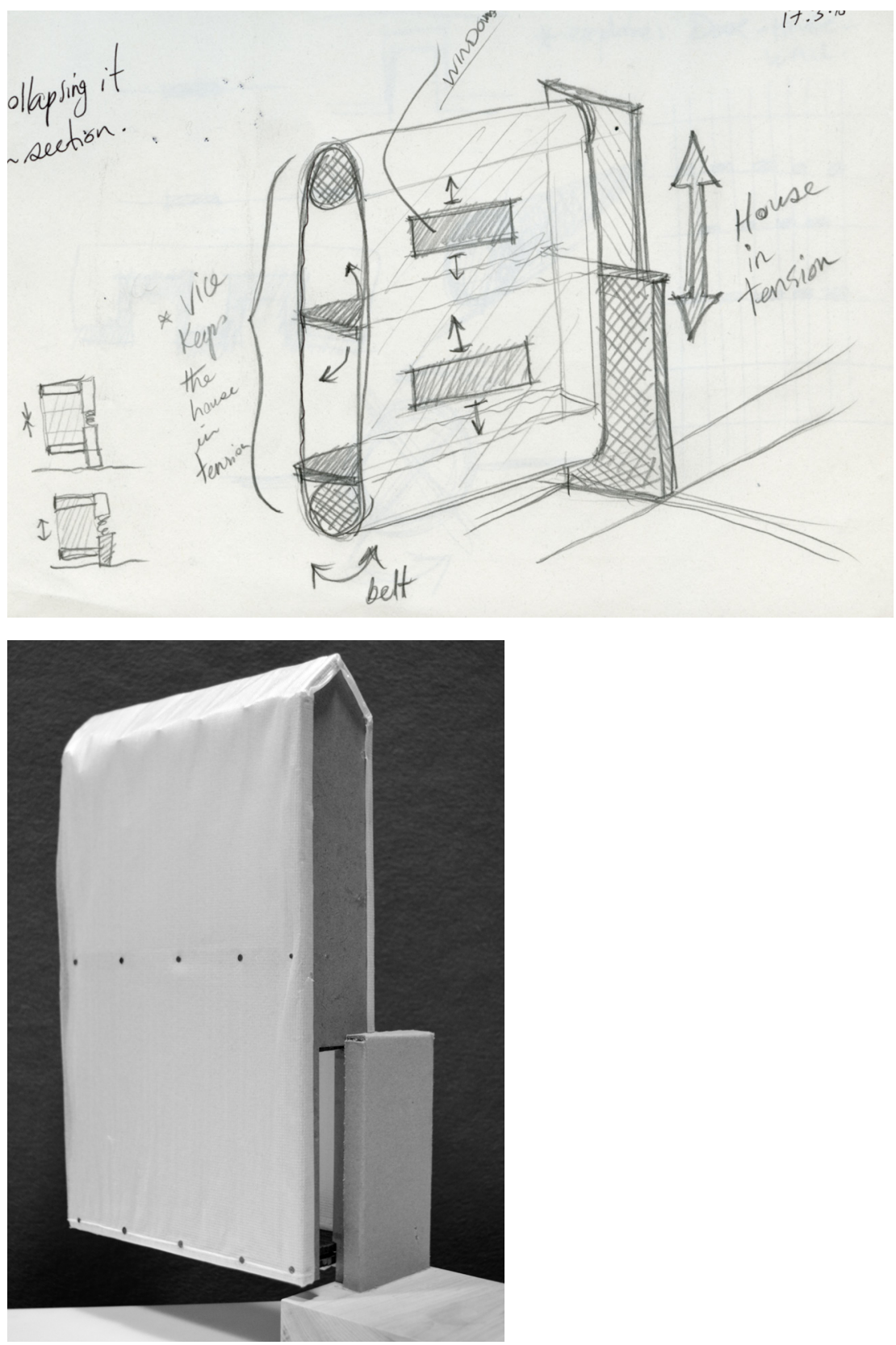


\subsubsection{SLAB: FLOATINC SLAB}

When the wall is a parachute, slabs float in the air. When it is the house that swings open, the wall is a parachute and the slab floats, the doorway acts as a slab-stopper. The doorway now is a colUMNLIKE ELEMENT OF CONSTRUCTION. In Flat World, because the slab floats, the height of buildings are in flux. The slab is now a persona: SLAB.
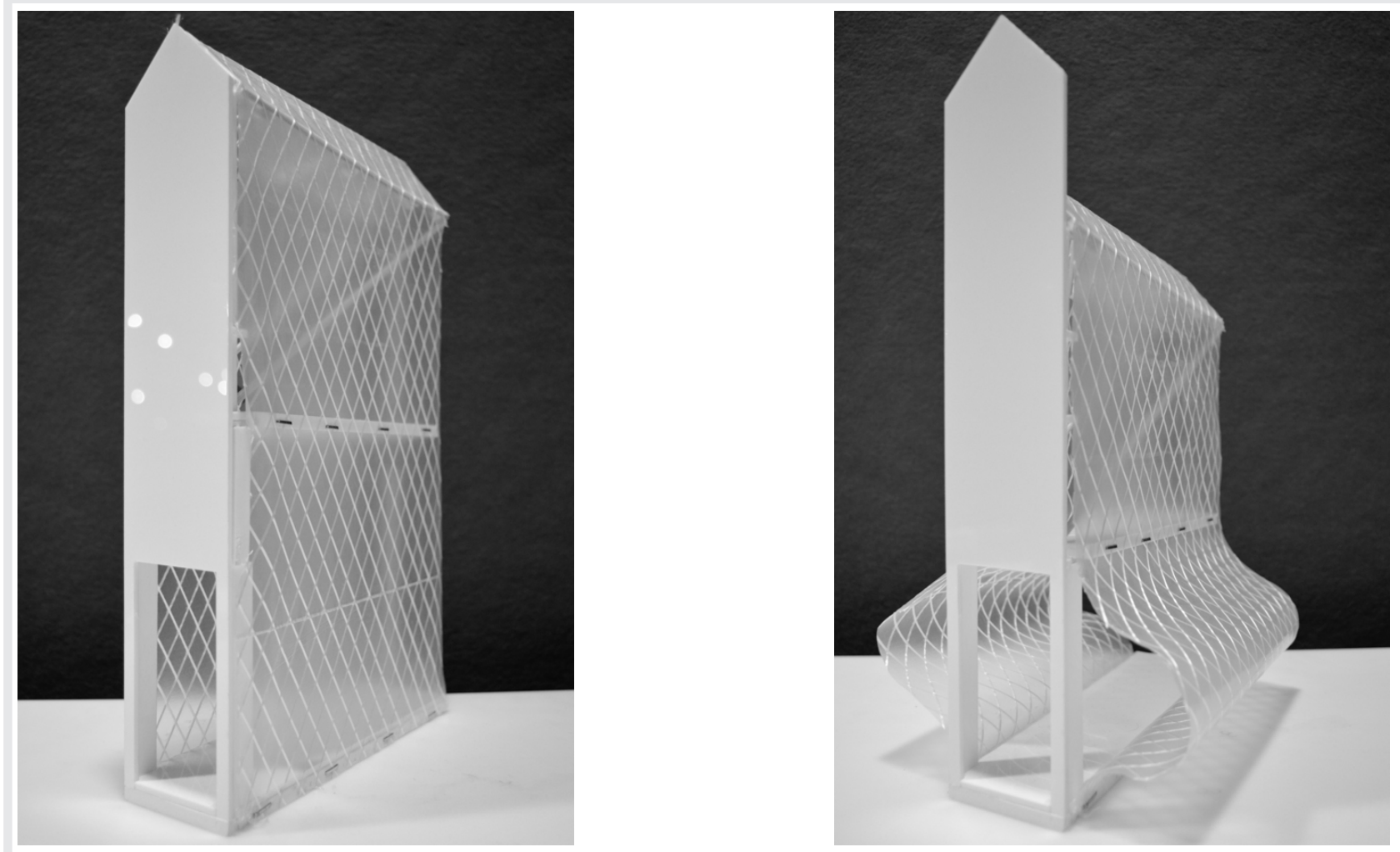
fig. 5-33 when the wall is a parachute, the height of the building is flexible. The doorway is now a column.
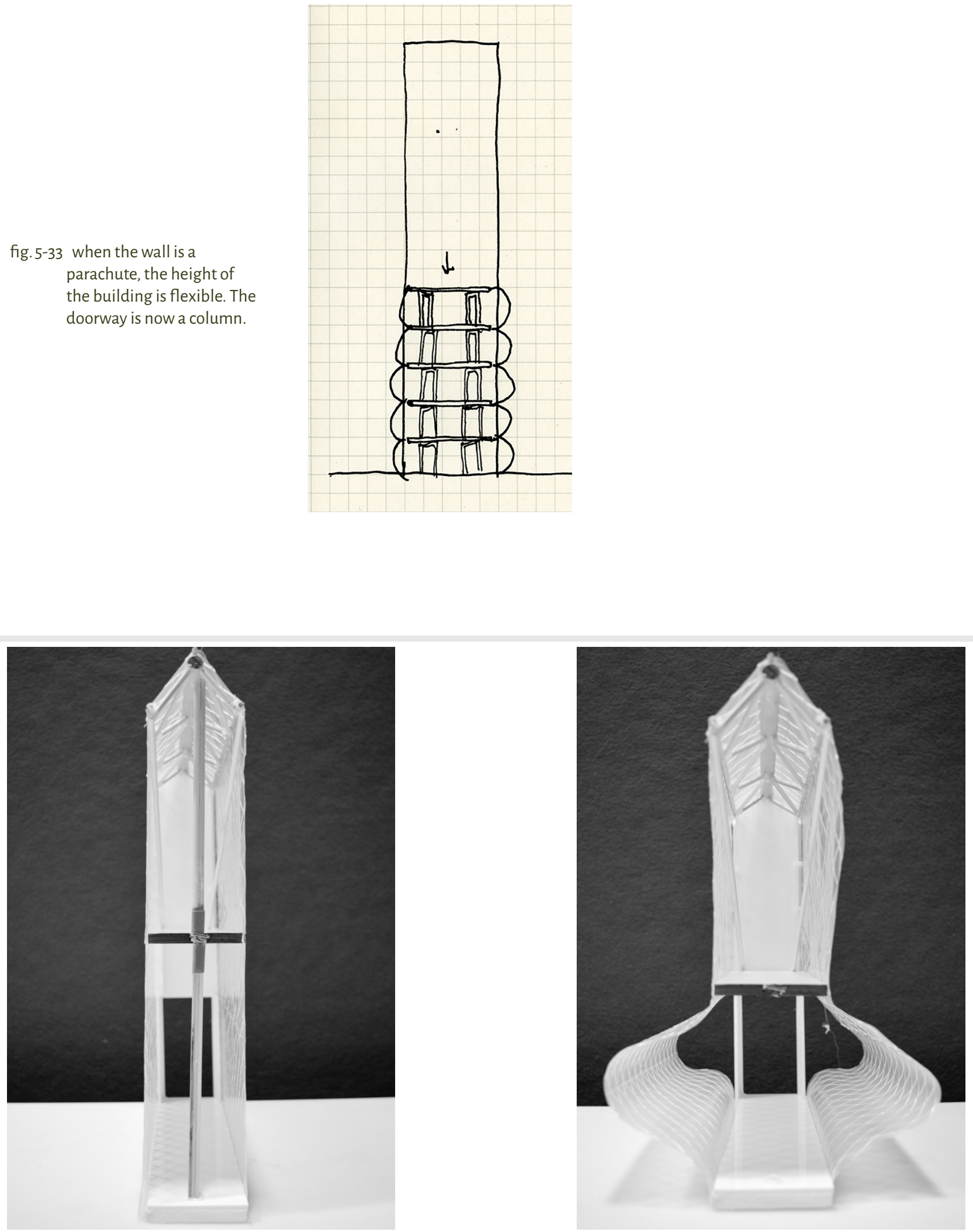


\subsection{THE COMMUnity (1): Blueline PARK}

Imagine a typical suburb. The architectural expression of the houses can say that there are in a suburb. Here, the level of permanence that is attributed to any architecture is dependant on the services that connect us to many networks of infrastructures that are fixed.

SO, WHAT WOULD HAPPEN IF WE STAYED,

\section{AND EVERYTHING ELSE MOVED?}

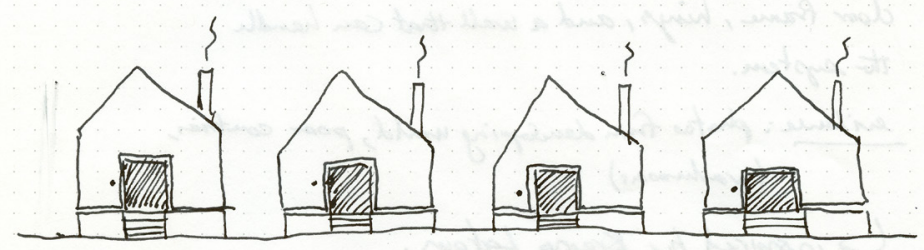

Everything that is meant to be updated, like services, is fixed. Everything that is meant to movable, like a door, is fixed. Everything that makes our days to be spent in travel, like cars, are fixed. Instead, it is the architecture that moves.

Here, the operation of the system, the spacing of houses, and the organization of the inhabitants are both individualistic and social. There is space to open and close the houses but without cars and with small roads, there is nowhere to go other than work and home; which happens to everybody at the same time. Everybody leaves Home at 9am, waits in the street for their house to leave and their work-place to arrive. Then, this cycle is repeated in at $5 \mathrm{pm}$ in reverse.

WHAT WOULD PEOPLE TALK ABOUT WHEN THEY ARE WAITINC ON THE STREET? fig. 5-34 Blueline Park, sketch

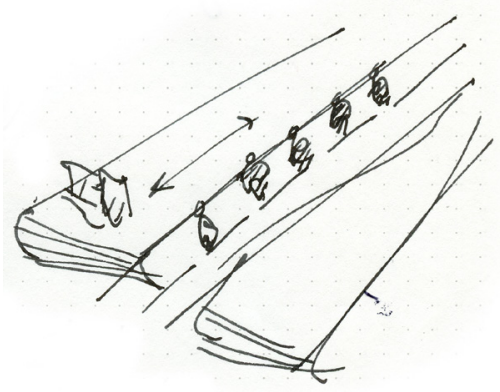

fig. 5-35 Blueline Park, sketch 


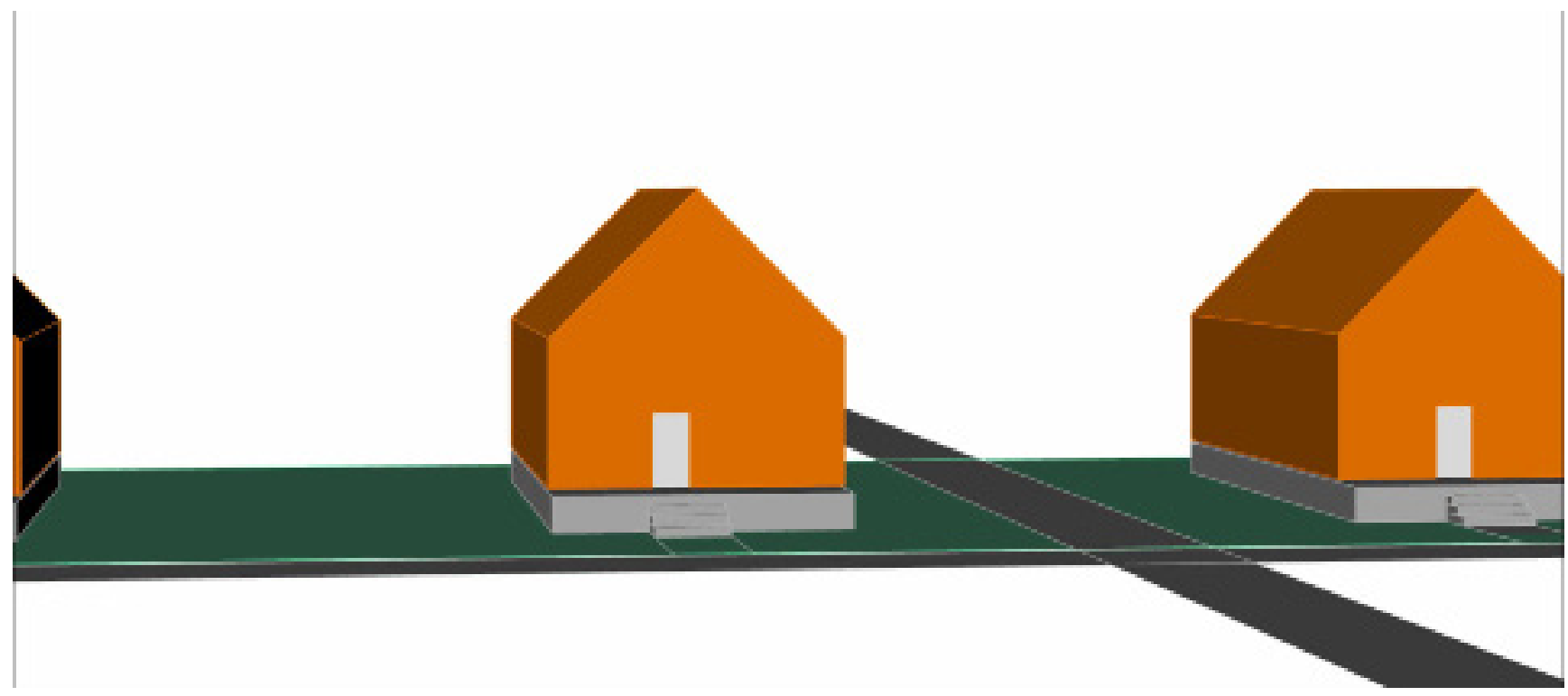

fig. 5-36 Blueline Park, animation

This anitmation is available online: https://vimeo.com/234093983 

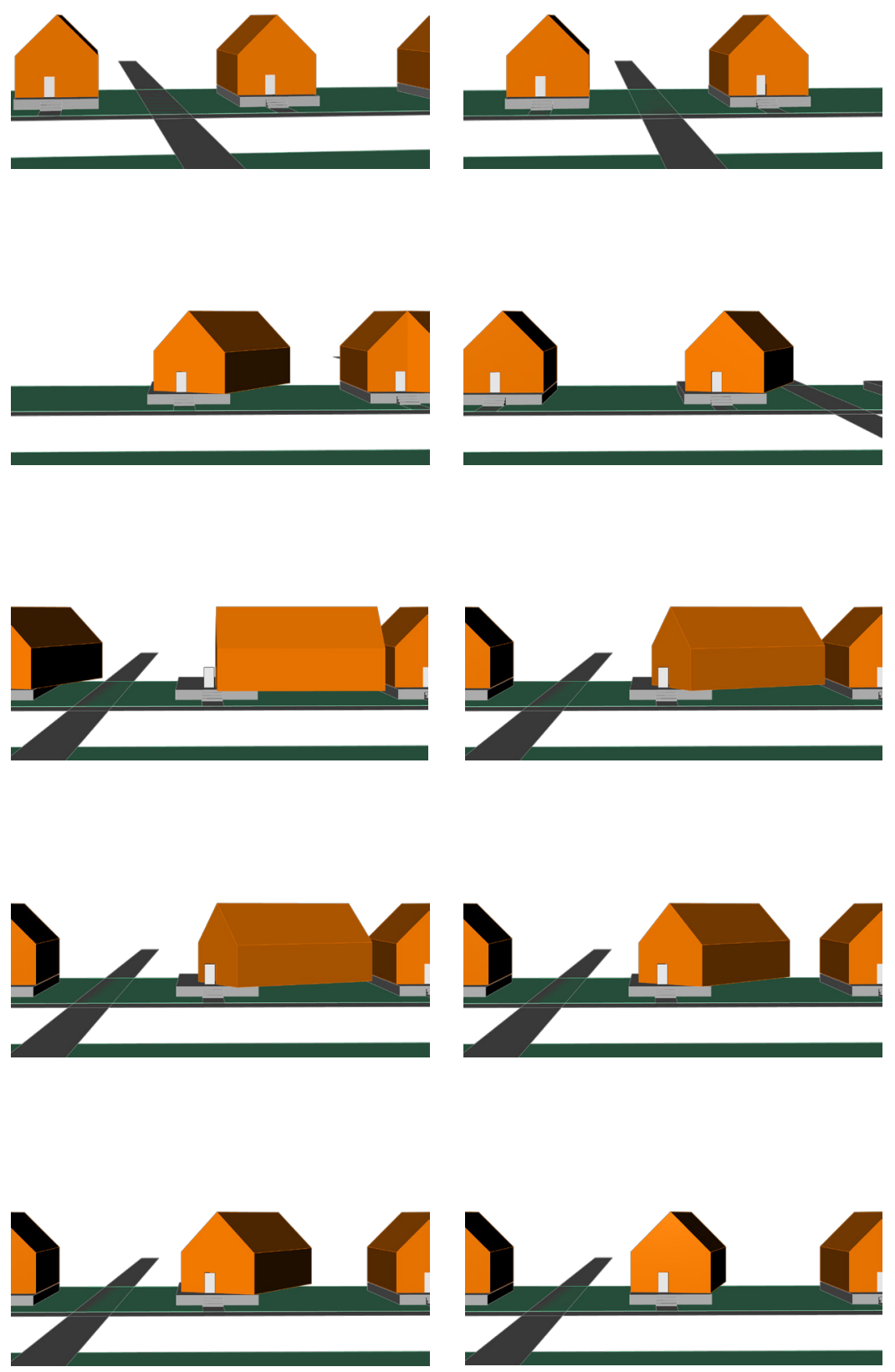

fig. 5-37 stills from Blueline Park animation
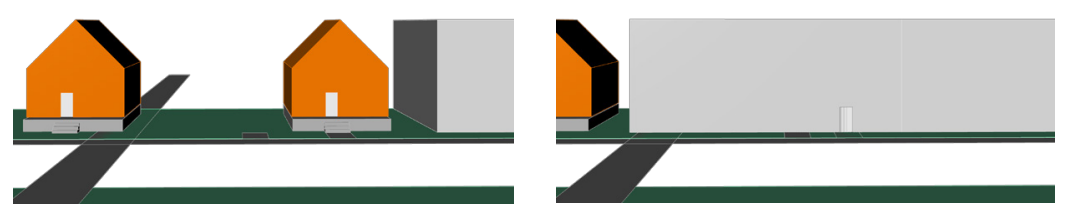
fig. 5-38 workings of Blueline Park, houses on rollers

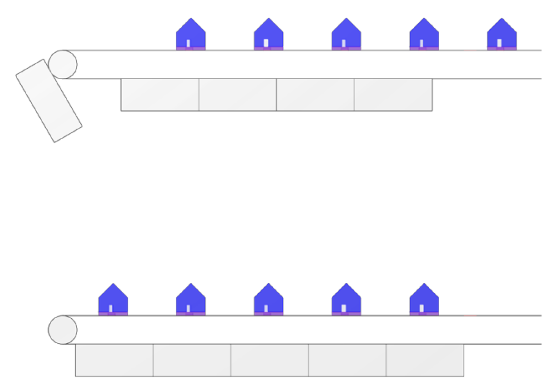

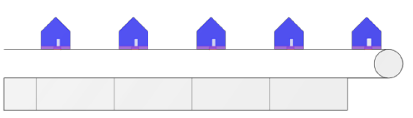
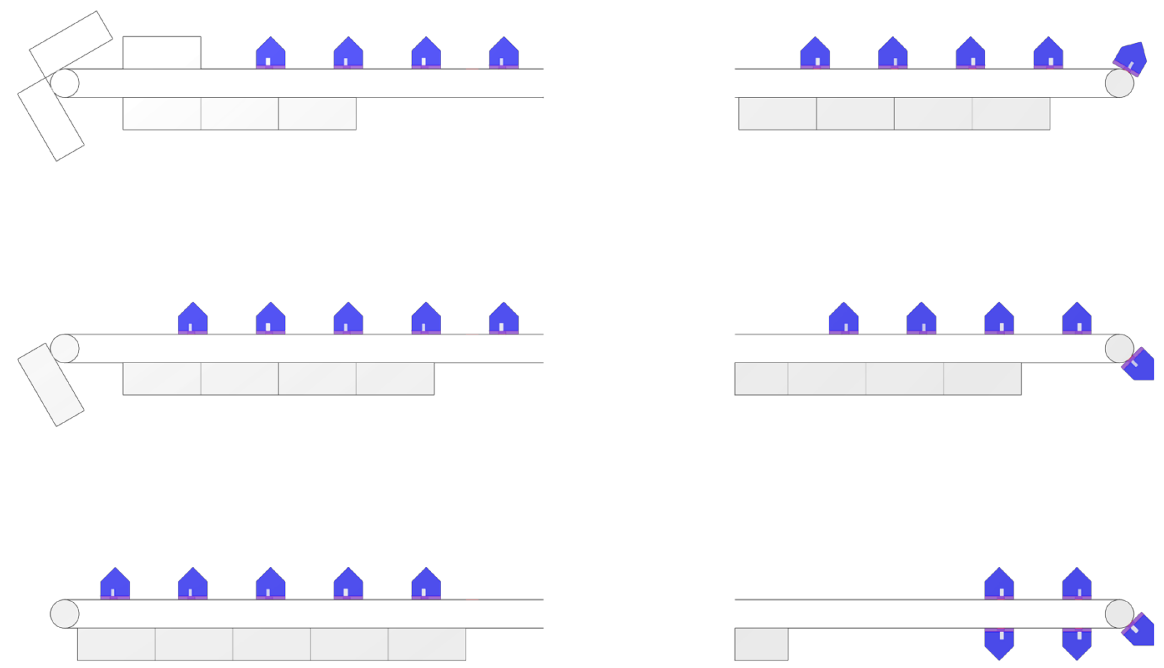

fig. 5-39 plan of the community on the Blueline Sheet

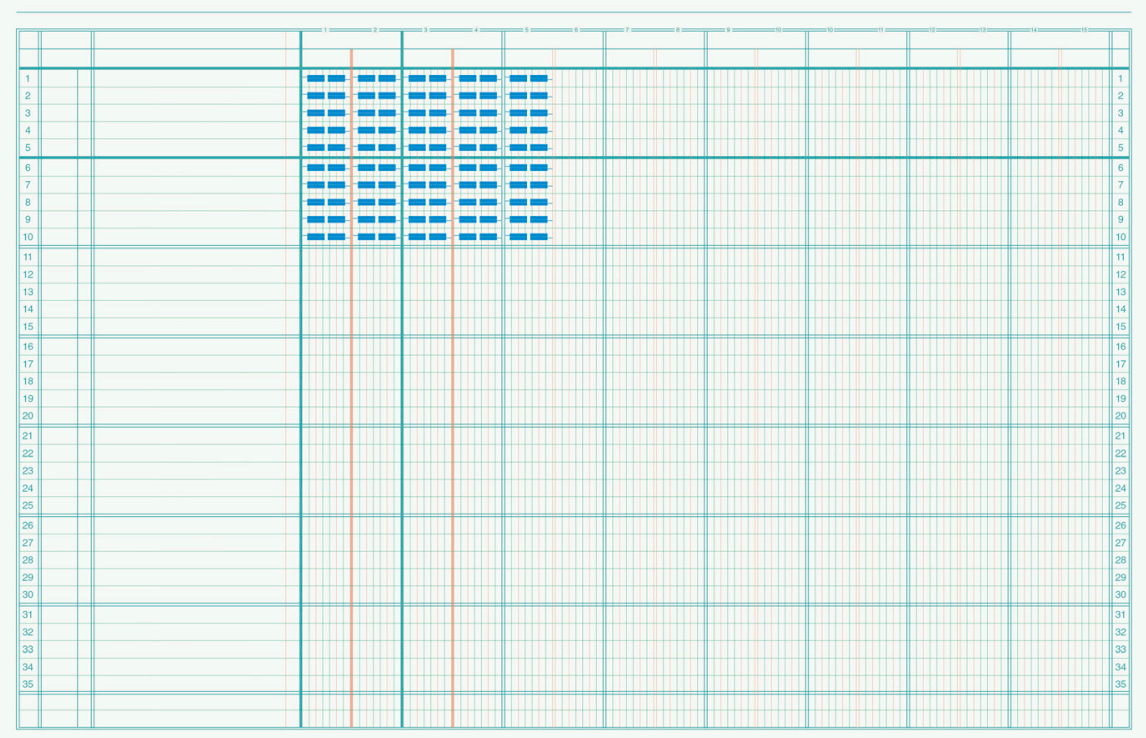


fig. 5-40 workings of Blueline Park

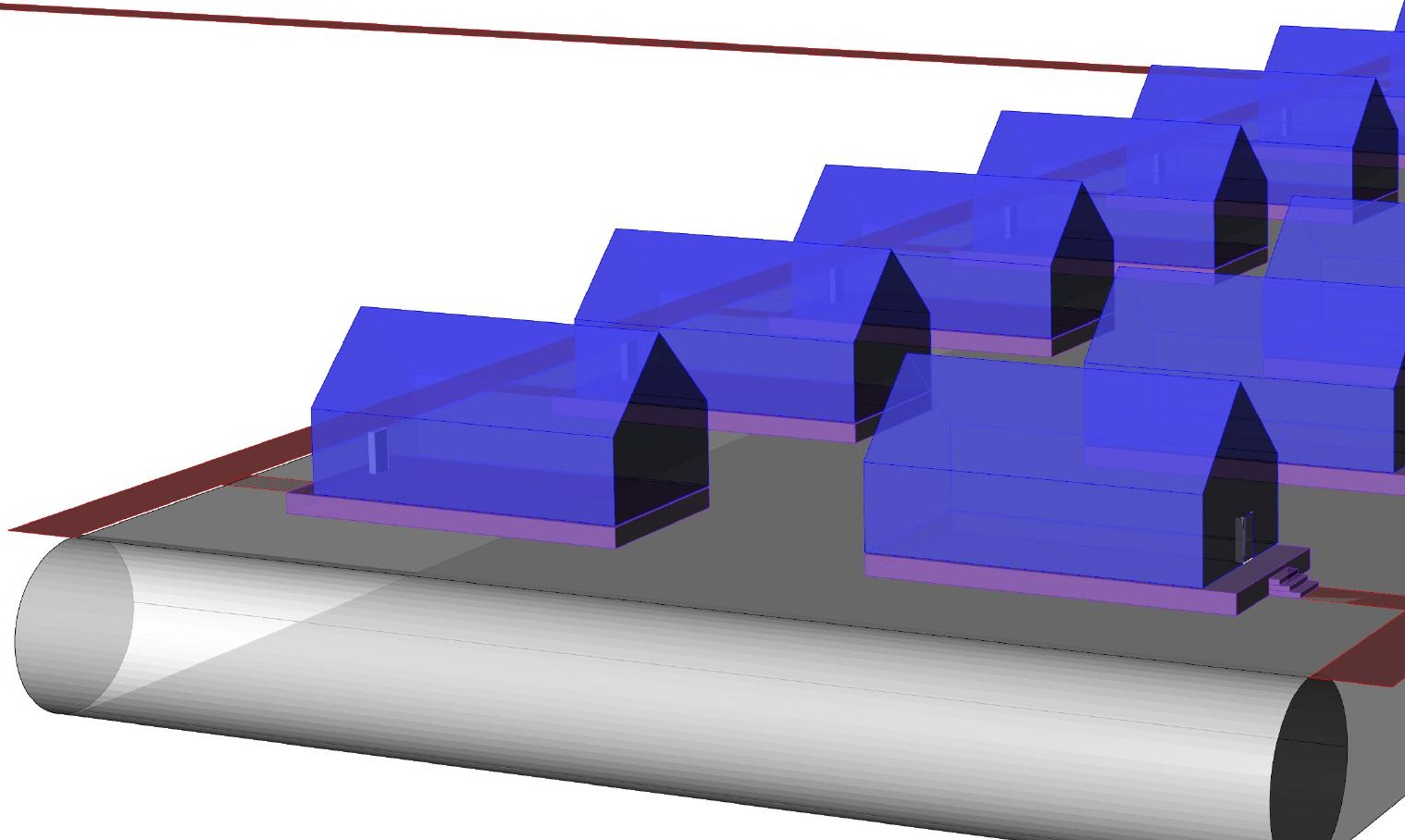




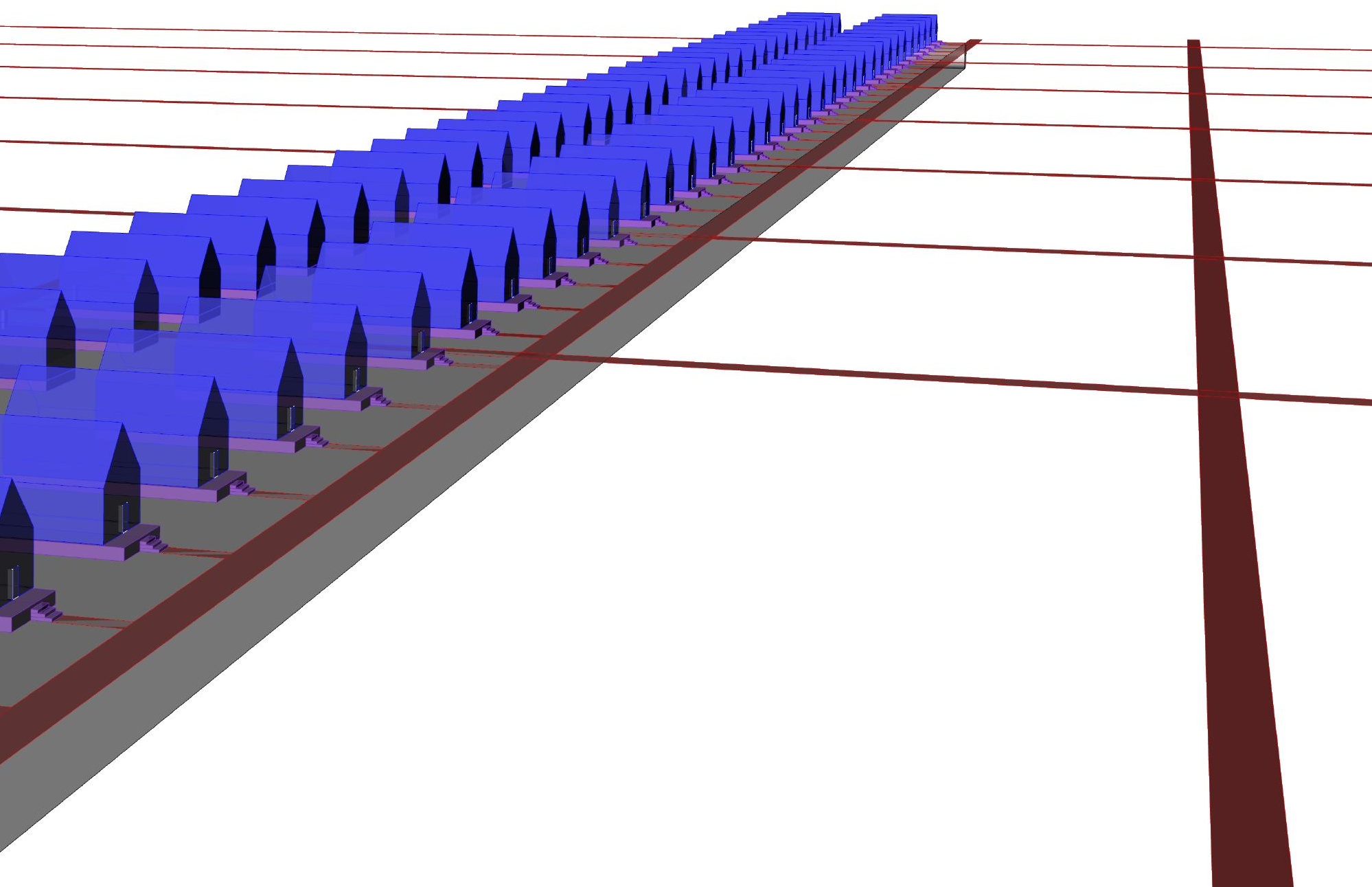




\subsection{A FLAT DWELLING}

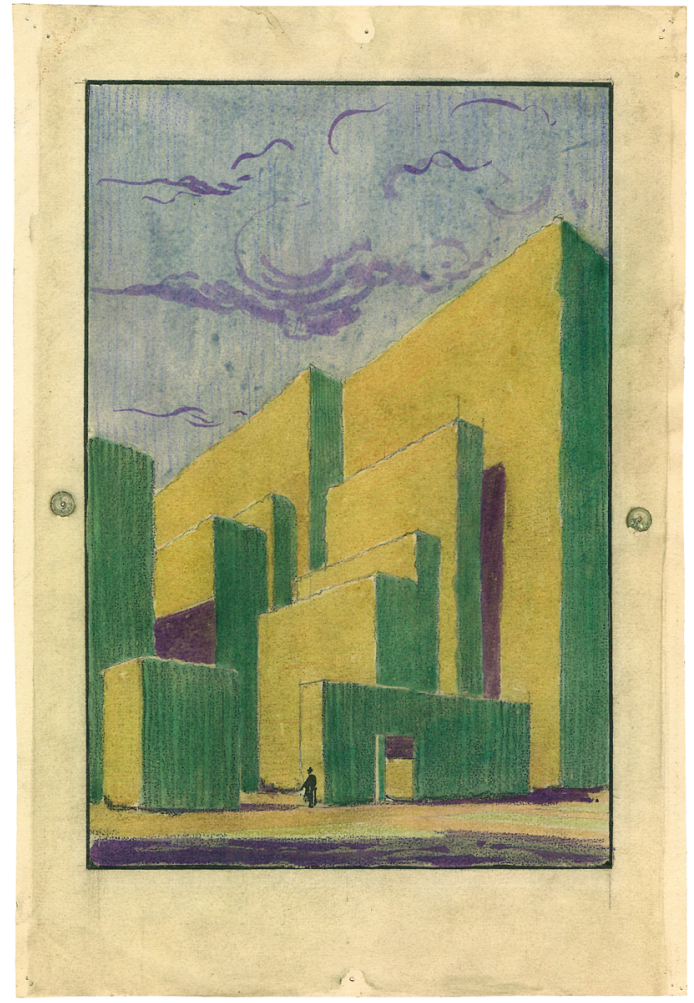

fig. 5-41 J. C. van Epen, Study for Skyscraper apartment block, 1926

"For a caveman, cave walls were taken for granted, and he opposed them by painting on them and expressing his will in opposition to nature (an expression of 'beauty'). Our walls are late and decadent forms of cave walls. The existential problem is as follows: Although our walls were made by human beings (by masons, architects and those who impose their ideology on masons and architects), they are nevertheless taken for granted as far as those living between them are concerned $[\ldots]$ even by those who built them."2o

-Vilém Flusser 


\subsubsection{THE WALL (2)}

If today, in SHORT REAL, "Living-between-Walls is part of the human condition,"21 then our designs must "make the best of them." To do so, a design must take into consideration that "even the most elusive and ubiquitous forces such as money, finance, globalization, and capital leave their inexorable, tangible traces"22 in any work of architecture.

In this context, not only the relationship between elements must be evaluated, but also the relationship between spaces that are materialized through the ELEMENTS OF CONSTRUCTION.

\section{CAN LIVING IN-BETWEEN A WALL BE ANOTHER CONDITION FOR HUMANITY?}

To dwell in-between a wall can be interpreted two ways: a very thin house or a very thick wall. In either case, the spaces cannot be taken for granted. The form of the building cannot be a reaffirmation of the conventions that reassert the same 'order of things'.
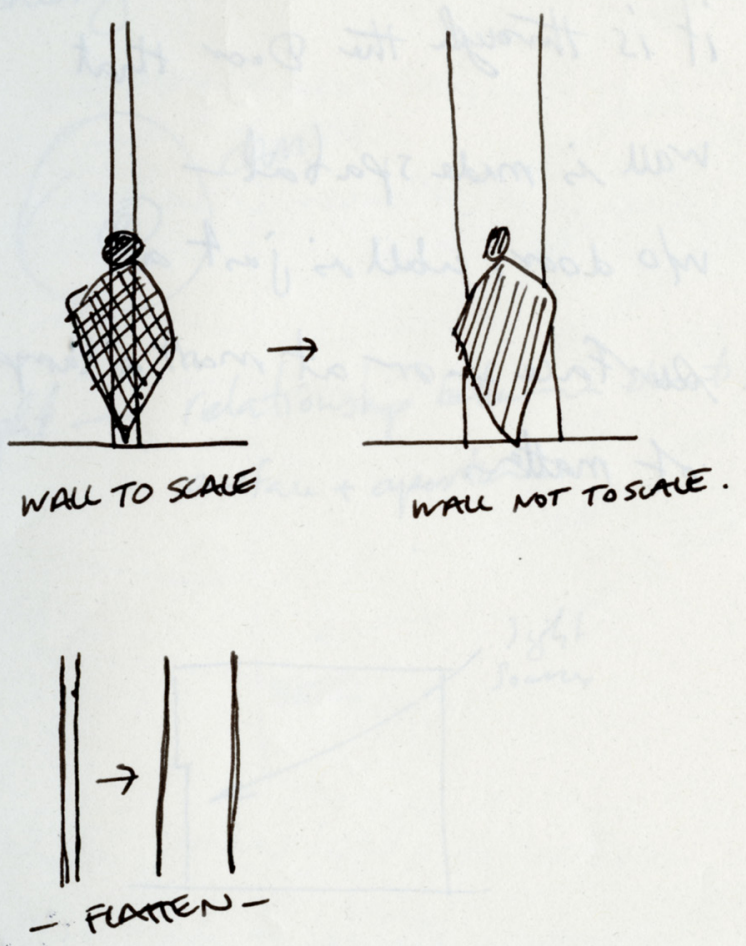
These case studies show some of the narrowest (thinnest) houses in the world. They all have one problem: the space needed to access the toilet and bathroom adds to the width of the house.

CAN THE CIRCULATION SPACE AND THE RELATIONSHIPS

BETWEEN DOMESTIC SPACES CHANGE?

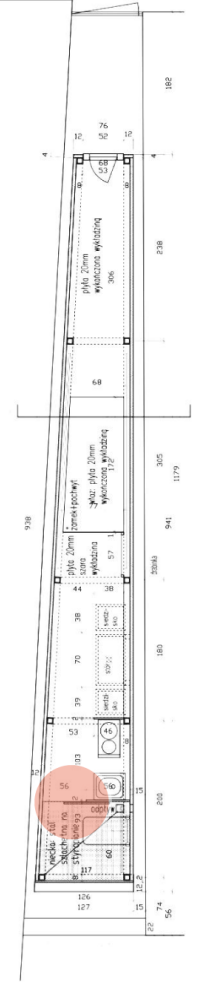

$1.22 \mathrm{~m}$

Keret House Warsaw, Poland

- Jakub Szczesny

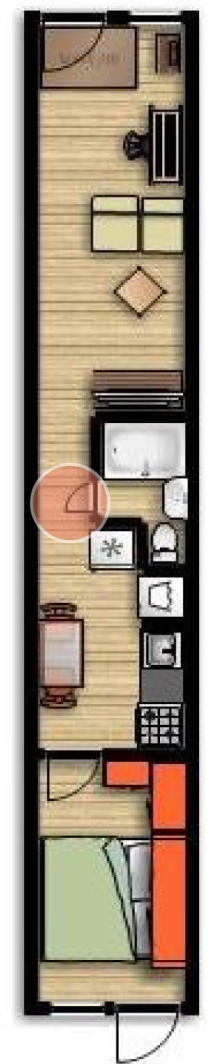

$2.1 \mathrm{~m}$

The Little House Toronto, Canada

- Arthur Weeden
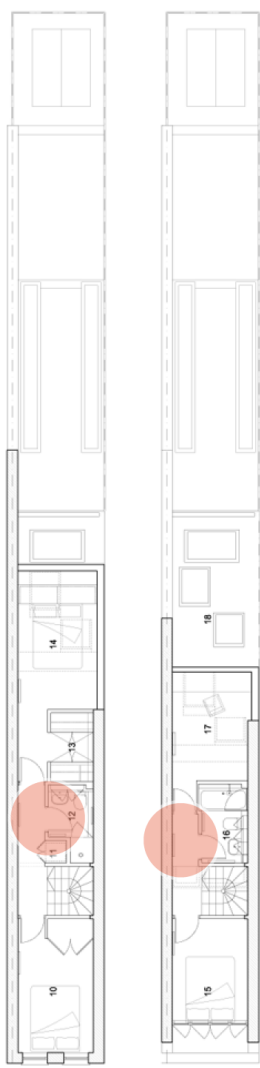

$2.3 \mathrm{~m}$

Slim House London, England

- Alma-nac

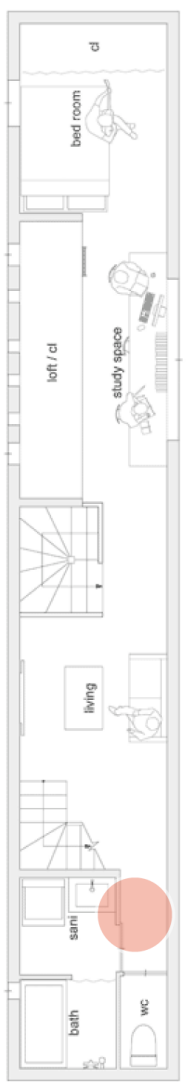

\section{$3 \mathrm{~m}$}

Imai House Aichi, Japan

- Katsutoshi Sasaki + Associates 

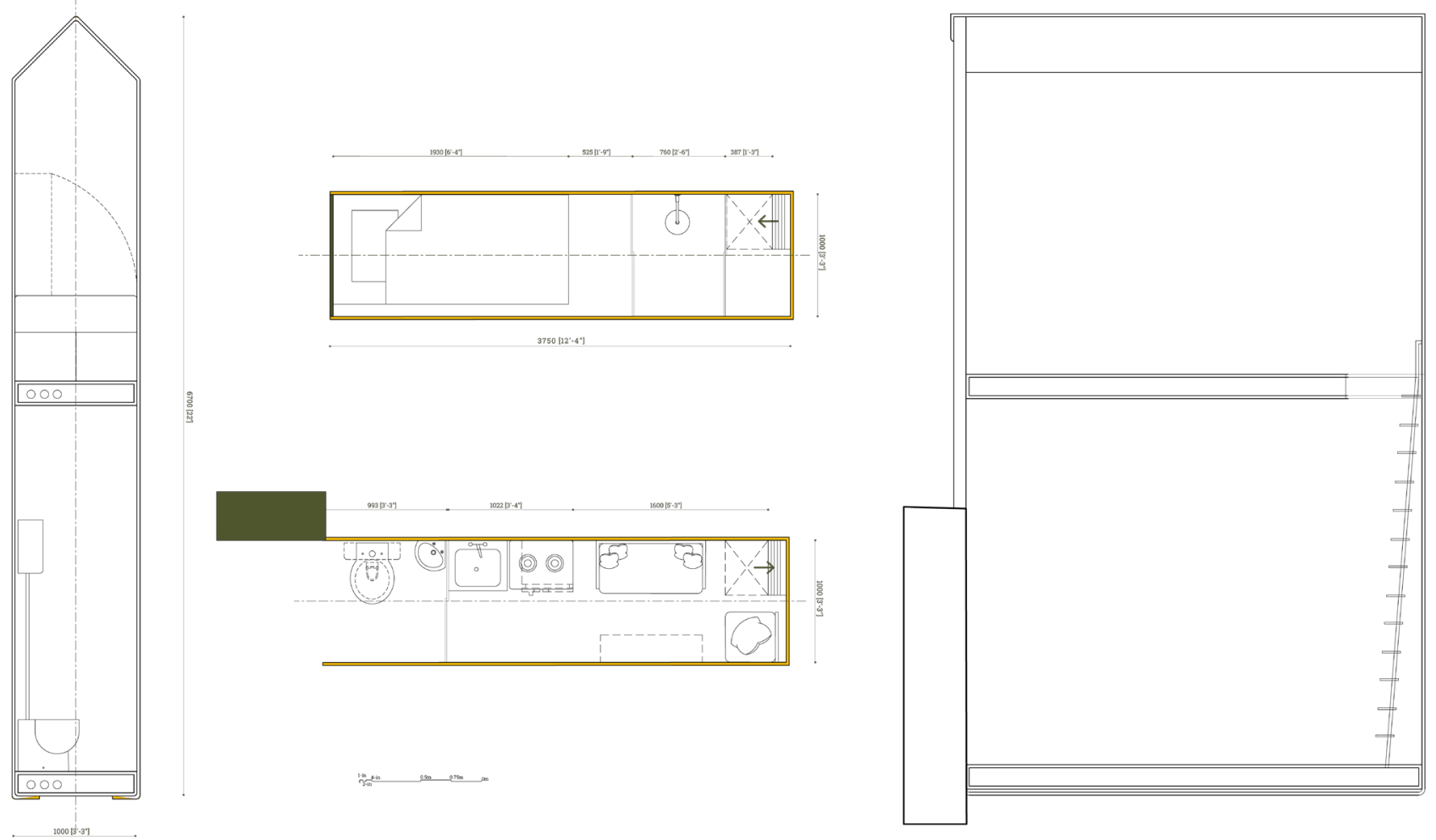

FIC. 5-44 Flat House, plans and sections

FIC. 5-45 FLAT HousE, other possibilities for the WORKINCS Of a PARACHUTE WALL.
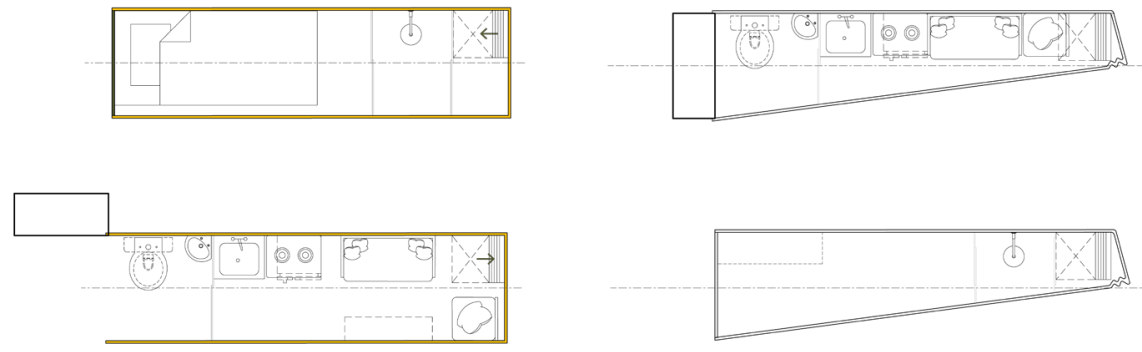

U

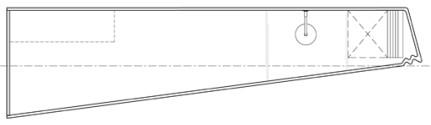

(1) 


\subsubsection{TOILET}

Imagine, in a conventional house, the amount of time we spend in the foyer is far less than the amount of time we spend on the toilet. The entrance or the foyer to the house is a transient space.

To accommodate for this thin wall-house, spaces had to be combined. When it is the house that swings around its door, the toilet becomes a foyer: a 'sanctuary' becomes a meeting place. The 'great equalizer,' becomes the great connector. Now, THE TOILET ASSUMES A PERSONA. IT IS TOILET.

A practical note: if the inhabitant is sitting on the toilet and someone knocks, then that person cannot open the door. But, isn't that how things already are?

fig. 5-46 the toilet as the foyer or the foyer as the toilet
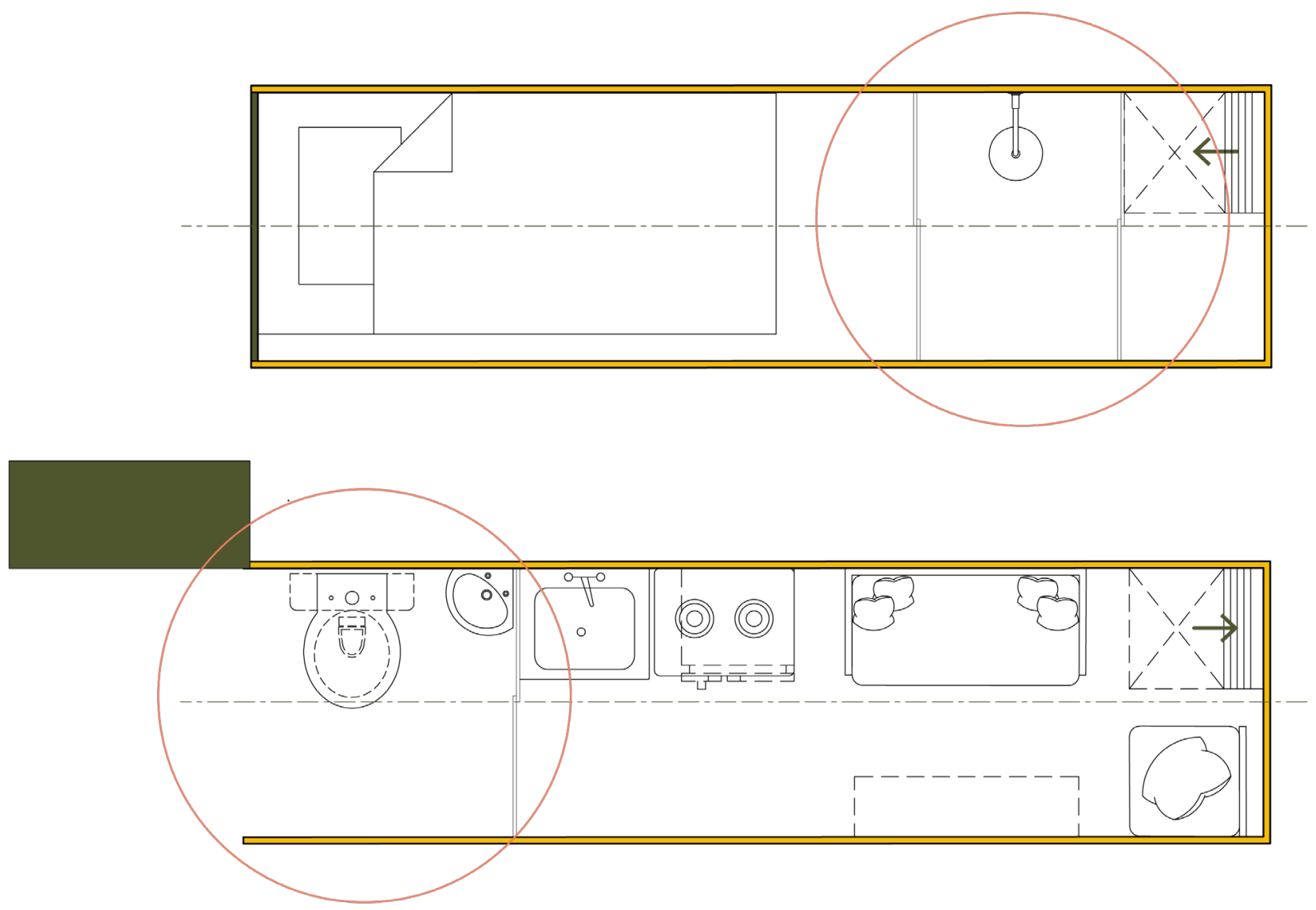
fig. 5-47 Antione Laugier's the primitive hut

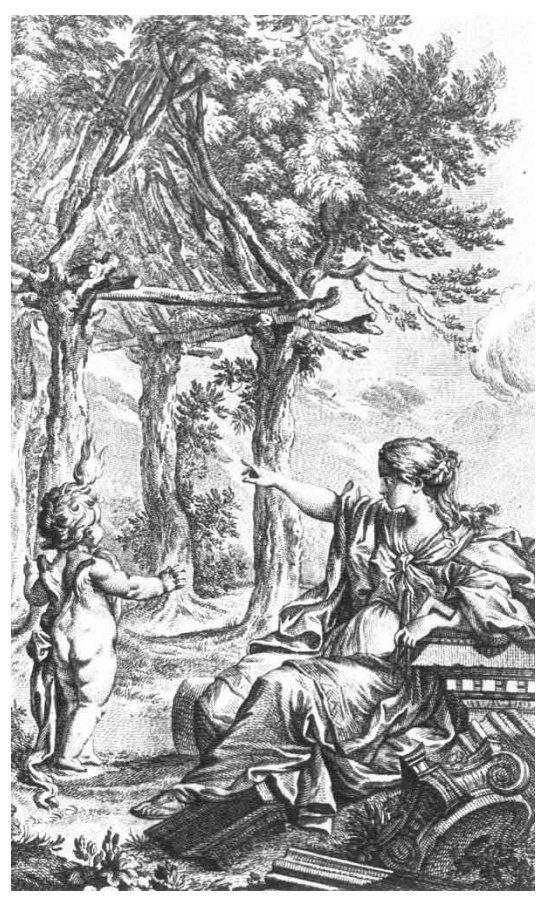

No one can really know how the first houses looked like. We can, however, assume that they were uncanny versions of the caves we lived in, or possibly trees that our ancestor in the steps of Africa called home.

The PcM activity that is the conception of the idea of the 'primitive hut' is the transference of the cultural biases of one group into the whole of the human history.

For example, Antoine Laugier's version-with four tree trunks standing at four corners, forming an enclosure, with a truss structure forming above it, and cupids pointing at it - might looks plausible. Yet, it is pure imagination. Like Dom-ino's 'platform' alter-ego, to make it look legitimate, it projects the image of rectangular home, like a Greek temple, onto nature. 

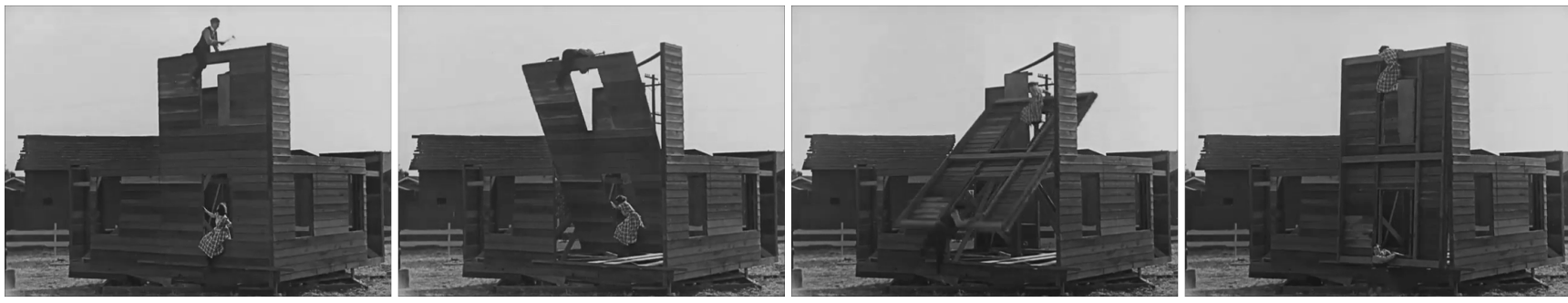

fig. 6-1 Buster Keaton, One Week, 1920

"Axioms are neither a collection of self-evident truth nor matters of empirical fact, but a set of rules necessary in order for there to be dialogue."

- Kojin Karatani

"Material practice is the shift from asking 'what does this mean?' to "what does this do?"”2

- Reiser + Umemoto

"It seems to Wittgenstein that there is a kind of paradox that inevitably arises when we consider the problem of following a rule. If anything can be made to accord with the rule by some interpretation, then anything can also be made to conflict with the rule, given some other ingenious interpretation, and you would get then neither accord nor conflict. It looks as if the rule would simply drop out as irrelevant, that it would play no role in the explanation of behaviour."

- John Searle ${ }^{3}$

1 Karatani, Architecture as Metaphor, 12.

2 Reiser and Umemoto, Atlas of Novel Tectonics, 23.

3 Magee, "Wittgenstein: Diaglogue with John Searle," 337. 


\section{ZERO, ZERO}

THIS CHAPTER FOCUSES ON THE LESSONS LEARNED FROM PREVIOUS PROJECTS TO ESTABLISH THE RULES THAT EMPOWER THE CRITICAL, INTERPRETATIVE AND DESICN CAPABILITIES OF FLAT WORLD. AS A RESULT, VARIOUS PHILOSOPHICAL UNDERPINNINCS THAT INFORM THE METAPHORIC THRESHOLD ('THRESHOLD') ARE EXAMINED AND NEGOTIATED.

ONE OF THE REASONS THAT THIS CHAPTER FOCUSES MORE ON THE CONCEPT OF THE 'THRESHOLD' OVER 'DOORNESS' IS THE PREVALENCE OF ITS USE IN THE CONTEM PORARY DISCOURSE. IT IS IMPORTANT TO RECOCNIZE THAT DESPITE THE CALL FOR A UNIVERSAL APPRECIATION OF A 'HUMAN PSYCHE', AN INHERENT EXCLUSIVITY EMERGES FROM THE NOTION OF 'THRESHOLD' BECAUSE OF ITS PHILOSOPHICAL AND METAPHORICAL UNDERPINNINCS. MOST IMPORTANTLY, ITS ASSOCIATION WITH THE CONCEPT OF 'PLACE' THAT SEEKS ONLY INSTANCES THAT CAN RECIPROCATE ITS IDEALISTIC AMBITIONS. 


\subsection{A 'PRIMITIVE CONDITION'}

According to Hayles and Gannon, in reconstructing Dom-ino as 3D axonometric drawings, and multiplying it in various configurations, Eisenman creates "an affect of technological development" that 'implies' a "history of a primitive form's articulation over time." Moreover, the idea of a 'primitive condition' is something that Eisenman refers to in his re-reading of Dom-ino, and writes that Dom-ino "is an idea only about itself, a self-referential statement"1 which becomes "a primitive though truly Modernist phenomenon."

For Aldo van Eyck, the question of a 'primitive condition' is inevitable because of the anthropological underpinning of his 'theory of threshold'. The fascination with the notion of 'primitive' for van Eyck and Eisenman might be a consequence of the general direction of the discourse in the 1960 - what Georges Teyssot refers to as the "anthropologization" ${ }^{2}$ of the discourse.

As Teyssot posits, Aldo van Eyck "was [...] one of the first designers to introduce work on 'primitive' architecture" 3 as he "published photographs of traditional habitation to illustrate keywords and leitmotivs, such as [...] 'the realm in the in-between', or 'the greater reality of the doorstep.".4

For Eisenman and van Eyck, the insistence on establishing a pedigree for their ideas through a primitive condition for architecture responds to a very particular and ironic development of the general Modernist paradigm in architecture.

However, as Adrian Forty recounts, the fascination in the discourse with the 'primitive condition' had only "the slightest regard for archeological facts." In fact, most times, it was employed "for the purpose of justifying the principles that should be followed in the architecture of the present." A tradition that goes back as far as Vitruvius and his Ten Books on Architecture, who described "the 'primitive hut" as the "mythical origin of architecture." For Vitruvius, "The idea that the orders originated as stone

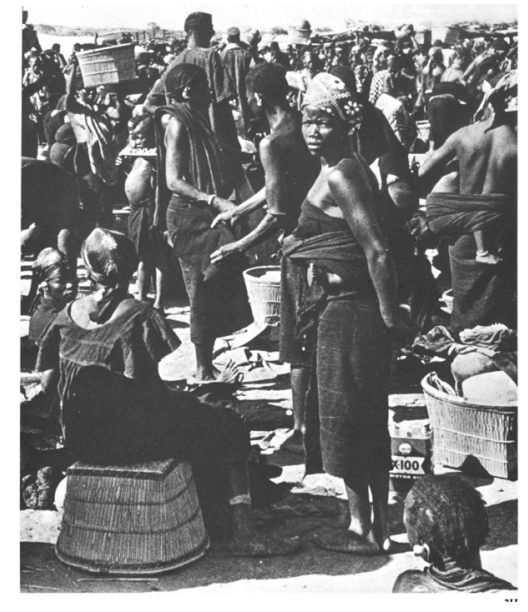

fig. 6-2 a photo of Dogon people published along side van Eyck's essay in the book Meaning in Architecture

1 Eisenman, "Aspects of Modernism," 124.

2 Teyssot, A Topology of Everyday Constellations, 154.

3 Ibid., 153.

4 Ibid.

5 Forty, Words and Buildings, 221.

6 Ibid. 
imitations of wooden structures" importance of the order in the design of any building.

$$
* * *
$$

Some of the post-modern attempts to counter Modernism and its universal dogma presented themselves as nothing more that romantic notions of the "noble savage" which itself was a Modernist notion. For instance, "Architecture without architects: A short introduction to non-pedigreed architecture" exhibition of 1964-5 at MoMA which was curated by Bernard Rudofsky ${ }^{8}$ set out to redeem the architectural quality of unknown places and forgotten monuments. For Rudofsky, vernacular is architecture because of its immutable and perfect adaptation to their surroundings. However, he is not concerned with the history, or story, behind the works he displays. He merely identifies their locality and why they fit into the show. Also, the attitude of a universal definition for vernacular architecture does not permit a detailed study of his subjects in the scope of an exhibition.

In "Architecture Without Architects," the aesthetic of vernacular is not defined through the aesthetics of primitivism ${ }^{9}$ as they project an image of a mode of life so different from our own. Here, vernacular happens in places that are serene, unchangeable and content, and man does his work through innate knowledge and unconscious intelligence.

\subsection{1 'MONODIC' (6)}

The 'monodic' idealism that is attached to the notion of 'primitive hut' enforces an 'eternal' and immutable image of an architecture unaffected by earthly concerns. Therefore, it comes to mean "the 'undisputed origin, genuine, done in the traditional or original way', it can also be that which is done 'in a way that faithfully resembles the original"'10 (like, the notion of making in the Platonic Idealism).

According to Robert Brown and Daniel Maudin, "the search for architecture's origins in the vernacular is a recurring theme in architectural theory where it appears as a notional primitive hut, a place of origin, rather than actual traditional buildings." In Indeed, the notion of 'primitive hut' (like the 'myth of balloon frame') has been "central to the construct of the notion of authenticity." In this instance, "The romanticizing of the primitive grants [any theory] an inherent dignity, unencumbered by the contingencies." Like Karatani's criticism of Plato's metaphoric architecture, Peter Blundell Jones argues that "an absolute sense of the authentic

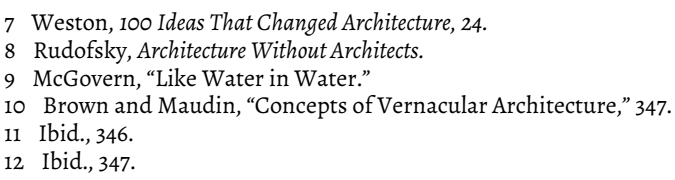


may be unobtainable, owing to selective manipulations of form, tectonics and meaning." ${ }^{13}$

In addition, as Robert Brown and Daniel Maudin propose, the issue of 'primitive condition' and vernacular is a topic that is "open to exploitation and the cultural value invested in regional architecture, historic or contemporary must be questioned." ${ }^{14}$ They further clarify the pitfall of such idealising the vernacular:

The association of traditional and neo-traditional building with peoples and places can quickly lead to questions of identity, with vernacular architectures appropriated as convenient symbols of national and sub-national identities.

Explaining this problem with the question of 'authenticity' and the 'primitive hut', Brown and Maudin further posit:

especially problematic when operating across boundaries, principally cultural but also geographic, economic, political, professional and social boundaries, arising from a tendency to presume that the cultural determinants that inform buildings are fixed and belong to specific social cultural groups; this is compounded by a propensity to look at other cultures as having 'internally consistent essences' [as] such ethnocentrism [...] may lead to misleading or reductive interpretations and conclusions. ${ }^{15}$
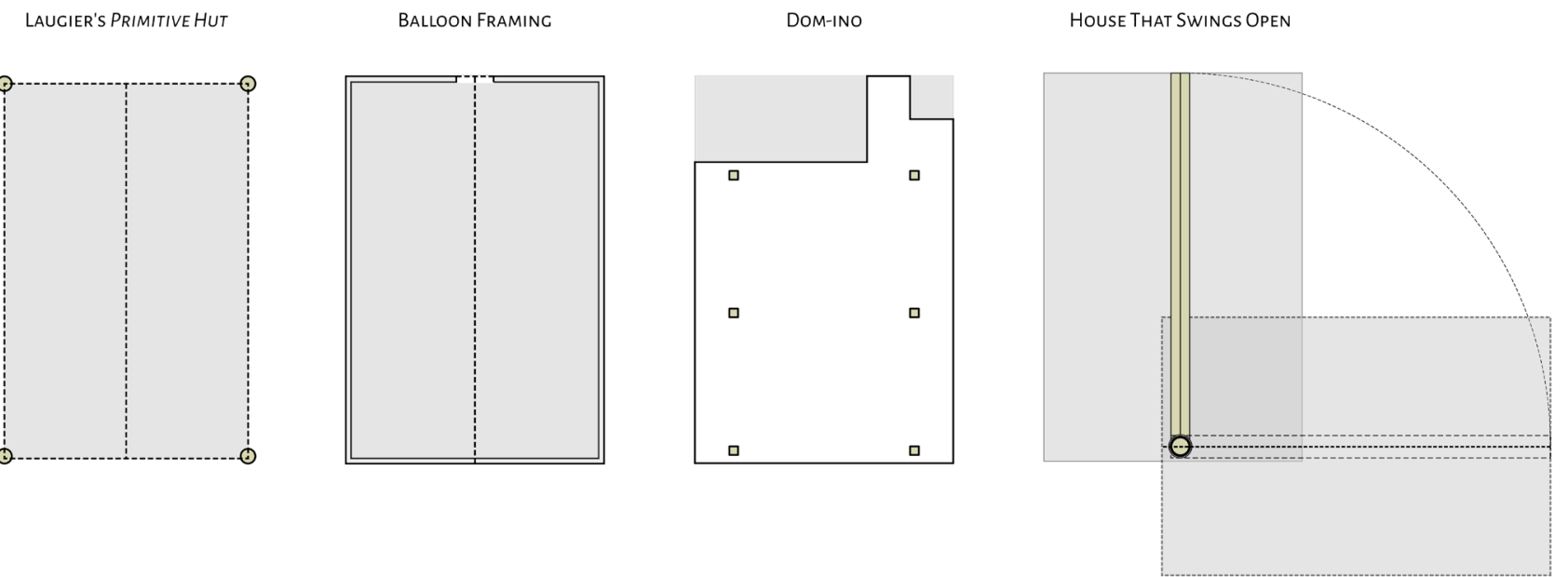

FIC. 6-3 HOUSE-THAT-SWINCS-OPEN-1 as a new beginning 


\subsubsection{HINGE (2)}

It is possible to assume that the HOUSE-THAT-SWINGS-OPEN-1 exists as a 'primitive condition'. This is not in the same sense that Eisenman or van Eyck have implied. More so, it has a 'primitive' condition because of the change in the sequences and the processes of construction.

To construct the HOSUE-THAT-SWINCS-OPEN-1, the hinge must be so powerful so it can support the whole of the house. Therefore, to build this house, the construction sequence does not start with the floor, subfloor, the wall, the roof and so on.

To build the HOUSE-THAT-SWINCS-OPEN-1, the hinge is constructed first, the walls are hung from its beam-like component and the floors are hung from its parachute walls. This change starts a chain reaction that revises the role and materiality of every other element of construction: the 'roof' is now carrying the 'walls' which are supporting the 'floors'. The first 'floor' is now off the ground.

In FLAT WORLD, the HOUSE-THAT-SWINGS-OPEN-1 looks normal but operates as a 'concrete irrationality' of a conventional house.

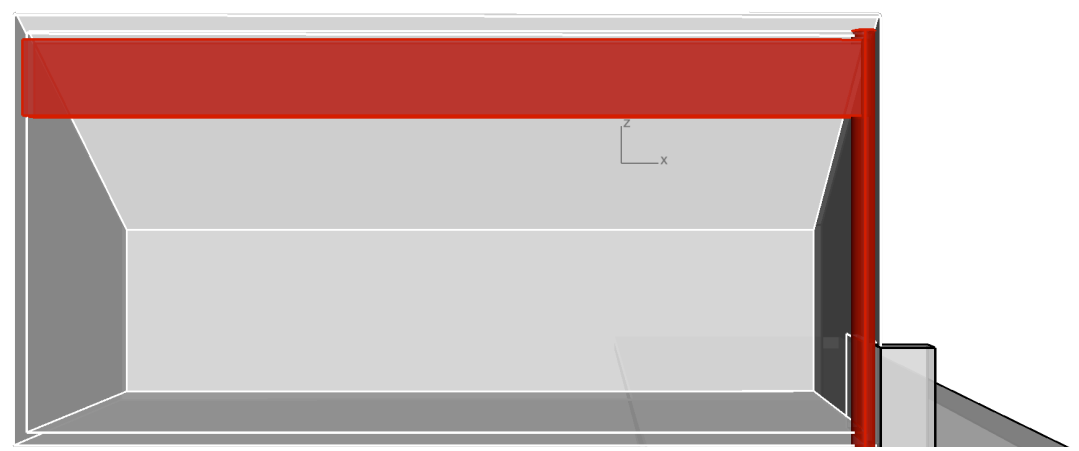

fig. 6-4 because of the hinge, the sequence of construction for HOUSE-THAT-SWINGS-OPEN-1 is very different from conventional methods. 
172 A Flat World for a Short Real 


\subsection{FLAT WORLD (2)}

THE HOUSE-THAT-SWINGS-OPEN-1 AND FLAT HOUSE WERE DESICNCONSPIRACIES THAT MADE USE OF THE THREE 'TACTICS' OF FLAT WORLDHYPOTHETICAL QUESTION, FlatTENING AND SECTIONINC. Also, itS CHANCE OF THE RELATIONSHIPS MAKES A NEW BEGINNING, OR A NEW DIRECTION, FOR DESICN.

THEREFORE, IT IS IMPORTANT TO EXAMINE HOW THE CRITICAL ASSESSMENT OF THE HOSUE-THAT-SWINCS-OPEN-1 CAN HELP US DEFINE A SET OF RULES FOR FLAT WORLD. THEN, IT IS IMPORTANT TO SEE HOW THESE CONSTRAINT (RULES) CAN FURTHER EXPOSE, CHALLENGE AND NECOTIATE THE CONSPIRACIES OF SHORT REAL.

$$
* * *
$$

IN THE 'UNIVERSE OF FORMS' (EISENMAN): OBJECTS HAVE 'ESSENCE'. OBJECTS ARE INTERPRETED BY MAN TO BE OBJECTS. OBJECT STAYS, MAN STAYS, EVERYTHING IS MODERN.

IN A 'PLACE' (VAN EYCK): OBJECTS ARE MORE THAN WHAT MEETS THE EYE. OBJECTS ARE OBJECTS BECAUSE OF WHAT THEY DO FOR MAN. OBJECTS STAY, MAN MOVES, OPPOSITIONS ARE RECONCILED.

In FLAT WORLD: EVERYBOdy IS AN OBJECT. MAN MOVE, OBJECTS MOVES, EVERYBODY MUST NECOTIATE.

$$
* * *
$$

THE FOLLOWING FIVE RULES ARE WHAT WAS LEARNED THROUGH ALL THE PREVIOUS PROJECTS. THESE RULES/CONSTRAINT/LEARNINCS WERE INSTRUMENTAL IN THE DESICN AND CRITICAL DIRECTION OF THE PROJECTS THAT FOLLOW THEM. 


\title{
6.3 RULE NO.1 OF FLAT WORLD
}

\author{
ELEMENTS OF CONSTRUCTION LIVE IN FLAT WORLD AS 'THE \\ UNCANNY'- 'CONCRETE IRRATIONALITY'- REFLECTION \\ OF HOW THEY ARE PERCEIVED TO BE IN SHORT REAL.
}

In FLAT WORLD, ELEMENTS OF CONSTRUCTION take on new personas. They become 'concrete irrationalities' or 'the uncanny' version of their counterparts in SHORT REAL.

In FLAT WORLD, where architecture is its ELEMENTS OF CONSTRUCTION, and those elements are only defined through their WORKINCS, ELEMENTS OF CONSTRUCTION might look like conventional elements but once we engage with them we realize that they are different.

In FLAT WORLD, when it is the house that swings around DOOR, all the operations of elements are only their workings, which they can interchange with each other.

The wall that is hung is now WALL, which is a parachute wall. The hinge is now the most prominent ELEMENT OF CONSTRUCTION that forms the structure of the house. It is now HINCE. The floor that does not rest on the ground is now SLAB. The roof that is hanging form HINCE is now ROOF. When it is the house that swings open, DOOR is WALL-LIKE, WALL is DOORLIKE and HINGE is BEAM-LIKE and COLUMN-LIKE. 
IN FLAT WORLD, WHERE IT IS THE HOUSE THAT SWINCS OPEN...

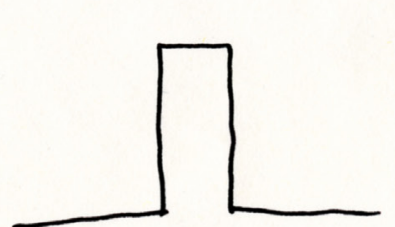

Door

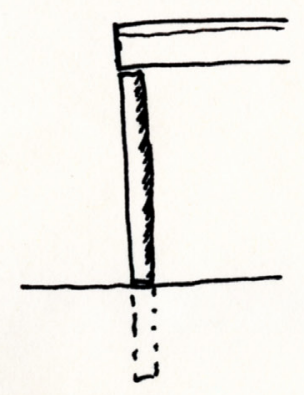

Hinge

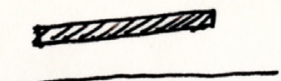

Slab

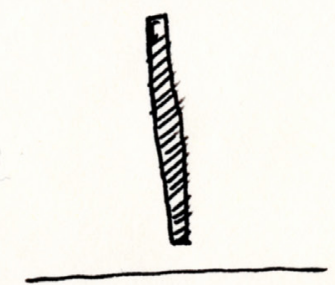

Wall
THE DOOR BECOMES DOOR.

Door has WALL-LIKE and DOORWAY-LIKE WORKINCS. It is the materialized version of the doorway and its 'threshold'.

Door looks like a door, but lacks conventional DOOR-LIKE WORKINCS.
THE HINGE BECOME HINGE.

Hinge has COLUMN-LIKE and BEAM-LIKE WORKINCS. For the most part, it retains its original HINCE-LIKE WORKINCS although it is now holding a house.
THE SLAB BECOMES SLAB.

Slab looks like a slab, but it is now floating. It has some odd WORKINCS which is unusual in architecture.

THE WALL OF BECOMES WALL.

Wall has some WALL-LIKE WORKINGS, like separation and protection. Yet, it lacks the typical feature that brings it to the ground.

As it stands above the ground, Wall now is more DOOR-LIKE. And, since it is hung from Hinge, it is also a parachute.

fig. 6-5 personas of elements of construction when involved in building the HOUSE-THAT-SWINGS-OPEN-1 


\subsection{RULE NO.2 OF FLAT WORLD}

\section{EVERYTHING IS AN ELEMENT OF CONSTRUCTION.}

In FLAT WORLD, ELEMENTS OF CONSTRUCTION are as capable as humans to change our perception about the realities of the built world. Since everything is FLATTENED, and design begins from a level field, even ELEMENTS OF CONSTRUCTION can possess the power to change the system at a fundamental level.

In FLAT WORLD, humans are also an element of construction. Abstract ideas and human-made concepts are also ELEMENTS OF CONSTRUCTION, if they can change and influence the mega-system that is architecture.

When it is the house that swings open, elements of construction can change their relationships as they exchange their WORKINCS.

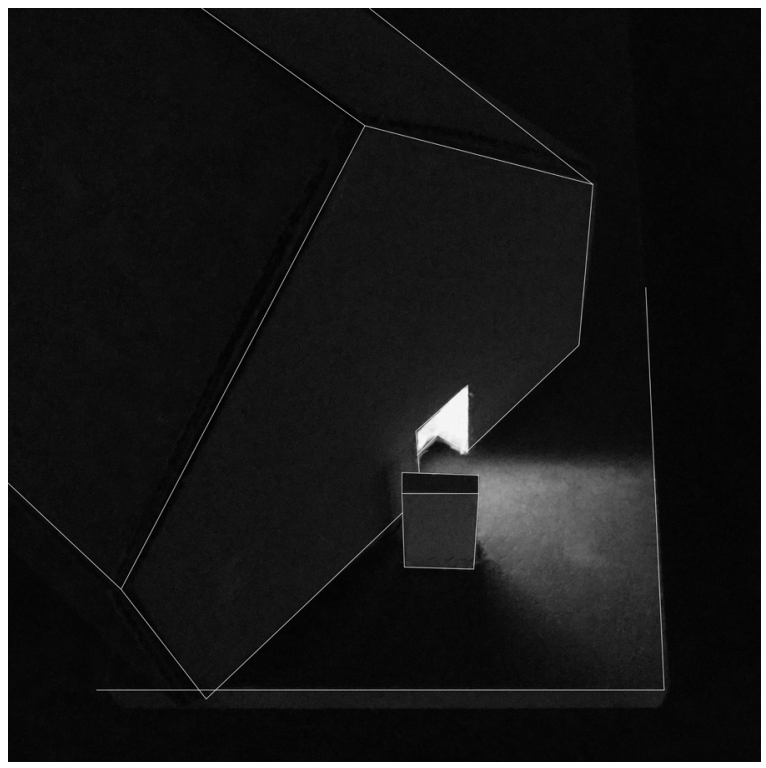

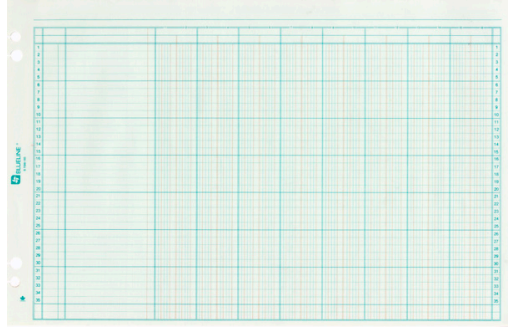

fig. 6-6 economy is an element of architecture.

fig. 6-7 light is an element of architecture. 
fig. 6-8 Sebastiano Serlio, Elevations for the City palace for the King

fig. 6-9 Sebastiano Serlio, House for bourgeois in the Italian and French manner
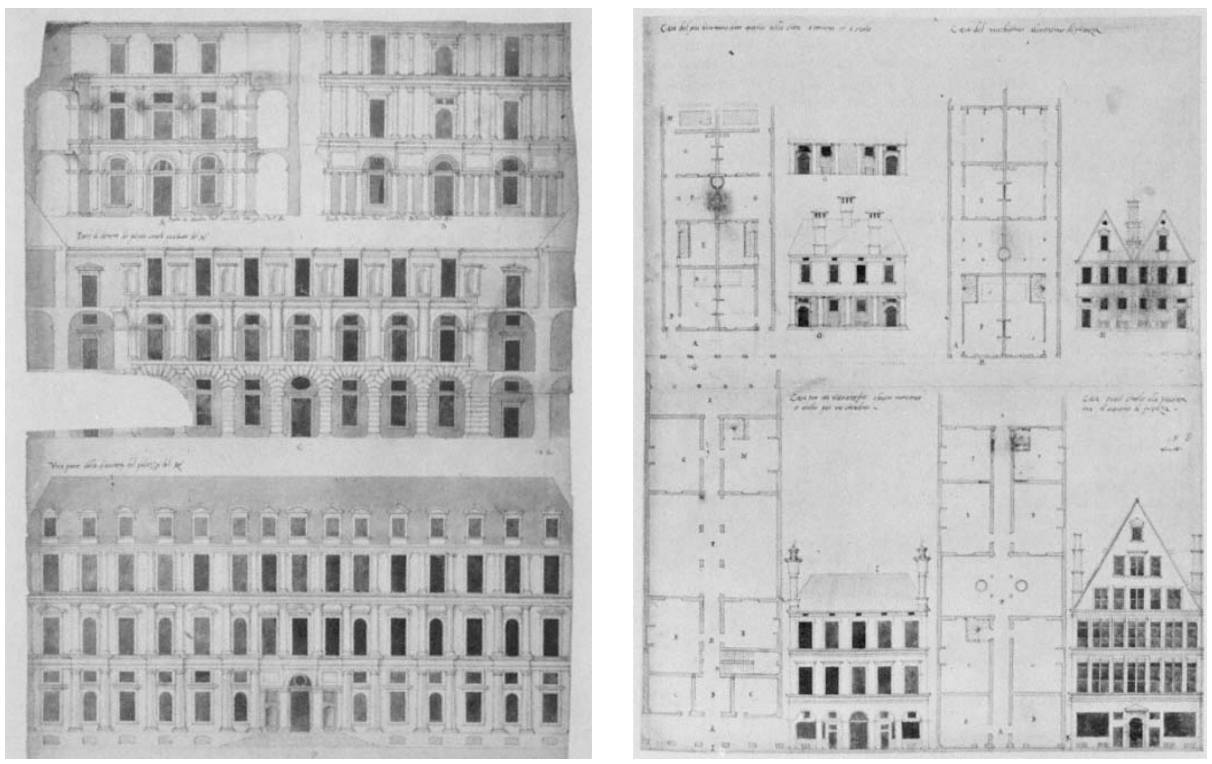

Renaissance architect, Sebastiano Serlio, would draw windows in the elevation of his buildings "as pure black voids." ${ }^{m 6}$ By doing so, he was "inverting the actual function of the window: neither a view in, nor, presumably, a view out is offered." There is a "philosophical lesson" in this representation "technique": "theoretically, windows function as openings to the inside, giving visual access to scenes of human activity. Yet before any actual inhabitation, they exist as pure potential, the interruptions that transform black wall into something that suggests inhabitation."

$$
* * *
$$

A closer look at Serlio's drawings reveals that the windows are not the only elements of construction that are blacked out. The doorway is also drawn in the same fashion.

Does this suggest any opening is a 'pure potential'?

But...

Are openings really 'voids'?

Could Serlio's technique suggest that even openings must be NECOTIATED AS PART OF THE MATERIALIZED REALITY OF ANY BUILDINC? 

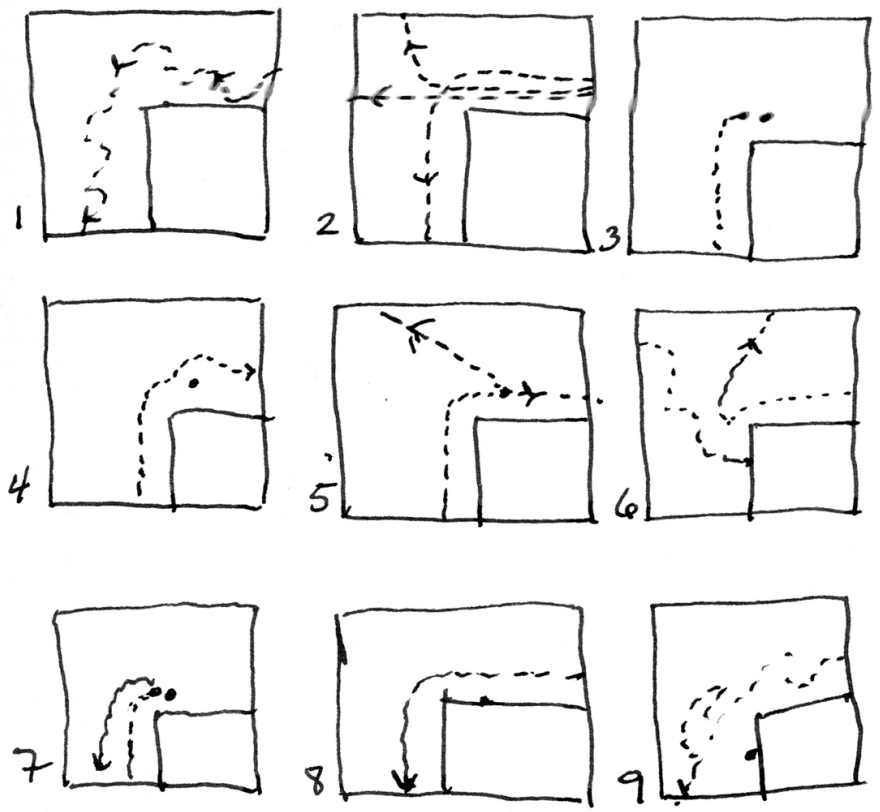

FIC. 6-10 NEGOTIATIONS:

Man-Dog-Bee

1. Bee alone.

4. Man avoids Dog.

7) Dog bites Man.
2. Man alone.

5) Man kicks Dog.

8) Bee sitting on the wall.
3) Dog standing, man arrives plays with Dog.

6) Bee scares Man.

9) Dog pissing on the wall. Man walks by. 


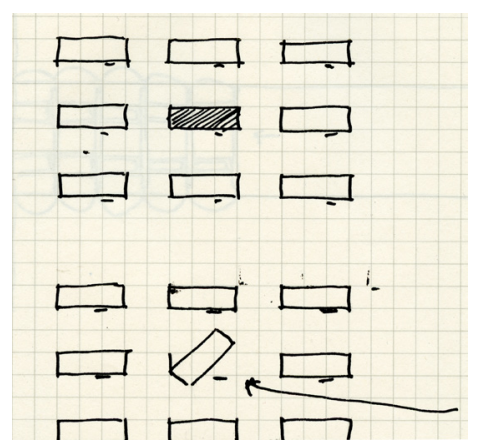

FIG. 6-11 NEGOTIATIONS at a community of houses that swing open

\subsection{THE COMMUNITY (2): DIPLOMATS}

WHAT IF, INSTEAD OF A LINEAR COMMUNITY (LIKE THE BLUELINE PARK) THE HOUSES WERE ARRANGED IN CLUSTERS?

Here, everything and everyone is FLATTENED. There is a perpetual tension between architecture and architectures, between user and users, between architectures and users. Here, architecture is political, its operation is diplomatic. This architecture is a social driver in the literal sense. This architecture is the source of both chaos and harmony, depending on how its users negotiate its operations. It is a paradox.

We must constantly NECOTIATE our spaces, our sequence of accessing our spaces. Regardless of our status, we are all bound by the same conditions. The experience of architecture is like a street corner. The sequence of arrival at the corner is often more important that the status or might of the ones who encounter each other there. fig. 6-12 a community of houses that swing open, plan

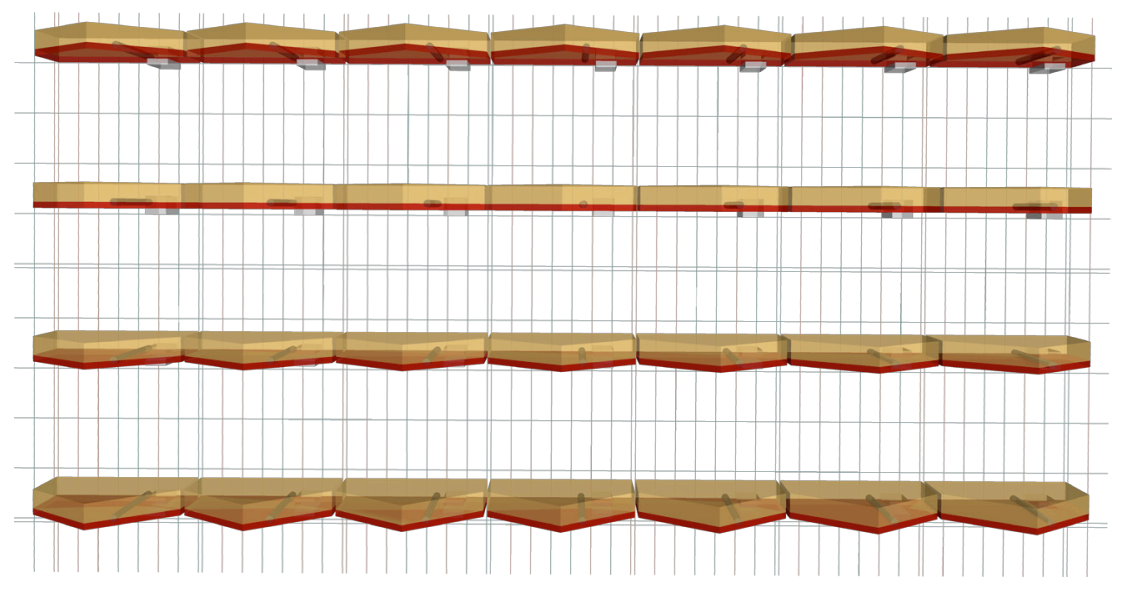


Here, the system is paradoxical. If some of the citizens arrive earlier on the site, they can close off access to a whole part of a grid, shutting off others from reaching their destinations. This is possible because when it is the house that swings open, and they are arranged in a cluster, the WORKINCS of the few houses together can act like a wall. Houses that are dwellings, can become walls that separate and divide.

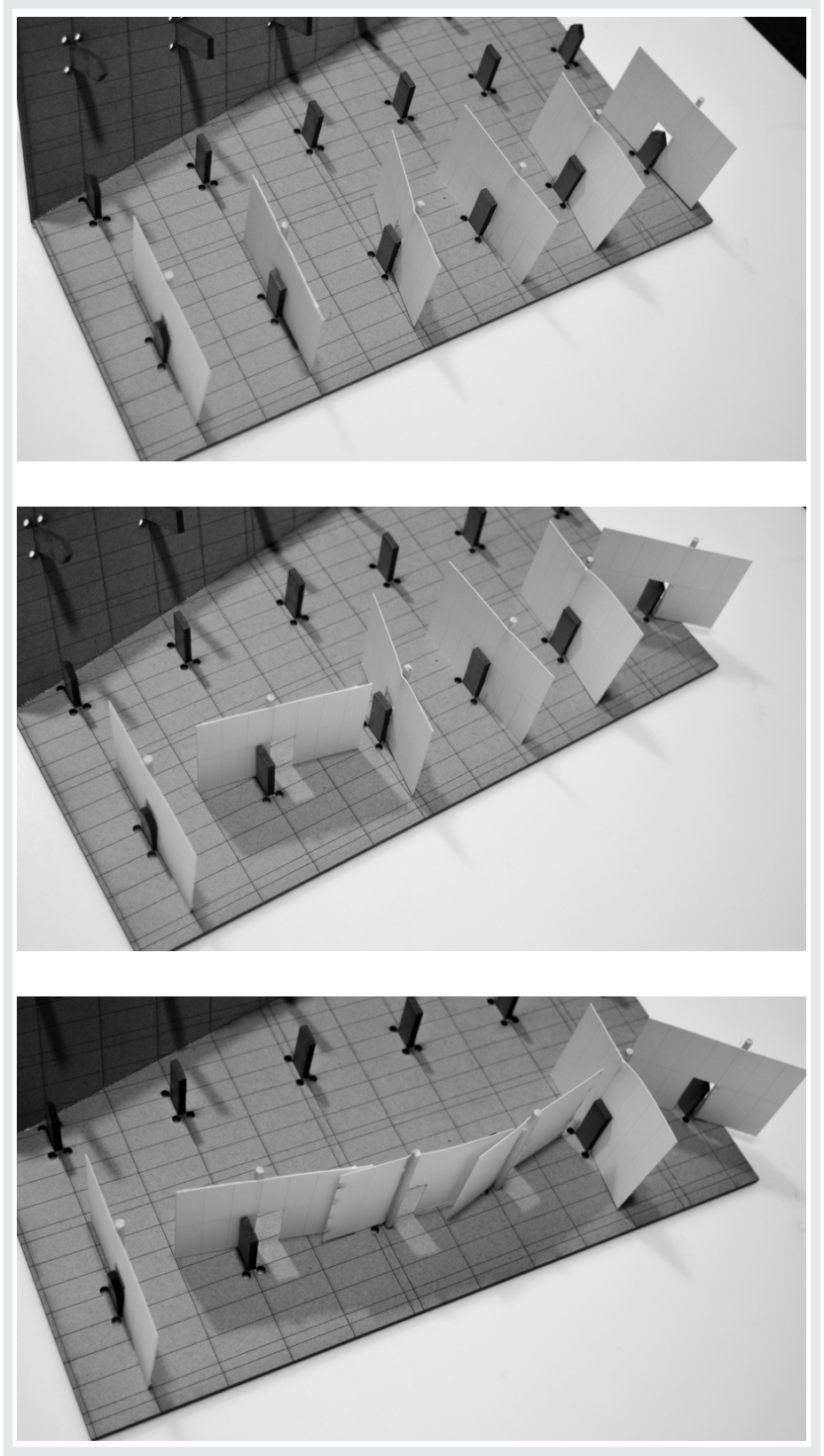

fig. 6-13 studies into the dynamics of a community made up of houses that swing open 
However, there is a catch: who ever attempts to use their house as a wall, must perpetually expose the inside of their home.

fig. 6-14 studies into the dynamics of a community made up of houses that swing open: houses that form a wall

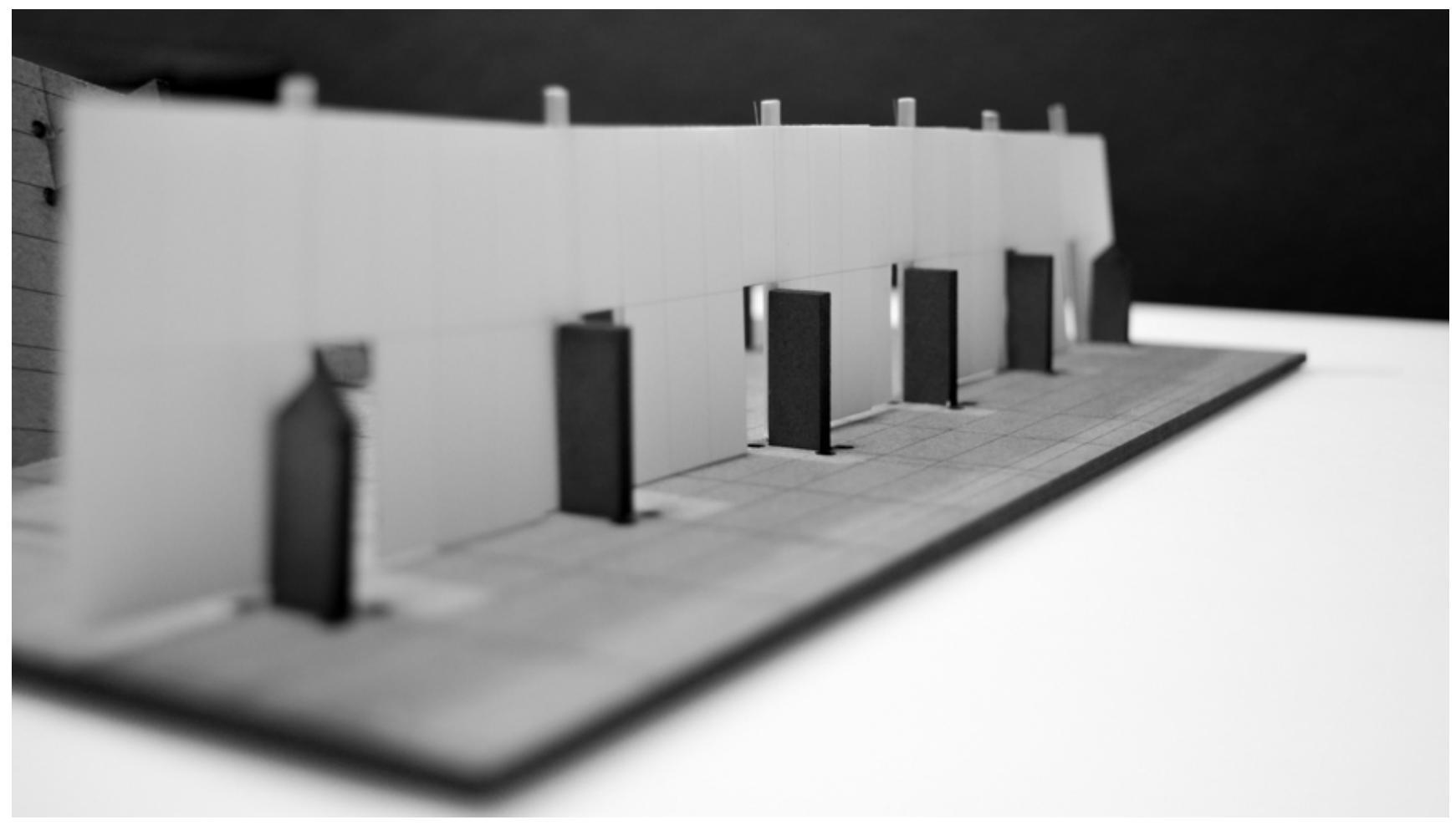


Here, in FLAT WORLD, and when it is the house that swings open, WORKINGS that denote isolation, separation or division are also made to be welcoming, vulnerable, and open.

HERE, THE WORKINGS OF THIS ARCHITECTURE IS ASYMMETRICAL AND DECEPTIVE. THAT IS WHY IT IS INFINITELY CONTINGENT.

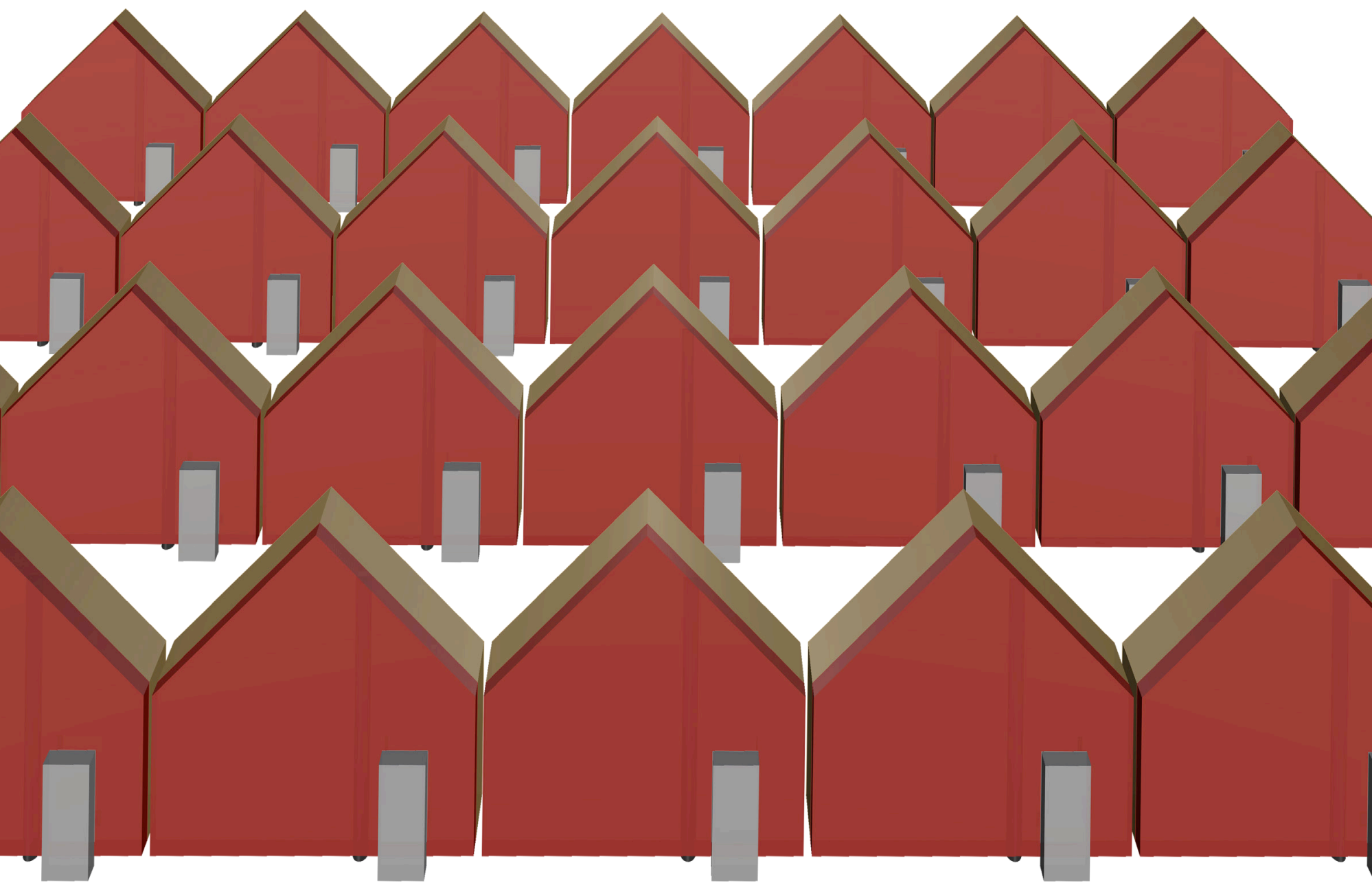


fig. 6-15 munition?

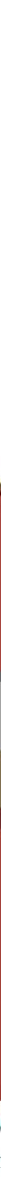




\title{
6.6 RULE NO.3 OF FLAT WORLD
}

\author{
ELEMENTS OF CONSTRUCTION ARE UNIVERSAL \\ BECAUSE OF THEIR WORKINCS.
}

ELEMENTS OF CONSTRUCTION HAVE NO 'ESSENCE'.

ELEMENTS OF CONSTRUCTION ARE NOT DEFINED BY METAPHORS.

ELEMENTS OF CONSTRUCTION DON'T TAKE SIDES IN BINARY OPPOSITIONS.

ELEMENTS OF CONSTRUCTION ARE NOT IDEALISTIC.

$$
* * *
$$

IN FLAT WORLD, THE ELEMENTS ARE ONLY KNOWN BY THEIR WORKINGS. A 'WALL' IS NOT AN ELEMENT BECAUSE IT HAS A 'WALLNESS' BUT BECAUSE IT HAS WALL-LIKE WORKINGS. ANYTHING THAT HAS SUCH WORKINCS CAN BE CALLED A 'WALL'.

IN FLAT WORLD, ARCHITECTURE IS THE SUM OF THE WORKINCS OF ITS ELEMENTS OF CONSTRUCTION.

"I believe fostering that architecture-to-be into real architecture itself is also architecture." ${ }_{17}$

- Sou Fujimoto

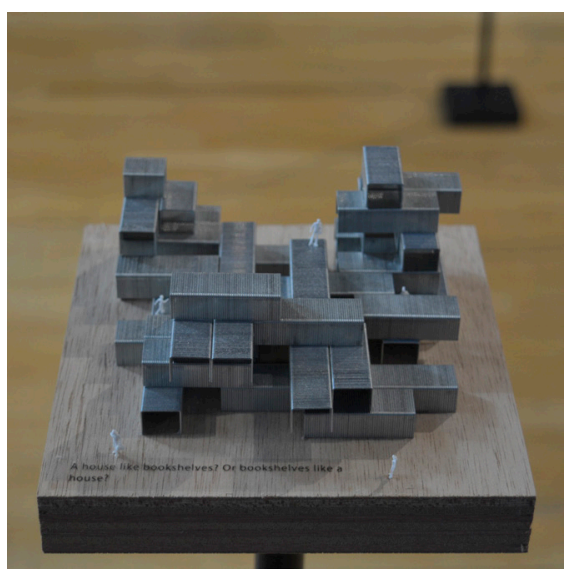

fig. 6-16 Sou Fujimoto, Everything is Architecture 

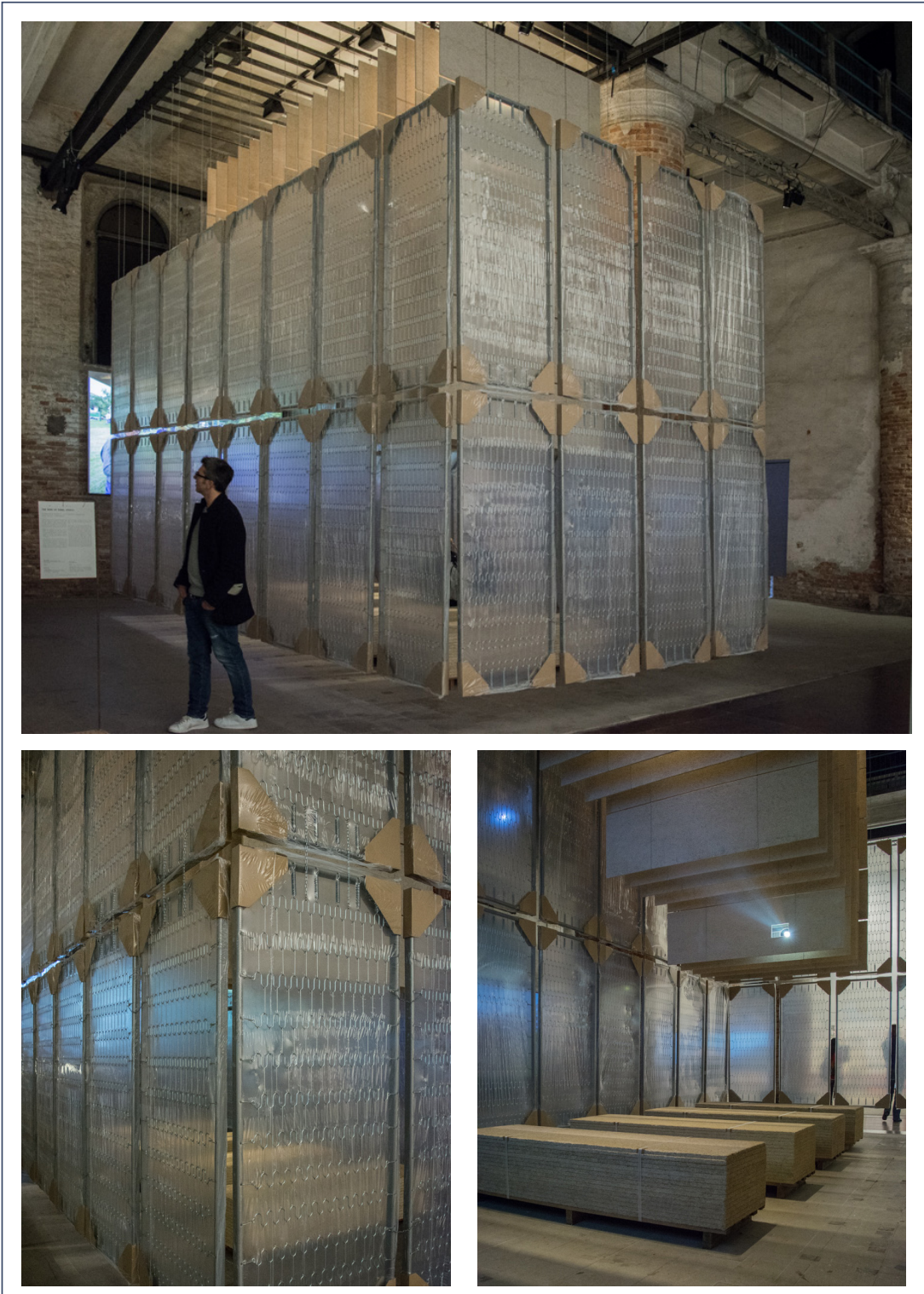

fig. 6-17 Rural Studio, The Theathre of the Useful "the act of hanging turns a bed into a wall and so on: this is an architectural change." ${ }^{\prime 18}$

—Alessandro Zorzetto, Domus, 26 Oct 2016

18 Zorzetto, "The Theatre of Useful." 


\subsection{1 'SPACE-PLACE OPPOSITION'}

As Adrian Forty observes, the prevalence of 'place' in the discourse in the 1960s related to very specific philosophical concepts that grew out of the discourse of Martin Heidegger; whose definition of 'space' was unlike any other definition that had persisted in the discourse of architecture. ${ }^{19}$ For Heidegger, 'space' was "unmeasurable and non-quantifiable." Most importantly, Heidegger's concept of 'space' was "addressed to philosophy"21 and not architecture. Nevertheless, for van Eyck, as Teyssot remarks, 'Space and time, created 'in the image of man' become place and event." ${ }^{22}$ As Adrian Forty quotes Aldo van Eyck:

I arrived at the conclusion that whatever space and time mean, place and occasion mean more, for space in the image of man is place, and time in the image of man is occasion. Split apart by the schizophrenic mechanism of determinist thinking, time and space remain frozen abstractions."23

The main aspiration for van Eyck and others (like von Meiss) to use the concept of 'place' is its humanistic implications. Unlike the concept of 'space' that for some of the avant-garde denoted an abstract concept, ${ }^{24}$ 'place' was something that could be understood in human terms.

Like the 'form-function' opposition, or the metaphor threshold ('threshold'), the concept of 'space' as "the purest, irreducible substance of architecture,"25-as the mark of its GENIUS "that sets it apart from all other artistic practice" - "did not exist in "the architectural vocabulary until the 1890s."

As Adrian Forty explains, the ambiguity" surrounding the concept of 'space' in the discourse of architecture relates to "a willingness to confuse it with a general philosophical category of 'space'." Like, 'form', 'threshold' and other metaphors that are borrowed from philosophy without due diligence, 'space' as a 'philosophical category' can pose a problem in thinking about architecture. As Forty explains:

as well as being a physical property of dimension or extent, 'space' is also a property of the mind, part of the apparatus through which we perceive the world. It is thus simultaneously a thing within the world, that architects can manipulate, and a mental construct through which the mind knows the world, and thus 
entirely outside the realm of architectural practice (although it may affect the way in which the results are perceived). ${ }^{26}$

The main problem of the concept of 'space' is the belief that "architects 'produce' space." Indeed, the introduction of the term 'place' by Aldo van Eyck in the 1950s served as an oppositional term for van Eyck to frame his "critique of the International Style"27 and its emphasis on the concept of 'space' as "the primary 'material' of architecture." ${ }^{28}$ The challenge in justifying the position taken in 'space-place' opposition is the fact that both the concept of 'space' and 'place' are philosophical metaphors that have colonized the discourse of architecture.

This distinction can relate back to the notion of 'autonomy' discussed earlier. The fact that although it is impossible to create an 'autonomous' building, it is permissible to assume that some buildings might find 'autonomy' in themselves. ${ }^{29}$ Therefore, the assumption that architects produce 'spaces' is as idiosyncratic as thinking that a 'self-referential $\operatorname{sign}^{\prime 30}$ can produce itself.

As Paul-Alan Johnson explains-like remarks by Christopher Wood and an autonomous architecture-it is not possible to build a 'place', but it is admissible to assume that some 'spaces' could become 'places' after they are built:

Indeed, the concept of place may forever elude architects as a predictable field because, like much design feedback, its recognition is always too late, and architects already teeter on the edge of the 'naturalistic fallacy' of projecting what ought to be from what is. ${ }^{31}$

As Johnson holds, unlike "moral philosophy"32 that refrains from engagement with "naturalistic fallacy, architectural thought has been projecting worlds of what ought to be from what is (or is not)."

\subsubsection{A HUMANIST CONSPIRACY}

In approaching a door, there is a universally learned operation that facilitates all the humans who engage with it. A Chinese man in a French designed building in Africa would not have any problem using a door. In this case, the door is not a universal code or sign. It is rather a universally operated architectural object. On the other hand, when the door is believed to be a 'threshold', as something that happens in the mind, the 'Histories' of those who engage with it also engage with the door, which poses a challenge. 
One question remains: when the HINGED-DOOR-LEAF (the door) is a 'threshold' is its designation understood by all people the same way? Is the door that is a 'threshold' an ELEMENT OF CONSTRUCTION that all people from all cultural backgrounds can engage with symmetrically (understood Ideally from both sides)? The answer to this question lies in the anthropological beginnings of the door (and other ELEMENTS OF CONSTRUCTION) that were designated as 'thresholds'; in a process that Georges Teyssot refers to and "anthropologization" of the discourse in the 1960s.

For van Eyck and von Meiss, 'threshold' as the 'place' of 'in-between' entails "the idea" ${ }^{33}$ that any "place originates in conventional activities and behaviour linked to conceptual schemes of memorable spatial situations." This proposal means that in a 'place' (and 'thresholds') there exists a "congenital condition of intuition, or archetype" ${ }^{34}$ that is shared by all humans-a universal "human psyche" 35 that is expressed through a "typology that seeks to comprehend the fundamental and structural characteristics of a built fabric." ${ }^{36}$ As a result, architectural "forms are associated with the events" that they accommodate "or once accommodated," which is not context-specific but is rather universally transferable between "other similar places and events." ${ }^{37}$ These conceptions of 'place' means that the concept of 'place' is about a sense of universal absolutes against the "confused immensity of the universe" which requires that "certain portions of space assume the value of place." ${ }^{38}$

$$
* * *
$$

But, are all 'places' similarly understood by all people?

If 'thresholds' are universal, do they share the same events?

Are some events better than others?

\subsubsection{AN ANTHROPOLOGICAL FALLACY}

Aldo van Eyck built his "theory of threshold" on the philosophy of Martin Buber. In turn, Buber had come to designate the door and the threshold to his philosophical ideals through the writings of "early-twentiethcentury" ${ }^{39}$ anthropologists like Arnold van Gennep.

Through the reliance on these anthropological analogies, for Buber and van Eyck, 'threshold' became a vehicle to assert a universal "human psyche." Yet, the anthological views that were the basis for these ideals where drawing on "a biased manipulation of French and German historians during the late nineteenth century." ${ }^{40}$

33 Meiss and Hakola, Elements of Architecture.

34 Teyssot, A Topology of Everyday Constellations, 167.

35 Ibid.

36 Meiss and Hakola, Elements of Architecture.

37 Ibid., 193.

38 Ibid.

39 Teyssot, A Topology of Everyday Constellations, 162.

40 Ibid., 159. 
fig. 6-18 The Family of Man, Museum of Modern Art, exhibition view,

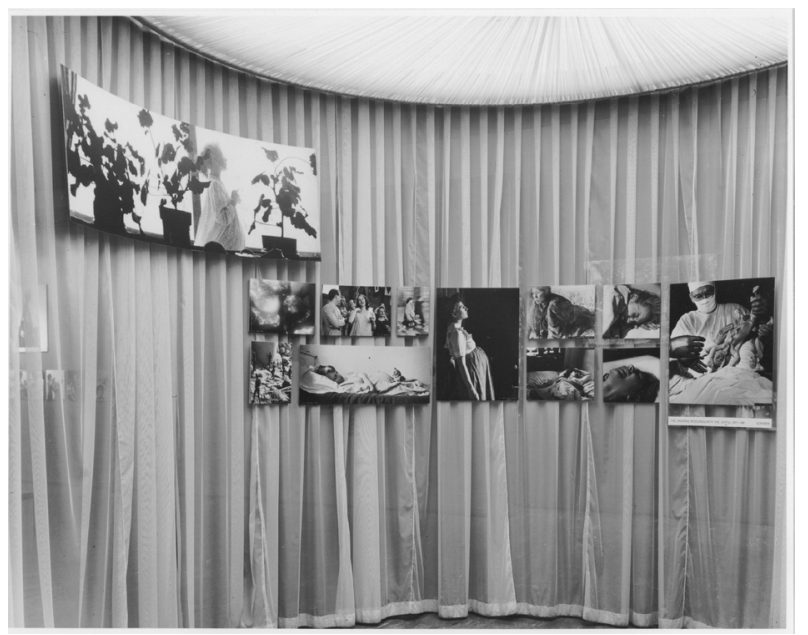

There is also a spiritual dimension to Buber's philosophy that presents an Idealistic definition for 'threshold'. As George Teyssot explains, Buber used a "respiratory metaphor" ${ }^{41}$ to denote the "intersubjectivity" of "communication between human beings." This metaphor insisted on a reciprocity between those involved in a dialogue like breathing, which allowed van Eyck to propose "that, like man himself, the in-between must 'breathe both in and out'."

However, as Georges Teyssot argues, since "man," ${ }^{42}$ and architecture, deal "with the real world," there must be a contingency for "the possibility of a separation between the individual and the whole." ${ }^{43}$ Buber and van Eyck fail to distinguish "how a state of relation" between people and objects "differs from a state of consciousness." There is no indication if this 'in-between' is a "relationship" in the real world, with all its complications, or "an idealistic" form of "pure conscience." Teyssot remarks that "With van Eyck, as with Buber, one has a sense of dissatisfaction with the definition of the in-between, as it fluctuates from the physical realm of things to the subjective domain of meeting places for people." ${ }^{44}$

\subsubsection{IDEALISM (2)}

The 'threshold is not an isolated 'mythology' unique to architecture. Indeed, in the 1950 s and 1960s, there were various cultural and artistic endeavours that asserted the existence of a universal 'human psyche', 'traditional forms' and a "human essence." ${ }^{45}$ For these works, beyond the "superficial diversity" that is visible to us hid an immutable and "a 
universal human nature." ${ }^{46}$ As a cluster of similarly idealist/essentialist views, the general critique of some of them seem to also apply to the concept of the 'threshold'

$$
* * *
$$

In his criticism of the exhibition The Family of Man, Roland Barthes notes that the "original" title was translated in France as "The Great Family of Man." For Barthes, if the original title denoted "what could [...] pass for a phrase belonging to zoology, keeping only the similarity in behaviour, the unity of a species," the French translation transforms it to something as "aptly moralized and sentimentalized." ${ }^{47}$ This change of terms further propagates a 'biased' interpretation of what he calls the "ambiguous myth of the human "community';" ${ }^{8}$ where, a "pietistic intention [...] aims to suppress the determining weight of History." ${ }^{49}$ For Roland Barthes, the "universal facts" like "children are always born" is not enough to assert universality amongst various 'Histories':

Whether or not the child is born with ease or difficulty, whether or not his birth causes suffering to his mother, whether or not he is threatened by a high mortality rate, whether or not such and such a type of future is open to him: this is what your Exhibitions should be telling people, instead of an eternal lyricism of birth..$^{50}$

Similarly, in constructing the notion of 'in-between', Buber connected theological and spiritual metaphors to things that could only denote 'similarities in behaviour'. Yet, his biased interpretation renders simple 'temporal fallacies' of similar actions and instances into universal concepts with 'pietistic intentions'. 


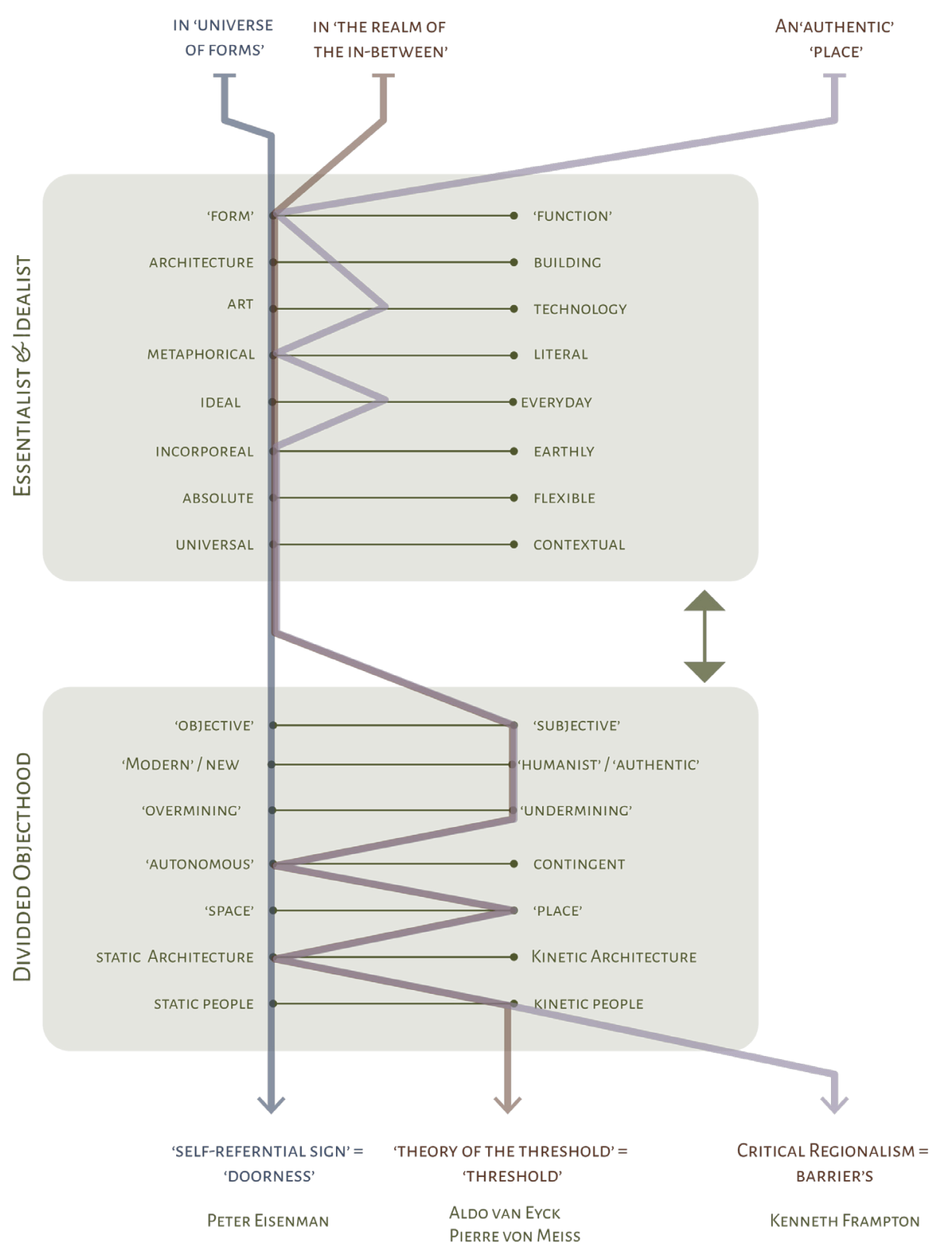

fig. 6-19 how 'doorness', the 'threshold' and critical regionalism connect to each other in SHORT REAL 


\subsection{5 'MONODIC' (6)}

The distinction between why a door (as a universally recognized element) can differ from 'doorness' and the 'threshold' (as universally implied idealisms) is an important one. For the 'threshold', this problem is exacerbated when it's association with the concept of the 'place', and the discourse of Martin Heidegger, is considered.

There is a 'monodic' aspect to the concept of 'place' that arises from the misreading of Heidegger's discourse on 'space' and 'dwelling'. In recent times, those influenced by van Eyck and the concept of 'place' have called for 'authenticity' and 'regionalism' to defuse and mend the destructive universality of Modernism. As Adam Sharr explains, "Where Heidegger's romantic provincialism is absorbed uncritically, it can allow right-wing ideologies to flourish." ${ }^{11}$

In developing his ideas of critical regionalism, Kenneth Frampton relied on the philosophy of 'Heidegger' as way to "redress the asymmetry between building and architecture." 52 Unlike Eisenman who saw the 'selfreferential sign' as a leveler between humans and objects in the world, Frampton argues for the reinstating of the same 'humanism' that places man at the centre of the world (Frampton pays an homage to van Eyck for designating the "production of place"s3 as a way to reinstate the "timelessness of man”).

In the opening segment of "Towards a Critical Regionalism," Frampton includes an excerpt from Paul Ricoeur's History and Truth. According to Ricoeur, the "advancement of mankind" 54 that is present in "the phenomenon of universalization" constitutes a "subtle destruction" of "not only of traditional cultures" but also of "the ethical and mythical nucleus of mankind." Therefore, as Ricoeur argues, to combat the forces of this 'phenomenon' means saving "the great civilizations of the past" and countering the "basic consumer culture" that has endangered "the old cultural past" that "has been the raison d'être" of any "nation."

As Neil Leach proposes, these ideologies discount the adaptability of humans and rather focus on the fragility of traditional culture in accepting modernity and technological development. This is a position that is repeated by others. If the main attribute for critical regionalism is to combat the rampant consumerism of the universal capitalism, their choice of concepts seems ironic. According to Neil Leach (drawing on Fredric Jameson and his critique of capitalism) the call for remaking of differences between 'places', "can be seen to be a product of the 
market." ${ }^{55}$ The postmodern call for "authenticity" ${ }^{56}$ is nothing more than a "nostalgic myth" that possesses "something of the inauthenticity of Disneyland." 57

As Keith Eggener elaborates, there is a "central paradox" 58 to Frampton's theory that as "a binary opposition" which inevitably partakes in a call for a "universal civilization." It seeks to prescribe a way "to become modern" while reviving the "old dormant" ideals of yesteryear. Must like Disneyland, the affectual 'critical regionalism' mirrors the attitude of modernism towards the vulgar commercial landscape that Learning From Las Vegas criticized: "Modern architecture has not so much excluded the commercial vernacular as it has tried to take it over by inventing and reinforcing a vernacular of its own, improved and universal." 59 


\title{
6.7 RULE NO.4 OF FLAT WORLD
}

\author{
WHEN NEGOTIATED, CONVENTIONS ARE NOT \\ NEGATED OR ERASED. THEY ARE DISPLACED.
}

\subsubsection{THE DOORFRAME}

In the HOUSE-THAT-SWINGS-OPEN-1 and FLAT HOUSE, the wall was a parachute and became WALL. Also, the slab was floating, because when the wall is a parachute the slab can move up and down. So, the slab became SLAB. When the wall is a parachute and the slab moves, what holds SLABS from dropping on each other (like pancakes) is the doorframe. When the slab floats, the doorframe is a slab-stop. This revelation opens a Pandora's box of other possibilities.

For one, why is the doorframe is more like a wall than a door? It seems the doorframe is not made for the door, but is make for the aperture in the wall (the sick wall).

SO, WHY IS EVERYTHING THAT IS ASSOCIATE WITH THE WALL ATTRIBUTED TO THE DOOR?

The doorframe is there so the hinge can mediate the relationship between the wall and the door. The doorframe is also there to protect the wall from crumbling down. Since before we can place a door in the wall, we must first create an opening in its surface. Once that opening is made, what prevents the wall from falling is a lintel.

But, in our modern world, where the wall is constantly made thinner, there is no place for a lintel anywhere. Most of the time, the lintel is also the slab, since the openings are floor-to-ceiling.

Here, the doorframe must take on a COLUMN-LIKE working. It now holds the wall and the door. Although, the doorframe and the door share the same words, the doorframe is made to preserve the integrity of the wall.

\subsubsection{THE THRESHOLD}

Like the doorframe, and its duty to preserve the integrity of the wall, the 'threshold' belongs to the wall as a way to protect our integrity. The 'threshold' (the metaphor) was a word borrowed by philosophers from 
fig. 6-20 the rite of 'The First Furrow'

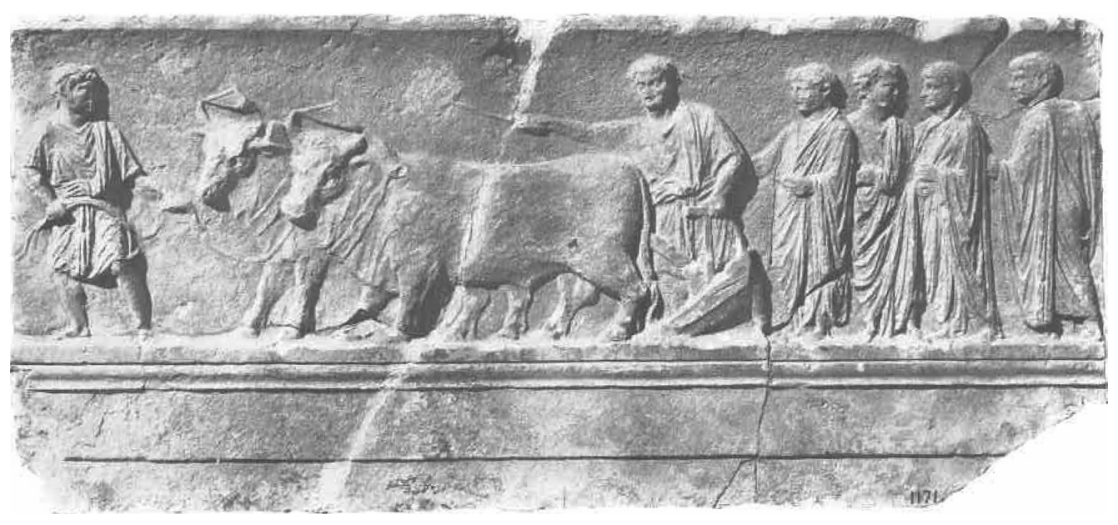

the vocabulary of architecture and its ELEMENTS OF CONSTRUCTION. But, the threshold (the element) is not made for the door either. It is there to ensure that the HINCED-DOOR-LEAF acts like a wall when it is closed. The threshold (the element) ensures the bottom of the door is always closed, when the door is meant to be the device that temporarily protects us.

\subsubsection{THE DOOR (8)}

The door-HINGED-DOOR-LEAF-can never be a 'threshold' because its construction and perception is asymmetrical; even though its WORKINCS are understood universally. A door is never absolute. It is never completely open or completely closed. In fact, for the most part, a door is only opened half-way before someone can pass through its temporary aperture. Unlike 'doorness' (that needs a 'sufficient' condition) or the 'threshold' (that needs to be interpreted subjectively), the door is architecture by itself.

\subsubsection{THE WALL (4)}

If everything that is philosophically attributed to the door belongs to the wall, why do philosophers and architects still associate the door with the 'threshold' (or 'doorness')?

$$
* * *
$$

The HINGED-DOOR-LEAF (the door) has changed "remarkably little"60 since the first time it appeared in our buildings. On the other hand, the wall has been in constant flux since day-one. For instance, the Egyptians used the wall to create "monumental effect" ${ }^{11}$ in their architecture. On the other hand, for the Greeks, "walls" were not the primary element of their architecture as they used "columns" to give 'order' to their architecture. Later, the Romans, like Egyptians, came to use the wall as the primary means 


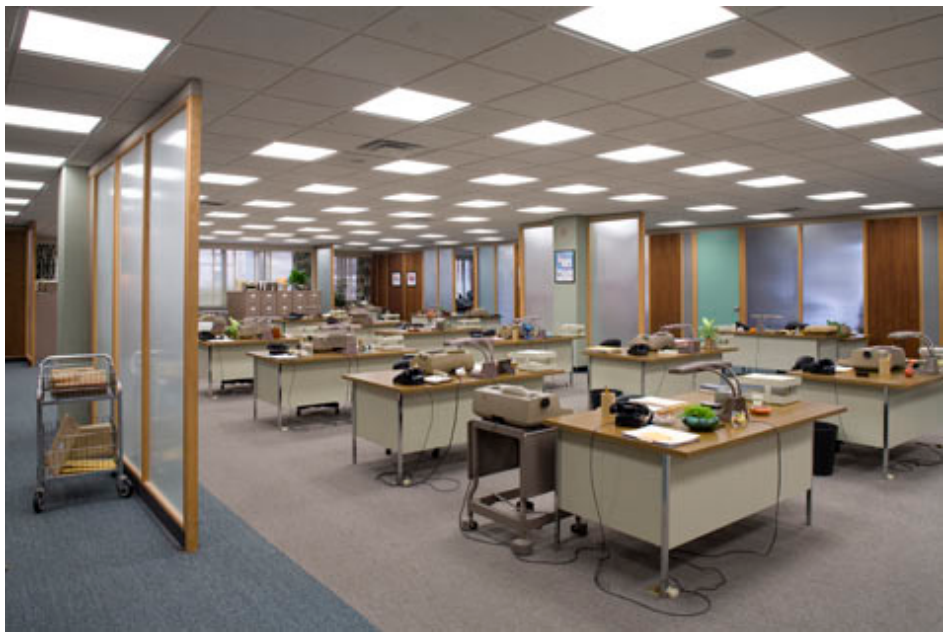

fig. 6-21 in modernism, it is the doorframe the holds up the wall. (set from Mad Men television series)

for "enclosing" their buildings. During the $15^{\text {th }}$ century, the importance of the wall shifts back and forth as the interest in different classical periods changes. Finally, in our time, thanks to Modernism, the wall became thin, transparent or completely dematerialized. It became so thin that it cannot possibly have a door to mend its aperture.

If any ideology (with 'monodic' aspirations) seeks to establish a universal and symmetrically understood concept, it would be wise to ignore the wall and choose the door. After all, the HINCED-DOOR-LEAF (the door) appears in almost every culture with very little change in its WORKINCS.

Although the 'threshold' (metaphor), the threshold (element), the doorframe and the doorway belong to the wall, to make their ideas of 'doorness' or 'threshold' universal, the likes of Eisenman and van Eyck had to choose the door and its undisputable history as their representative.

\subsection{5 'PORTARE'}

One of the reasons why the door, 'doorness' and 'threshold' have been linked together is the linguistic underpinning of their conceptions. One story is related to the etymology of the Italian word for the door.

According to Joseph Rykwert, in Roman times, when founding a new city the chieftain and his followers gathered around a desired spot and "ploughed around the site of the city." ${ }^{2}$ The plow, drawn by a "ox and cow," would project the boundary of the future city onto the ground. When it reached the place of the future gates of the city, the plow was taken "out of the ground and carried [...] over the span of the gate." This action of carrying the blade of the plow for the length of the future 
opening to the city was "portare;" which, "is the root of [the Italian word for the door] porta, a gate."

As Rykwert recounts, the boundary established by the furrow was "sacred," ${ }^{63}$ which meant that the walls that were built on the lines dug into the earth by the plow were also "sacred, while the gates were subject to civil jurisdiction." In other words, the walls were considered universal, while the doors where contextual. Therefore, if there is any sacredness to 'threshold' it belongs to the wall, or more aptly, to the projected line of the furrow that gives the wall its right on the land.

The act of 'portare' and its etymological kinship to 'porta' does not mean that they are the same thing, and that the door is the 'threshold' and as a 'place' that is necessarily a pleasant and neutral location. In fact, the sacredness of the city walls and the distinction between what falls outside of the line of the furrow to what resides inside that line could suggest that 'threshold' and 'place' are more about control. According to Rykwert, during the tracing of the boundary- 'First Furrow'-- when "any earth happened to fall outside the furrow" ${ }^{64}$ the people would "pick it up and throw it inside the city boundary."

It is possible to suggest that The First Furrow was the beginning of 'threshold' through its association with the concept of the 'place' and the discourse of Martin Heidegger who viewed the 'threshold' as the "boundary into a 'place' cleared for settlement."

\subsubsection{THE DOORWAY}

The 'threshold' (and 'doorness') belong to the wall. But, it is not the materialized part of the wall. The 'threshold' as something that happens in the mind (the 'sufficient condition') that is the part of the wall that is missing. It is immaterialized wall that is the 'threshold'. It is the doorway that is a 'place' of the 'in-between'.

However, as much as the door is about negotiations and asymmetrical fairness, the doorway is about control and possessiveness. What the doorway projects is 'order' in its most dangerous form: as an image of an idea. A doorway is a blueprint for order without any material to NECOTIATE it. The doorway is the HINGED-DOOR-LEAF negated, subverted and weaponized, and "the more [we] abandon the physical, the more [we] surrender to an Orwellian, insidious situation."

The real 'threshold' (the applied metaphor) is about control. It is a 'sick wall' that is made whole again as something that 'happens in the mind'. It is an imaginary door. 
The door is about NECOTIATIONS, and its workings are asymmetrical. On the other hand, the doorway is seemingly asymmetrical in its construction, but its meaning is meant to be understood symmetrically. That is why when it comes to doorway, like any social contract, "The strongest [...] is never strong enough to be always master, unless he transforms strength into right, and obedience into duty." ${ }^{67}$

Not surprisingly, at places that require the most amount of control it is not the door that is in place but a doorway. It is easier to control an imaginary wall-a 'threshold'-than that it is to 'man a door.'

The doorway, like the 'threshold', represents the philosophical ideal of a 'dialogue'. With the doorway, there are only two directions available to us: 'in' or 'out'. Therefore, as a 'threshold', the wORKINCS of the doorway is comparable to the window. The doorway allows our bodies to pass through the two surfaces of the wall, which is unlike a window. But, like a window, its WORKINCS are binary: there are only two view frames available to us: going out or coming in.

The door, on the other hand, as it opens it reveals multiplicity of views and depths of perception. To operate the door, one must move with their body, changing perceptions and views as they do it. With the door, it is impossible to be an idealist. 
fig. 6-22 inherent binary oppositions in the rite of first furrow

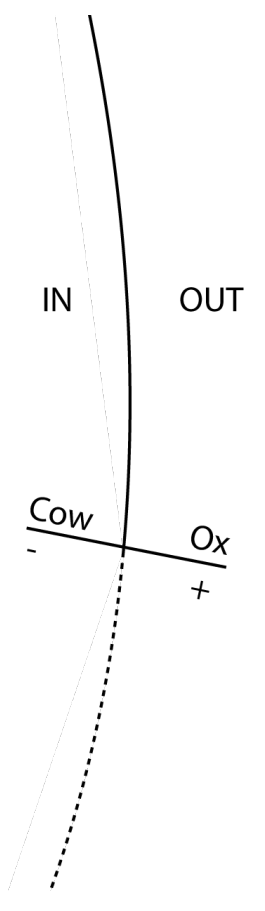

The use of two different animals could have had an empirical beginning. The natural difference between their strength and pulling power would have meant that the line-in-the-sand would gently curve to close the circle. In fact, the placement of "the ox on the outside of the boundary, the cow on the inside" ${ }^{168}$ can suggest such rationalization. On the other hand, cows are domesticated animals bred for their usefulness to produce milk, while ox are used for heavy work. In this case, ox are castrated which makes them easier to control by human. 


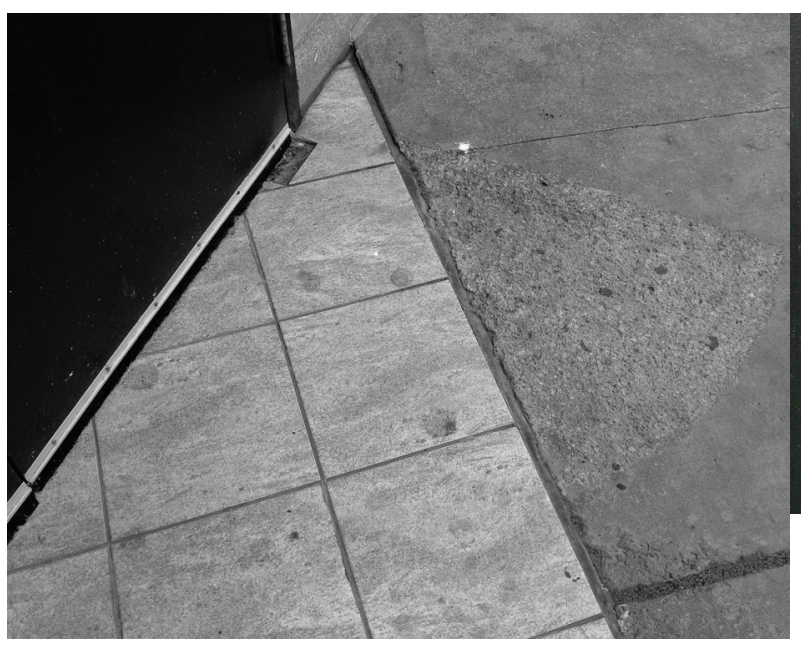

Why is the sidewalk scraped in the shape of the door swing? (left image)

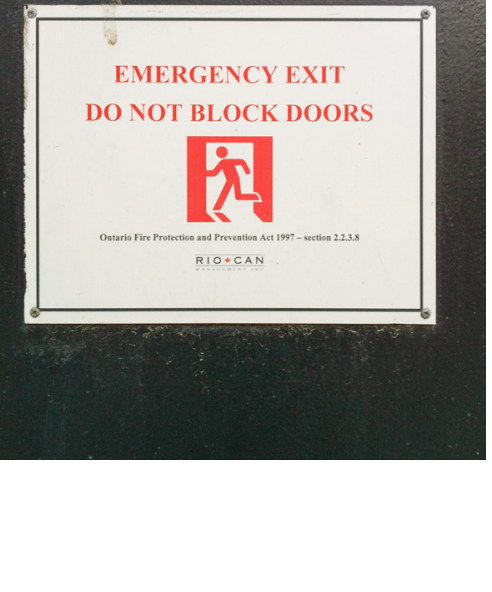

fig. 6-23 What is wrong with this image?

Because the designer only saw the door as a doorway, which is evident from the diagram posted on the door (right image) 
ZERo, Zero

| 201

rial.

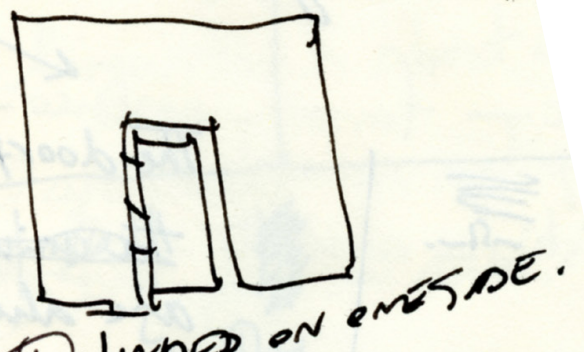

(1) Hinged on em

fig. 6-24 the door is never symmetrical

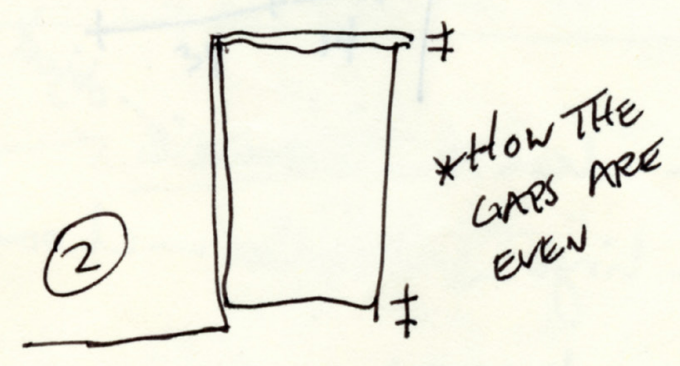

(3)

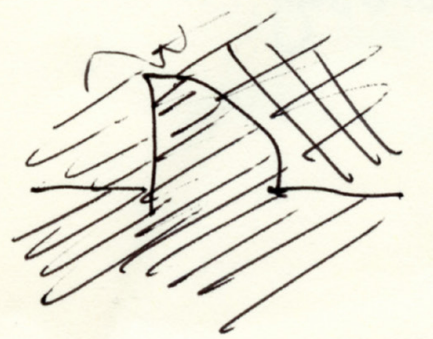

the sting the la sk spare. 


\subsubsection{THE DOOR (7)}

The doorway is a lack of material. It belongs to the wall, but it is an absence of wall. Even though the door betrays the wall as its 'concrete irrationality', they are both materialized and can interchange their WORKINCS. That is why doors and walls are very similar. They always match their compositions.

For example, in North America, a typical interior wall is made up of studs that are sheathed by drywall on both sides. A typical door that finds this wall is also of the same structure of materials. Here, the door is a lighter version. It is a simple wooden framework, with sheets of Masonite covering its faces.

All around the world, doors and walls show the same affinity toward each other. For example, in traditional Japanese architecture, walls and doors are almost indistinguishable. In classical Persian architecture, walls and doors are very ornamental, and sometimes a door also plays a window. In Classical architecture, any door is a mini-building, while the walls are massive, and sometimes are what defines the architecture.

However, in modern architecture, doors are neglected because walls are neglected. In Modernism, where everything is 'recognized in the mind', walls are so thin and dematerialize that a door cannot possibly be found that could work under those conditions.

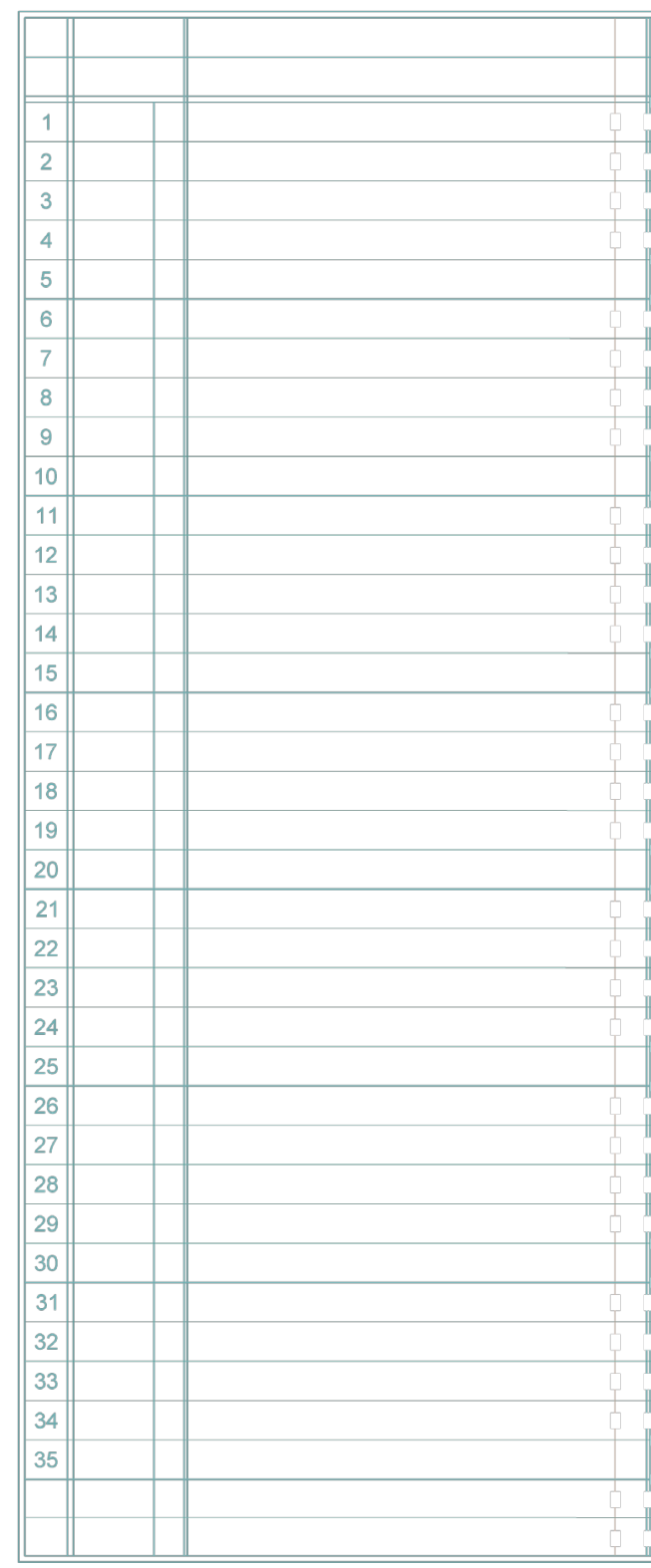




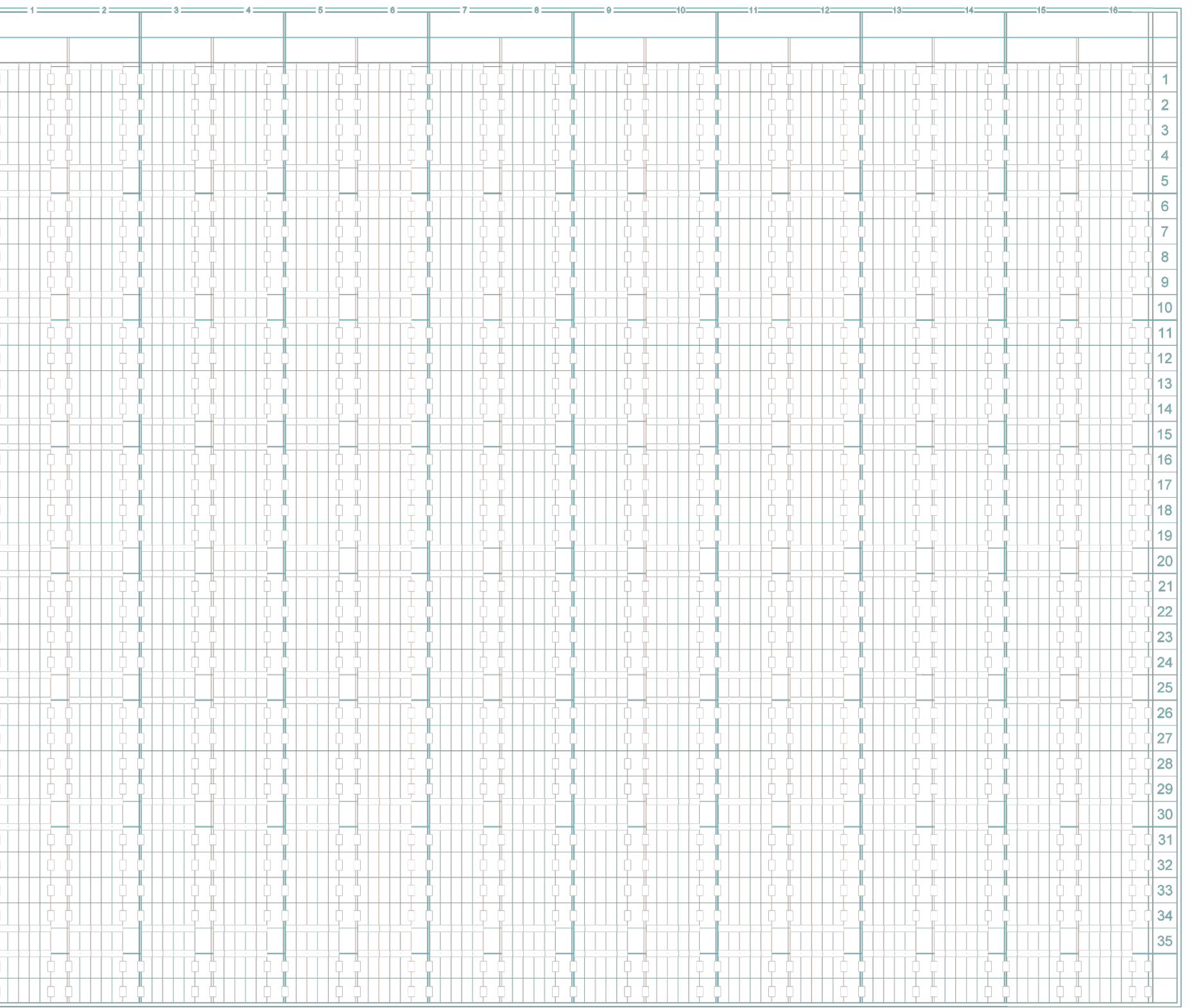




\subsection{RULE NO.5 OF FLAT WORLD:}

\section{EVERYTHING THAT IS MATERIALIZED CAN BE NECOTIATED.}

\subsubsection{THE GRID}

The grid is like the concept of 'form': it is a mental projection onto the world as something superior to what already exists. The way a grid is projected onto the earth is like the act of 'portare' as a way to make a 'place' and demarcate it for 'dwelling. Therefore, it is not hard to see how any grid carries it with all the possible doorways.

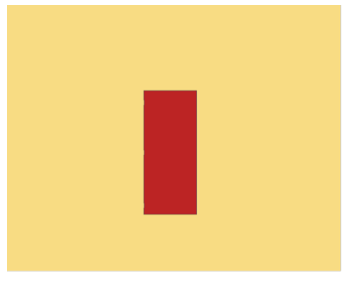

HINGED-DOOR-LEAF

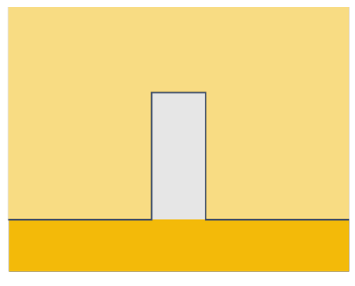

THE DOORWAV

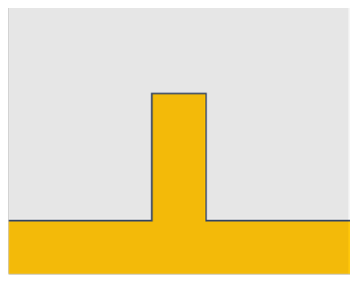

DOOR

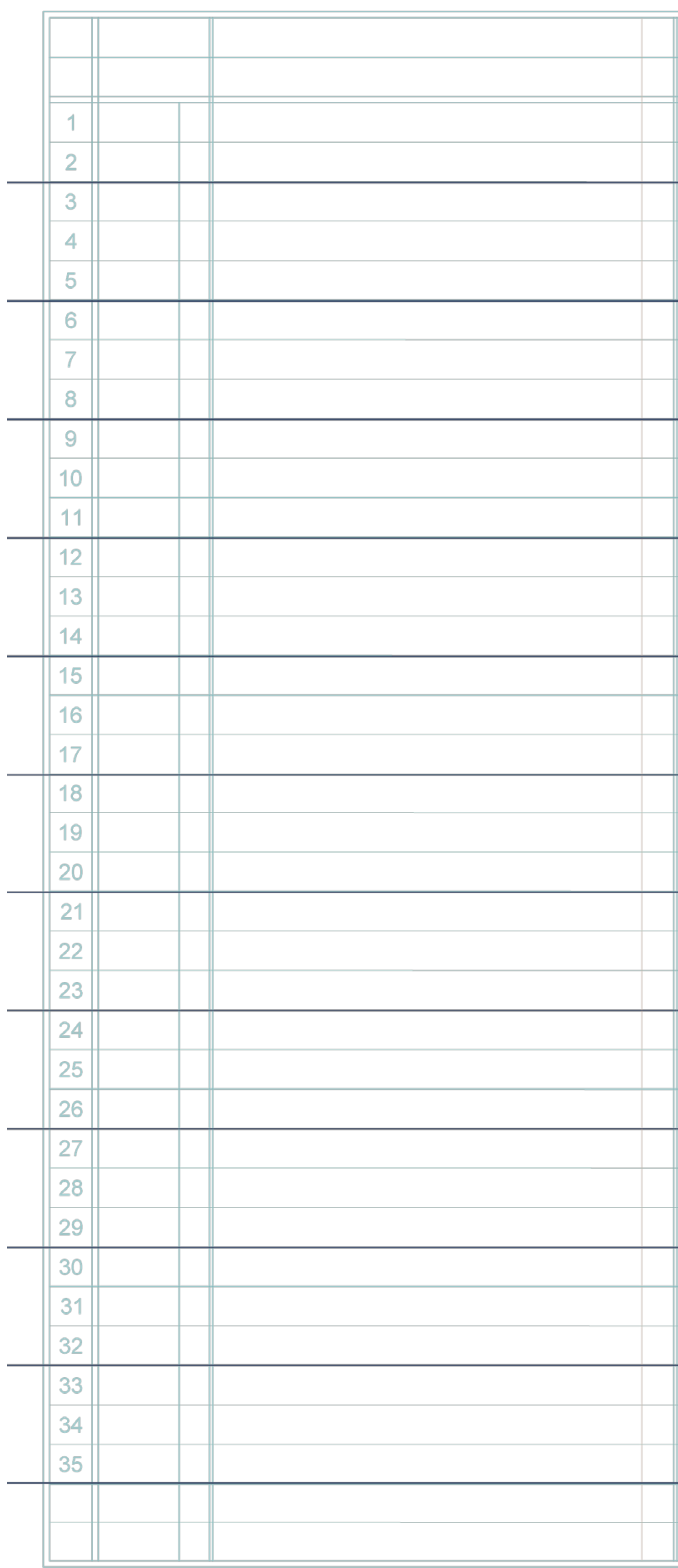

fig. 6-26 the door, the doorway and Door 


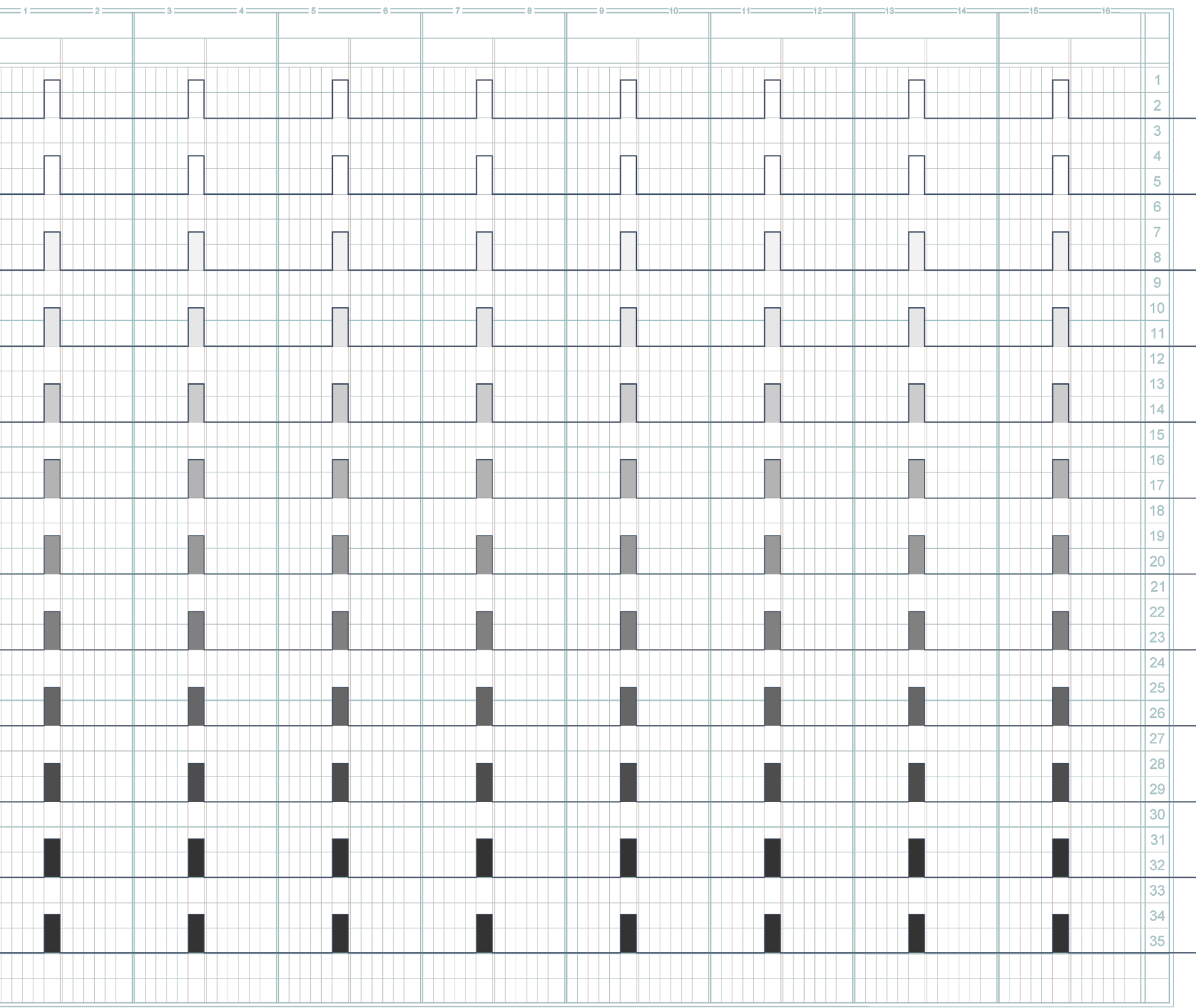

fig. 6-27 all Doors in the grid 


\subsubsection{DOOR}

In FLAT WORLD, when it is the house that swings open, Door is both WALL-LIKE and DOORWAY-LIKE. It stops the house from opening too far and influence how we approach a house that swings open. It changes the way the light exits the house. In a sense, Door is the doorway materialized. And, when materialized the doorway can be NECOTIATED.

In FLAT WORLD, the relationship between ELEMENTS OF CONSTRUCTION can NECOTIATE the grid.

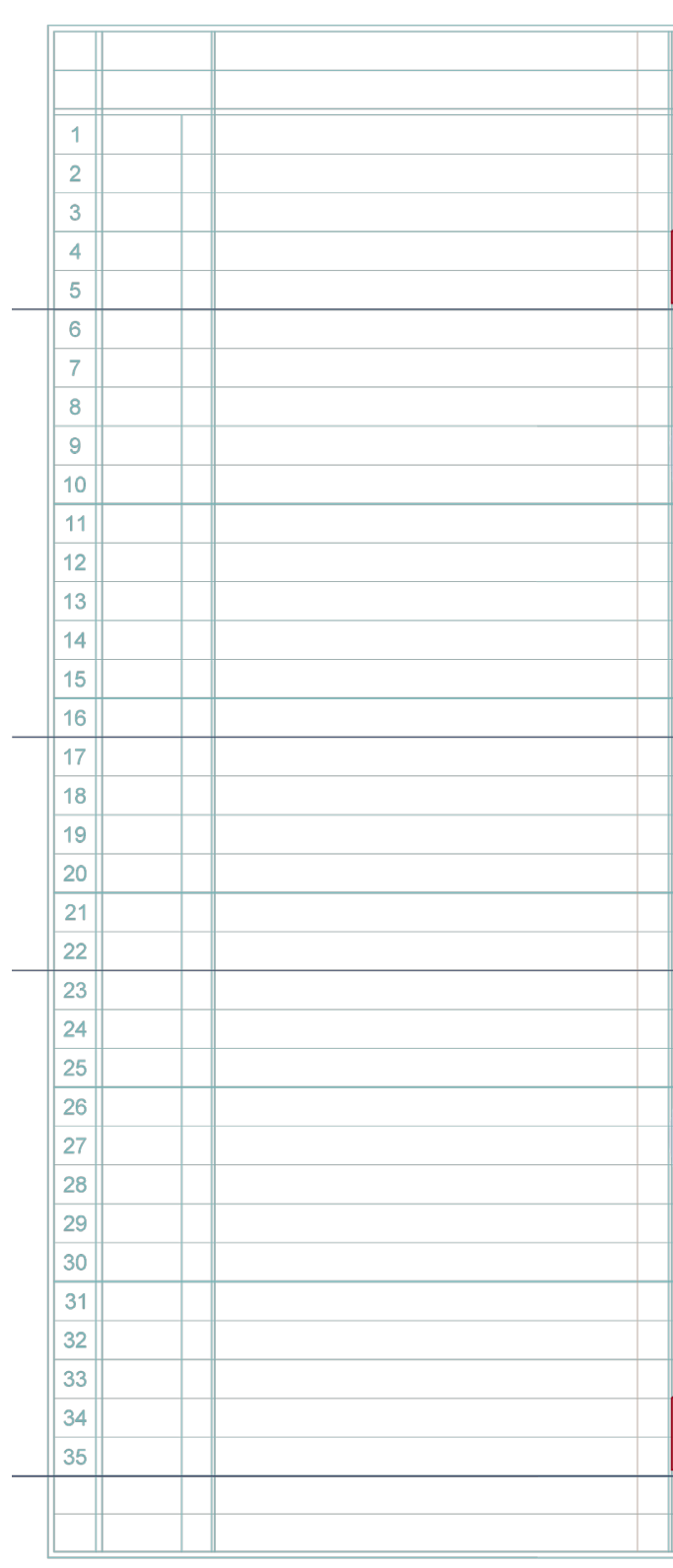




\subsection{3 'FORM'}

IN FLAT WORLD, 'FORM' OF THE HOUSE IS NECOTIATED BY THE RELATIONSHIP BETWEEN DOOR AND HINGE.

In these designs, the change in the relationship between the ELEMENTS OF CONSTRUCTION that make a house swing around DOOR, can also change the 'form' of the house.

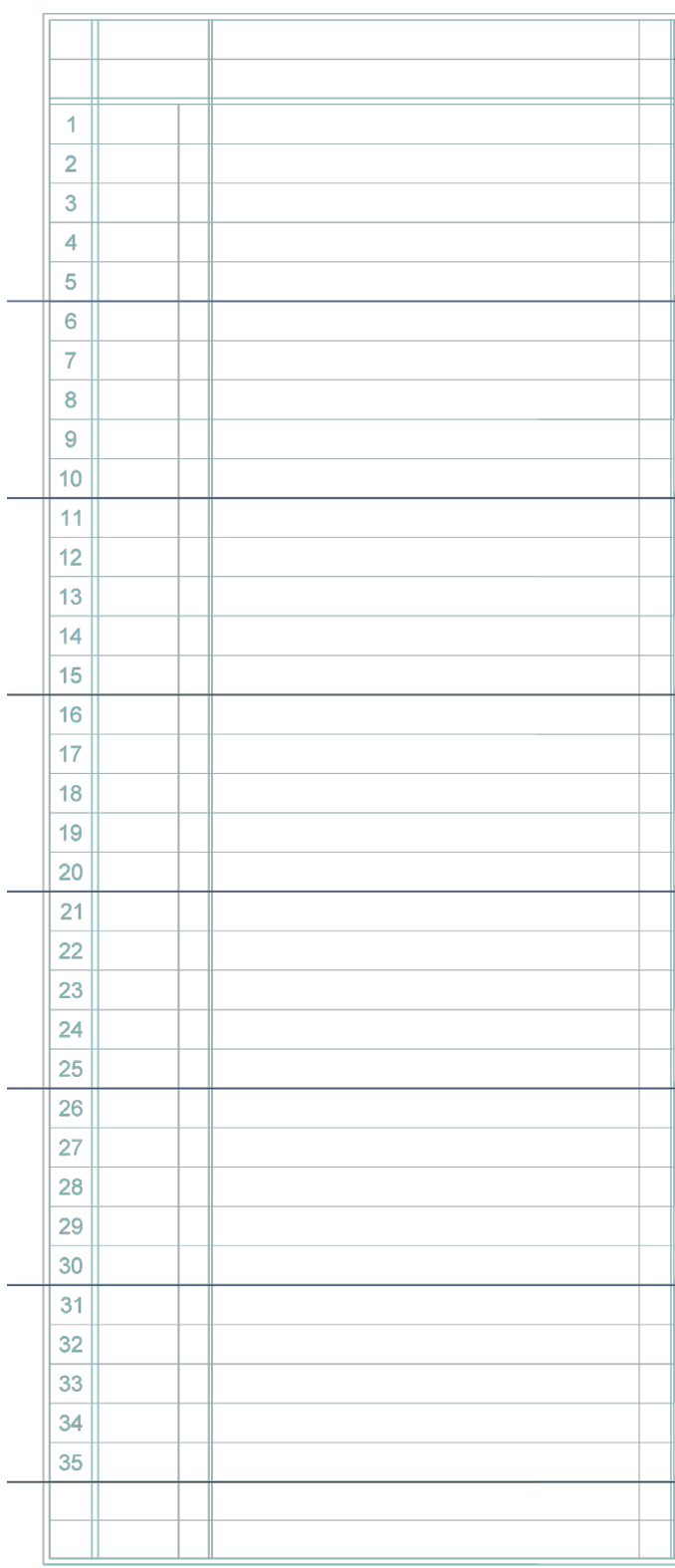




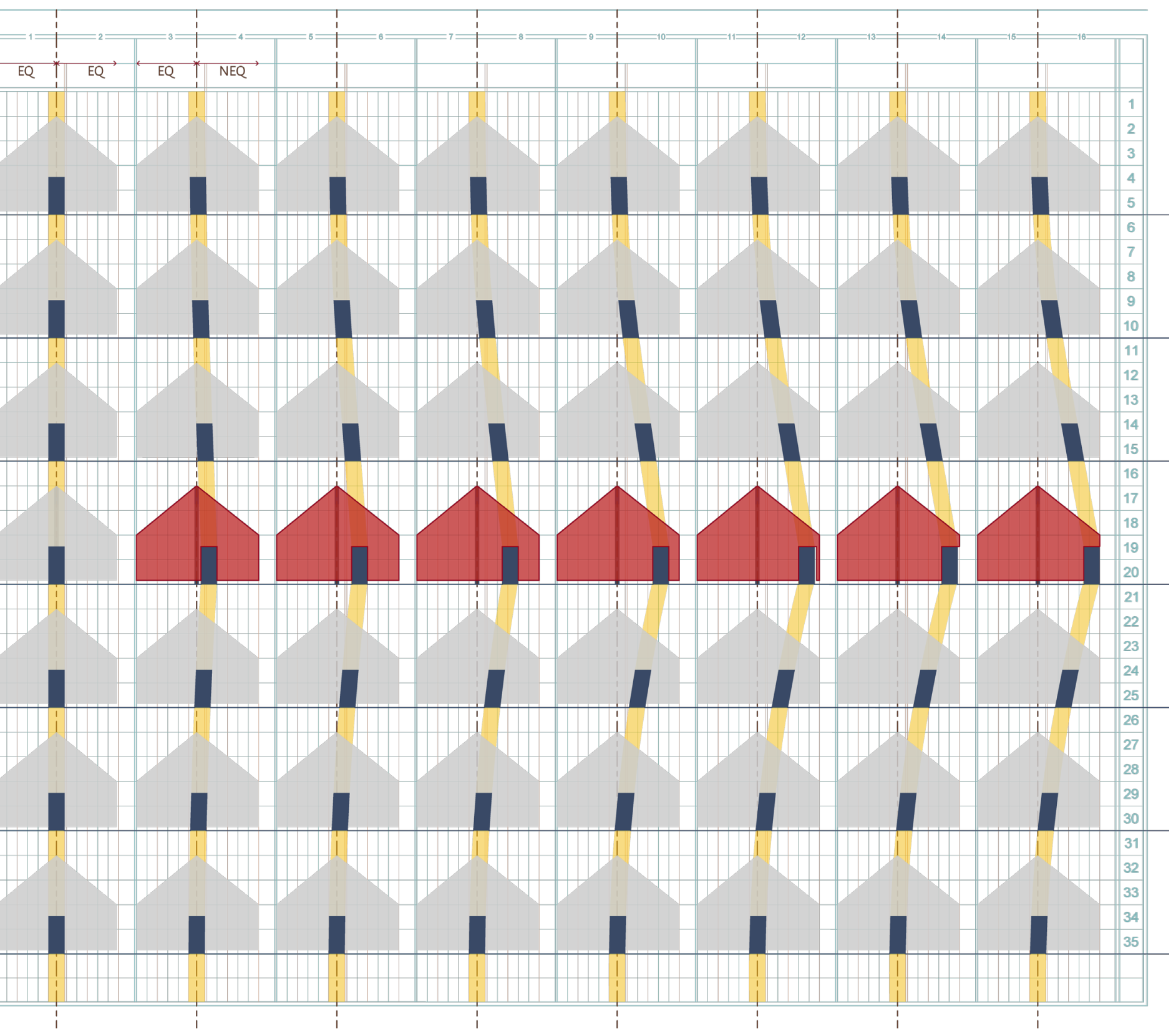

fig. 6-29 the change in the relationship between Door, Hinge and Wall changes the form of the house that swings open and NECOTIATES the grid. 
210

A Flat World for a Short Real

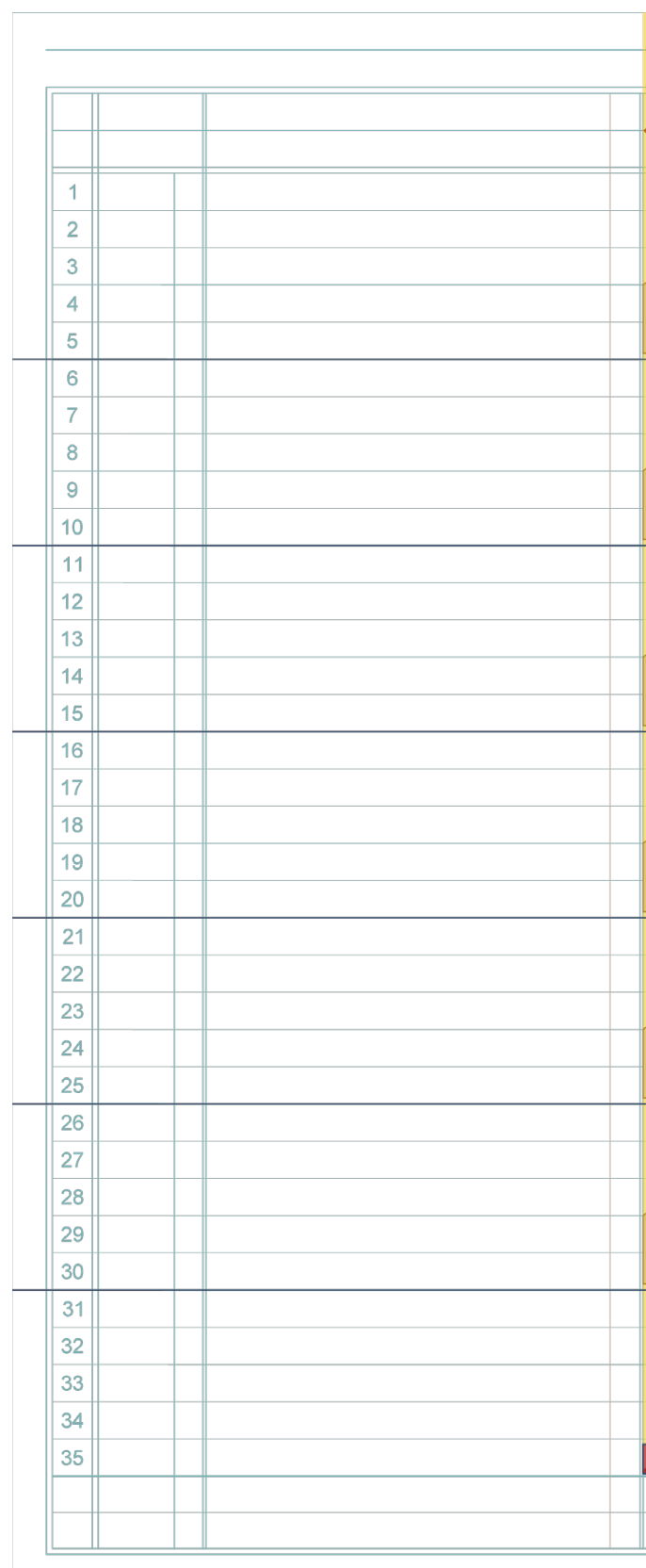




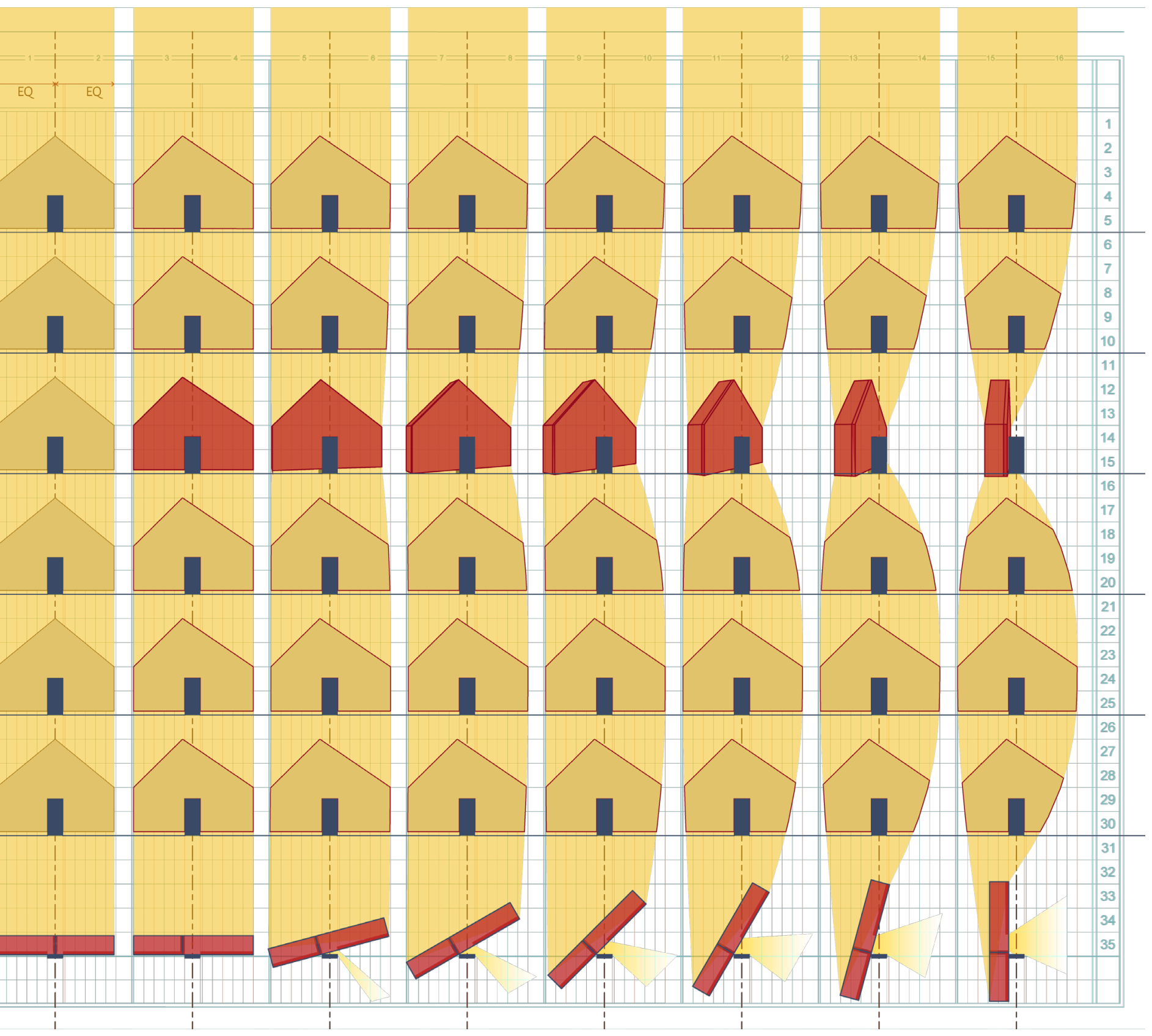

fig. 6-30 the change in the relationship between Door, Hinge and Wall changes the form of the house that swings open and NECOTIATES the grid. 
"It must be notes that the two terms 'outside' and 'inside' pose problems of metaphysical anthropology that are not symmetrical. To make inside concrete and outside vast is the first task, the first problem, it would seem, of an anthropology of the imagination. But between concrete and vast, the opposition is not a true one. At the slightest touch, asymmetry appear. And it is always like that: inside and outside do not receive in the same way the qualifying epithets that are the measure of our adherence. Nor can one live the qualifying epithets attached to inside and outside in the same way. Everything, even size, is a human value [...] that miniature can accumulate size. It is vast in its way." ${ }^{99}$

- Gaston Bachelard fig. 6-31 a 'walled world'
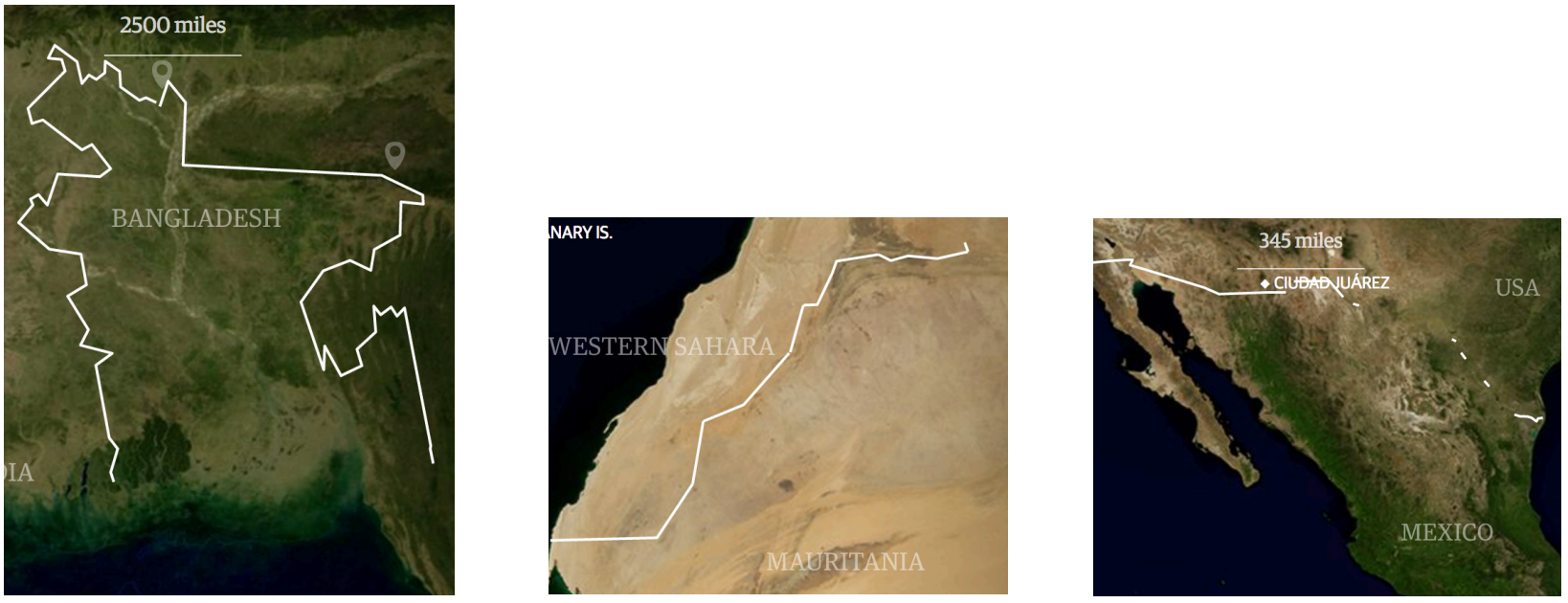

"INDIA-BANGLADESH BORDER"*

"MOROCCAN-OCCUPIED WESTERN

SAHARA"*

"first built in 1980"

constructed from: "mostly sand, also

landmines and barbed wire"

approx. $2736 \mathrm{Km}$ of continuous barrier, "world's longest and oldest functioning security barrier"

supposed insiders: Moroccans

supposed outsiders: Sahrawis

\section{"US-MEXICO BORDER"}

"first built in 2006"

constructed from: "steel, concrete, wire mesh"

approx. $555 \mathrm{Km} \mathrm{Km}$ of barrier; continuous at parts

supposed insiders: US citizens

supposed outsiders: Mexican citizens

69 Bachelard and Jolas, The Poetics of Space, 231.

* Rice-Oxley, Mark, Guardian Interactive team, and Guardian correspondents. "Walled World: How Walls Are Springing up to Divide Populations Everywhere." The Guardian, November 19, 2013, online edition, sec. World News. https://www.theguardian.com/world/ng-interactive/2013/nov/walls\#intro. 


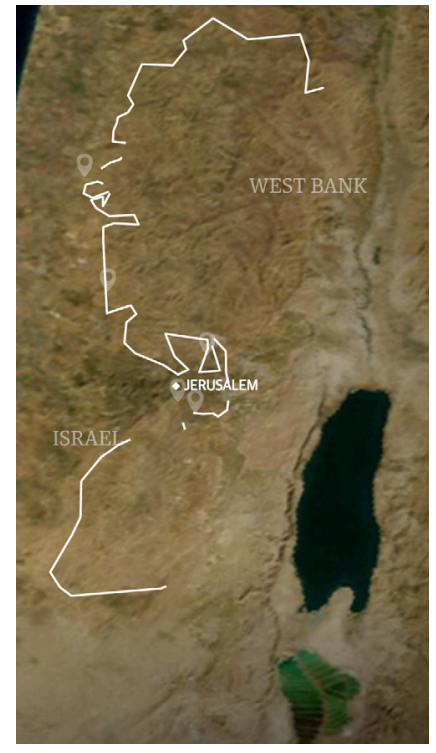

"ISRAEL AND THE WEST BANK"*

"first built in 2002"

constructed from: "concrete, steel, razor wire"

"Six segments" of approx. $498 \mathrm{Km}$ of barriers to date

supposed insiders: "Israeli settlers"

supposed outsiders: "Palestinian militants"

"Walls are there for us to defend ourselves against the outside world, not against the world over our heads. [...] they are munitions. They are made up of two walls: The outside wall turns to face dangerous aliens (lurking on the outside), would-be-immigrants; the inside wall turns inward to the inmates of the house like a jailer responsible for their security." 70

-Vilém Flusser

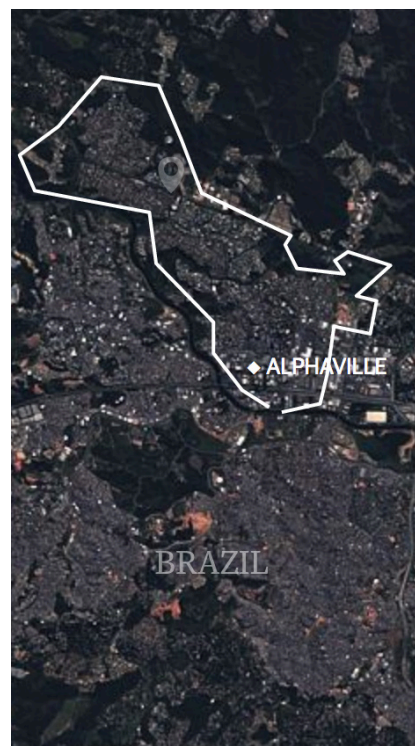

"AlPhAVILLE" IN "SÃo PAUlo, BRAZIL"*

"first built in 1978"

constructed from: "concrete"

approx. $64 \mathrm{Km}$ of continuous barrier supposed insiders: "metropolitan elite" supposed outsiders: "inner-city" criminals

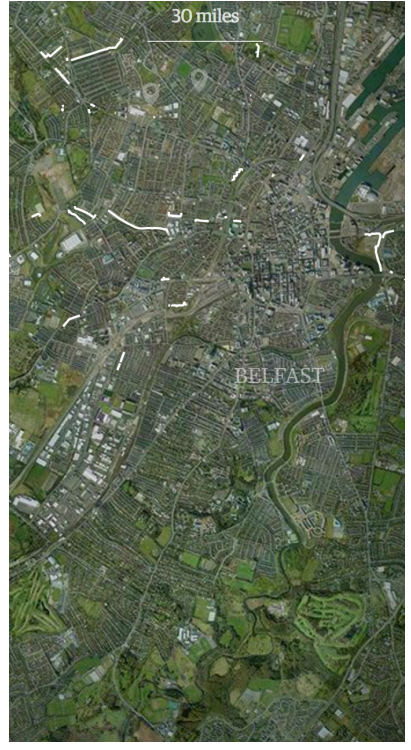

"BELFAST AND DERRY" IN NORTHERN IRELAND*

"first built in 1969"

constructed from: "wire fence, barbed wire" "99 separate walls" that make up approx. $48 \mathrm{Km}$ of barrier

supposed insiders: "working class Protestants"

supposed outsiders: "Catholic communities" 


\subsection{SHORT REAL (2): A WALL-LIKE WORLD}

\subsubsection{WALL-LIKE BARRIERS: INSIDE OR OUTSIDE}

The English word wall is "derived from the Latin word vallum," which in Roman times was part of the system for "fortification" using "earthwork". In ancient cultures, like Egyptians, walls were the main device for adding "monumental effect."72 In German (Mauern) and French (murs), wall means "to protect." "'?3 What they protect is our "personal integrity"74 against "the rest of humanity and nature."

In SHORT REAL, when facing "the confused immensity of the universe," 75 people are compelled to build WALL-LIKE monuments to demarcate a "certain portion of space" as a 'place.' It is against the WALL-LIKE operation of elements that "Man identifies himself as a creature who opposes the formless chaos represented by the world." ${ }^{76}$ Yet, there is a high price for this feeling of absolute and symmetrical ideal. Each WALL-LIKE edifice protects the group that built it while simultaneously turning them into a society "cretinized [...] by an architecture of self-punishment."

$$
* * *
$$

For 'Heidegger', "walls" ${ }^{78}$ were the primary definer for any building as they "enable us to dwell," "protect us" and provide us with means to have "peace." In this process, "a building should be on and of the soil, of the location on which it is built."

As Neil Leach traces the question of 'place' to the initial ideas proposed by Heidegger and its influence on the Post-modern ideas, reveals that the "Postmodern calls for 'place' echo post-modern calls for domus, ${ }^{\text {'80 }}$ which signals a "sentimental evocation of traditional forms" that is represented in the contemporary discourse of critical regionalism.

According to Jon Henley, "since" century ago, the world has been busy building walls" at an unprecedented

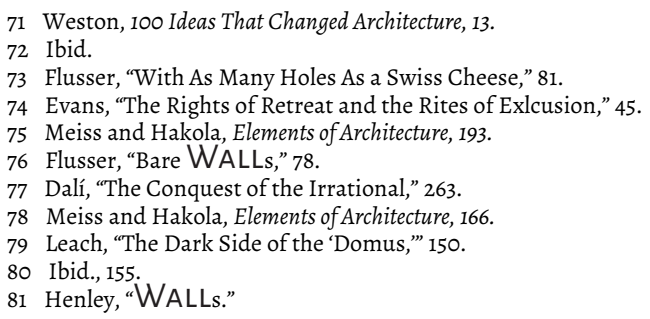


"rate perhaps unequalled in history." It is estimated that since 1991 almost ten thousand kilometers of "wire, concrete, steel, sand, stone, mesh," or "anything" capable of keeping "people out—or in," has been constructed around the world.

Their purpose is simple. Like any element with a WALL-LIKE operation, these barriers are meant "to protect, keep out, demarcate and divide." ${ }^{2}$ Ironically, all of this has happened in an age of "global economy, multinationals, vanishing trade barriers" and at a time where policies are geared towards "the free movement of goods, capital, services and people'."

In a paradoxical turn of events, as "physical walls appear to be crumbling," ${ }^{83}$ the world is busy building new physical WALL-LIKE barriers. Surprisingly, in the age of communication where "technology has affected the space of interpersonal relationships," ${ }^{84}$ the Post-modern movement of "Regionalism" ${ }^{85}$ has positioned 'place' as a remedy for the "very placelessness of the contemporary society."

Every wall protects in a paradoxical way. As a wall holds outside out, it also keeps inside in. That is why every wall is two walls: the "outside wall" ${ }^{86}$ that faces the danger and elements and the "inside wall" that faces the "inmates of the house like a jailer responsible for their security." 


\subsection{BUILDING PARALLEL}

\subsubsection{DOOR-LIKE WALLS OR WALL-LIKE DOORS}

These days, in SHORT REAL, WALL-LIKE WORKINCS are in vogue again. In our desperate desire for an ideal dialogue-symmetrical, universal and absolute - we have forgotten how to NECOTIATE.

WALL-LIKE WORKINCS help us build 'thresholds' that communicate asymmetrically the control of some people over other people. In SHORT REAL, a wall is built after the 'threshold' is established. Combined with the concept of 'portare', it is easy to see how a wall is always viewed as something that is imposed on the landscape (as the plow ruptures the earth). That is probably why we built walls in the first place: to impose our will over the land that we have demarcated for 'dwelling'.

An ideal wall, which holds its WALL-LIKE WORKINGS despite changes in time and matter, remains non-negotiable because it has an 'essence' that is incorporeal. It remains immutable as long its myth is understood symmetrically by all of those who encounter it. An Ideal wall is built and maintained by "conventions" 87 that possess the mind of those who constructed it and those who meet it.

In FLAT WORLD, where the ELEMENTS OF CONSTRUCTION include humans and laws, and all the elements are FLATTENED, there is an alternative narrative possible. 


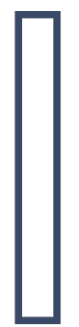

$\downarrow$

fig. 6-32 how SHORT REAL sees the wall

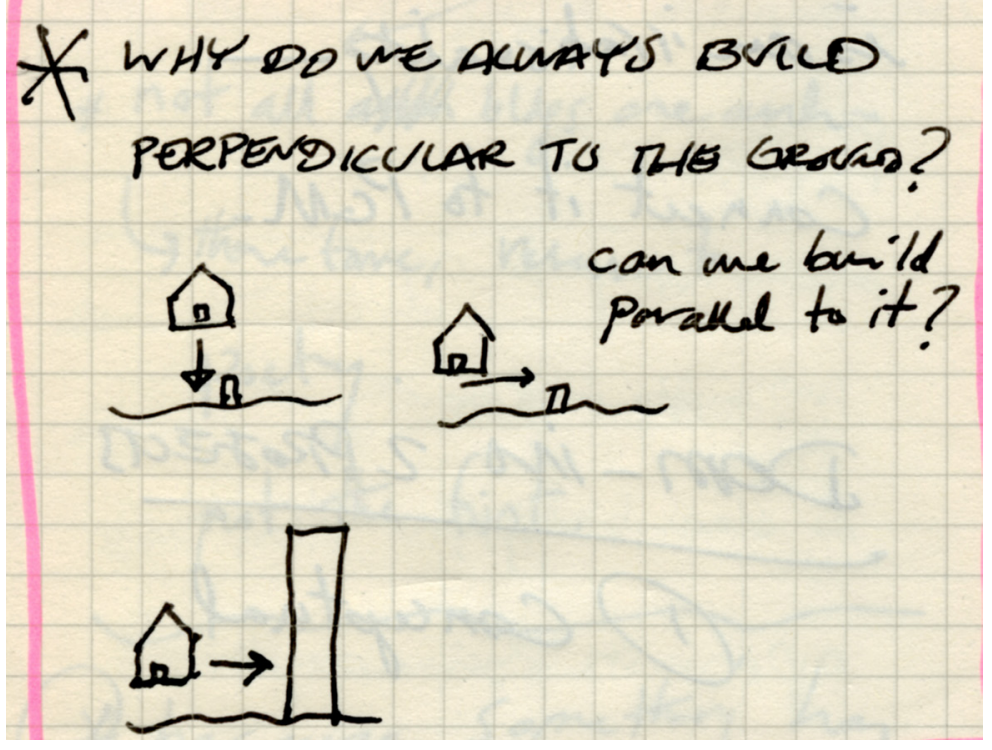

fig. 6-34 sketch, building parallel 
In FLAT WORLD, a wall is not held responsible for the 'essence' that it is bestowed on it (beyond its materialized realities). In FLAT WORLD, it is understood that once a wall is built, it is not an imposition on the landscape, but it is now part of the landscape. It is an ideal that is materialized.

In FLAT WORLD, what is built in SHORT REAL to divide people, can be NECOTIATED to bring them together. In the case of the walllike barriers around the world, they can be dividers as long as they are ideal and incorporeal. Once they are built, like anything materialized, they can be NECOTIATED.

Since anything that is materialized can be NECOTIATED, then a WALLLIKE barrier that is made to separate us can provide opportunities for NEGOTIATING the idealistic ambitions behind its construction. This is how the wall-like barriers that have been dividing people into 'outsider' and 'insiders' - demarcate and protect—are NECOTIATED to be Doors for houses that swing open. 
fig. 6-36 how FLAT WORLD sees the wall 


\subsubsection{HOUSE-THAT-SWINCS-OPEN-3}

Here, a wall that is built as a barrier can interchange its workings with Door (the wall-like door for the Hosue-that-swings-open-1). Therefore, a WALL-LIKE barrier can be also a WALL-LIKE door. The difference between the scale of the two is resolved by FLATTENINC and the interchangeability of the WORKINCS of the ELEMENTS OF CONSTRUCTION.
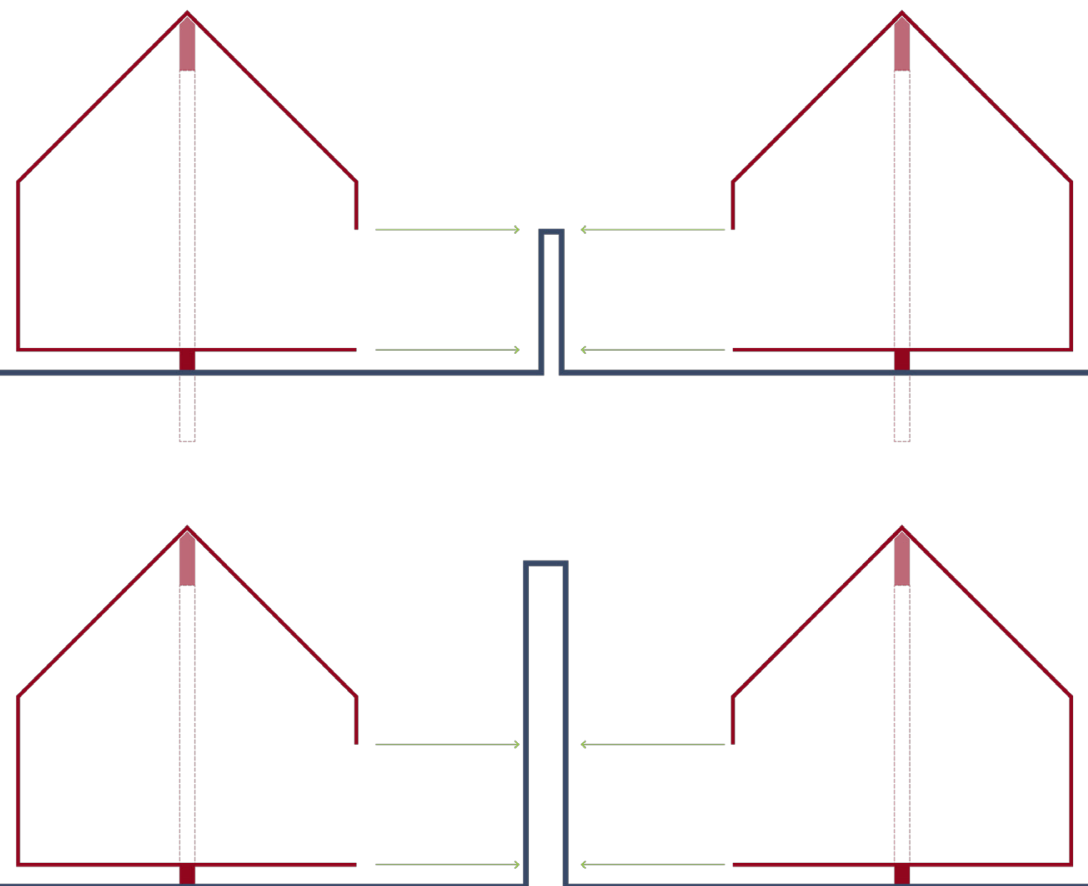

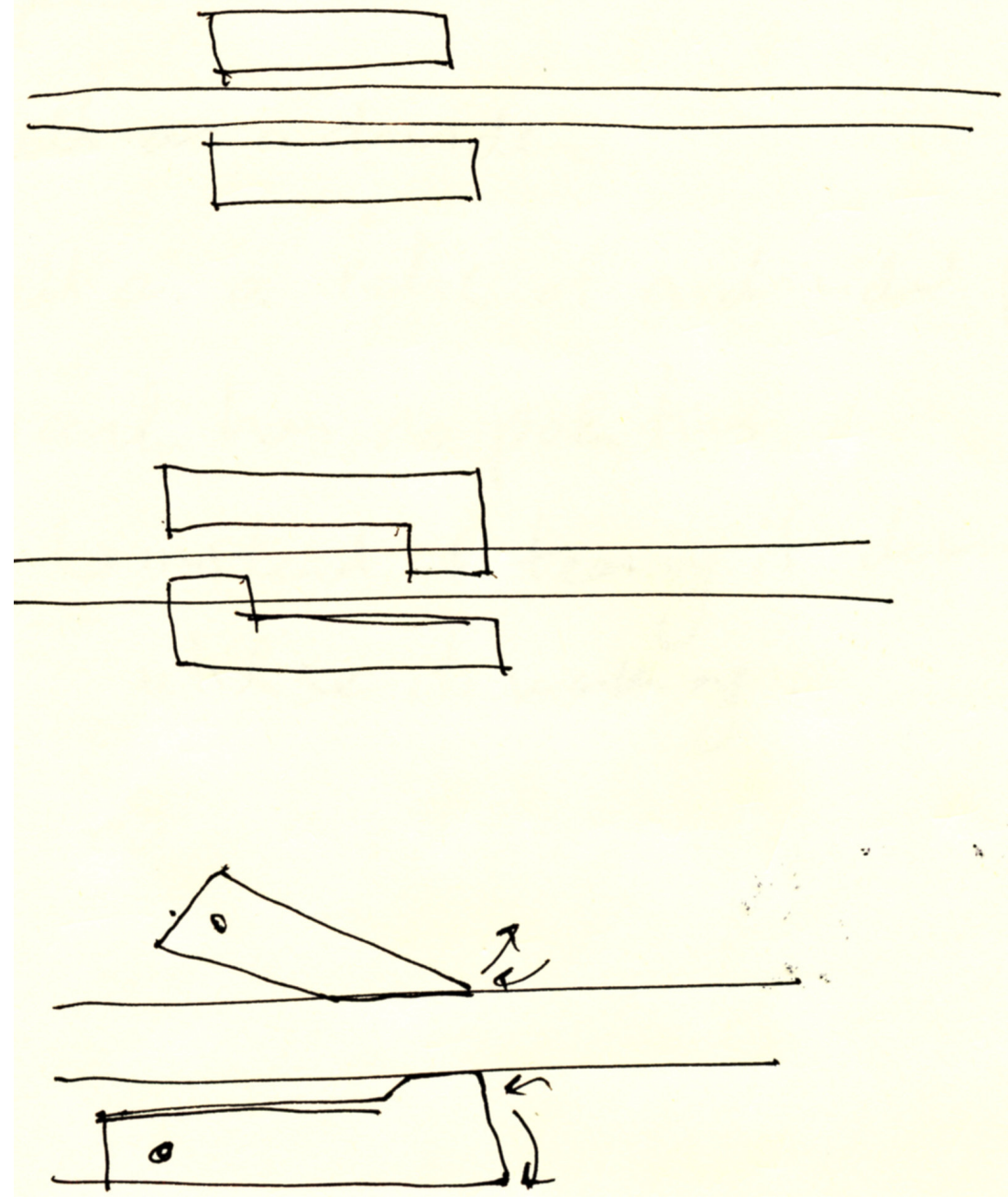

fig. 6-38 building parallel, sketch 

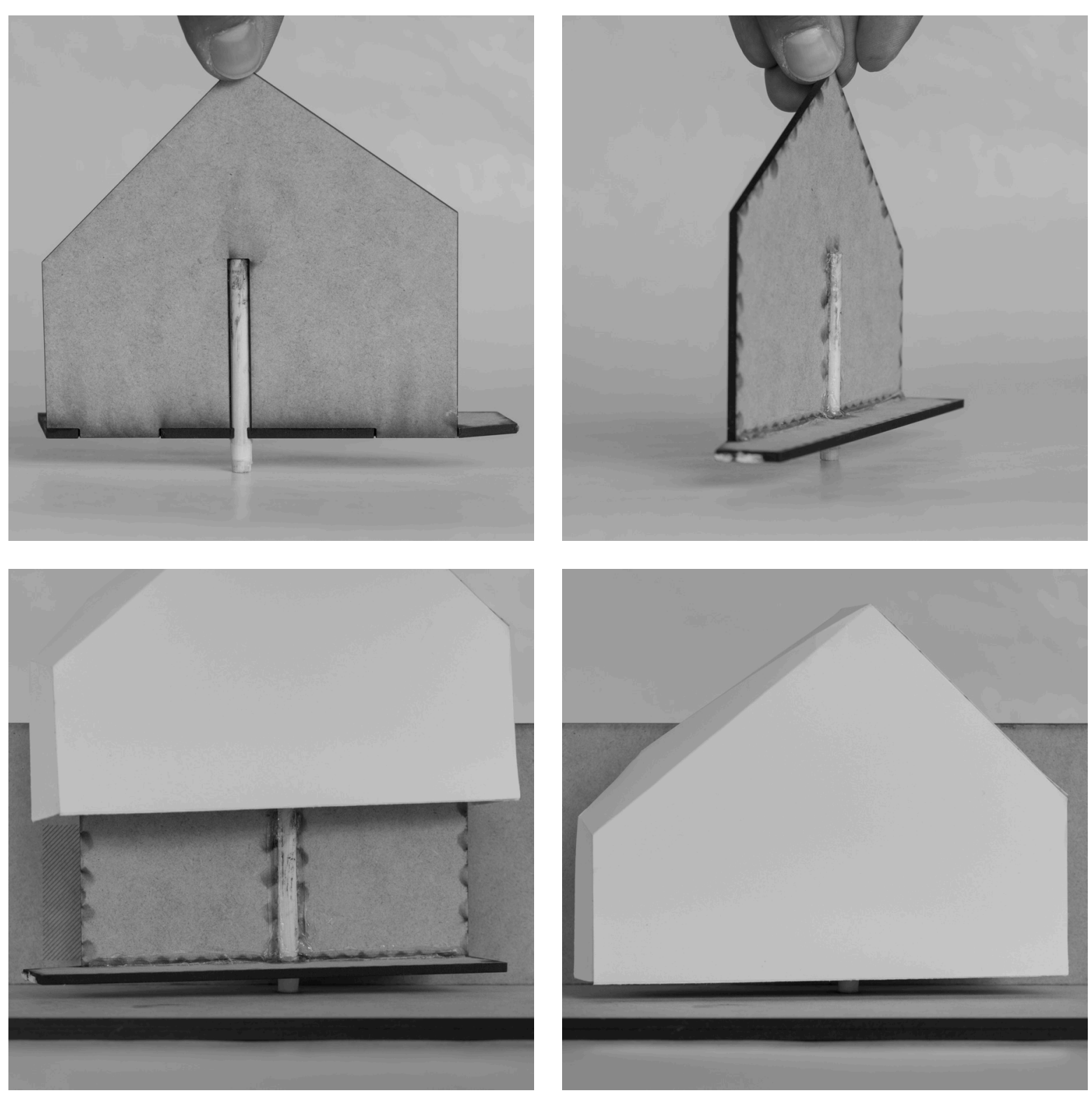

FIC. 6-39 HOUSE-THAT-SWINGS-

OPEN-3, functioning model 

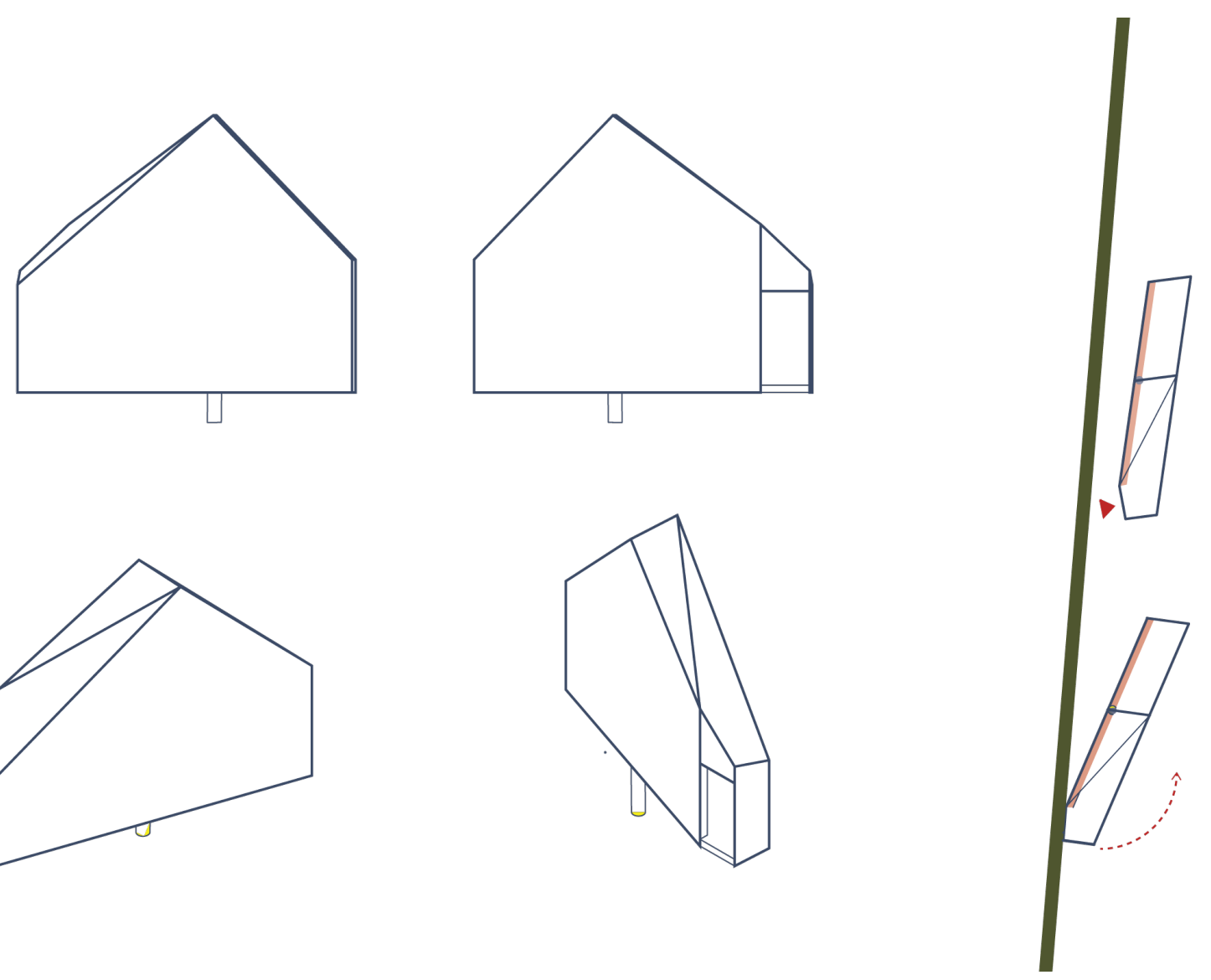

(1)
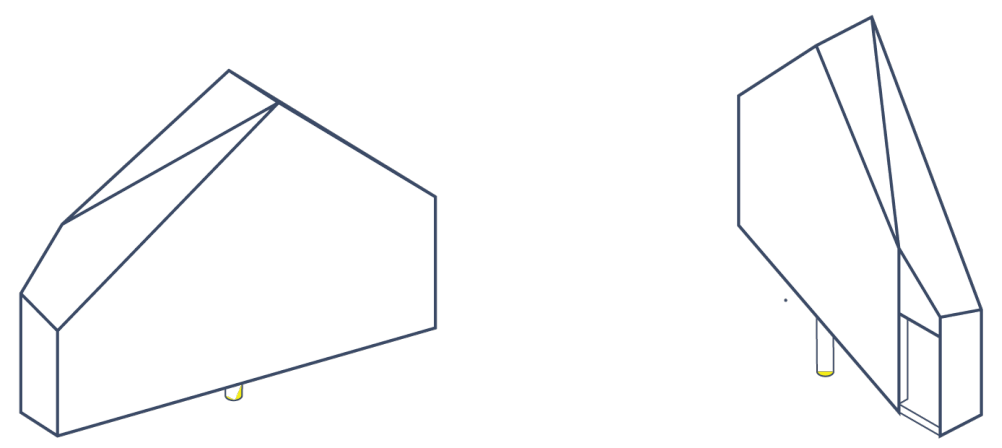

(1)

FIG. 6-40 HOUSE-THAT-SWINGSOPEN-3, axonometric drawings and plans 


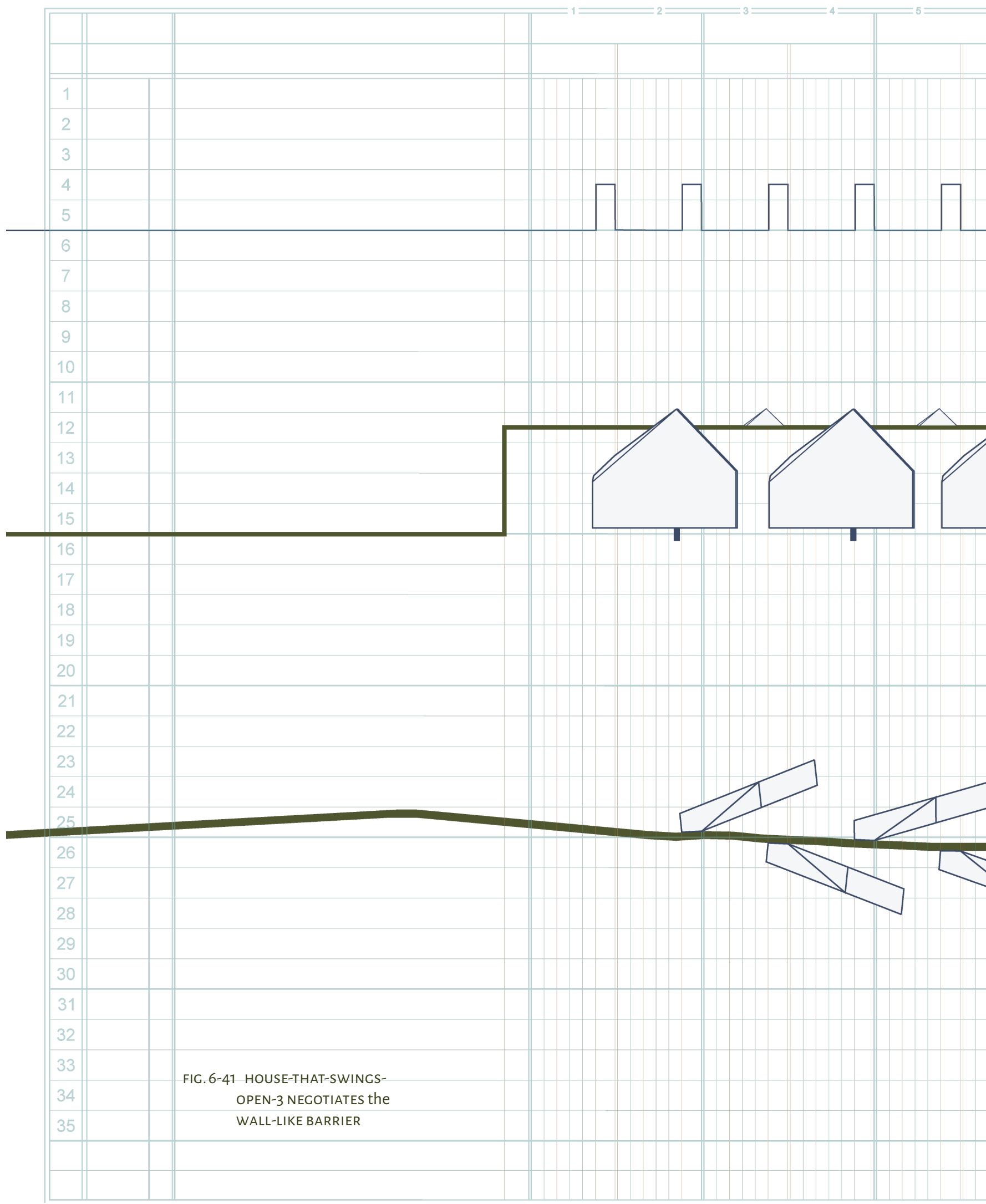




\section{0}

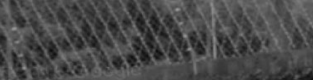
astions.
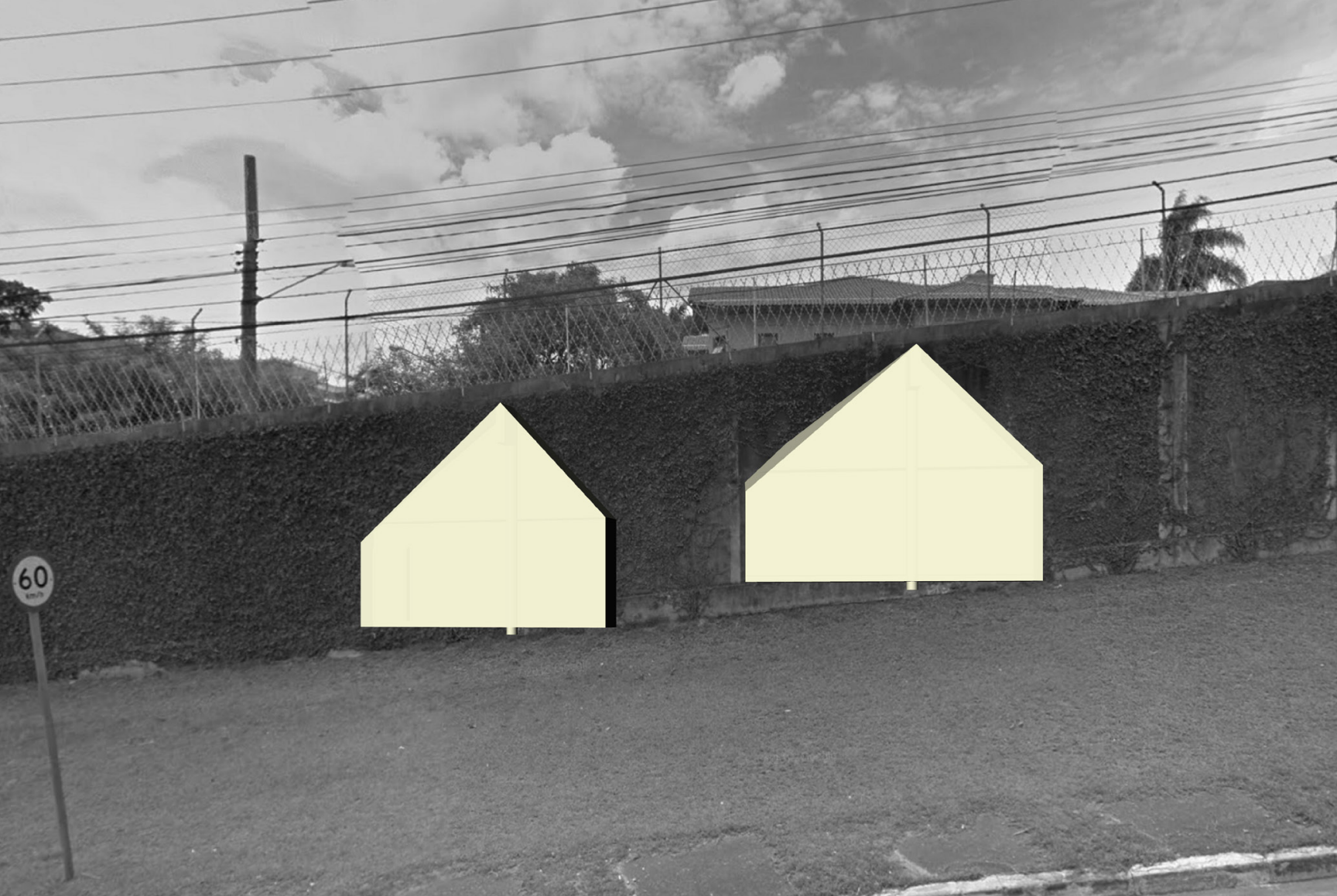

FIG. 6-42 HOUSE-THAT-SWINCS-OPEN-3 in Sao Paolo, Brazil NECOTIATING a WALL-LIKE barrier that divides Alphaville from the rest of the city 


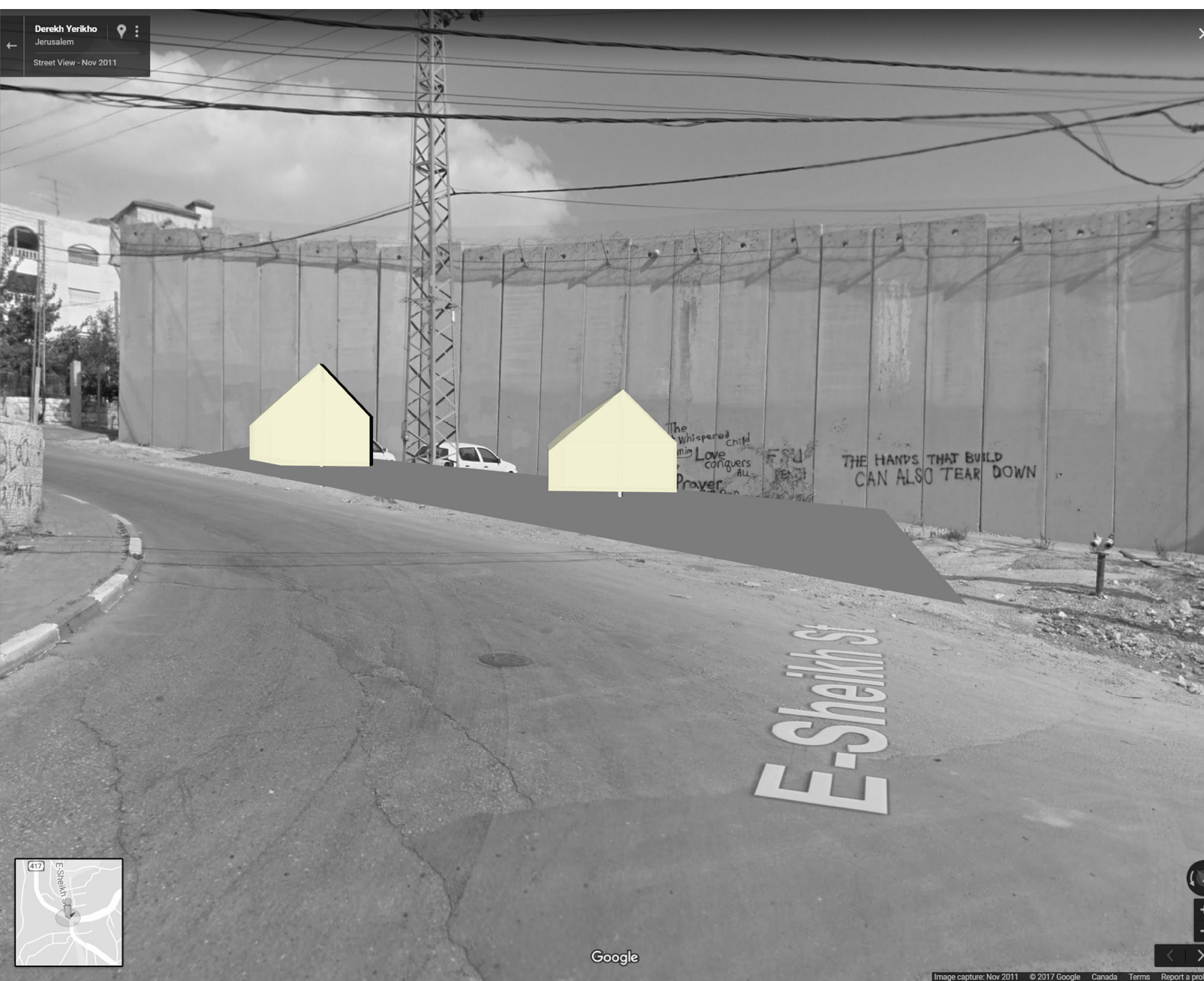

FIG. 6-43 HOUSE-THAT-SWINGS-OPEN-3 in Jeruselum NEGOTIATING a WALL-LIKE barrier 


\subsubsection{THE GRID (2)}

One of the effects of Modernism was projecting the grid not only on the ground, but also in front of us. This is evident in all the buildings that we have been constructing based on the Blueline grid. Since any grid carries all the doorways and DooRs, what are the other ways for the houses that swing open to become DESIGN-CONSPIRACIES?

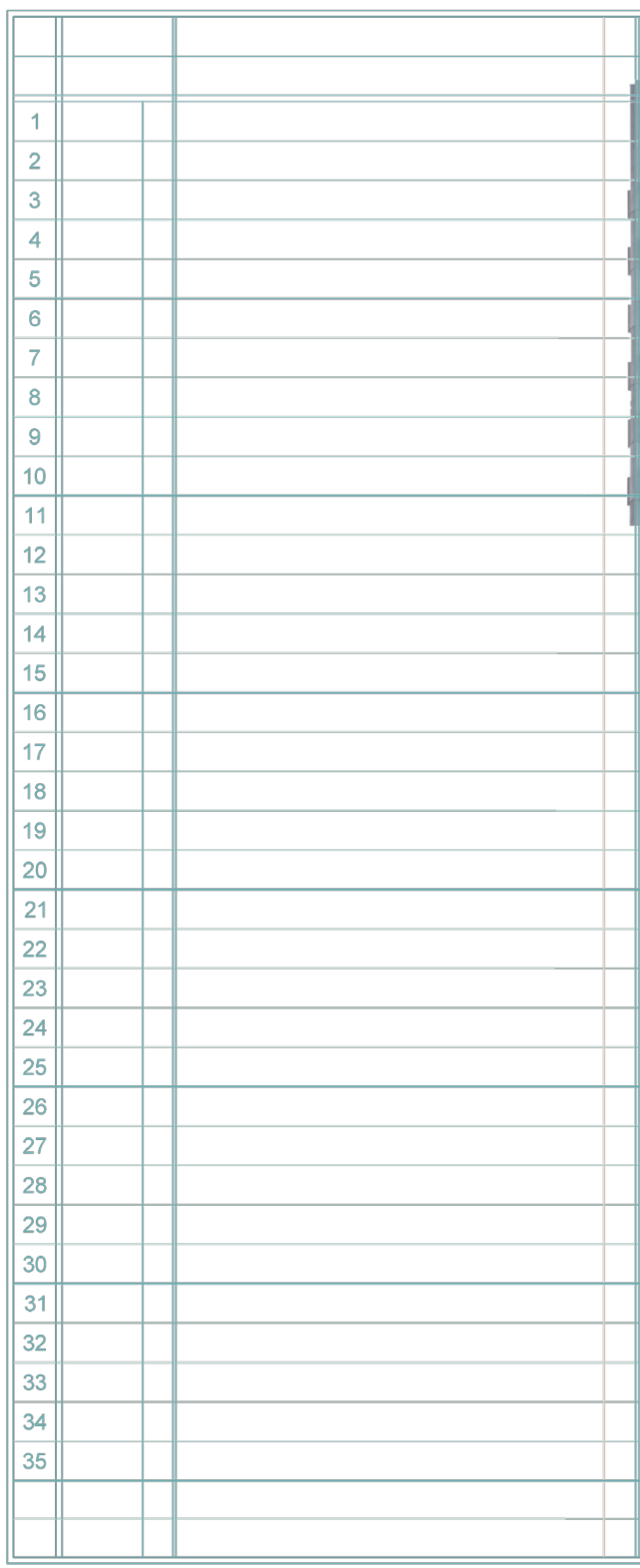




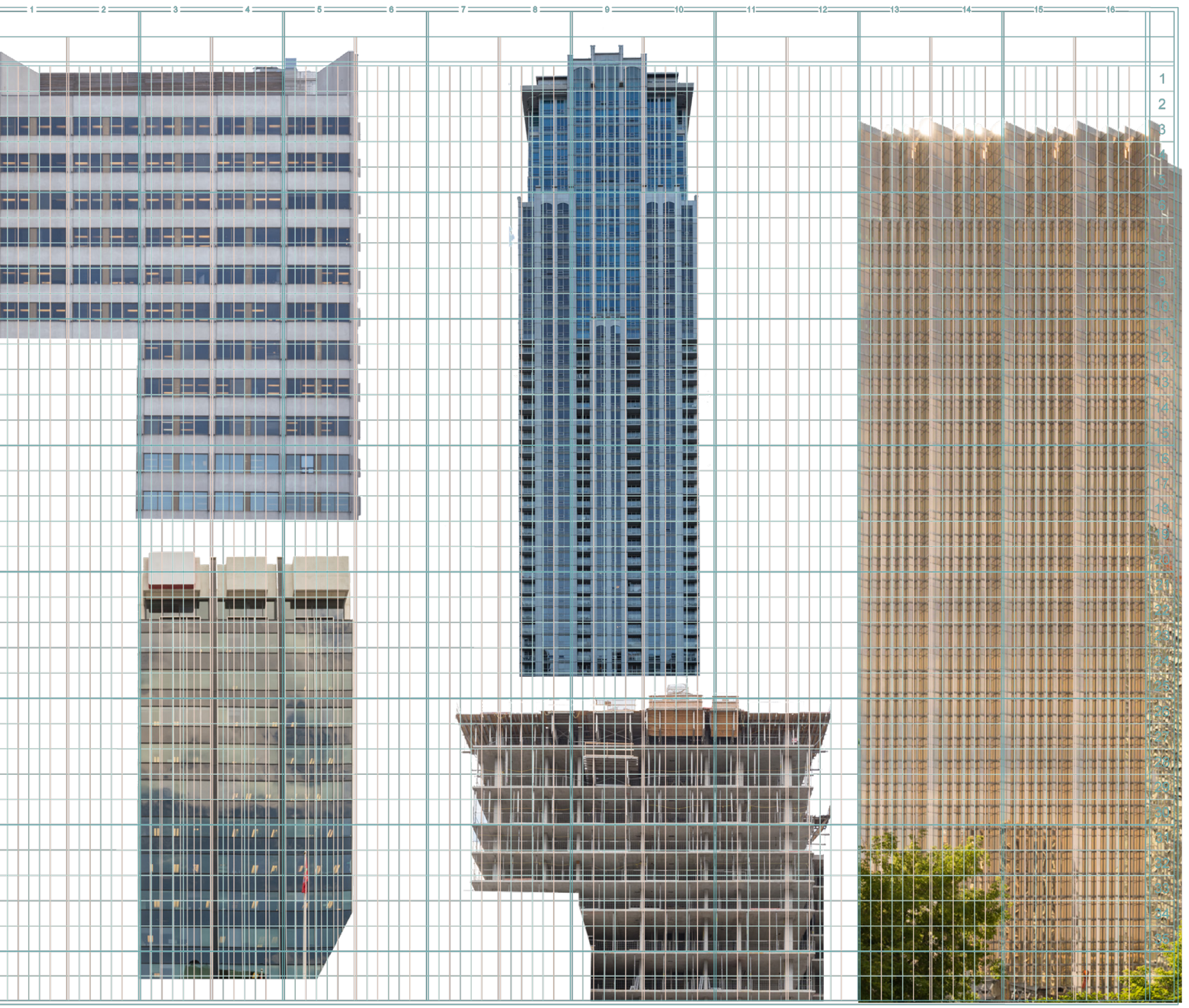

fig. 6-44 grid elevationas 
6.10.4 HOUSE-THAT-SWINGS-OPEN-4
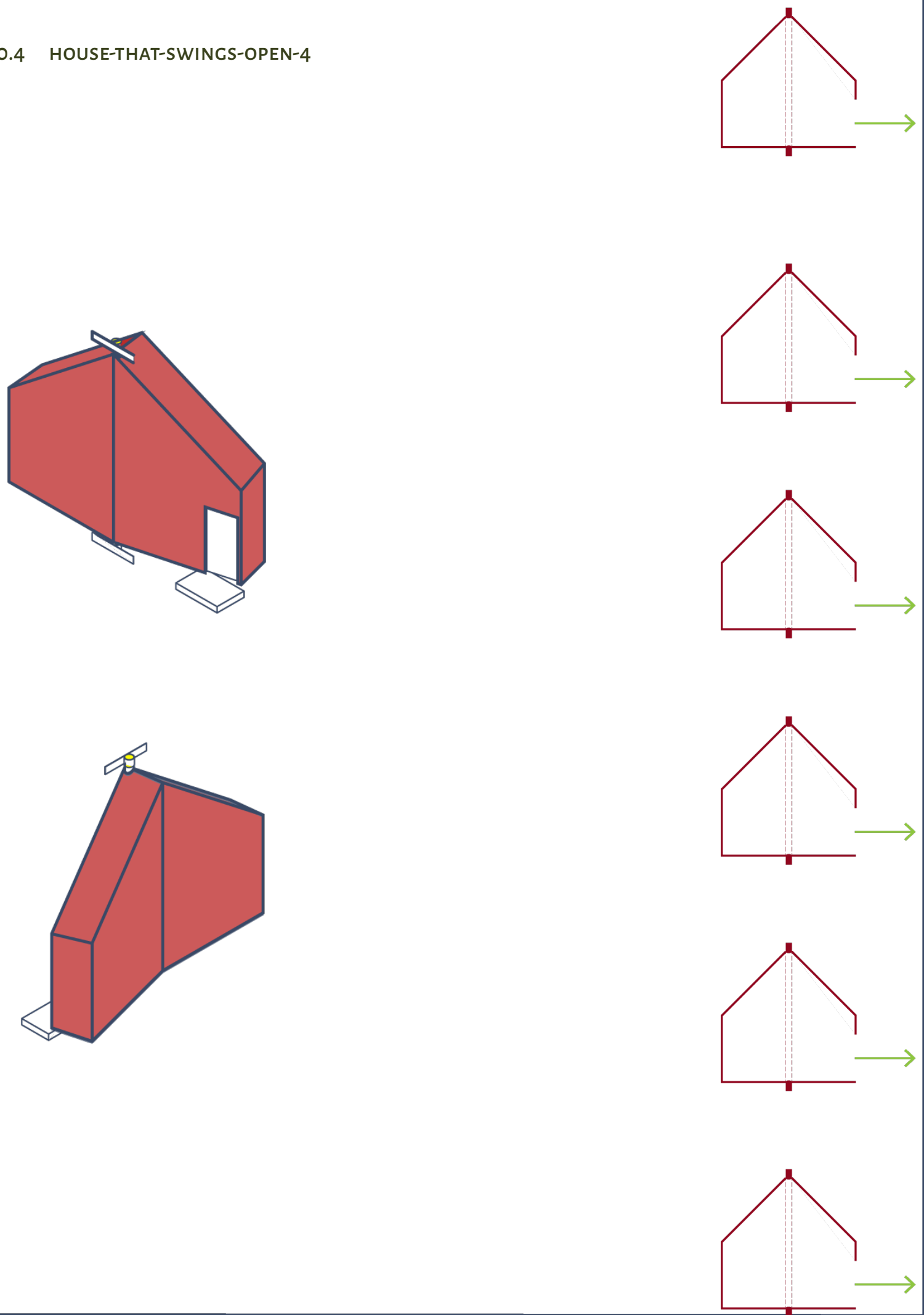
fig. 6-48 (right) HOUSE-THAT-SWINGS-OPEN-4 NECOTIATING a WALL-LIKE tower in Toronto, Canada

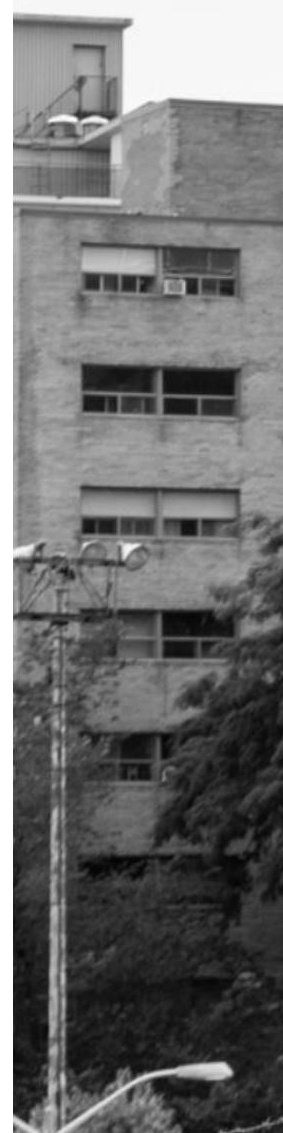




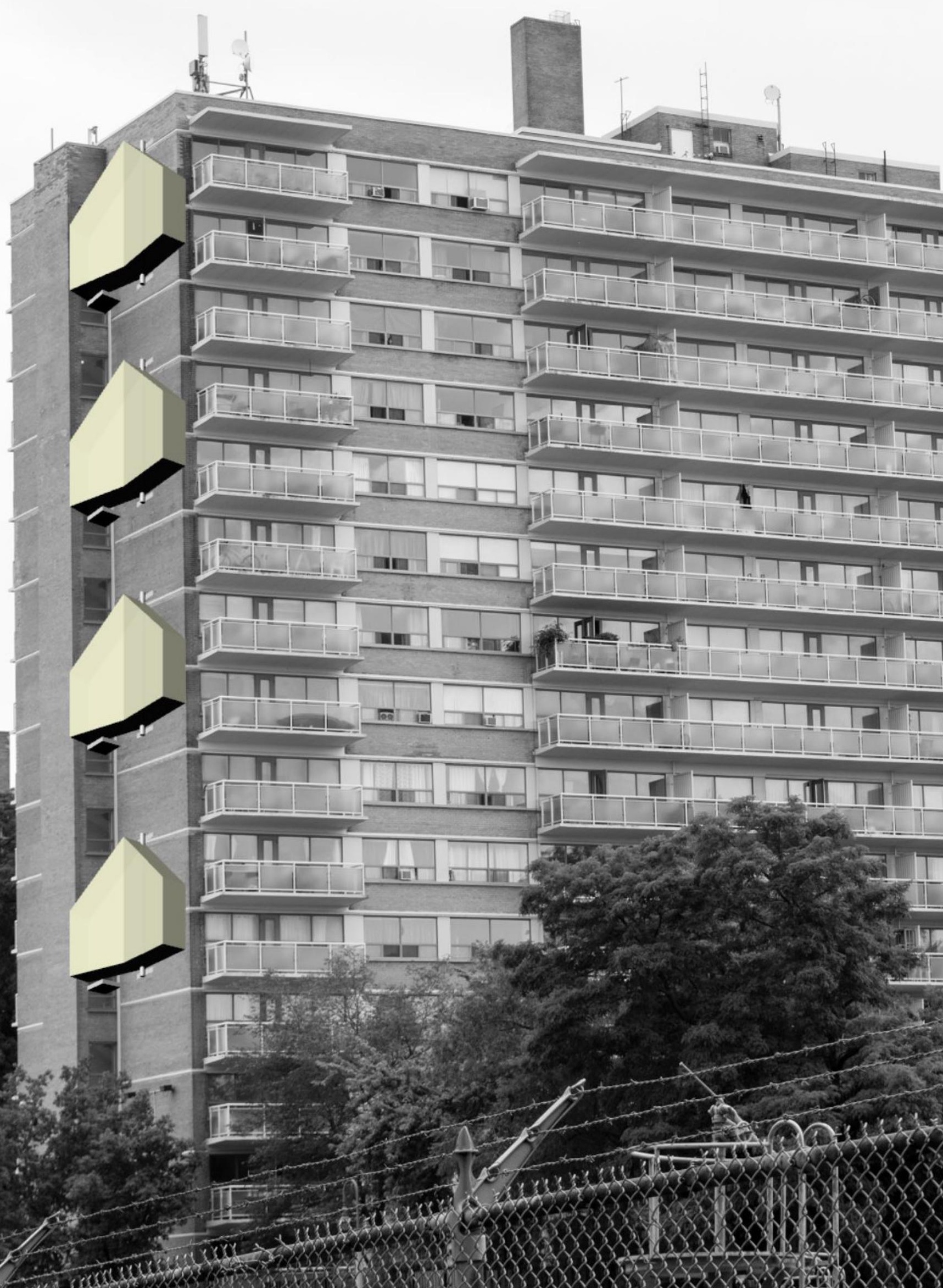




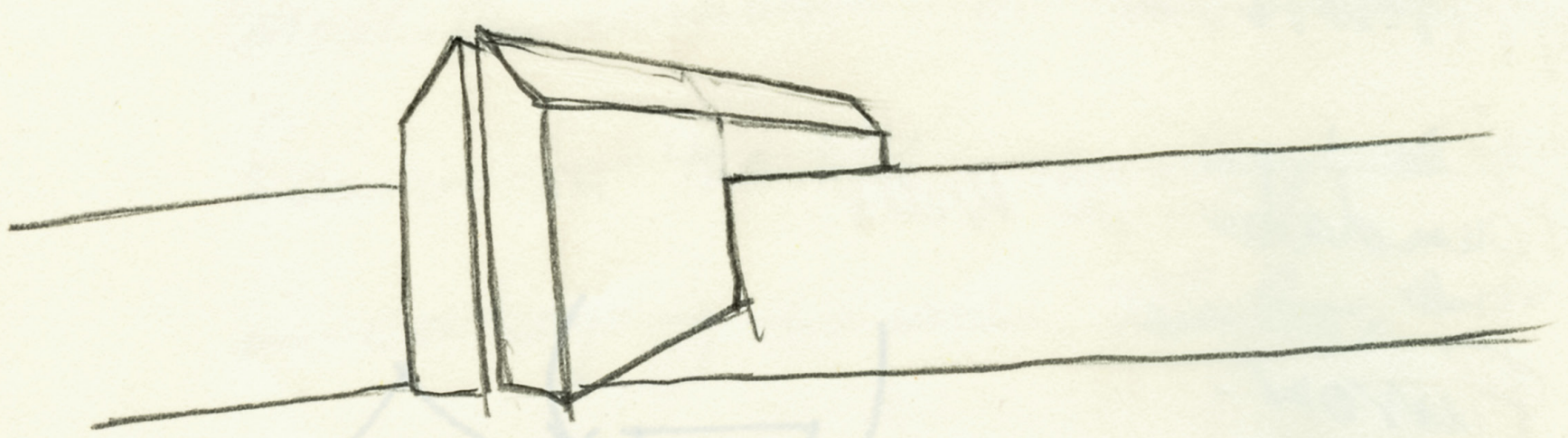

"The flexible field of any door is a prediction and speculation on the clearances, tolerances, meeting points and leeway. Therefore, the WORKINCS of any door always create a territory for negotiations."

fig. 7-1 houses that sit on walls, sketch

from: page 74 of this document

"If the doors of perception were cleansed everything would appear to man as it is, infinite. For man has closed himself up, till he sees all things thro' narrow chinks of his cavern." ${ }^{\prime}$

-William Blake

"The diagram is an invisible matrix, as set of instructions, that underlies - and most importantly, organizes - the expression of features in any material construct. The diagram is the expression of features in any material construct. The diagram is the reservoir of potential that lies at once active and stored within an object or an environment (or in every aggregate or section of these). It determines which features (or affect) are expressed and which are saved. It is, in short, the motor of matter, the modulus that controls what it does. ${ }^{2}$

- Sanford Kwinter

1 "The Doors of Perception."

2 Kwinter, "The Judo of Cold Combustion," 12. 


\section{THE GENIUS OF THE HINGED-DOOR-LEAF}

ALL THE EXPLORATION OF THIS THESIS BRINGS US BACK TO DISCOVERINC THE GENIUS OF ARCHITECTURE THROUGH THE GENIUS OF ITS ELEMENTS OF CONSTRUCTION, LIKE THE HINGED-DOOR-LEAF.

HERE, THE ASSUMPTION IS THAT THERE ARE MANY POSSIBILITIES THAT RESIDE IN THE GENIUS OF ELEMENTS OF CONSTRUCTION, AND WHEN GIVEN A CHANCE, CAN REDEFINE SOME OF OUR FUNDAMENTAL ASSUMPTIONS OF HIERARCHICAL PERCEPTION ABOUT HOW HUMANS, ARCHITECTURE AND THE BUILT-WORLD RELATE TO EACH OTHER. 


\subsection{THE ORDER OF THINGS 3}

It is possible to assume that most everyday-houses have four sides: two long and two shorter. There is an ambiguity in the 'form' of the HOUSE-THATSWINCS-OPEN-5 that provides an unexpected opportunity.

The difference between this house and the other version of a house that swings open is how it both uses an element with wall-like workings (DooR or barriers) as its Door. Also, it takes advantage of the fact when it is the house that swing open, HINGE has COLUMN-LIKE WORKINCS. Since a separating wall can also be looked at as a series of closely places columns, the HOUSE-THAT-SWINCS-OPEN-5 utilizes the workings of the WALL-LIKE barrier as part of the COLUMN-LIKE WORKINCS of HINGE for a house that both swings open and sits on a wall.

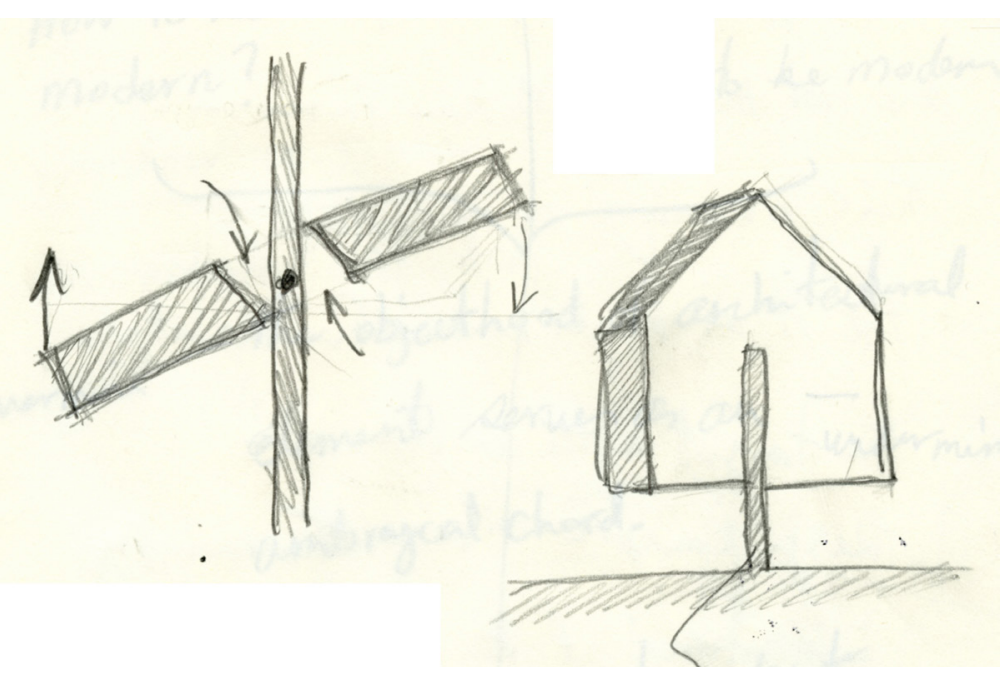

FIG. 7-2 HOUSE-THAT-SWINCS-OPEN-5, sketch 
1
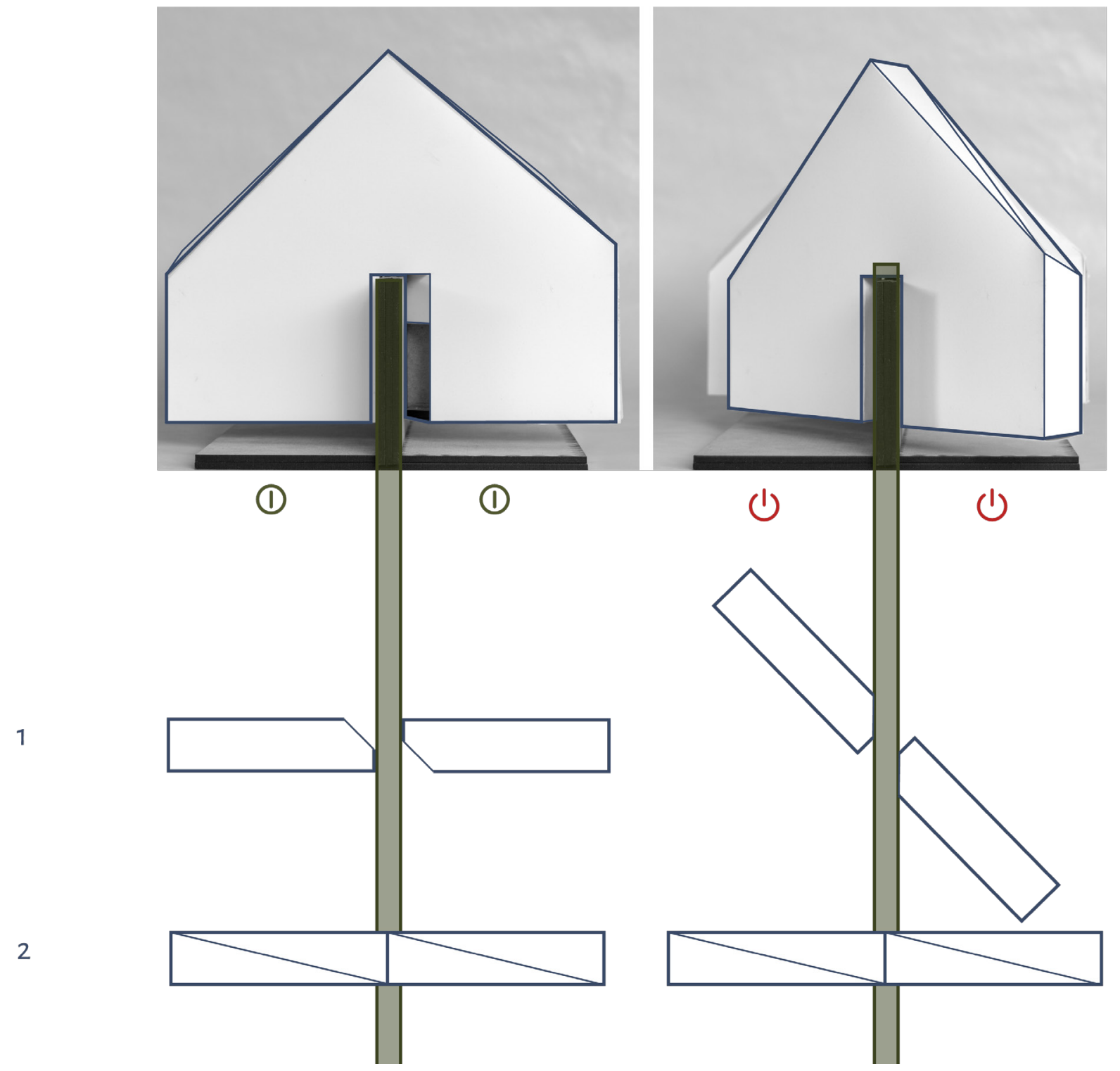

fig. 7-3 the WORKINGS of the

HOUSE-THAT-SWINGS-OPEN-5,

plan and elevation 
According to Paolo Vittorio Aureli, "Since the beginning of its history, the house is not only a potent symbol of the owner's mastery over the family as its private realm. It is also the locus of economy in its original sense of oikonomia, oikos nemein, or house management." 4 In the original Creek implications of the term, and in the philosophy of Aristotle, "economy is distinguished from politics as the house (oikos) is distinguished from the city (polis)." In this sense, "the relationships" that co-exist in "the realm of the house" are not "political." Instead, they are "despotic (master/slave), paternal (father/son), marital (husband/wife) and seen as natural and unchangeable."
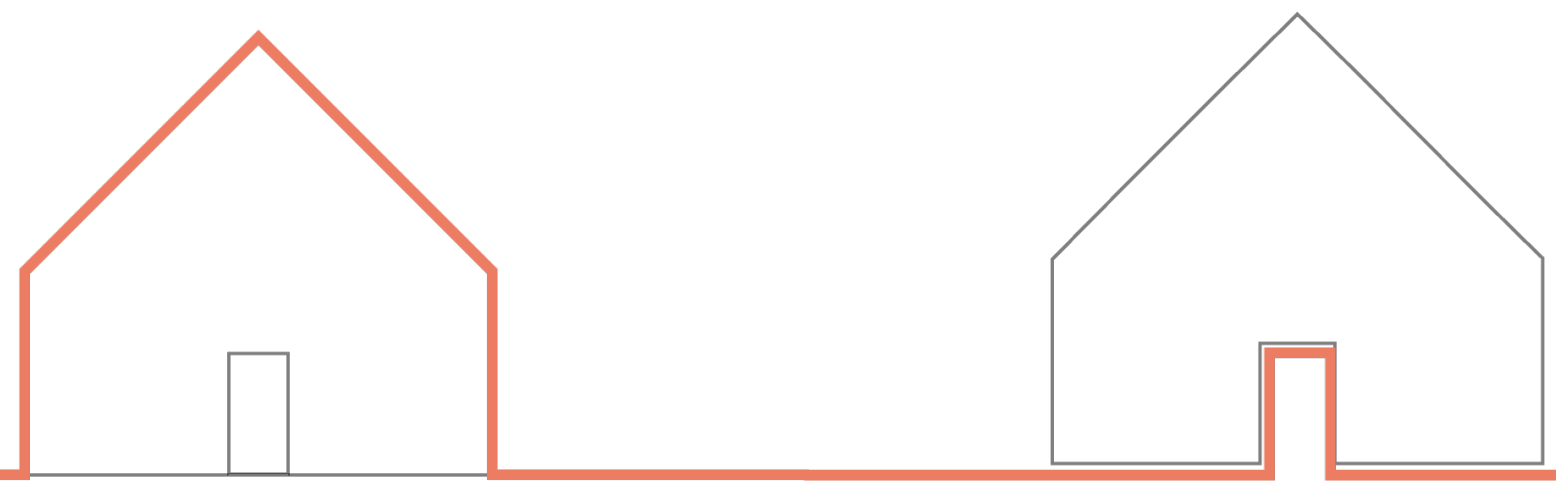

fig. 7-4 from the 'house' to the houses that swing open 
In a sense, oikonomia — as "household management" _ _ "can be described as a taxonomic order that assigns every detail of life to a specific place in the house." As such a definition implies, "economy" can be seen as "the translation of life into a typical spatial management." Thus, making "the form of the house [into] the most tangible manifestation of economy." Also, it is possible to see "economy" as "means that are strictly related to their end." Since, "the technique of administrating a large territory and its population always starts from the management of the most basic private space."

$$
* * *
$$

HERE, THE TWO LONG SIDES ARE MADE IN ONE CONTINUOUS MATERIAL (FABRIC?) WHICH LEAVES US TO PONDER HOW THE INTERIOR SPACE OF A HOUSE THAT SWINGS OPEN AND SITS ON A WALL COULD BE. 


\subsubsection{HOUSE-THAT-SWINGS-OPEN-5: POSSIBILITY 1}

One possibility is to assume that the whole house belongs to one family.

In this case, the idea of 'outside' and 'inside' is only relative to one inhabitant.

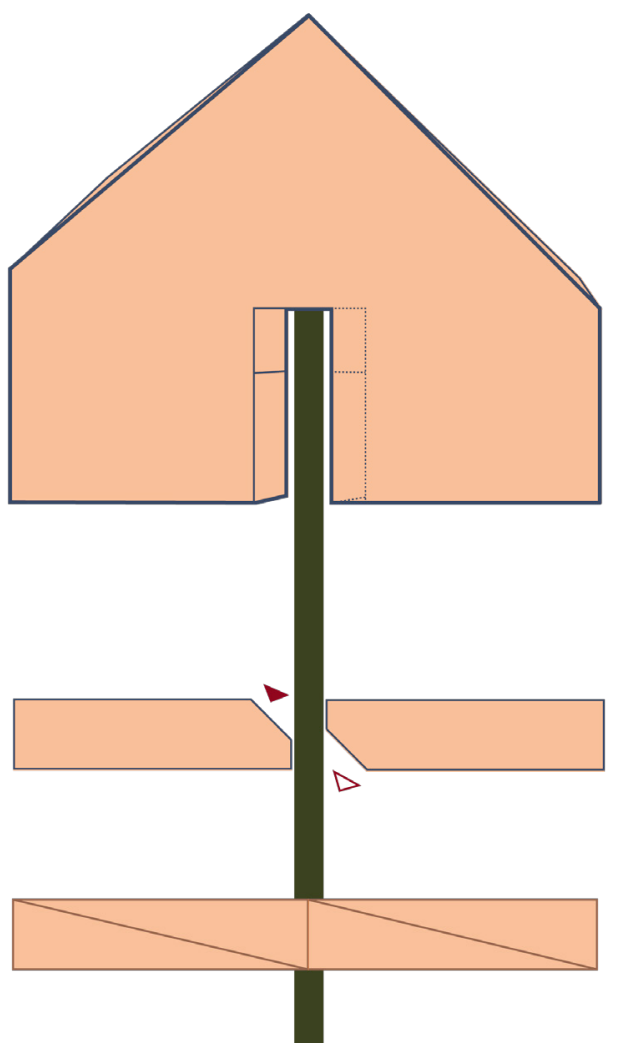

FIC. 7-5 HOUSE-THAT-SWINCS-OPEN-5, possibility-1
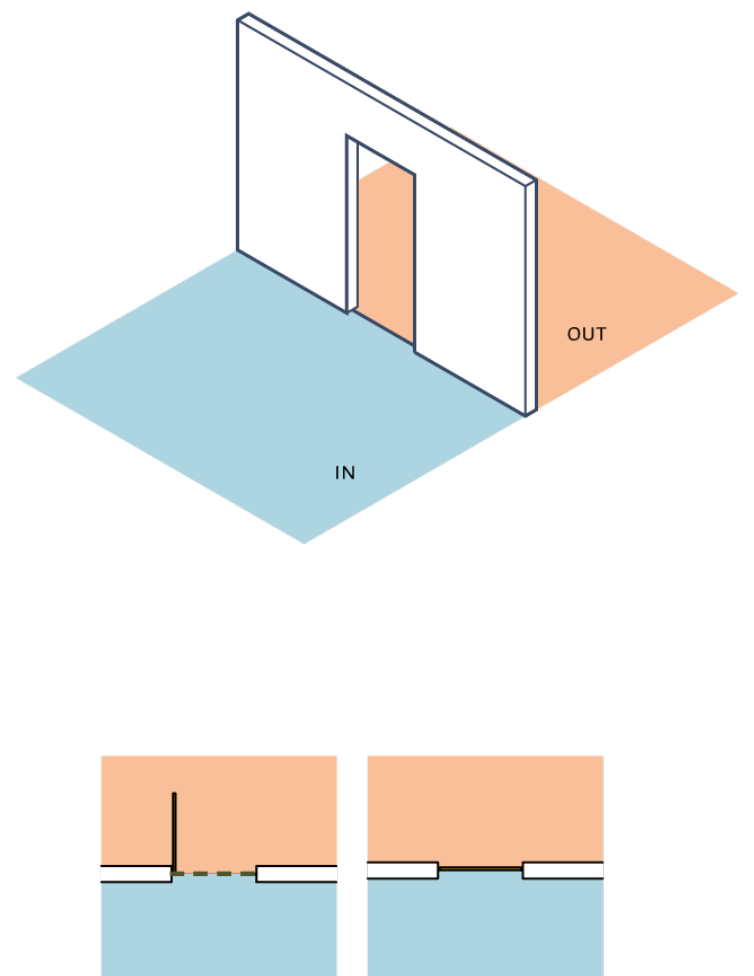

fig. 7-6 how 'doorness' and the 'threshold' see the door 


\subsubsection{HOUSE-THAT-SWINGS-OPEN-5: POSSIBILITY 2}

Following the pattern of critical inquiry that preceded this project -namely, THE COMMUNITY (2): DIPLOMATS and HOUSE-THAT-SWINCSOPEN-3 - it was the desire to further investigate the possibilities of architecture as a way to NECOTIATE 'monodic' ideals about the world through the GENIUS of the HINCED-DOOR-LEAF.

ANOTHER POSSIBILITY THAT MIGHT ADDRESS THIS CONCERN WOULD BE TO ASSUME THAT THE HOUSE-THAT-SWINCS-OPEN- 5 is shared by tWo inhabitants that live in two different 'places' demarcated the WALLLIKE BARRIER.

AT FIRST LOOK, THIS OPTION MIGHT SEEM LIKE THE ONE THAT SPEAKS ABOUT THE GENIUS of the HINGED-DOOR-LEAF, and its power to negotiate 'monodic' ideologies. However, at a closer look, it is possible to see how it mimics the way 'doorness' (the tease) and the 'threshold' (the fraud) have pigeon-holed the door into binary WORKINCS.

FIC.7-7 HOUSE-THAT-SWINGS-OPEN-5, possibility-2
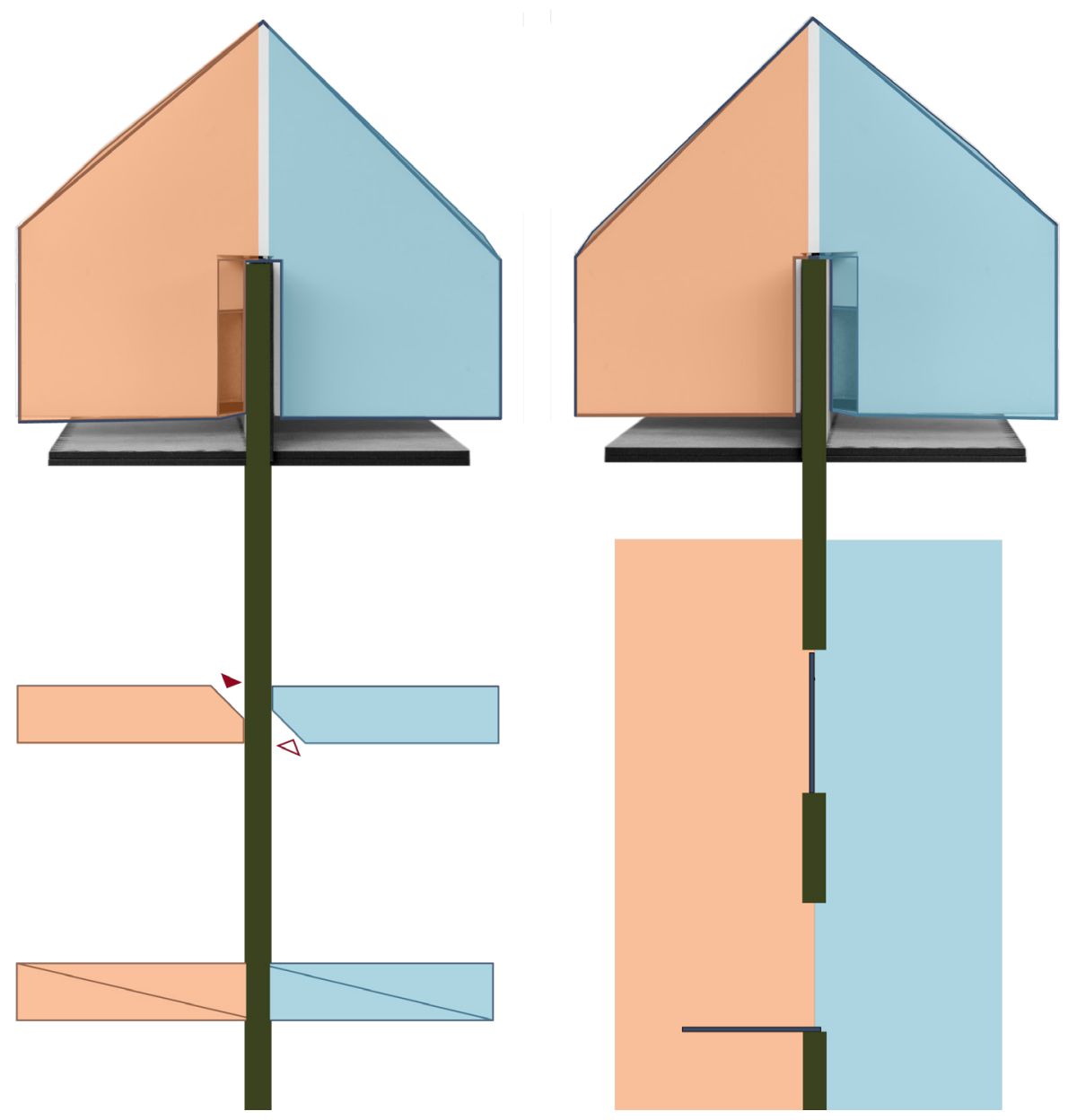

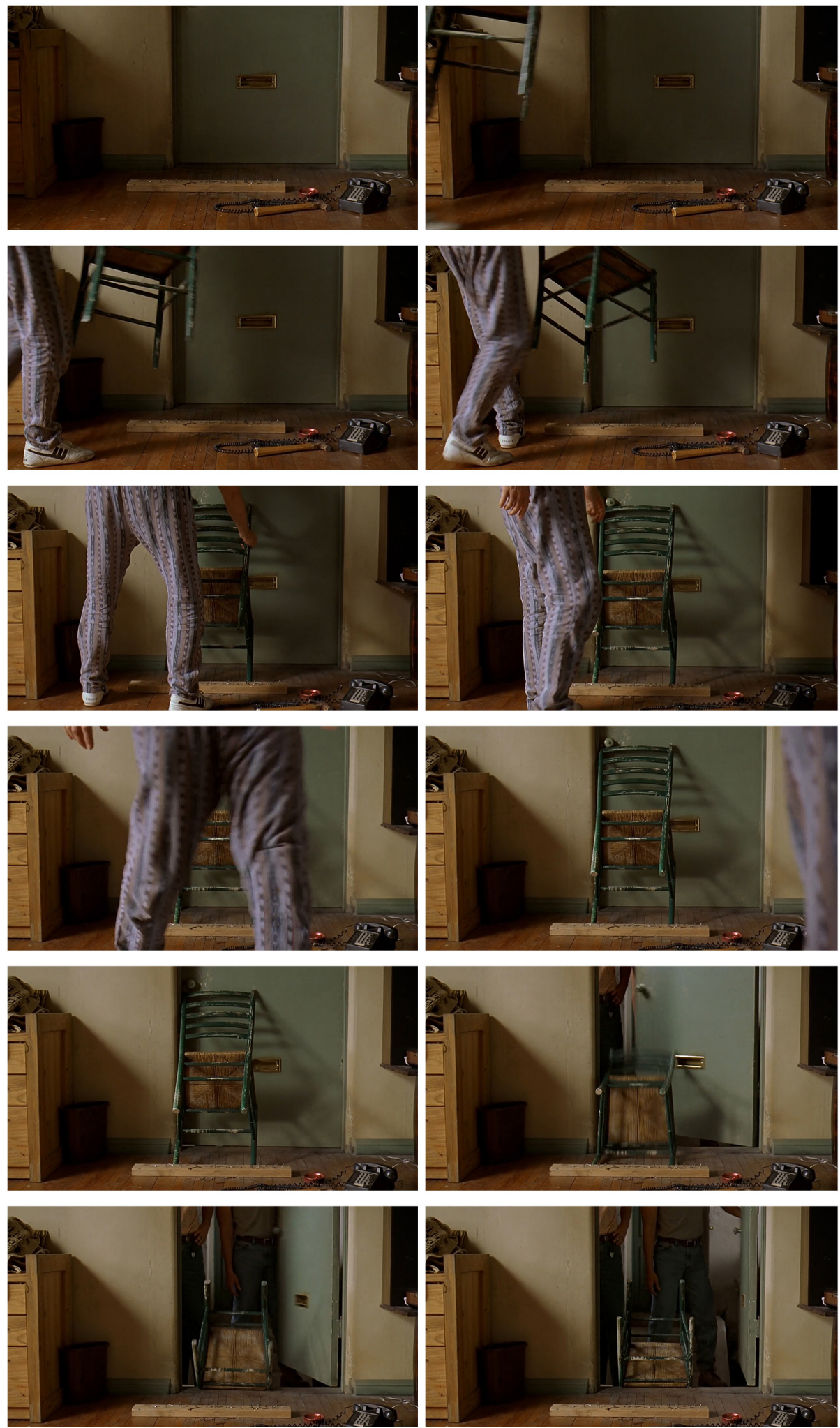

fig. 1-1 screenshot from The Big Lebowski 

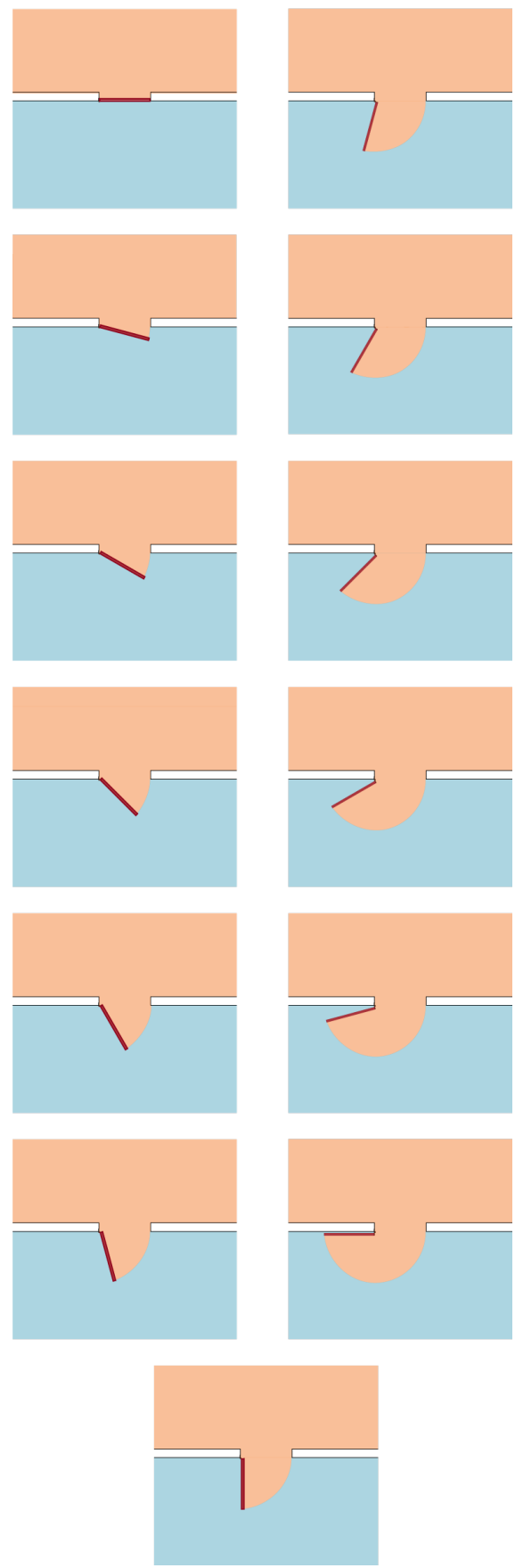

fig. 7-8 GENIUS OF THE HINGEDDOOR-LEAF (THE DOOR): NECOTIATION

\subsubsection{THE DOOR (9)}

Another interpretation of economy can be that it is about recording and balancing our losses and gains. The notion of 'balance' sheet and how an accountant recuperates losses at one column with gains from others. In fact, the matter of fact approach to economy as the bottom-line can itself present opportunities for DESICNCONSPIRACIES.

In SHORT REAL, when a wall-like barrier is constructed to mark a 'threshold' and divide, protect and imprison people from the both sides, material and energy is spent on building that wall.

The door is a universal conversation that operates as a territory for NECOTIATIONS. Therefore, as the door offers options, it also offers vulnerability, because our frame of reference, our position is always in flux in relationship to its asymmetrical WORKINCS.

Paradoxically, on the first look, the direction of swing might seem like an unfair advantage. But the cost of having the door swing to your side, is offset by how you can reinforce your control over its operation. You can have decided when it is a door, and when it is a wall. 

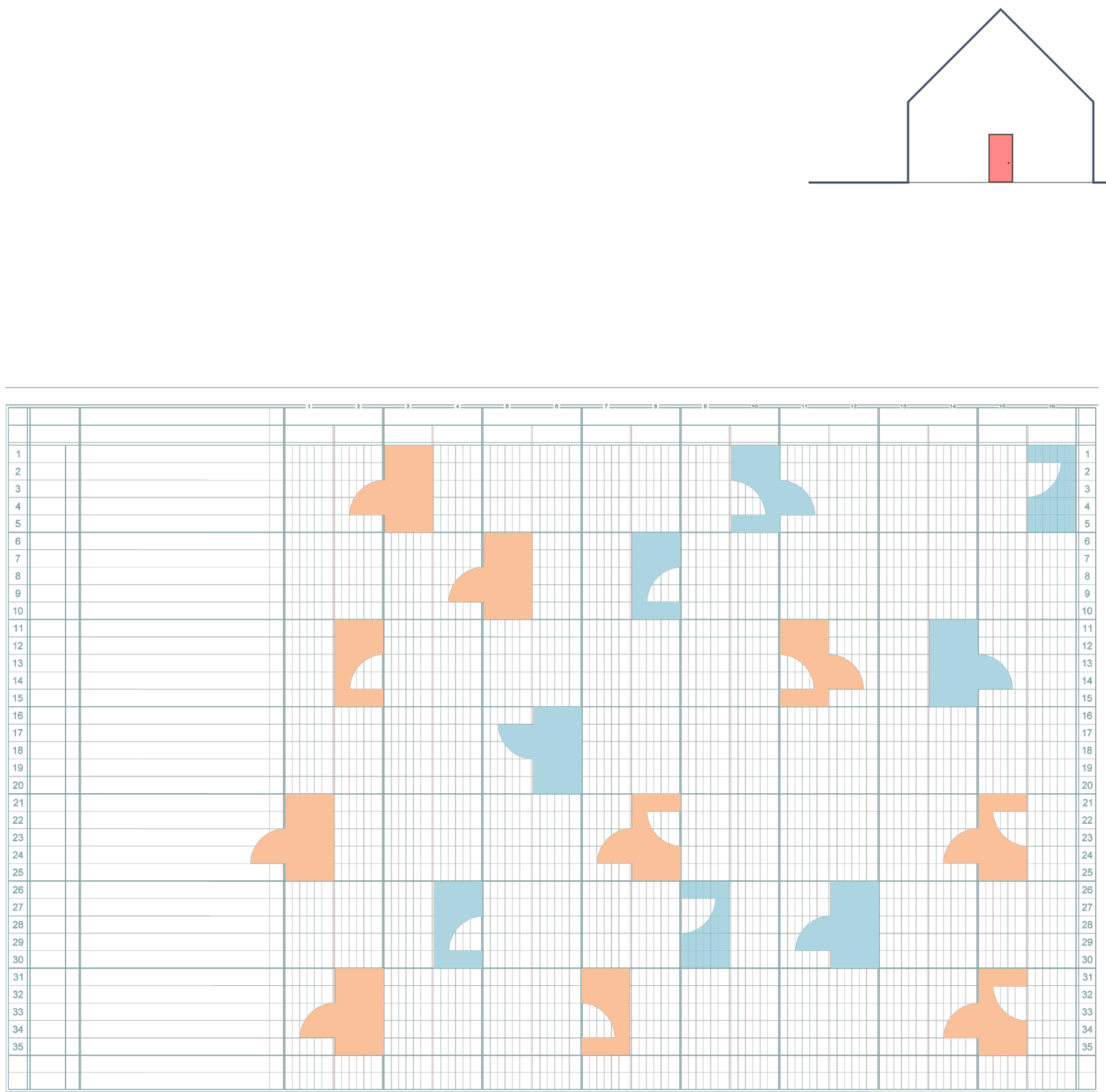


\subsection{THE COMMUNITY (3): NEIGHBOURS IN DIFFERENT 'PLACES'}

There is no site for this house, and like HOUSE-THAT-SWINCS-OPEN-3 it can be placed on any wall on the list of world barriers. For instance, it could work at a place like Belfast (pg. 212-13) as the walls that were once dividing the population are now part of the everyday landscape of the inhabitants. Maybe instead of tearing them down they can be NECOTIATED. Because tearing down a wall does not necessary erase the ideologies that built it. But those ideologies can be NECOTIATED when they are materialized as walls that can be DOOR-LIKE in FLAT WORLD.

HOUSE-THAT-SWINGS-OPEN-5 NECOTIATES wall-like barriers that demarcate two separates 'places'. As a result, it displaces wall and the 'monodic' perceptions that built it.

Here, people are also displaced but only to NECOTIATE the WALL-LIKE barriers. They transgress the wall everyday through the HOUSES THAT SIT ON THE WALL. They enter from one 'place' and cross the 'threshold' to live in another.

They are neighbours even though they live in different 'places'. 


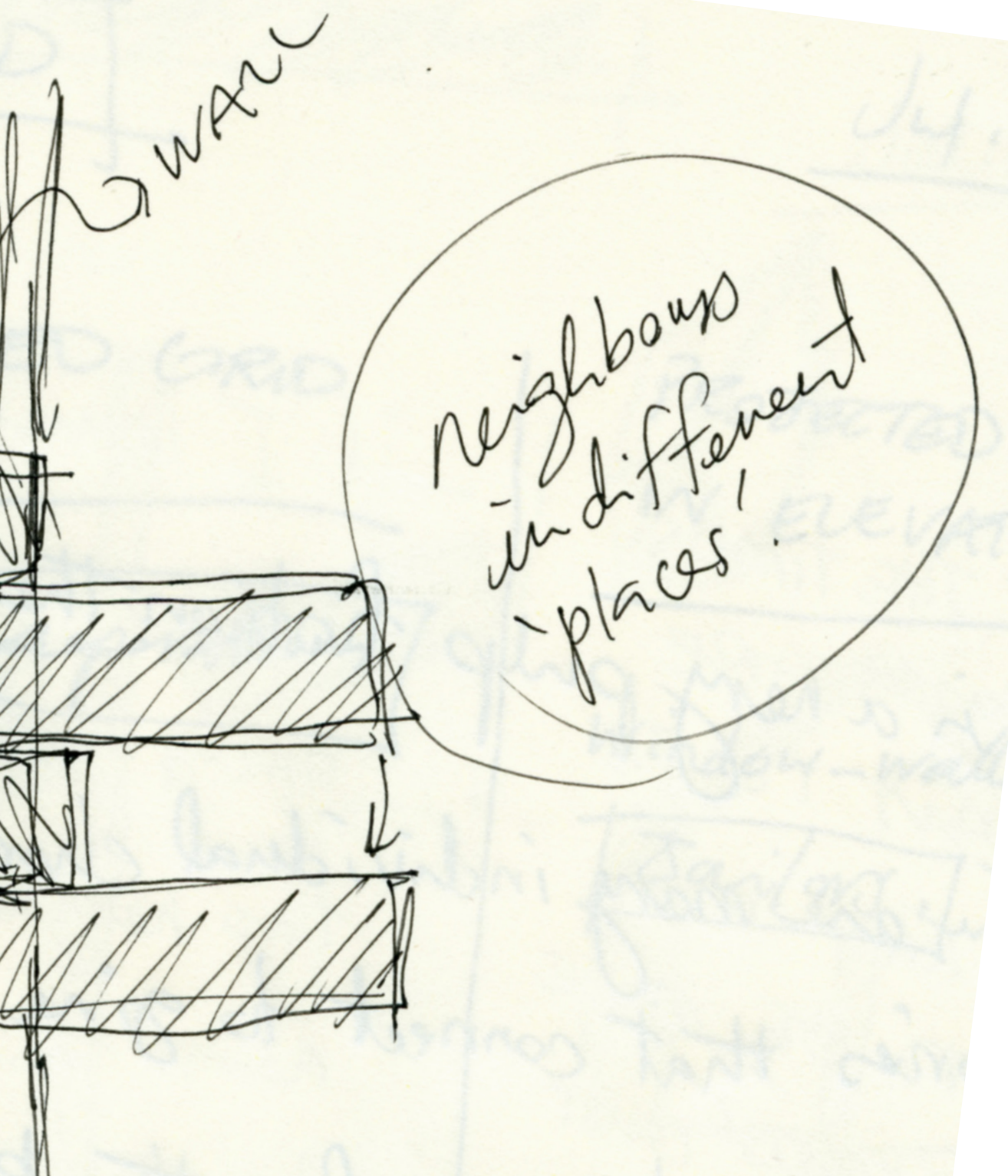

fig.7-11 neighbours in different 'places', sketch 


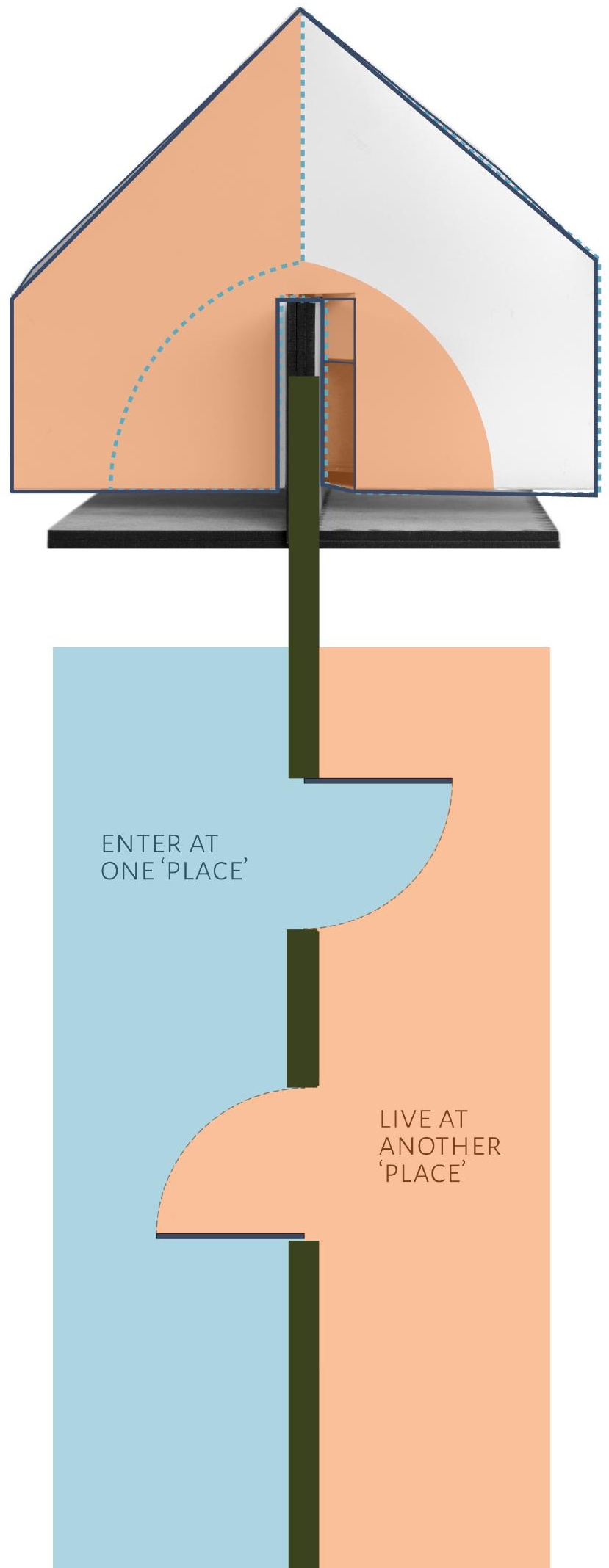

FIG. 7-12 HOUSE-THAT-SWINGSOPEN-5: neightbours in different 'places' 
FIC. 7-13 HOUSE-THAT-SWINCSOPEN-5: neightbours in different 'places'

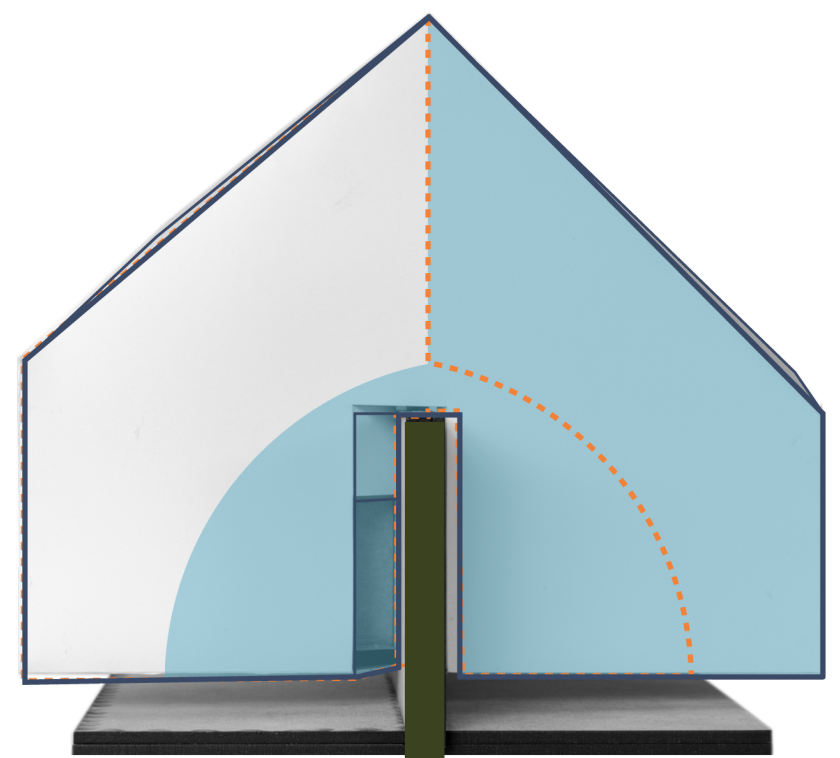

ENTER AT

ONE 'PLACE'

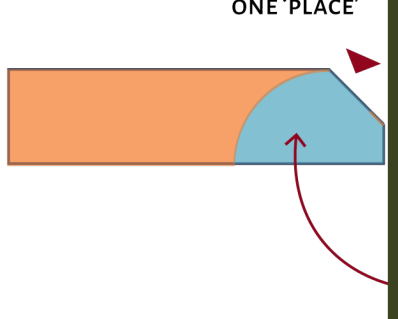

ENTER AT ONE 'PLACE'

LIVE AT

ANOTHER

'PLACE'
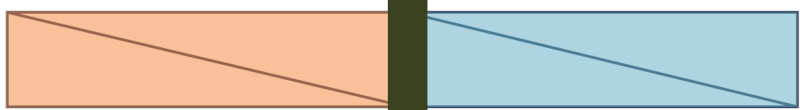

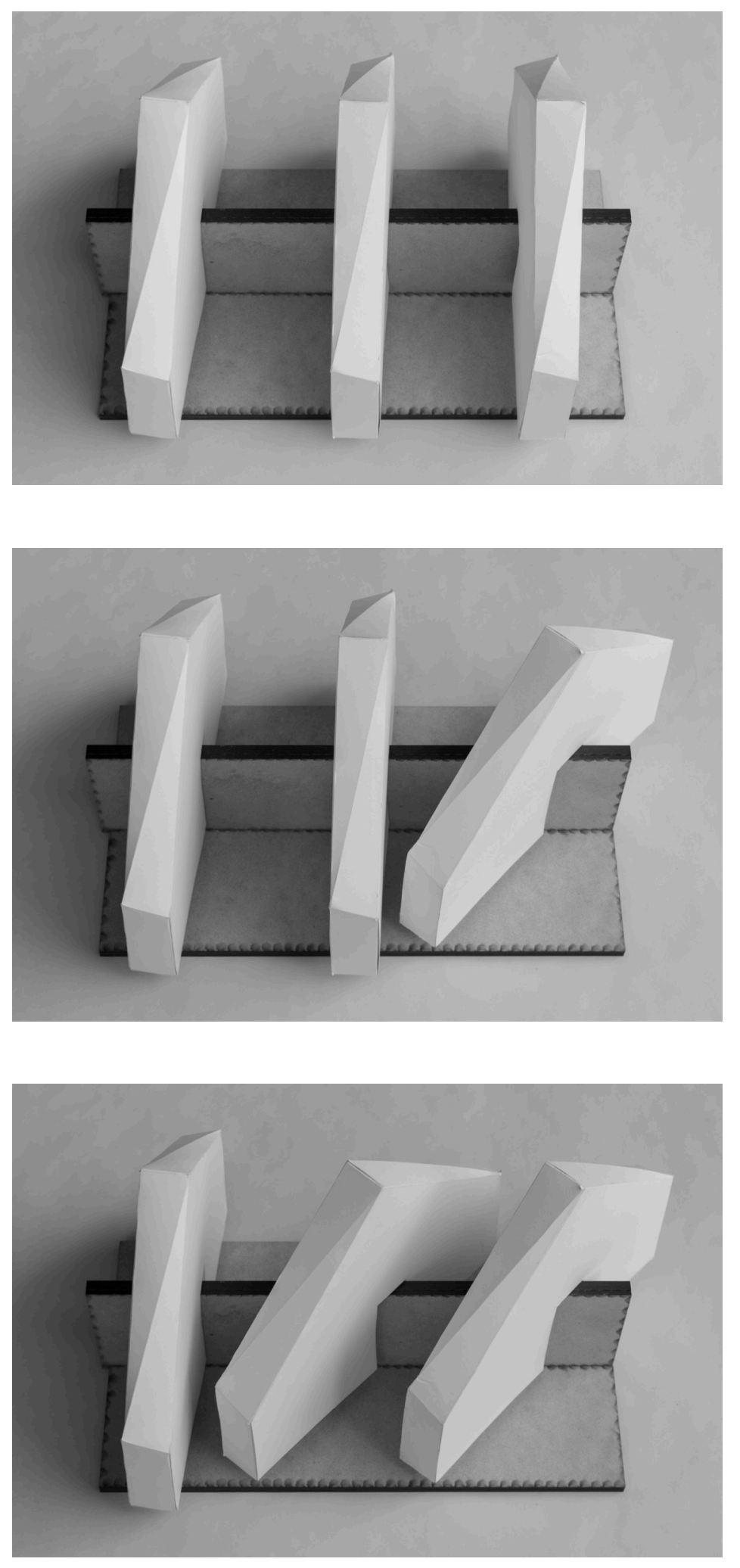

FIC. 7-14 HOUSE-THAT-SWINGSOPEN-5, functional models 


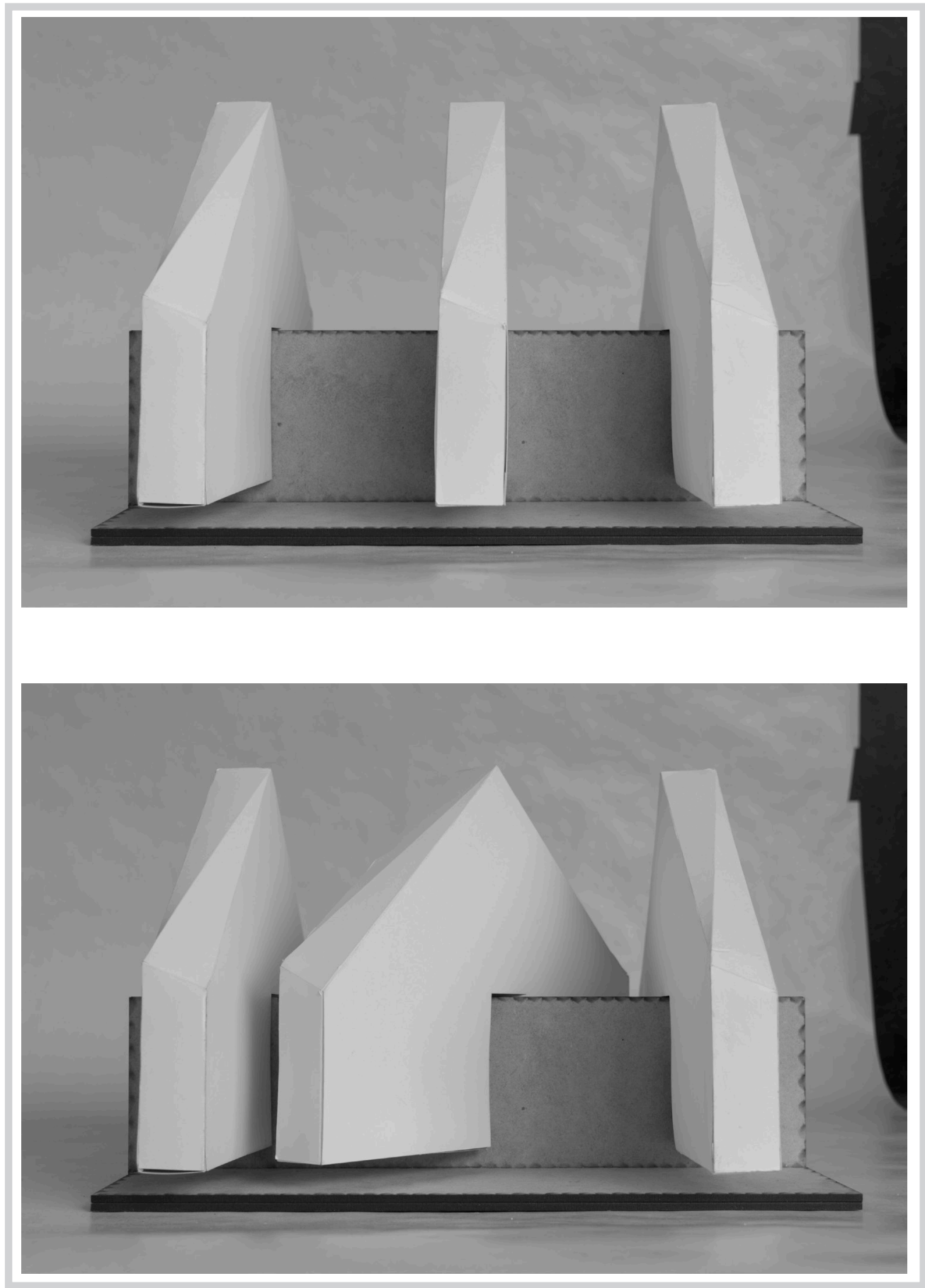

FIC. 7-15 HOUSE-THAT-SWINCS-

OPEN-5, functional models 


\subsection{CODA}

"Ideology provides a type of knowledge whose major effect is the preservation of existing social systems and their institutions rather than the explanation of that reality. (...) Thus, in order to make the separation or distinction between an architectural ideology and Architecture (theory), one needs to define the former as the object of study of the latter."

-Mario Gandelsonas, "Linguistics in Architecture"

$$
* * *
$$

A work of architecture is an event and operates in multiplicities of dimensions. It changes our frame of reference for today, yesterday and tomorrow. Also, the work itself undergoes changes as it is occupied, interpreted, and weathers. It is constantly remade and exists in a state of constant becoming. So, a work of architecture is an event by itself and for itself. As an 'event', architecture is autonomous and contingent, and it is all understood retroactively.

Referring to Žižek's comment that 'event is an effect that seems to exceed its causes,' and Karatani's referring to architecture 'as an event par excellence', we can see how architecture operates in a paradoxical state. Architecture as an image, drawing, building, or idea (and ideal) is always understood retroactively; while it must have a direct effect on the material world.

The canon of architecture is relatively small. For instance, modern architecture can be distilled down to few handful of 'events' (Dom-ino House, Barcelona pavilion) that changed the course of architecture. As ideas, or ideals, these buildings were retroactively understood to have shifted how we constructed the world around us. They were the result and solution to the socio-economic issues of their days, but their importance stems from their understanding of precedents, techniques and tectonics of architecture, alongside the larger social developments around them.

$$
* * *
$$

The focus on the earthly and everyday realities of architecture as personified through the HINGED-DOOR-LEAF (THE DOOR) is not an anti-theoretical or anti-imaginative approach to architecture. Instead, it is an speculative approach that aims to define a locus for its operations within the very earthly and everyday realities of architecture. 
This passage from "Give me a gun and I will make buildings move," by Bruno Latour, explains the thinking here:

Only by generating earthly accounts of buildings and design processes, tracing pluralities of concrete entities in the specific theoretical frameworks outside architecture, will architectural theory become a relevant field for architecture, for end user, for promoters, and for builders. That is, a new task for architectural theory in coming to the fore: to [...] tackle the admittedly daunting task of inventing a visual vocabulary that will finally do justice to the 'thingly' nature of buildings, by contrast to their tired, old 'objective' nature. ${ }^{9}$

The projects in this thesis might seem 'political' in the sense that they deal with some of the contemporary problems of our world. Yet, they are only political in the sense that they seek to examine the CENIUS of architecture as a mega-system and expand its possibilities through the CENIUS of its everyday and earthly ELEMENTS OF CONSTRUCTION. This attitude might be best described by the distinction made between 'scientific' and 'political' work by Umberto Eco:

Every scientific work has a positive political value in that it contributes to the development of knowledge (every action that aims at stopping the process of knowledge has a negative political value); but on the other hand, every political enterprise with a chance of success must be grounded in the scientific diligence. ${ }^{10}$

And, an active position toward understanding and exploring the door free from dogmas and binary oppositions might not only reveal some previously unexplored possibilities of architecture but also other possibilities about the whole of our designed world. As Angelus Eisinger believes, "architecture manifests itself as an instrument for exploring the world."11

$$
<<>>>
$$


8 APPENDIX 


\subsection{Diagram: NutRIENT SYNTHESIS}

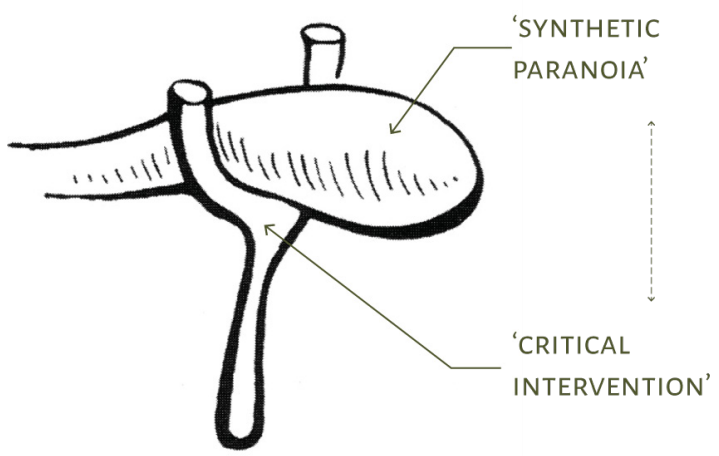

In Delirious New York, Koolhaas reproduces a diagram made by Dalí that illustrates PcM at work. He does this twice, with two different captions. The first time, it refers to Dalís interpretation of PcM as a "limp, unprovable conjectures generated through the deliberate simulation of paranoiac thought process." The second instance, Koolhaas compares the PcM diagram to that of a diagram for reinforced concrete:

a mouse-grey liquid with the substance of vomit, held up by steel reinforcements calculated according to the strictest Newtonian physics; infinitely malleable at first, then suddenly hard as rock. ${ }^{2}$

fig. 8-1 Salvador Dali, Diagram of the workings of the Paranoid-critical Method [text added by author] 


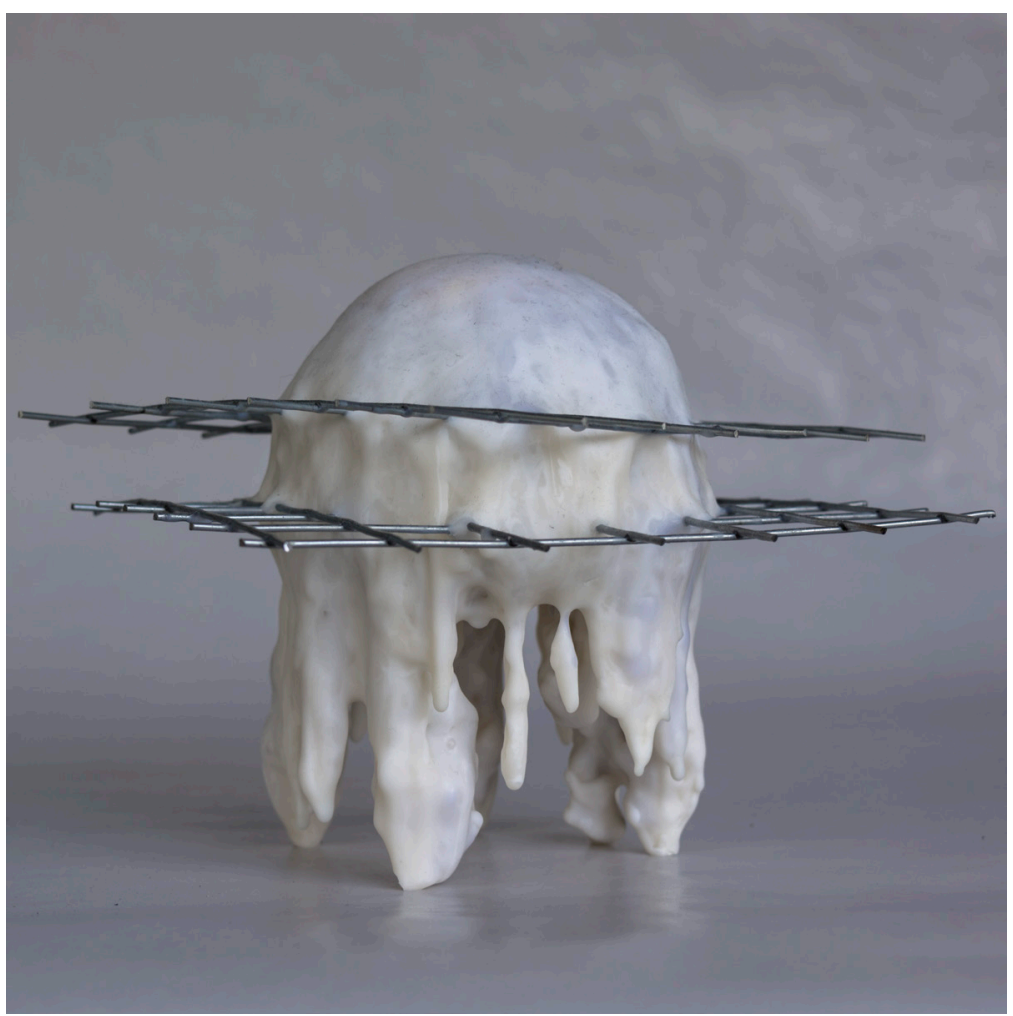

fig. 8-2 material synthesis of PcM diagram 

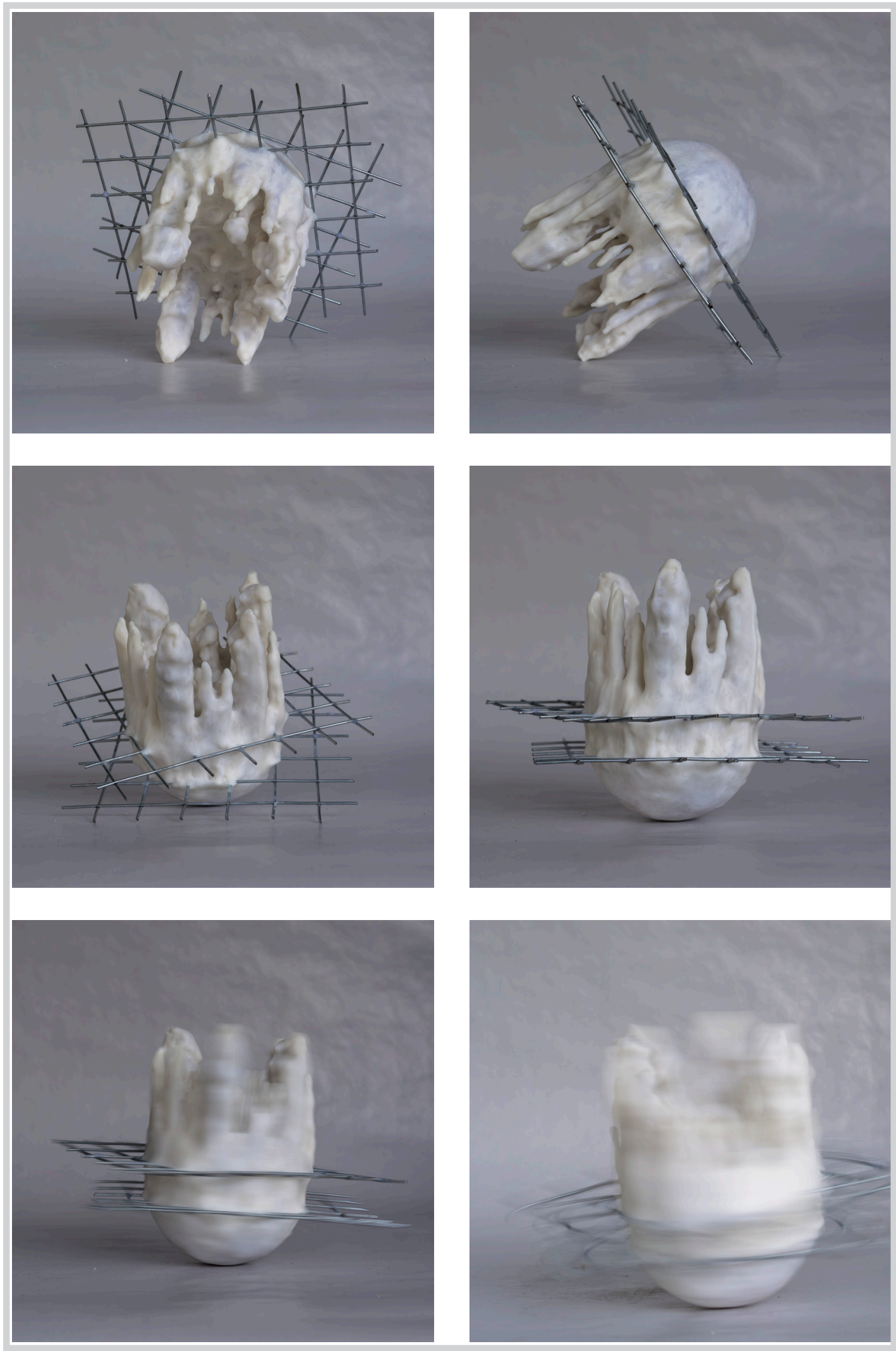

fig. 8-3 material synthesis of PcM diagram 
fig. 8-4 scanographs of the material synthesis of PcM diagram
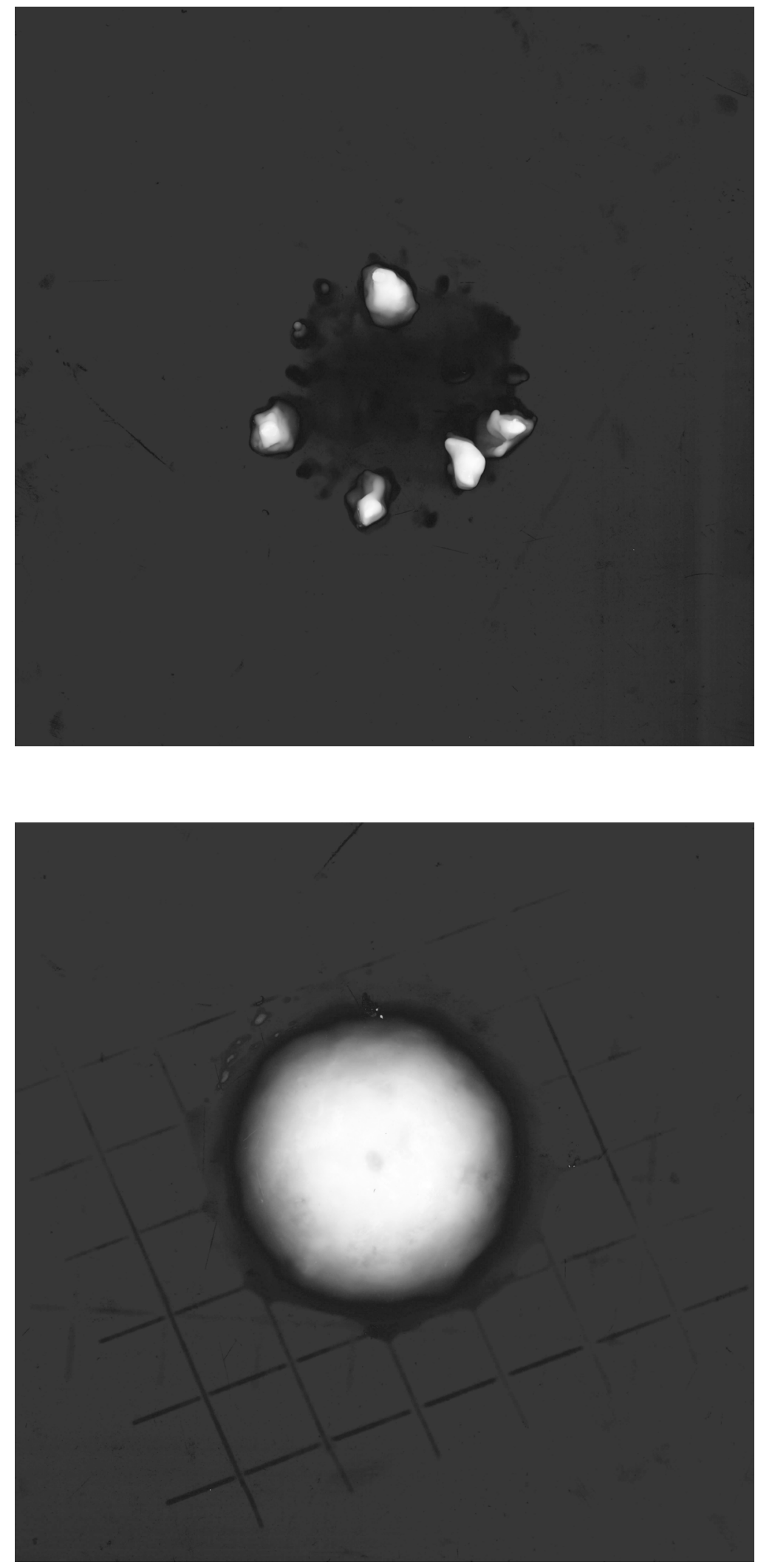


\subsection{One Door, Few Flat Houses}

\subsubsection{MINIMUM OPENING}

When it is the house that swings open, the house does not have to fully open to give the inhabitants access to the inside. Flat House only needs to turn 60-degrees. What are the possibilities of this?

\section{CAN MORE THAN ONE HOUSE ATTACH TO THE SAME DOOR?}

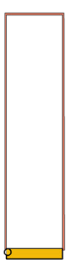

$0^{\circ}$

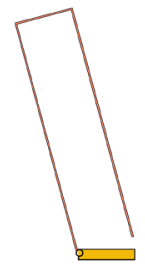

$15^{\circ}$

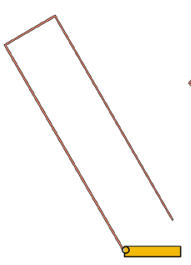

$30^{\circ}$

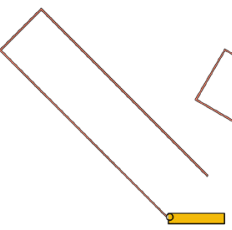

$45^{\circ}$

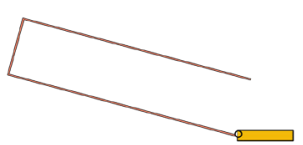

$75^{\circ}$

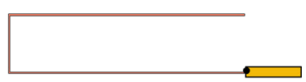

$90^{\circ}$

fig. 8-5 minimum opening of a flat house 
8.2.2 FEW HINGED HOUSES

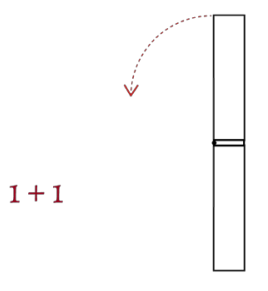

(1)

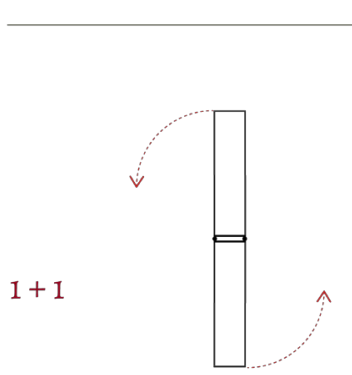

(1)
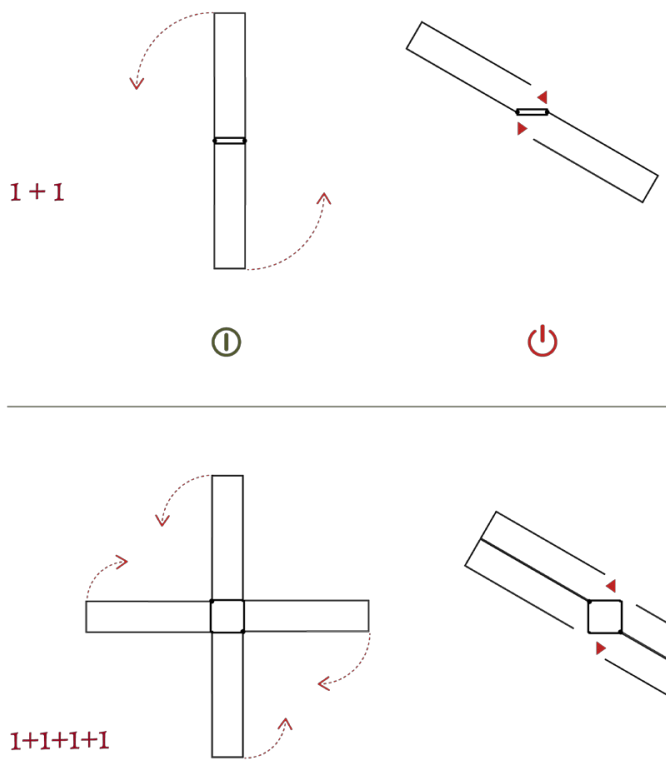

(1)
し

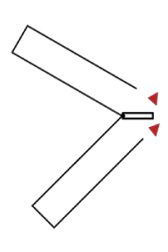

し
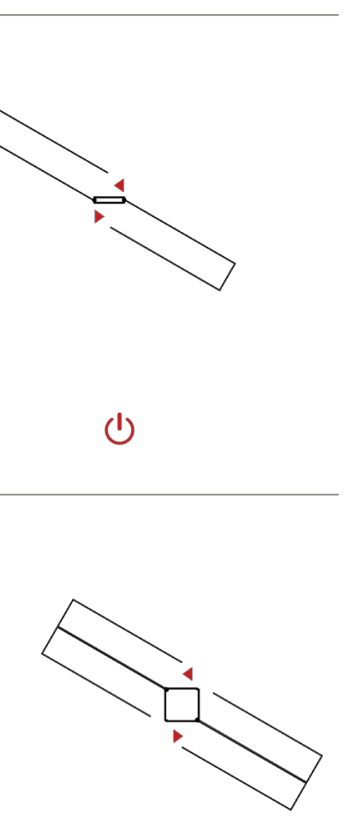

১

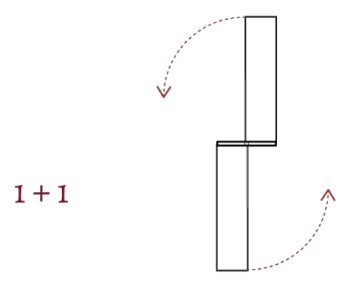

(1)

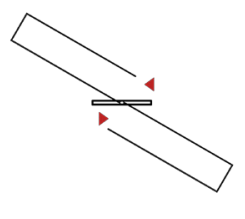

()

2
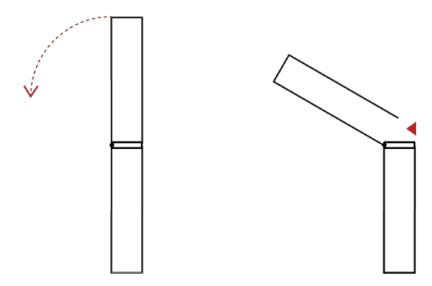

(1)

()

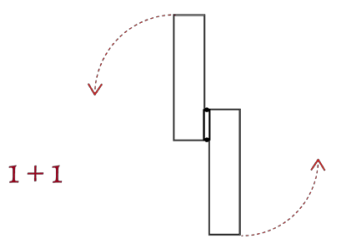

(1)<smiles>C1CCCCC1</smiles>

U)

fig. 8-6 few hinged houses 

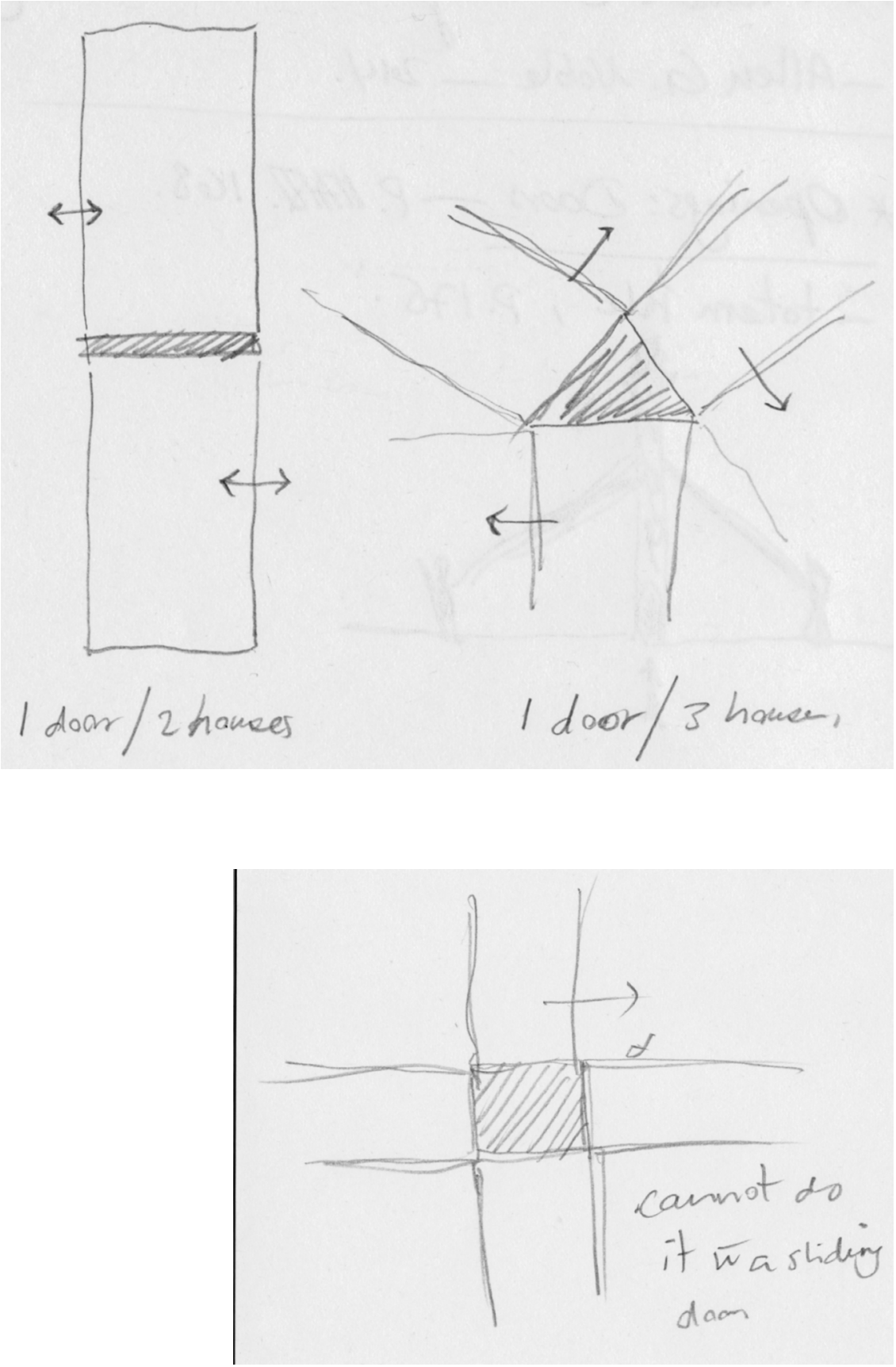

fig. 8-7 possibilities of a sliding house, sketch fig. 8-8 possibilities of a sliding house, sketch 


\subsubsection{FEW SLIDING HOUSES}

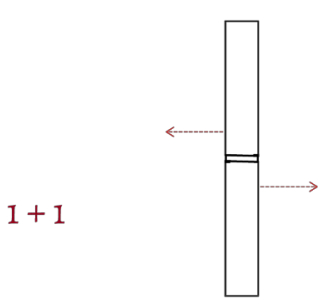

(1)
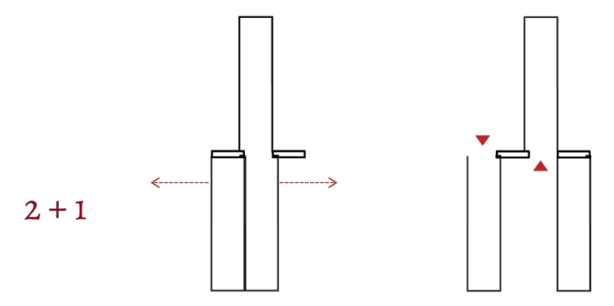

(1)

(J)

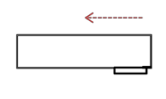

1

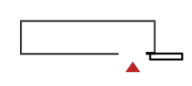

(1)

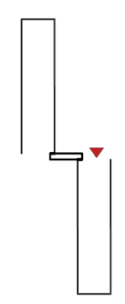

山
(1)

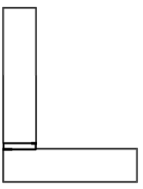

(1)

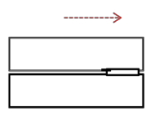

(1)

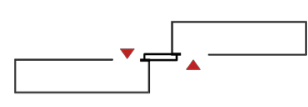

()

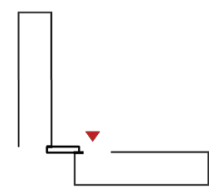

(J)

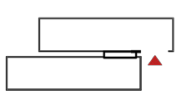

১) 

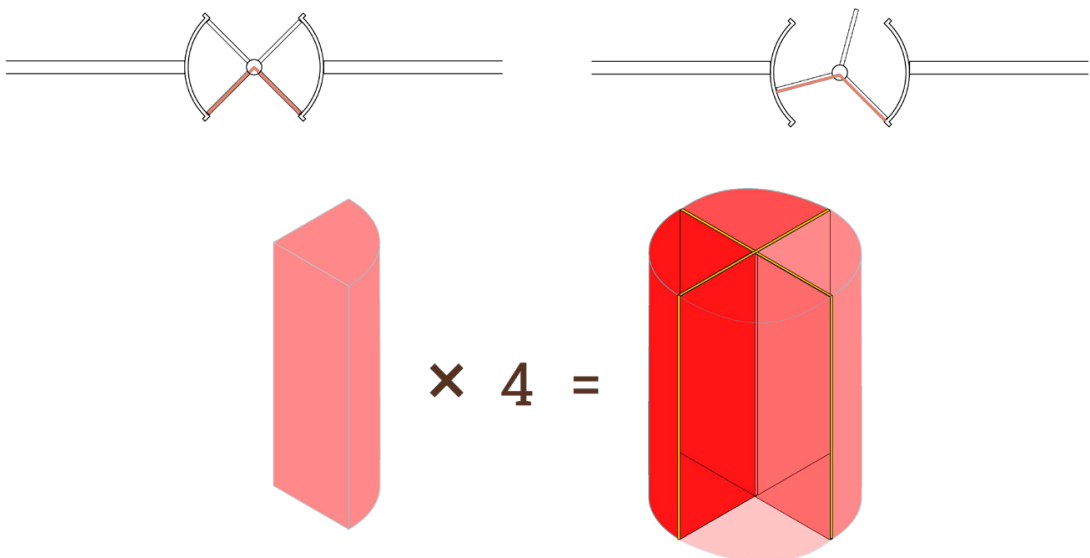

fig. 8-10 flexible space of a revolving door

Revolving Doon - always clased.
R.K. -DooR. Ps.620-l
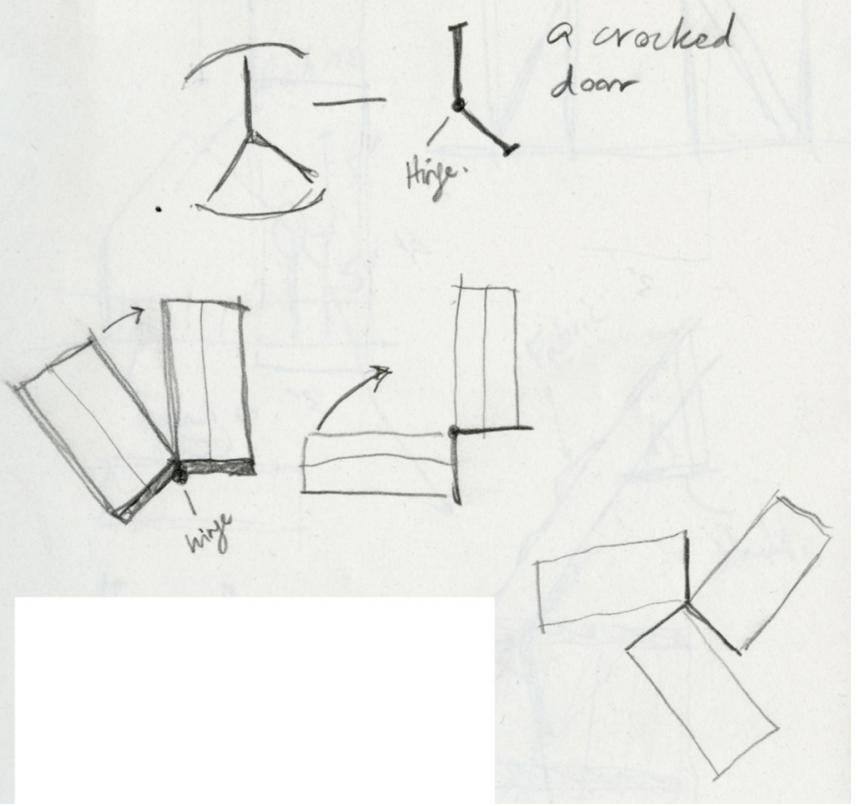

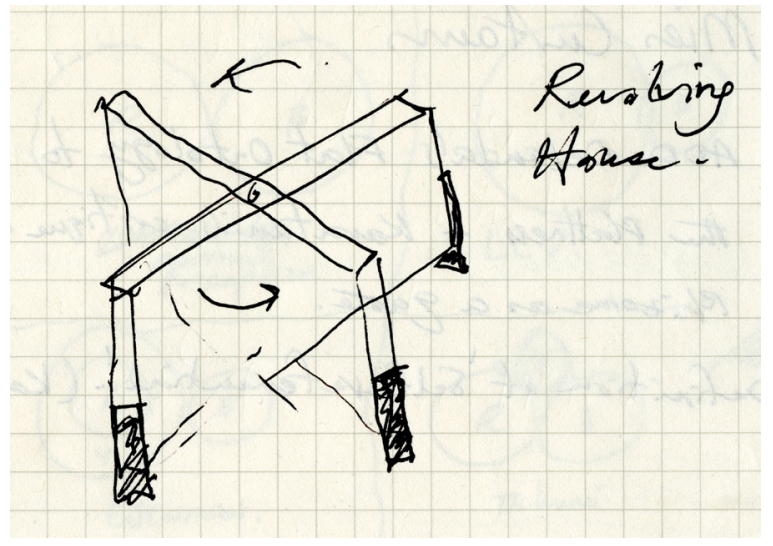

fig. 8-11 possibilities of a revolving house, sketch

fig. 8-12 possibilities of a revolving house, sketch 


\subsubsection{FEW REVOLVING HOUSES}

\subsubsection{The House That SWINGS Open (V.6)}
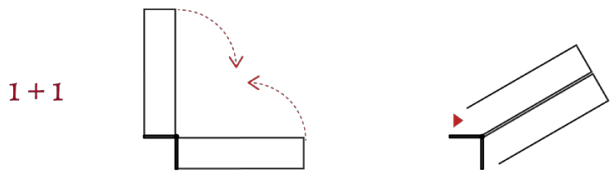

(1)

し

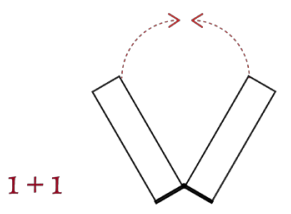

(1)

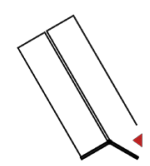

し

山

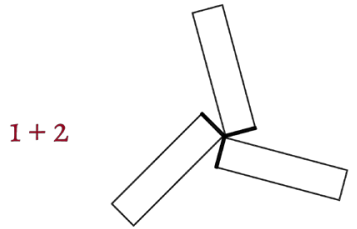

(1)

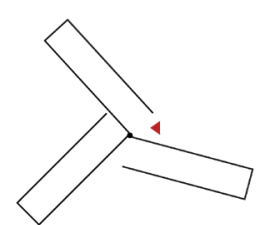

()
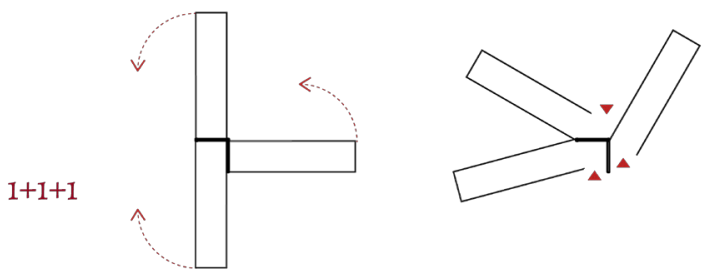

(1)

১

$1+2$

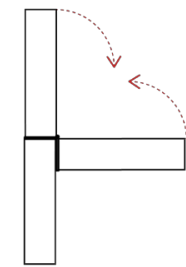

(1)

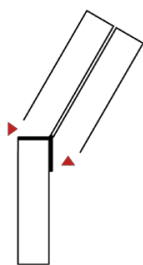

(1)

fig. 8-13 few revolving houses? 


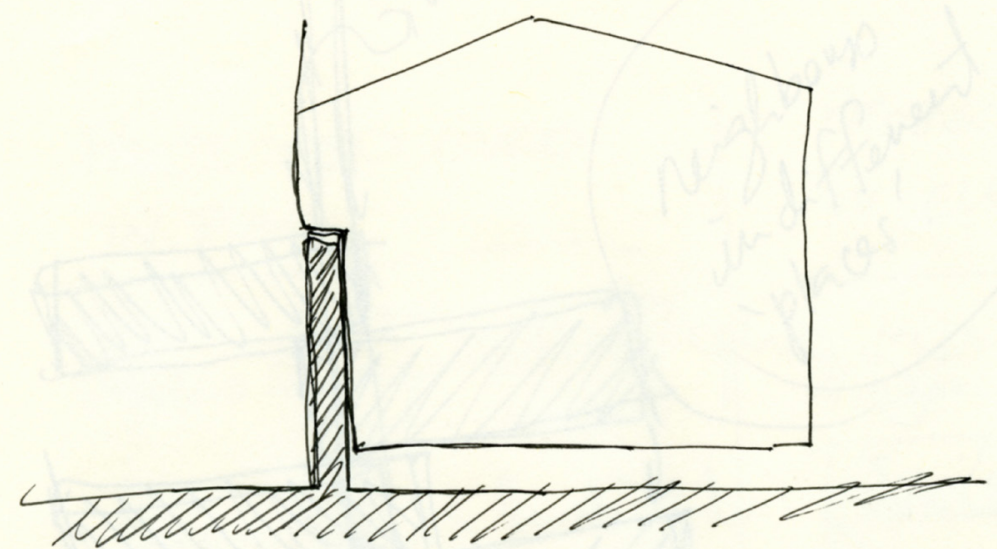

fig. 8-15 house-that-swings-open-6, sketch

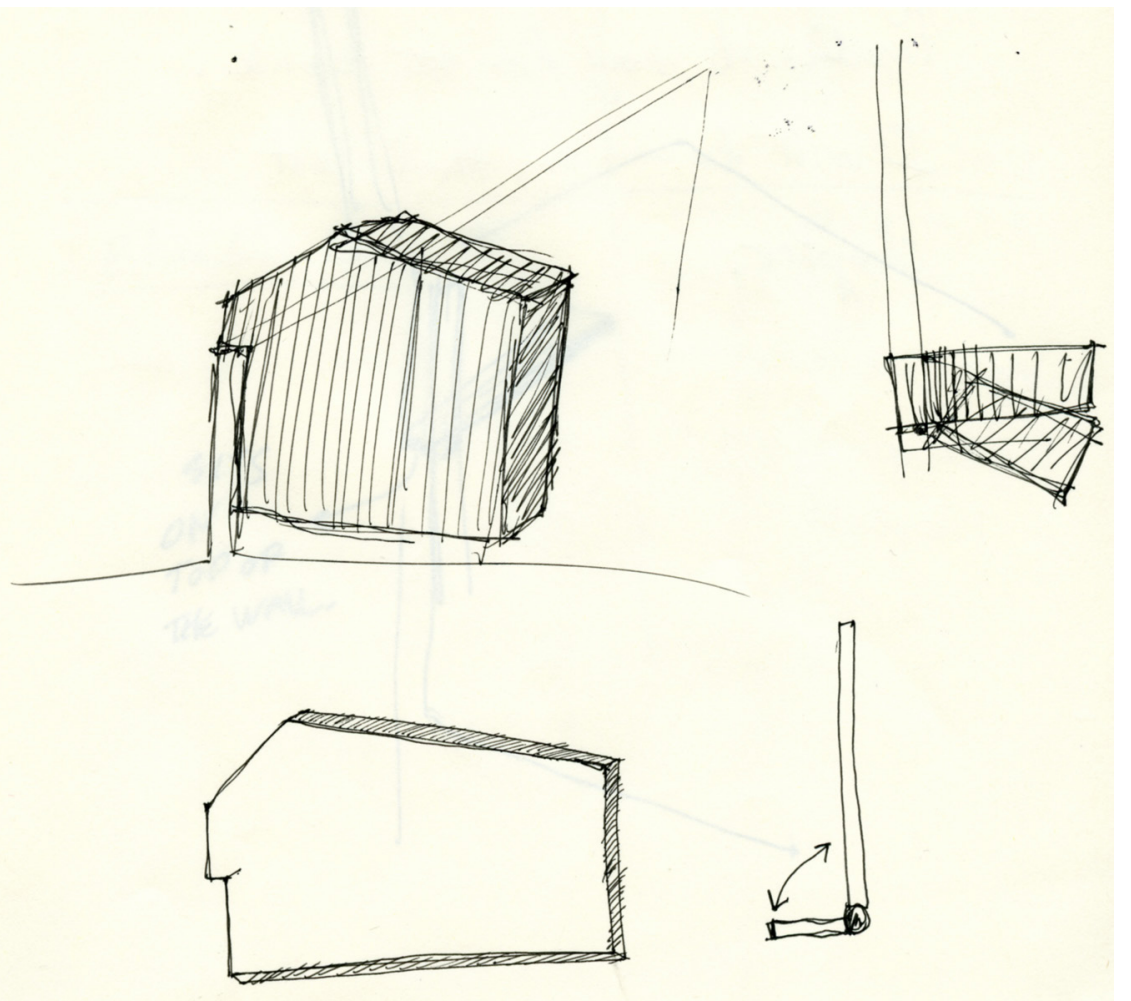

fig. 8-16 house-that-swings-open-6, sketch 
fig. 8-17 house-that-swings-open-6, sketch
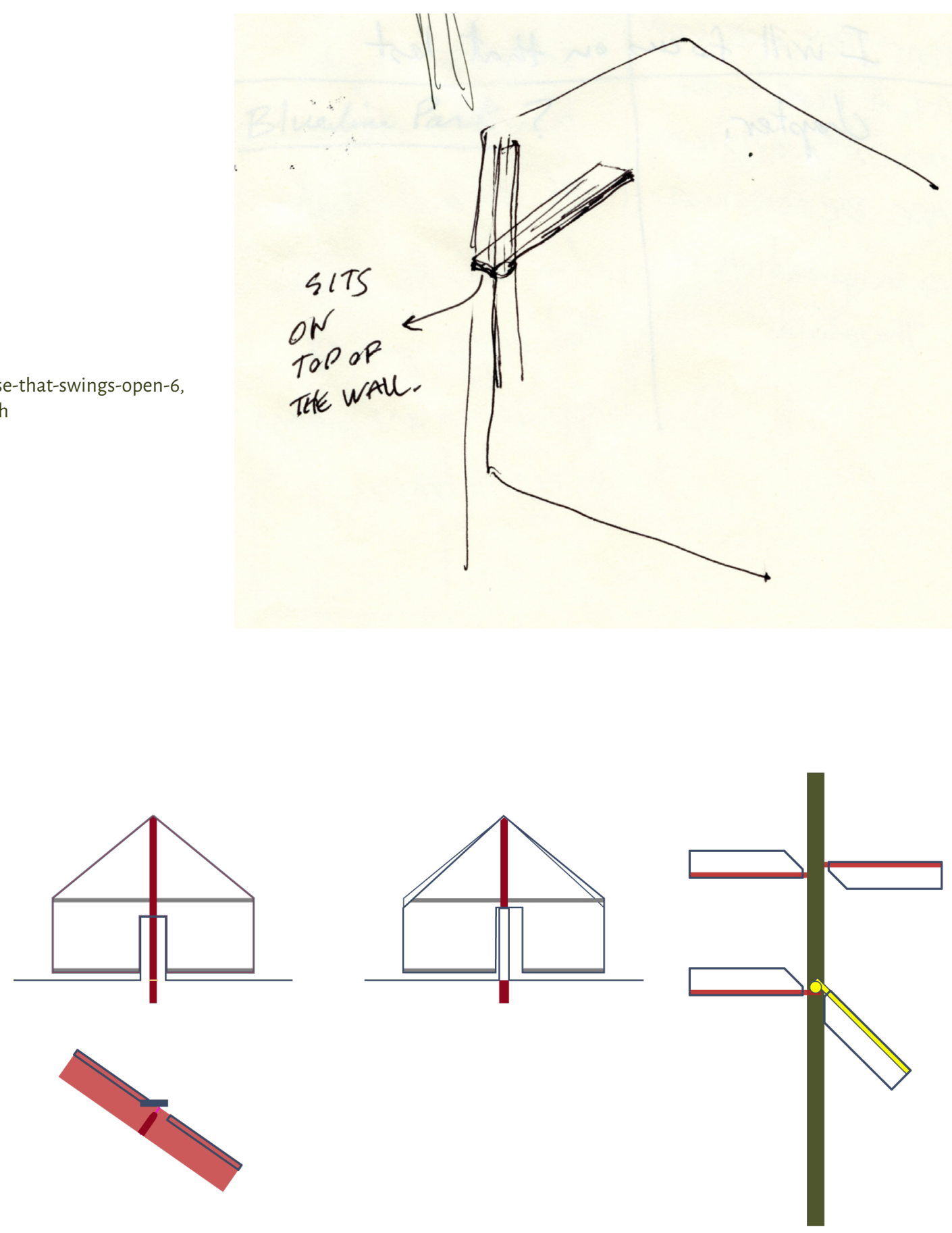

fig. 8-18 house-that-swings-open-6, diagram 


\section{BIBLIOGRAPHY}

Alison, Jane. “The Surreal House.” In The Surreal House, edited by Jane Alison, Mary Ann Caws, and Barbican Art Gallery, 14-33. London : New Haven, CT: Barbican Art Gallery; In association with Yale University Press, 2010.

Anderson, Stanford. "Rational Reconstructions and Architectural Knowledge." In Architecture in the Age of Empire: 11th International Bauhaus-Colloquium [Weimar, April 1st 5th 2009]; Symposium Reader = Die Architektur Der Neuen Weltordnung; 11. Internationales Bauhaus-Kolloquium [Weimar, 1. - 5. April 2009]; Tagungsband, edited by Kristian Faschingeder, Kari Jormakka, Norbert Korrek, Olaf Pfeifer, Gerd Zimmermann, Internationales Bauhaus-Kolloquium, Bauhaus-Universität Weimar, and Bauhaus-Universität Weimar, 160-73. Weimar: Verl. der Bauhaus-Univ, 2011.

“Thinking in Architecture." In Ptah, 08:72-86. Helsinki: Alvar Aalto Academy, 2009.

Aureli, Pier Vittorio. “The Dom-Ino Problem: Questioning the Architecture of Domestic Space." Log, no. 30 (2014): $153-68$.

Bachelard, Gaston, and M. Jolas. The Poetics of Space. Boston: Beacon Press, 1994.

The Poetics of Space. New edition. Penguin Classics. New York, New York: Penguin Books, 2014.

Baggini, Julian, and Peter S. Fosl. The Philosopher's Toolkit: A Compendium of Philosophical Concepts and Methods. 2nd ed. Oxford; Malden, Mass: Wiley-Blackwell, 2010.

Baldick, Chris. "Allegory.” Oxford University Press, 2015. http://www.oxfordreference.com/ view/10.1093/acref/9780198715443.001.0001/acref9780198715443-e-30.

Barthes, Roland. Mythologies. Translated by Jonathan Cape Ltd, 1972.
Bingham, Neil. 100 Years of Architectural Drawing: 1900-2000. London: Laurence King, 2013.

Böhme, Gernot. "Metaphors in Architecture - a Metaphor?" In Metaphors in Architecture and Urbanism: An Introduction, edited by Andri Gerber and Brent Patterson, 47-57. Architecture 19. Bielefeld: Transcript-Verl, 2013.

Brown, Robert, and Daniel Maudin. "Concepts of Vernacular Architecture." In The SAGE Handbook of Architectural Theory, edited by C. Greig Crysler, Stephen Cairns, and Hilde Heynen, 340-55. Los Angeles ; London ; New Delhi ; Singapore ; Washington DC: SAGE Publications, 2012.

Colomina, Beatriz. Privacy and Publicity: Modern Architecture as Mass Media. MIT Press, 1994.

Dalí, Salvador. "New General Considerations Regarding the Mechanism of the Paranoiac Phenomenon from the Surrealist Point of View." In The Collected Writings of Salvador Dalí, translated by Haim N. Finkelstein, 256-62. Cambridge, U.K: Cambridge University Press, 1998.

"The Conquest of the Irrational." In The Collected Writings of Salvador Dali, translated by Haim N. Finkelstein, 262-72. Cambridge, U.K: Cambridge University Press, 1998.

."The Stinking Ass." In Surrealist Painters and Poets: An Anthology, edited by Mary Ann Caws. Cambridge, Mass: The MIT Press, 2001.

De Landa, Manuel. Intensive Science and Virtual Philosophy. Transversals. London; New York: Continuum, 2002.

"Definition of OBLATE." Accessed September 18, 2016. http:// www.merriam-webster.com/dictionary/oblate. 
Diller, Elizabeth, and Anthony Vidler. "Architecture Is a Technology That Has Not yet Discovered Its Agency." Log, no. 28 (2013): 21-26.

Eco, Umberto. How to Write a Thesis. Translated by Caterina Mongiat Farina and Geoff Farina. Cambridge, Massachusetts: MIT Press, 2015.

Eco, Umberto, and Richard Dixon. Inventing the Enemy and Other Occasional Writings, 2013.

"Economy | Define Economy at Dictionary.Com." Accessed August 29, 2017. http://www.dictionary.com/browse/ economy.

Edwardes, Martin. The Origins of Grammar: An Anthropological Perspective. London; New York: Continuum, 2010.

Eggener, Keith L. "Placing Resistance: A Critique of Critical Regionalism." Journal of Architectural Education 55, no. 4 (May 1, 2002): 228-37. doi:10.1162/104648802753657932.

Eisenman, Peter. "Aspects of Modernism: Maison Dom-Ino and the Self-Referential Sign." Edited by Kenneth Frampton. Oppositions: Le Corbusier 1905-1933 15/16 (Winter/ Spring 1979): 118-28.

Eisinger, Angelus. "Stop Making Sense." In Explorations in Architecture: Teaching, Design, Research, edited by Reto Geiser. Basel; Boston: Birkhäuser, 2008.

Evans, Robin. "The Rights of Retreat and the Rites of Exlcusion." In Translations from Drawing to Building and Other Essays, 34-53. AA Documents 2. London: Architectural Association, 1997.

Fijalkowski, Krzysztof, and Michael Richardson. "Introduction." In Surrealism: Key Concepts, edited by Krzysztof Fijalkowski and Michael Richardson, 1 [edition]., 1-16. Key Concepts. London; New York: Routledge, Taylor \& Francis Group, 2016.

Finger, Brad. Surrealism: 50 Works of Art You Should Know. Munich ; London ; New York: Prestel, 2013.

Flusser, Vilém. "About the Word Design.” In The Shape of Things: A Philosophy of Design, translated by Anthony Mathews, 17-21. London: Reaktion, 1999.
"Bare Walls." In The Shape of Things: A Philosophy of Design, translated by Anthony Mathews, 78-80. London: Reaktion, 1999.

"Form and Material." In The Shape of Things: A Philosophy of Design, translated by Anthony Mathews, 22-29. London: Reaktion, 1999.

"With As Many Holes As a Swiss Cheese." In The Shape of Things: A Philosophy of Design, translated by Anthony Mathews, 81-84. London: Reaktion, 1999.

Forty, Adrian. “The Empire of Language.” Thesis // BauhausUniversität<Weimar> Heft 3 (2003): 23-26.

.Words and Buildings: A Vocabulary of Modern Architecture. New York: Thames \& Hudson, 2000.

.Words and Buildings: A Vocabulary of Modern Architecture. 1st paperback ed. New York, NY: Thames \& Hudson, 2004.

Foster, Hal, Rosalind Krauss, Yve-Alain Bois, Benjamin H.D. Buchloh, and David Joselit. Art since 1900: Modernism, Antimodernism, Postmodernism. 2nd ed. New York, NY: Thames \& Hudson, Inc, 2011.

Frampton, Kenneth. "On Reading Heidegger." In Oppositions Reader: Selected Essays 1973-1984, edited by K. Michael Hays, 1 edition., 3-6. New York: Princeton Archit. Press, 1999.

"Towards a Critical Regionalism: Six Points for an Architecture of Resistance." In The Anti-Aesthetic: Essays on Postmodern Culture, edited by Hal Foster, 16-30. Port Townsend, Washington: Bay Press, 1983.

Freud, Sigmund. “The Uncanny.” In The Uncanny, translated by David Mclintock, 123-62. London, U.K.: Penguin Books, 2003.

Gandelsonas, Mario. "Linguistics in Architecture." In Architecture Theory since 1968, edited by K. Michael Hays, 114-22. Cambridge, Mass: The MIT Press, 1998.

Giedion, S. Space, Time and Architecture: The Growth of a New Tradition. 5th ed., And enl. Charles Eliot Norton Lectures, 1938-1939. Cambridge, Mass: Harvard University Press, 1967. 
Hagberg, Garry L. "Metaphor." In The Routledge Companion to Aesthetics, edited by Berys Nigel Gaut and Dominic Lopes, 285-95. London; New York: Routledge, 2001. http://site.ebrary.com/id/2002431.

Harman, Graham. The Quadruple Object. Epub. Winchester, U.K.: Zero Books, 2011.

Hayles, N. Katherine, and Todd Gannon. "Virtual Architecture, Actual Media." In The SAGE Handbook of Architectural Theory, edited by C. Greig Crysler, Stephen Cairns, and Hilde Heynen, 484-500. Los Angeles ; London ; New Delhi ; Singapore ; Washington DC: SAGE Publications, 2012.

Heath, Kingston Wm. "False-Front Architecture on Montana's Urban Frontier." Perspectives in Vernacular Architecture 3 (1989): 199-213. doi:10.2307/3514305.

Hendrix, John Shannon. The Contradiction Between Form and Function in Architecture. Hoboken: Taylor and Francis, 2013. http://public.eblib.com/choice/publicfullrecord. aspx?p=1128265.

Henley, Jon. "Walls: An Illusion of Security from Berlin to the West Bank.” The Guardian, November 19, 2013, online edition, sec. World News. https://www.theguardian. com/uk-news/2013/nov/19/walls-barrier-belfast-westb-ank.

Hight, Christopher. "Manners of Working: Fabricating Representation in Digital Based Design.” In The SAGE Handbook of Architectural Theory, edited by C. Greig Crysler, Stephen Cairns, and Hilde Heynen, 410-29. Los Angeles ; London ; New Delhi ; Singapore ; Washington DC: SAGE Publications, 2012.

Hollier, Denis. "Architectural Metaphors.” In Architecture Theory since 1968, edited by K. Michael Hays, 192-96. Cambridge, Mass: The MIT Press, 1998.

Hunt, Jamer. "Paranoid, Critical, Methodical, Dali, Koolhaas, And ..." In Paranoia within Reason: A Casebook on Conspiracy as Explanation, edited by George E. Marcus, 21-30. Late Editions 6. Chicago: University of Chicago Press, 1999.

Johnson, Deborah G., and Jameson M. Wetmore, eds. Technology and Society: Building Our Sociotechnical Future. Inside Technology. Cambridge, Mass: MIT Press, 2009.
Johnson, Paul-Alan. The Theory of Architecture: Concepts, Themes $\&$ Practices. New York: Van Nostrand Reinhold, 1994.

Jonas, Wolfgang. "Mind the Gap! On Knowing and Not Knowing in Design; Or: There Is Nothing More Theoretical than a Good Practice." In EAD 5. Barcelona, 2003. http://home.snafu.de/jonasw/JONAS4.html.

Karatani, Kōjin. “Architecture and Association.” Thesis // Bauhaus-Universität<Weimar> Heft 3 (2003): 23-26.

Architecture as Metaphor: Language, Number, Money. Edited by Michael Speaks. Translated by Sabu Kohso. Writing Architecture. Cambridge, Mass: MIT Press, 1995.

Kearney, Richard. "Introduction." In The Poetics of Space, by Gaston Bachelard, xvii-xxv. translated by Maria Jolas, New edition. Penguin Classics. New York, New York: Penguin Books, 2014.

Kipnis, Jeffrey. Perfect Acts of Architecture. New York : Columbus, Ohio: Wexner Center for the Arts: Museum of Modern Art, 2001.

Kleinman, Ken. "Introduction." In The Poetics of a Wall Projection, Epub. AA Words ; 3. London: Architectural Association, 2009.

Koolhaas, Rem. Delirious New York: A Retroactive Manifesto for Manhattan. New ed. New York: The Monacelli Press, 1994.

, ed. Fundamentals: 14th International Architecture Exhibition. First edition. Venice: Marsilio, 2014.

, ed. “One-to-One Dom-Ino." In Fundamentals: 14th International Architecture Exhibition, First edition., 184-85. Venice: Marsilio, 2014.

Koolhaas, Rem, AMO, Harvard Graduate School of Design, and Irma Boom. Door. Venezia: Marsilio, 2014.

Kostof, Spiro, and Greg Castillo. A History of Architecture: Settings and Rituals. 2nd ed. New York: Oxford University Press, 1995.

Kwinter, Sanford. “The Judo of Cold Combustion.” In Atlas of Novel Tectonics, by Jesse Reiser and Nanako Umemoto, 12-15, 1st ed. New York: Princeton Architectural Press, 2006 
La Marche, Jean. “Surrealism's Unexplored Possibilities in Architecture." In Surrealism and Architecture, edited by Thomas Mical, 273-89. London; New York: Routledge, 2005. http://public.eblib.com/choice/publicfullrecord. aspx?p=199421.

Langmuir, Erika. Allegory: A Closer Look. Redesigned ed. A Closer Look. London : [New Haven]: National Gallery ; Distributed by Yale University Press, 2010.

Latour, Bruno. “Give Me a Gun.” In Explorations in Architecture: Teaching, Design, Research, edited by Urs Staub and Reto Geiser, 80-89. Basel ; Boston: Birkhäuser, 2008.

"Where Are the Missing Masses, Sociology of a Few Mundane Artefacts." In Technology and Society, Building Our Sociotechnical Future, edited by Deborah J. Johnson and Jameson M Wetmore, 151-80. Cambridge, Mass.: MIT Press, 2008.

"Where Are the Missing Masses? The Sociology of a Few Mundane Artifacts." In Shaping Technology/Building Society: Studies in Sociotechnical Change, edited by Wiebe E. Bijker and John Law, 225-58. Cambridge, MA; London, England: MIT Press, 1992.

Le Corbusier. Le Corbusier Le Grand. New York: Phaidon Press, 2008.

Precisions on the Present State of Architecture and City Planning: With an American Prologue, a Brazilian Corollary Followed by The Temperature of Paris and The Atmosphere of Moscow. Cambridge, Mass: MIT Press, 1991.

Leach, Neil, ed. Rethinking Architecture: A Reader in Cultural Theory. New York: Routledge, 1997.

"The Dark Side of the 'Domus': The Redomestication of Central and Eastern Europe." In Architecture and Revolution: Contemporary Perspectives on Central and Eastern Europe, 150-62. London; New York: Routledge, 1999. http://site.ebrary.com/id/10095026.

Lewis, Paul, Marc Tsurumaki, and David J. Lewis. Situation Normal--. Edited by Mark Lamster. Pamphlet Architecture 21. New York: Princeton Architectural Press, 1998.

Linder, Mark. Nothing Less than Literal: Architecture after Minimalism. Cambridge, Mass: MIT Press, 2004.
Magee, Bryan. “Wittgenstein: Dialogue with John Searle.” In The Great Philosophers: An Introduction to Western Philosophy, 321-47. Oxford ; New York: Oxford University Press, 1988.

McGovern, John. "Like Water in Water': Primitivism and Modernity." In Myth and the Making of Modernity: The Problem of Grounding in Early Twentieth-Century Literature, edited by Michael Bell and Peter Poellner. Amsterdam; Atlanta, GA: Rodopi, 1998.

McGowan, Todd. "We Are Already Dwelling: Hegel and the Transcendence of Place." In The Missed Encounter of Radical Philosophy with Architecture, edited by Nadir Lahiji, 55-68. A\&C Black, 2014.

Meiss, Pierre von, and Theo Hakola. Elements of Architecture: From Form to Place + Tectonics. 2nd edition. London: Routledge, 2013.

Mical, Thomas. "Introduction." In Surrealism and Architecture, edited by Thomas Mical, 1-10. London; New York: Routledge, 2005.

Monteyne, David. "Framing the American Dream." Journal of Architectural Education 58, no. 1 (September 1, 2004): 24-33. doi:10.1162/1046488041578194.

Otero-Pailos, Jorge. "Architectural Phenomenology and the Rise of the Postmodern." In The SAGE Handbook of Architectural Theory, edited by C. Greig Crysler, Stephen Cairns, and Hilde Heynen, 136-51. Los Angeles ; London ; New Delhi ; Singapore ; Washington DC: SAGE Publications, 2012.

Picon, Antoine. "Dom-Ino: Archetype and Fiction." Log, no. 30 (2014): 169-75.

Porter, Tom. Archispeak: An Illustrated Guide to Architectural Terms. London; New York: Taylor \& Francis, 2004.

Quintal, Becky. "AD Interviews: Sou Fujimoto / Chicago Architecture Biennial.” ArchDaily, October 23, 2015. http://www.archdaily.com/775921/ad-interviews-soufujimoto-chicago-architecture-biennial.

Reiser, Jesse, and Nanako Umemoto. Atlas of Novel Tectonics. 1st ed. New York: Princeton Architectural Press, 2006. 
Richardson, Michael, and Krzysztof Fijalkowski. "The Supreme Point." In Surrealism: Key Concepts, edited by Krzysztof Fijalkowski and Michael Richardson, 1 [edition]., 248-54. Key Concepts. London ; New York: Routledge, Taylor \& Francis Group, 2016.

Robilant, Manfredo di, Niklas Maak, Rem Koolhaas, AMO, Harvard Graduate School of Design, and Irma Boom. Window. Venezia: Marsilio, 2014.

Rousseau, Jean-Jacques, Susan Dunn, and Gita May. The Social Contract; and, The First and Second Discourses. Rethinking the Western Tradition. New Haven: Yale University Press, 2002.

Rudofsky, Bernard. Architecture Without Architects: A Short Introduction to Non-Pedigreed Architecture. 1 vols. New York: Doubleday, 1964.

Rykwert, Joseph. The Idea of a Town: The Anthropology of Urban Form in Rome, Italy and the Ancient World. MIT Press, 1988.

Seligmann, Claus. "What Is a Door? Notes toward a Semiotic Guide to Design." Semiotica 38, no. 1-2 (January 1, 1982): 55-76.

Sharr, Adam. Heidegger for Architects. Thinkers for Architects. London; New York: Routledge, 2007.

Sheringham, Michael. Everyday Life: Theories and Practices from Surrealism to the Present. Oxford; New York: Oxford University Press, 2006.

Simpson, Deane. "Performative Modernities: Rem Koolhaas's Delirious New York as Inductive Research." In Explorations in Architecture: Teaching, Design, Research, edited by Urs Staub and Reto Geiser, 12-13. Basel ; Boston: Birkhäuser, 2008.

Soleimani-Deilamani, Saman. "Delirious New York, the Movie." Precis for "Current Topics in Architectural Praxis." Toronto, Canada: Ryerson University, December 12, 2016.

Sorrentino, Paolo. “Episode \#1.9." The Young Pope (season one). Sky Atlantic / HBO / Canal+, November 18, 2016.

Strauven, Francis. "Aldo van Eyck. Shaping the New Reality From the In-between to the Aesthetics of Number." CCA Study Centre Mellon Lectures, 2007. http://taak.me/ wp-content/uploads/2013/05/in-betweenness_Aldovan-Eyck.pdf.
Teyssot, Georges. A Topology of Everyday Constellations. Writing Architecture. Cambridge, US: The MIT Press, 2013.

“The Doors of Perception." Wikipedia, August 12, 2017. https:// en.wikipedia.org/w/index.php?title=The_Doors_of_ Perception\&oldid $=795209794$.

"The Medium Is the Massage." Wikipedia, the Free Encyclopedia, September 12, 2016. https://en.wikipedia. org/w/index.php?title=The_Medium_Is_the Massage\&oldid $=739074935$.

“Threshold." Dictionary.Com, n.d. http://www.dictionary.com/ browse/threshold.

Till, Jeremy. "Architecture and Contingency." Field 1, no. 1 (2007): 120-135.

“Transduction | Microbiology | Britannica.Com.” Accessed September 18, 2016. https://www.britannica.com/science/ transduction-microbiology.

Tschumi, Bernard. Architecture and Disjunction. Cambridge, Mass.: MIT Press, 1996.

- Questions of Space: Lectures on Architecture. Architectural Association. London: Architectural Association, 1990.

The Manhattan Transcripts. 2nd ed. London: Academy Editions, 1994.

Turnovský, Jan. The Poetics of a Wall Projection. Epub. AA Words ; 3. London: Architectural Association, 2009.

Van Valin, Robert D. An Introduction to Syntax. Cambridge, UK; New York: Cambridge University Press, 2001. http:// dx.doi.org/10.1017/CBO9781139164320.

Venturi, Robert, Denise Scott Brown, and Steven Izenour. Learning From Las Vegas: The Forgotten Symbolism of Architectural Form. 17th print. Cambridge, Mass.: The MIT Press, 2000.

Veseley, Dalibor. “Surrealism, Myth \& Modernity.” In Surrealism, 87-95. AD Profiles 11. London: Architectural Design Magazine, 1978.

"Werner Herzog Would Watch You Reading the Phone Book -- Vulture." Accessed September 16, 2016. http://www. vulture.com/2007/07/werner_herzog_would_watch_ you.html. 
Weston, Richard. 100 Ideas That Changed Architecture. London: King, 2011.

"Wittgenstein House." VIENNA - Now. Forever. Accessed September 1, 2017. https://www.wien.info/en/sightseeing/ sights/from-s-to-z/wittgenstein-house.

Wood, Christopher. “Why Autonomy?” Perspecta 33 (2002): 48. doi:10.2307/1567296.

Zhou, Tony. Buster Keaton: The Art of the Gag. Youtube video. Every Frame a Painting. Vancouver, 2015. https://www. youtube.com/.

Žižek, Slavoj. Event: Philosophy in Transit. Great Britain: Penguin Books, 2014.

Zorzetto, Alessandro. “The Theatre of Useful." Domusweb.It. October 26, 2016, sec. Architecture, Interviews. http:// www.domusweb.it/en/architecture/2016/10/26/ the_theatre_of_the_usefull.html. 
<smiles>C1CCCCC1</smiles><smiles>C1CCCC1</smiles><smiles>CCCCCCC</smiles><smiles>C1CCCC1</smiles><smiles>C1CCCC1</smiles><smiles>CCCCC</smiles><smiles>C1CCCC1</smiles><smiles>CCCC</smiles> 